\title{
Análise de Provas de Carga Estática em Estacas Pré-Moldadas Cravadas na \\ Cidade de Curitiba e Região Metropolitana
}

Ana Paula Fontana Vianna

Dissertação apresentada à Escola de Engenharia de São Carlos da Universidade de São Paulo, como parte dos requisitos para obtenção do título de Mestre em Geotecnia.

Orientador: Prof. Dr. José Carlos A. Cintra

São Carlos

2000 


\section{Folha de Aprovação}

Dissertação defendida e aprovada em

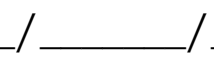

pela comissão julgadora

(Assinatura)

(Nome/Instituição)

(Assinatura)

(Nome/Instituição)

(Assinatura)

(Nome/Instituição)

Coordenador da Área

Presidente da CPG 
"Aplausos, quando não fundamentam o mérito, afagam certamente o espirito e dão algum verniz de celebridade; mas quem tem vontade de aprender e quer fazer alguma coisa, prefere a lição que melhora ao ruído que lisonjeia"

Machado de Assis 
Ao meu pai, Ernani, e meus tios Neusa e Cesar, os meus exemplos de vida. 


\section{AGRADECIMENTOS}

A Deus pelo dom da vida e a oportunidade de aprendizado todos os dias.

Ao Prof. Dr José Carlos A. Cintra pela amizade, orientação e estimulo. Ao CNPq pela concessão da bolsa de estudo.

Ao Departamento de Geotecnia da Escola de Engenharia de São Carlos (EESC/USP) pela infra estrutura oferecida para o programa de pósgraduação, através do quadro de docentes e funcionários.

Ao Prof. Dr. Nelson Aoki pelas sugestões e ensinamentos transmitidos.

Aos professores Paulo Roberto Chamecki e Alessander Morales Kormann pelo incentivo e sugestões.

Ao Eng. ${ }^{\circ}$ Adalberto B. T. Amaral (Estacas Benapar S/A) pela cessão dos resultados das provas de carga.

Ao engenheiro Herivelto pelos serviços de informática prestados.

As minhas grandes amigas Ana Carina, Kênia, Sandra, e Túlia por sempre estarem presente, me dando força e incentivando a seguir em frente. 


\section{SUMÁRIO}

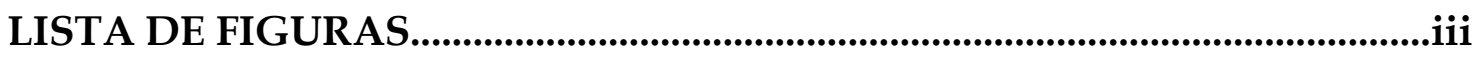

LISTA DE TABELAS......................................................................................

LISTA DE ABREVIATURAS E SIGLAS........................................................xiii

LISTA DE SÍMBOLOS...........................................................................................xiv

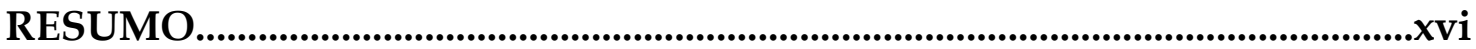

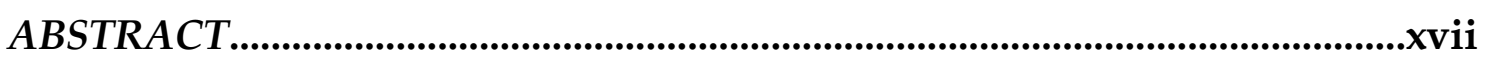

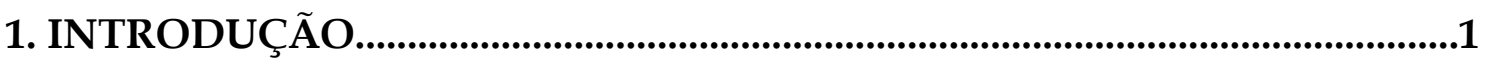

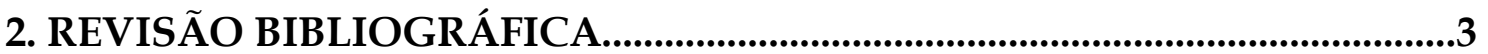

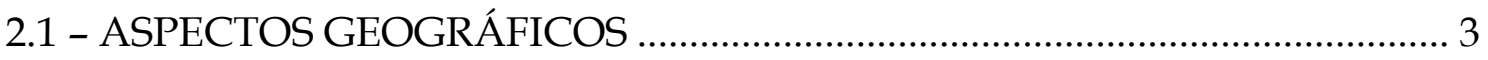

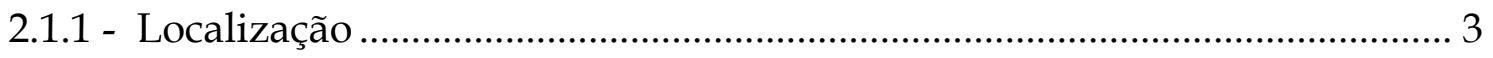

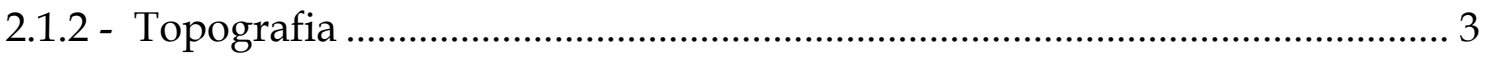

2.1.3 - Uso e Ocupação do Solo ............................................................................. 5

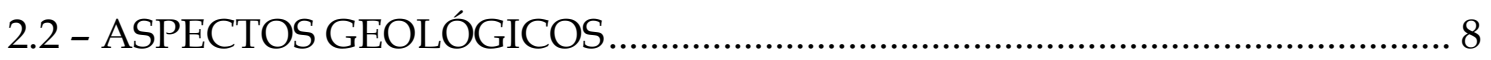

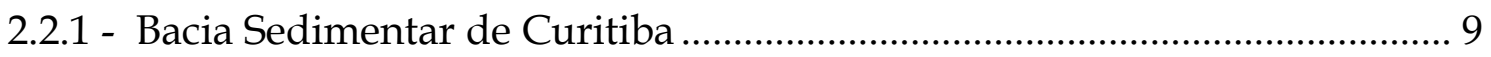

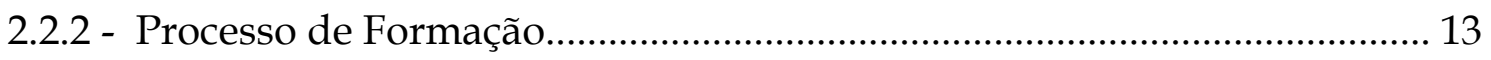

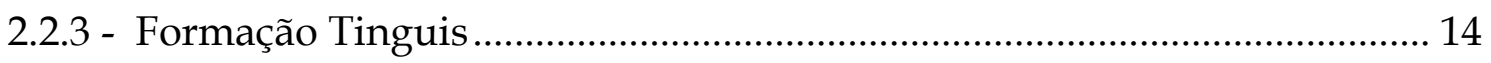

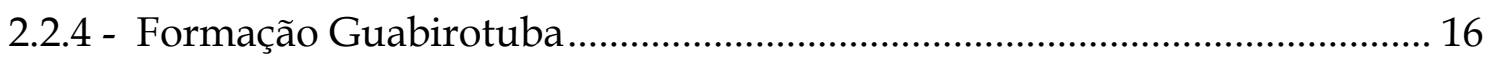

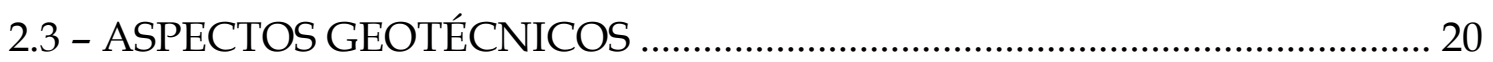

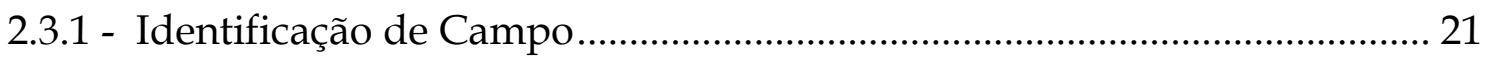

2.3.2 - Ensaios de Caracterização Laboratorial ....................................................... 25

2.3.3 - Parâmetros de Compressibilidade, Permeabilidade e Resistência .......... 30

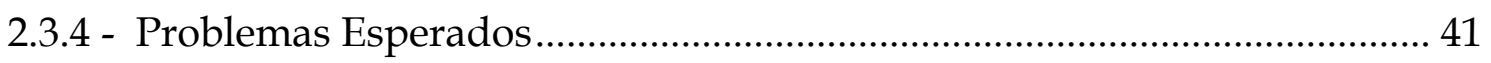

2.4 - PREVISÃO DA CAPACIDADE DE CARGA E INTERPRETAÇÃO DA

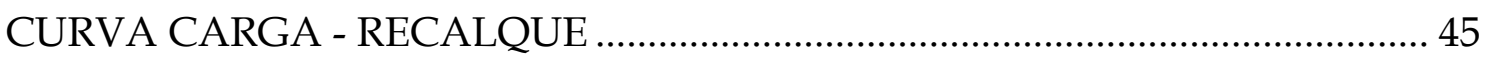

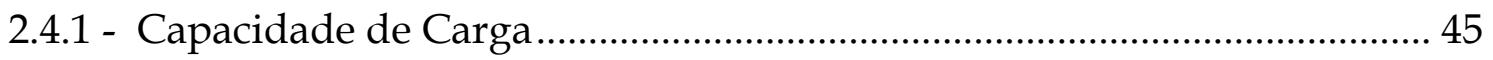

2.4.2 - Interpretação da Curva Carga - recalque................................................... 50

3. MÉTODOS DE PREVISÃO DA CAPACIDADE DE CARGA........................54

3.1 - MÉTODO AOKI - VELLOSO (1975) ........................................................... 57 


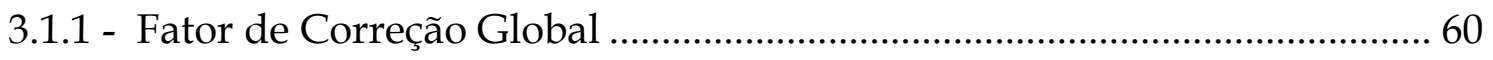

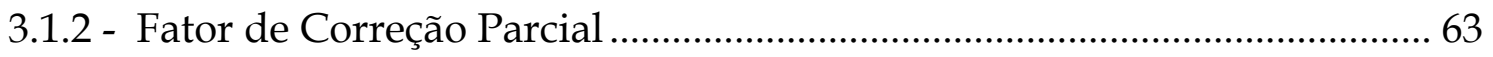

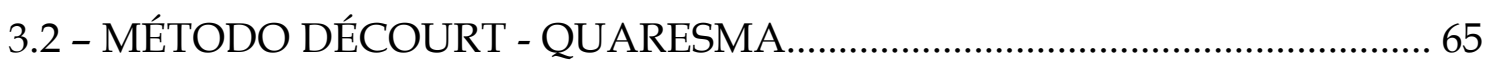

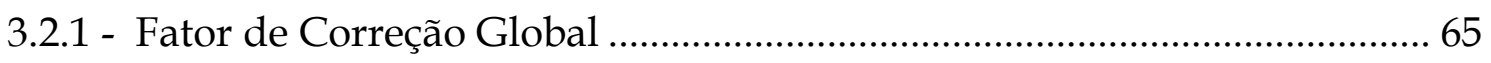

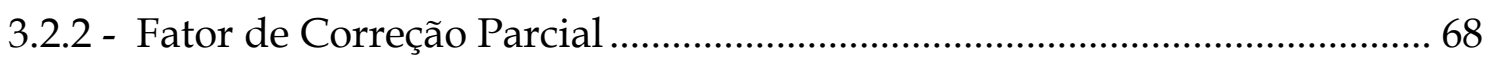

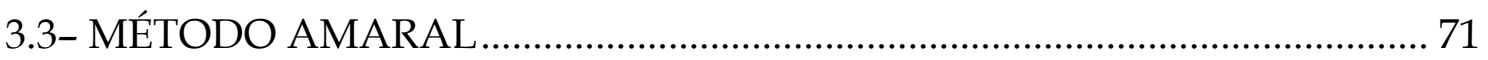

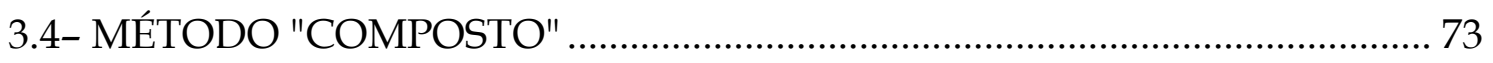

4. INTERPRETAÇÃO DA CURVA CARGA - RECALQUE................................75

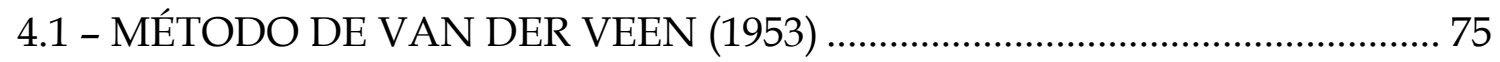

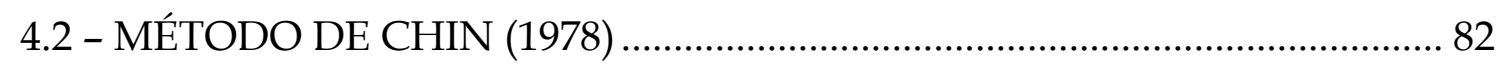

5. ESTIMATIVA DE RECALQUE E PREVISÃO DA CURVA CARGA RECALQUE $\quad 83$

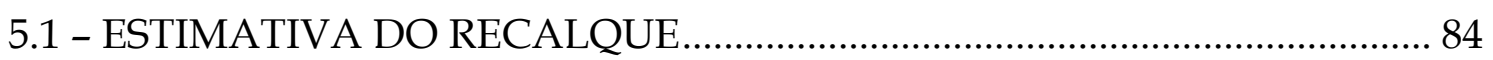

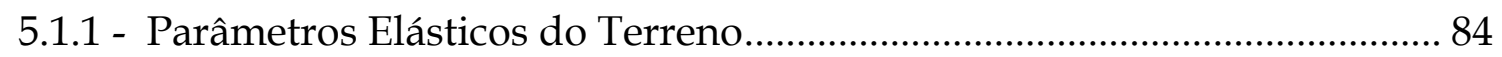

5.1.2 - Diagramas de Transferência de Carga ......................................................... 85

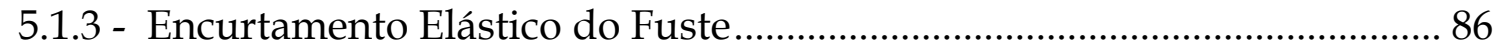

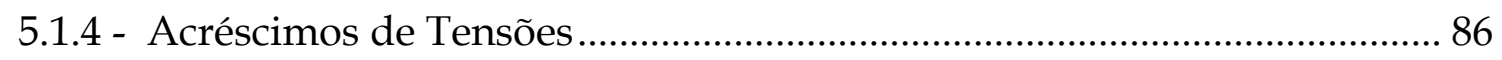

5.2 - PREVISÃO DA CURVA CARGA - RECALQUE ............................................ 88

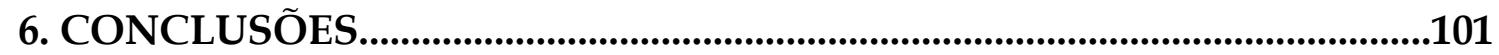

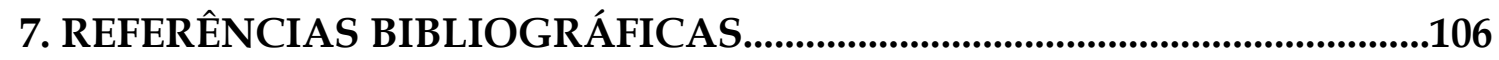

8. ANEXO 1

9. ANEXO 2

10. ANEXO 3

11. ANEXO 4

12. ANEXO 5 


\section{LISTA DE FIGURAS}

FIGURA 2.1 - Associação entre malha urbana da Região Metropolitana de Curitiba) e contexto regional (Siedlecki, 1998) 4

FIGURA 2.2 - Distribuição da Formação Guabirotuba na RMC (DNPM/MINEROPAR, 1989 apud Felipe, 1998) 6

FIGURA 2.3 - Modelo digital do terreno visualizando os constituintes litológicos da área estudada (Salamuni, 1998) 8

FIGURA 2.4 - Bolsões de material orgânico que contém palinomorfos dentro de argilitos da Formação Guabirotuba (Salamuni, 1998) .10

FIGURA 2.5 - Aspecto das alternâncias centimétricas de argilas e arcósios em sedimentos argilosos da Formação Guabirotuba (Felipe et al., 1994).... .12

FIGURA 2.6 - Solo transportado separado por uma linha de seixos da Formação Guabirotuba (Salazar Jr., 1996).

FIGURA 2.7 - Modelo digital de terreno com a sobreposição dos litotipos sedimentares da Bacia de Curitiba e do seu embasamento (Salamuni, 1998)

FIGURA 2.8 - Sondagens de simples reconhecimento na região de Araucária PR (Massad et al., 1981)

FIGURA 2.9- Dados de ensaios de CPTU em duas áreas de estudo (Chamecki et al., 1998)

FIGURA 2.10 - Resultados do ensaio DPL em duas áreas de estudo (Chamecki et al., 1998)

FIGURA 2.11 - Perfil esquemático (Chamecki et al., 1998)..................................24

FIGURA 2.12 - Distribuição granulométrica (Duarte, 1986)................................26

FIGURA 2.13 - Posição na carta de plasticidade (Duarte, 1986)...........................27

FIGURA 2.14 - Curvas de adensamento para ensaio sobre solo indeformado (Duarte, 1986) 31

FIGURA 2.15 - Curva recalque x log tempo para ensaio sobre solo indeformado (Duarte, 1986). 31 
FIGURA 2.16 - Envoltória de resistência para o solo sedimentar da Bacia de Curitiba (Nascimento, 1992).

FIGURA 2.17 - Resistência à compressão simples e envoltória de cisalhamento direto para o solo sedimentar da Bacia de Curitiba (Nascimento, 1992). .35

FIGURA 2.18 - Ensaio triaxial rápido pré-adensado saturado por contrapressão - argila cinza da Formação Guabirotuba (Massad et al., 1981).... .36

FIGURA 2.19 - Ensaio triaxial rápido pré-adensado saturado por contrapressão - argila vermelha da Formação Tinguis (Massad et al., 1981). .37

FIGURA 2.20 - Comparação simplificada entre comportamentos tensão $x$ deformação de argilas normalmente adensadas e pré-adensadas em condições drenadas (Duarte, 1986)

FIGURA 2.21 - Ensaio de cisalhamento direto com grandes deformações para a argila cinza da Formação Guabirotuba (Massad et al., 1981).

FIGURA 2.22 - Envoltórias de resistência, em termos de tensões efetivas para o solo da Formação Guabirotuba, obtidas através de ensaios de cisalhamento direto com reversão múltipla (Duarte, 1986).

FIGURA 2.23 - Movimento de massa gravitacional "rastejo" e suas conseqüências no loteamento Santa Rosa em campina Grande do Sul (RMC) (Felipe, 1998).

FIGURA 2.24 - Aspecto do empastilhamento e trincas causados pela retração nas argilas cinza-esverdeadas da Formação Guabirotuba (Felipe et al., 1994)

FIGURA 2.25 - Risco de escorregamento em sedimentos da Formação Guabirotuba, desprovidos de solo e cobertura vegetal (Oliveira et al., 1997) .45

FIGURA 2.26 - Curva carga x recalque genérica (Amaral et al., 1999). . .48

FIGURA 2.27 - Gráfico $\rho / p$ x $\rho$ para uma estaca de ponta (Chin, 1978)

FIGURA 2.28 - Gráfico $\rho / \mathrm{p}$ x $\rho$ para uma estaca que trabalha pela ponta e por atrito lateral (Chin, 1978) .52 
FIGURA 2.29 - Gráfico $\rho / p \times \rho$ para uma estaca que sofreu danos estruturais durante a cravação (Chin, 1978).

FIGURA 2.30 - Gráfico $\rho / p \times \rho$ para uma estaca que sofreu sérios danos na ponta (Chin, 1978) .53

FIGURA 3.1a - Comparação do método Aoki - Velloso com a carga última de Van der Veen. .55

FIGURA 3.1b - Comparação do método Décourt - Quaresma com a carga última de Van der Veen 55

FIGURA 3.1c - Comparação do método Amaral com a carga última de Van der Veen 56

FIGURA 3.2 - Comparação do método Aoki - Velloso original e adaptado com os valores da carga última de Van der Veen. .59

FIGURA 3.3 - Comparação do método Aoki - Velloso adaptado $\left(R^{*}\right)$ e do método corrigido com o fator global ( $\left.R^{\prime}\right)$ com a carga última de Van der Veen.62 FIGURA 3.4 - Comparação do método Aoki - Velloso adaptado $\left(R^{*}\right)$ e do método Aoki - Velloso adaptado e corrigido com o fator parcial ( $\left.\mathrm{R}^{\prime \prime}\right)$ com a carga última de Van der Veen.

FIGURA 3.5 - Comparação do método Décourt - Quaresma original e do corrigido como fator global com os valores da carga última de Van der Veen...67 FIGURA 3.6 - Comparação do método Décourt - Quaresma original e do corrigido com fator parcial com carga última de Van der Veen. .70

FIGURA 3.7 - Comparação do método Amaral original e do corrigido com fator global com os valores da carga última de Van der Veen. .72

FIGURA 3.8 - Comparação do método composto com os valores da carga última de Van der Veen .74

FIGURA 5.1 - Diagrama de transferência de carga..............................................85

FIGURA 5.2 - Distribuição de pressões (Aoki, 1985). 86

FIGURA 5.3a - Comparação entre a curva prevista da estaca 03 para carga $\mathrm{P}_{1}$ e a curva experimental. .89 
FIGURA 5.3b - Comparação entre a curva prevista da estaca 03 para a carga $\mathrm{P}_{2}$ e a curva experimental

FIGURA 5.3c - Comparação entre as curvas prevista da estaca 03 para carga $\mathrm{P}_{3}$ e a curva experimental.

FIGURA 5.3d - Comparação entre a curva ajustada pelos três pontos da estaca 03 e a curva experimental.

FIGURA 5.4a - Comparação entre a curva prevista da estaca 06 para carga $\mathrm{P}_{1} \mathrm{e}$ a curva experimental.

FIGURA 5.4b - Comparação entre a curva prevista da estaca 06 para carga $\mathrm{P}_{2} \mathrm{e}$ a curva experimental.

FIGURA 5.4c - Comparação entre a curva prevista da estaca 06 para carga $\mathrm{P}_{3} \mathrm{e}$ a curva experimental.

FIGURA 5.4d - Comparação entre a curva ajustada pelos três pontos da estaca 06 e a curva experimental.

FIGURA 5.5a - Comparação entre a curva prevista da estaca 10 para carga $\mathrm{P}_{1} \mathrm{e}$ a curva experimental.

FIGURA 5.5b - Comparação entre a curva prevista da estaca 10 para carga $\mathrm{P}_{2} \mathrm{e}$ a curva experimental.

FIGURA 5.5c - Comparação entre a curva prevista da estaca 10 para carga $\mathrm{P}_{3} \mathrm{e}$ a curva experimental.

FIGURA 5.5d - Comparação entre a curva ajustada pelos três pontos da estaca 10 e a curva experimental. .90

FIGURA 5.6a - Comparação entre a curva prevista da estaca 11 para carga $\mathrm{P}_{1} \mathrm{e}$ a curva experimental.

FIGURA 5.6b - Comparação entre a curva prevista da estaca 11 para carga $\mathrm{P}_{2} \mathrm{e}$ a curva experimental

FIGURA 5.6c - Comparação entre a curva prevista da estaca 11 para carga $\mathrm{P}_{3} \mathrm{e}$ a curva experimental.

FIGURA 5.6d - Comparação entre a curva ajustada pelos três pontos da estaca 11 e a curva experimental. 
FIGURA 5.7a - Comparação entre a curva prevista da estaca 15 para carga $\mathrm{P}_{1} \mathrm{e}$ a curva experimental.

FIGURA 5.7b - Comparação entre a curva prevista da estaca 15 para carga $\mathrm{P}_{2} \mathrm{e}$ a curva experimental.

FIGURA 5.7c - Comparação entre a curva prevista da estaca 15 para carga $\mathrm{P}_{3}$ e a curva experimental.

FIGURA 5.7d - Comparação entre a curva ajustada pelos três pontos da estaca 15 e a curva experimental.

FIGURA 5.8a - Comparação entre a curva prevista de estaca 17 para carga $\mathrm{P}_{1}$ e a curva experimental.

FIGURA 5.8b - Comparação entre a curva prevista da estaca 17 para carga $\mathrm{P}_{2} \mathrm{e}$ a curva experimental.

FIGURA 5.8c - Comparação entre a curva prevista da estaca 17 para carga $\mathrm{P}_{3} \mathrm{e}$ a curva experimental.

FIGURA 5.8d - Comparação entre a curva ajustada pelos três pontos da estaca 17 e a curva experimental.

FIGURA 5.9a - Comparação entre a curva prevista da estaca 20 para carga $\mathrm{P}_{1} \mathrm{e}$ a curva experimental.

FIGURA 5.9b - Comparação entre a curva prevista da estaca 20 para carga $\mathrm{P}_{2} \mathrm{e}$ a curva experimental.

FIGURA 5.9c - Comparação entre a curvas prevista da estaca 20 para carga $\mathrm{P}_{3} \mathrm{e}$ a curva experimental.

FIGURA 5.9d - Comparação entre a curvas ajustada pelos três pontosl da estaca 20 e a curva experimental. .93

FIGURA 5.10a - Comparação entre a curva prevista da estaca 21 para carga $P_{1}$ e a curva experimental.

FIGURA 5.10b - Comparação entre a curva prevista da estaca 21 para carga $P_{2}$ e a curva experimental .93

FIGURA 5.10c - Comparação entre a curva prevista da estaca 21 para carga $\mathrm{P}_{3} \mathrm{e}$ a curva experimental. 
FIGURA 5.10d - Comparação entre a curva ajustada pelos três pontos da estaca 21 e a curva experimental.

FIGURA 5.11a - Comparação entre a curva prevista da estaca 23 para carga $P_{1}$ e a curva experimental.

FIGURA 5.11b - Comparação entre a curva prevista da estaca 23 para carga $R_{2}$ e a curva experimental.

FIGURA 5.11c - Comparação entre a curvas prevista da estaca 23 para carga $\mathrm{P}_{3}$ e a curva experimental.

FIGURA 5.11d - Comparação entre a curva ajustada pelos três pontos da estaca 23 e a curva experimental.

FIGURA 5.12a - Comparação entre a curva prevista da estaca 25 para carga $\mathrm{P}_{1} \mathrm{e}$ a curva experimental.

FIGURA 5.12b - Comparação entre a curva prevista da estaca 25 para carga $\mathrm{P}_{2}$ e a curva experimental.

FIGURA 5.12c - Comparação entre a curva prevista da estaca 25 para carga $\mathrm{P}_{3} \mathrm{e}$ a curva experimental.

FIGURA 5.12d - Comparação entre a curva ajustada pelos três pontos da estaca 25 e a curva experimental. .95

FIGURA 5.13a - Comparação entre a curva prevista da estaca 30 para carga $P_{1}$ e a curva experimental.

FIGURA 5.13b - Comparação entre a curva prevista da estaca 30 para carga $P_{2}$ e a curva experimental.

FIGURA 5.13c - Comparação entre a curva prevista da estaca 30 para carga $\mathrm{P}_{3} \mathrm{e}$ a curva experimental.

FIGURA 5.13d - Comparação entre a curva ajustada pelos três pontos da estaca 30 e a curva experimental. .96

FIGURA 5.14a - Comparação entre a curva prevista da estaca 31 para carga $\mathrm{P}_{1} \mathrm{e}$ a curva experimental. .96

FIGURA 5.14b - Comparação entre a curva prevista da estaca 31 para carga $\mathrm{P}_{2}$ e a curva experimental .96 
FIGURA 5.14c - Comparação entre a curva prevista da estaca 31 para carga $\mathrm{P}_{3} \mathrm{e}$ a curva experimental.

FIGURA 5.14d - Comparação entre a curva ajustada pelos três pontos da estaca 31 e a curva experimental. 96

FIGURA 5.15a - Comparação entre a curva prevista da estaca 33 para carga $\mathrm{P}_{1}$ e a curva experimental.

FIGURA 5.15b - Comparação entre a curva prevista da estaca 33 para carga $\mathrm{P}_{2}$ e a curva experimental .97

FIGURA 5.15c - Comparação entre a curva prevista da estaca 33 para carga $\mathrm{P}_{3} \mathrm{e}$ a curva experimental.

FIGURA 5.15d - Comparação entre a curva ajustada pelos três pontos da estaca 33 e a curva experimental. .97

FIGURA 5.16a - Comparação entre a curva prevista da estaca 34 para carga $\mathrm{P}_{1} \mathrm{e}$ a curva experimental.

FIGURA 5.16b - Comparação entre a curva prevista da estaca 34 para carga $\mathrm{P}_{2}$ e a curva experimental.

FIGURA 5.16c - Comparação entre a curva prevista da estaca 34 para carga $\mathrm{P}_{3}$ e a curva experimental. .98

FIGURA 5.16d - Comparação entre a curva ajustada pelos três pontos da estaca 34 e a curva experimental. .98 


\section{LISTA DE TABELAS}

TABELA 2.1 - Análise granulométrica para o solo da Formação Tinguis em termos percentuais (Duarte, 1986)......

TABELA 2.2 - Análise granulométrica para o solo da Formação Guabirotuba em termos percentuais (Duarte, 1986)

TABELA 2.3 - Valores de $\rho, \rho_{\mathrm{s}}, \mathrm{w}_{\mathrm{L}}, \mathrm{w}_{\mathrm{p}}, \mathrm{IP}, \mathrm{w}_{\text {nat }}$ e $\mathrm{e}_{\mathrm{o}}$ para os solos da Formação Tinguis e Formação Guabirotuba.

TABELA 2.4 - Resultados dos ensaios de expansão livre para amostras no estado natural e secas ao ar (Pereira, 1999).

TABELA 2.5 - Resultados dos ensaios de pressão de expansão (Pereira, 1999)

TABELA 2.6 - Contração das amostras secas ao ar retiradas para os ensaios de pressão de expansão (Pereira, 1999).

TABELA 2.7 - Dados iniciais do ensaio e coeficientes de compressibilidade do solo da Formação Guabirotuba (Duarte, 1986).

TABELA 2.8 - Valores de $c_{v}$, Eed e k estimados a partir das curvas recalque $\mathrm{x}$ log tempo de ensaios edométricos (Duarte, 1986).

TABELA 2.9 - Índices físicos iniciais (Massad et al., 1981). .39

TABELA 2.10 - Valores do coeficiente K .50

TABELA 3.1 - Valores da média, desvio padrão e coeficiente de variação da relação $\mathrm{R} / \mathrm{Pu}$ para cada método. .57

TABELA 3.2 - Características das estacas ensaiadas até a ruptura. .57

TABELA 3.3 - Valores da média, desvio padrão e coeficiente de variação das relações $\mathrm{R} / \mathrm{Pu}$ e $\mathrm{R}^{*}$ / Pu para o método Aoki - Velloso. .59

TABELA 3.4 -Valores das resistências de ponta, lateral e de ruptura obtidos pelo método Aoki - Velloso adaptado. .60

TABELA 3.5 - Valores da média, desvio padrão e coeficiente de variação da relação $\mathrm{R} / \mathrm{Pu}$ para as provas que atingiram a ruptura .61 
TABELA 3.6 - Valores da média, desvio padrão e coeficiente de variação das relações $\mathrm{R}^{*} / \mathrm{Pu}$ e $\mathrm{R}^{\prime} / \mathrm{Pu}$.

TABELA 3.7 - Valores da média, desvio padrão e coeficiente de variação da relação $\mathbf{R}_{\ell}^{\prime \prime} / \mathbf{R}_{\ell}^{*}$ para as provas que atingiram a ruptura

TABELA 3.8 - Valores da média, desvio padrão e coeficiente de variação da relação $\mathrm{R}^{*} / \mathrm{Pu}$ e $\mathrm{R}^{\prime \prime} / \mathrm{Pu}$ .65

TABELA 3.9 - Valores das resistências de ponta, lateral e de ruptura obtidos pelo método Décourt - Quaresma..

.66

TABELA 3.10 - Valores da média, desvio padrão e coeficiente de variação da relação $\mathrm{R} / \mathrm{Pu}$ para as provas que atingiram a ruptura .66

TABELA 3.11 - Valores da média, desvio padrão e coeficiente de variação da relação R/Pu e R'/Pu. .68

TABELA 3.12 - Valores recalculados da resistência de ponta. 68

TABELA 3.13 - Valores da média, desvio padrão e coeficiente de variação da relação $\mathbf{R}_{p} / R_{p}$ para as provas que atingiram a ruptura .69

TABELA 3.14 - Valores da média, desvio padrão e coeficiente de variação da relações $\mathrm{R} / \mathrm{Pu}$ e R" / Pu. .70

TABELA 3.15 - Valores da resistência de ponta, lateral e de ruptura do método Amaral .71

TABELA 3.16 - Valores da média, desvio padrão e coeficiente de variação da relação $\mathrm{R} / \mathrm{Pu}$ para as provas que atingiram a ruptura 71

TABELA 3.17 - Valores da média, desvio padrão e coeficiente de variação das relações $\mathrm{R} / \mathrm{Pu}$ e R" / Pu. .73

TABELA 3.18 - Valores da média, desvio padrão e coeficiente de variação da relação $\mathrm{R} / \mathrm{Pu}$

TABELA 4.1 - Carga última de Van der Veen (Pu, em kN) com o avanço do ensaio .77

TABELA 4.2 - Variação (em \%) da carga última de Van der Veen em relação ao estágio anterior. .78 
TABELA 4.3 - Erro (em \%) na carga última em cada estágio em relação ao valor experimental. .78

TABELA 4.4a - Variação da carga última de Van der Veen entre os dois últimos estágios $(|\Delta \mathrm{Pu}| \leq 10 \%)$.

TABELA 4.4b - Variação da carga última de Van der Veen entre os dois últimos

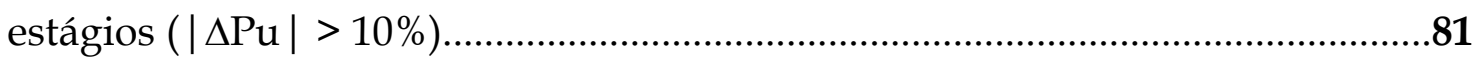

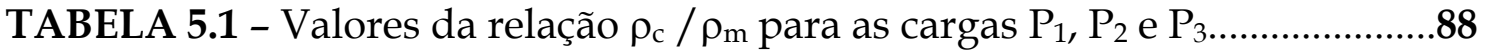

TABELA 5.2 - Distância entre a ponta da estaca e o limite inferior da sondagem (h) 


\section{LISTA DE ABREVIATURAS E SIGLAS}

CPTU Ensaio de Penetração de Cone com Medida de pressão Neutra

DPL Penetrômetro Dinâmico Leve

IP Índice de plasticidade

ISRM International Society of Rock Mechanics

RMC Região Metropolitana de Curitiba

RSA Razão de Sobreadensamento

SPT Standart Penetration Test

UFPR Universidade Federal do Paraná 


\section{LISTA DE SÍMBOLOS}

$\rho \quad$ Recalque

$\phi_{\mu} \quad$ Ângulo de atrito intrínseco

$\Delta \sigma_{\mathrm{i}} \quad$ Acréscimo de tensão vertical

$\sigma_{\mathrm{ad}} \quad$ Pressão de pré-adensamento

$\rho_{c} \quad$ Recalque calculado

$\rho_{\mathrm{m}} \quad$ Recalque medido

$\sigma_{\mathrm{n}}$ Tensão vertical

$\phi_{\mathrm{R}} \quad$ Ângulo de atrito residual

$\rho_{\mathrm{s}} \quad$ Massa específica dos sólidos

a Coeficiente de forma da curva de Van der Veen

$\mathrm{A}_{\mathrm{p}} \quad$ Área de ponta

b Intercepto no eixo dos recalques da curva de Van der Veen

$\mathrm{C}_{\mathrm{c}} \quad$ Índice de compressão

$\mathrm{C}_{\mathrm{e}} \quad$ Índice de expansão

$\mathrm{C}_{\mathrm{V}} \quad$ Coeficiente de adensamento

D Diâmetro das estacas

$\mathrm{E}_{\mathrm{c}} \quad$ Módulo de elasticidade da estaca

E $\quad$ Módulo de deformabilidade confinado efetivo

$\mathrm{e}_{\mathrm{o}} \quad$ Índice de vazios inicial

$\mathrm{f}_{\mathrm{c}} \quad$ Atrito lateral unitário

h Distância entre a ponta da estaca e o limite inferior da sondagem

$h_{i} \quad$ Distância entre o centro da camada $i$, ao longo do fuste, e o centro da camada j abaixo da ponta da estaca

$h_{j} \quad$ Distância entre a ponta da estaca e o centro da camada $j$

k Coeficiente de permeabilidade

K Coeficiente de Aoki - Velloso

$\ell_{\mathrm{i}} \quad$ Espessura da camada $\mathrm{i}$

L Comprimento das estacas 
$\mathrm{N}_{\mathrm{p}} \quad \mathrm{SPT}$ médio na ponta da estaca

$\mathrm{N}_{\ell} \quad$ SPT médio no fuste da estaca

P Carga aplicada no topo da estaca

$\overline{\mathrm{P}_{\mathrm{e}}} \quad$ Carga nominal admissível estruturalmente

$\mathrm{q}_{\mathrm{c}} \quad$ Resistência de ponta do cone

$\mathrm{Q}_{\mathrm{i}} \quad$ Esforço normal na estaca na cota correspondente ao topo da camada $\mathrm{i}$

R Capacidade de carga

$\mathrm{R}^{*} \quad$ Capacidade de carga obtida pelo método adaptado

$\mathrm{R}^{\prime} \quad$ Capacidade de carga obtida pelo fator de correção global

R” Capacidade de carga obtida pelo fator de correção parcial

$\mathrm{R}_{\mathrm{p}} \quad$ Carga de ponta

$\mathrm{R}_{\mathrm{p}}^{*} \quad$ Carga de ponta obtida pelo método adaptado

$R_{p}^{\prime} \quad$ Carga de ponta obtida pelo fator de correção global

$R_{p}^{\prime \prime} \quad$ Carga de ponta obtida pelo fator de correção parcial

$\mathrm{R}_{\ell} \quad$ Carga lateral

$\mathrm{R}_{\ell}^{*} \quad$ Carga lateral obtida pelo método adaptado

$\mathrm{R}_{\ell}^{\prime} \quad$ Carga lateral obtida pelo fator de correção global

$\mathrm{R}_{\ell}^{\prime} \quad$ Carga lateral obtida pelo fator de correção parcial

$\mathrm{R}_{\ell_{\mathrm{i}}} \quad$ Parcela de atrito lateral na camada $\mathrm{i}$

So Grau de saturação inicial

$\mathrm{WL}_{\mathrm{L}} \quad$ Limite de liquidez

$\mathrm{W}_{\text {nat }}$ Umidade natural

$\alpha \quad$ Coeficiente de Aoki - Velloso em função do tipo de solo

$\mathrm{w}_{\mathrm{p}} \quad$ Limite de plasticidade 


\section{RESUMO}

Vianna, A. P. F. (2000) - Análise de Provas de Carga Estática em Estacas Prémoldadas Cravadas na Cidade de Curitiba e Região Metropolitana. Dissertação de Mestrado, USP / São Carlos.

Nesta dissertação são analisadas 34 provas de carga estática realizadas em estacas pré-moldadas de concreto, cravadas em diferentes locais da cidade de Curitiba e Região metropolitana, sendo a maioria delas na Formação Guabirotuba.

Três métodos de previsão da capacidade foram analisados: Aoki Velloso (1975), Décourt - Quaresma (1978) e Amaral (1982, 1999). Para cada método foram propostos fatores de correção global e/ou parcial que tornam o valor da capacidade de carga mais próximo do valor da carga última obtida pelo critério de Van der Veen (1953).

Com base em quatro provas de carga conduzidas até a ruptura, estudou-se a aplicabilidade do método de Van der Veen (1953) e determinouse um critério para avaliar a extrapolação da curva carga $x$ recalque em ensaios encerrados sem atingir a ruptura.

Finalmente fez-se uma análise dos recalques comparando-se os valores medidos com os calculados, para três níveis de carregamento, além da comparação das curvas carga $x$ recalque ajustadas com as experimentais.

PALAVRAS CHAVES: Prova de carga, carga última, curva carga x recalque. 


\begin{abstract}
Vianna, A. P. F. (2000) - Analysis of static loading tests in concrete drive pile carried out in Curitiba City and Metropolitan Area. Dissertação de Mestrado, USP / São Carlos.
\end{abstract}

This Thesis presents the analysis of 34 static loading tests in concrete drive pile, located at different places of the Curitiba City and Metropolitan Area, in Guabirotuba Formation.

Three methods of the bearing capacity prediction were assessed: Aoki - Velloso (1975), Décourt - Quaresma (1978) and Amaral (1982,1999). For each method is proposed global correction factors and/or partial that turned the bearing capacity value close to the ultimate load obtained for the Van der Veen criteria (1953).

Based on four static loading test carried out to failure, the applicability of the Van der Veen criteria was assessed and was determined a rule to evaluate the extrapolation of the load - settlement curve in tests stopped before of the failure.

Finally, it was made an analysis of the settlements, where it was compared the observed values and the predicted values, for three loading level, and also a comparison between the experimental load-settlement curve and the predicted load-settlement curve.

KEYWORD: Static load test, ultimate load, load -settlement curve. 


\section{INTRODUÇÃO}

Um estudo geotécnico da Formação Guabirotuba tem grande importância regional devido sua presença significativa na Região Metropolitana de Curitiba, englobando várias áreas da Capital (centro, bairros Água Verde, Batel e Juvevê, Centro Politécnico, Cidade Industrial, etc.) além de cidades próximas (Campo Largo, Araucária, Piraquara, Quatro Barras, São José dos Pinhais). Suas características e comportamento mecânico peculiares são fatores que enfatizam também a importância deste estudo.

$\mathrm{O}$ rápido desenvolvimento desta região, devido principalmente à instalação de grandes indústrias multinacionais e ao crescimento demográfico acelerado, trás à tona a necessidade de conhecer e entender melhor o comportamento deste tipo de solo de forma a evitar prejuízos materiais em obras de engenharia.

Muitos estudos sob o ponto de vista geológico já foram realizados a respeito. Porém, pesquisas mais direcionadas a problemas de engenharia vêm sendo desenvolvidos há pouco tempo.

Nesta dissertação são analisadas 34 provas de carga estática realizadas em estacas pré-moldadas de concreto, cravadas em diferentes locais da cidade de Curitiba e Região Metropolitana, sendo a maioria situada na Formação Guabirotuba. As curvas obtidas nos ensaios estão apresentadas no anexo 1, inclusive na forma de gráficos $\log \mathrm{P} \times \rho$. 
Primeiramente procurou-se adaptar alguns métodos de previsão de capacidade de carga ao tipo de estaca estudada na região em questão. Para isso aplicaram-se às quatro estacas levadas à ruptura os métodos Aoki Velloso (1975), Décourt - Quaresma (1978) e Amaral (1982,1999). Os valores resultantes da capacidade de carga $(\mathrm{R})$ de cada método foram comparados aos valores da carga última $(\mathrm{Pu})$ obtidos através da extrapolação pelo método de Van der Veen das curvas carga $x$ recalque das provas de carga. Com isto foram obtidos coeficientes de correção global e/ou parcial para cada método mencionado, de forma a obter um novo valor de $\mathrm{R}$ mais próximo de $\mathrm{Pu}$.

Também se estudou a aplicabilidade do método de Van der Veen (1953), o qual tem sido amplamente utilizado para a extrapolação de curvas obtidas em provas de carga que não foram levadas à ruptura. Para verificação da validade deste procedimento, foram utilizadas quatro provas de carga conduzidas até a ruptura. Utilizou-se a expressão matemática de Van der Veen, modificada por Aoki (1976), para não impor que a curva carga $x$ recalque passe pela origem, determinando-se um critério para garantir uma boa extrapolação destas curvas.

O método proposto por Chin (1978) para avaliação da condição estrutural de uma estaca também foi aplicado ao conjunto de estacas, sem a possibilidade de comprovação.

Finalmente fez-se uma análise dos recalques. Calculou-se o recalque para três níveis diferentes de carregamento em cada estaca e comparou-se com os respectivos recalques medidos. Para cada um destes valores de recalque fez-se a previsão da curva carga $x$ recalque comparando-as com as curvas experimentais. Também utilizou-se o método de Van der Veen (1953) para ajustar a curva pelos três valores de recalque calculados para cada estaca. 


\section{REVISÃO BIBLIOGRÁFICA}

\subsection{ASPECTOS GEOGRÁFICOS}

\subsubsection{Localização}

A malha urbana de Curitiba e Região Metropolitana tem limites praticamente coincidentes com a distribuição geográfica dos sedimentos da

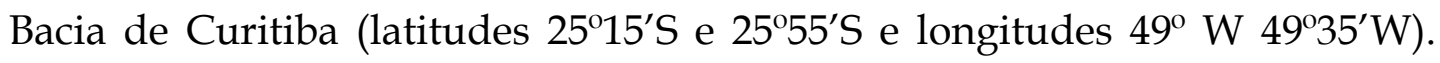
Esta bacia abrange uma área de cerca de $3000 \mathrm{~km}^{2}$ e possui contornos irregulares, sendo limitada por todos os lados por terrenos pré-cambrianos que constituem seu embasamento. Siedlecki (1998) elaborou o mapa apresentado na figura 2.1 utilizando fontes da COMEC (1995) e Fortin (1989).

\subsubsection{Topografia}

O planalto curitibano pode ser caracterizado como colinoso, apresentando altitudes variáveis entre 880 e 960 m. Os relevos são descritos como tipicamente de ondulações suaves e amplas planícies de inundação, que se estendem para mais de $800 \mathrm{~km}^{2}$. Essas planícies ocorrem em forma de calhas aluviais. (Ab'Saber, 1966). 


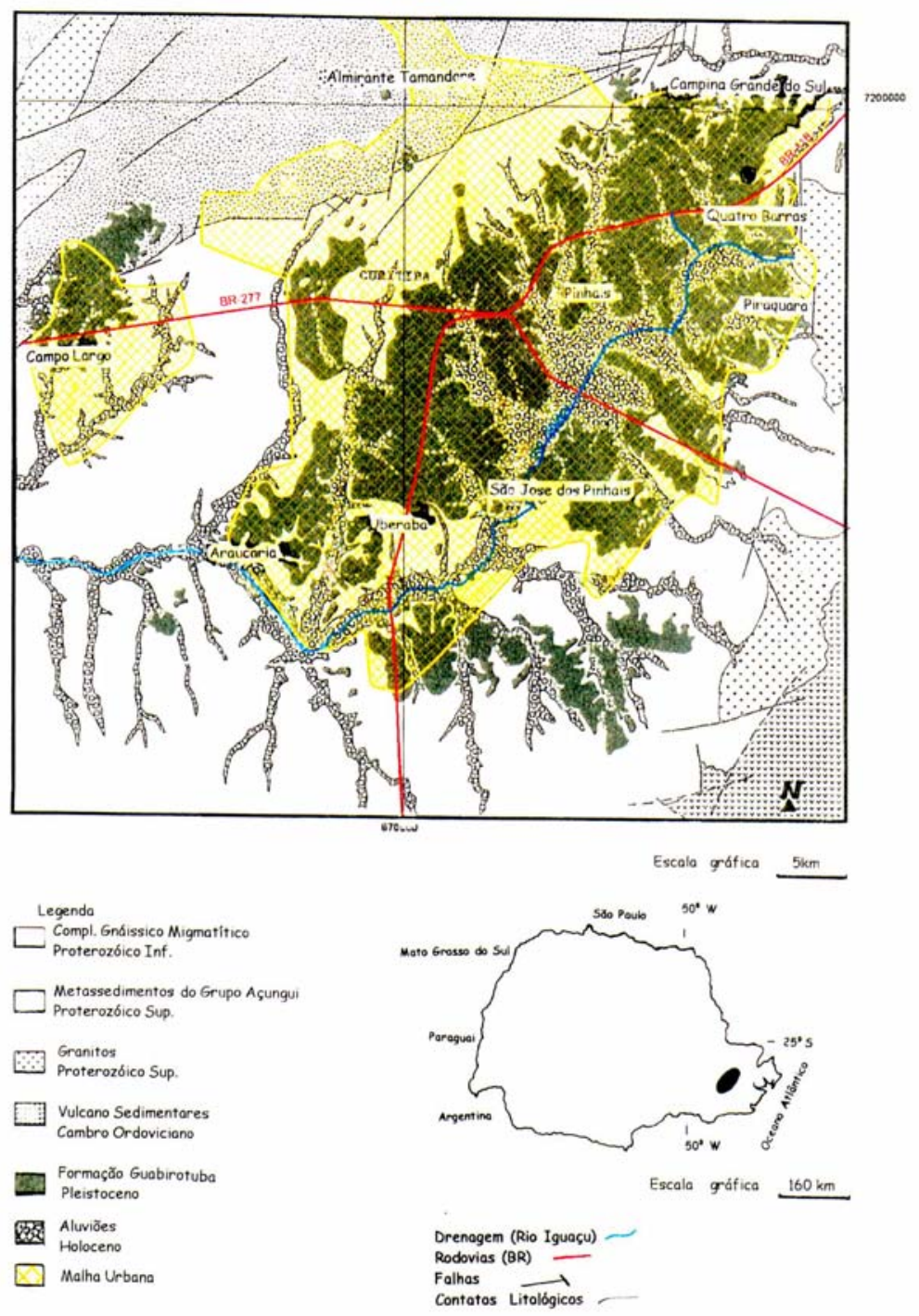

Figura 2.1 - Associação entre malha urbana da Região Metropolitana de Curitiba e contexto regional (Siedlecki, 1998)

Canali \& Muratori (1981), retomando a linha de Bigarella et al. (1965), descrevem a morfologia atual como constituída por amplas colinas, articulada para talvegues de altitudes inferiores através de uma sucessão de patamares, cuja declividade é inferior a 6\%. As encostas são dissecadas por talvegues menores que separam os remanescentes de sedimentos.

Giusti (1989) apresenta a variação do relevo de acordo com as regiões descritas a seguir: 
A porção nordeste encontra-se profundamente entalhada pelos afluentes do Rio Passaúna e suas nascentes, sendo então uma região montanhosa rebaixada do nível geral do primeiro planalto paranaense.

Nesta porção o relevo é mais enérgico, com espigões alongados, vertentes íngremes e vales em $\mathrm{V}$.

Na porção centro-sul o relevo é mais suave quando ocorrem rochas do embasamento cristalino e as planícies aluviais são extremamente amplas e desenvolvem-se ao longo do Rio Iguaçu e de seus afluentes. Estas áreas passam a planícies de soleira em alguns locais.

Nas regiões recobertas pelos sedimentos cenozóicos da Bacia de Curitiba, a topografia é pouco acidentada, modulada em elevações de baixa altura e encostas muito suaves com vales muito abertos e de fundo chato.

\subsubsection{Uso e Ocupação do Solo}

A área da Região Metropolitana de Curitiba (RMC) faz parte de um território cuja colonização teve início com a mineração do ouro, posteriormente a criação de gado, a cultura do mate e a extração da madeira, com a consolidação das vias de Curitiba e São José dos Pinhais (COMEC, 1997).

As características morfológicas do terreno da Bacia Sedimentar de Curitiba tiveram influência sobre o desenvolvimento urbano da cidade e dos municípios de sua região metropolitana, já que a ocupação do solo se deu de modo a evitar terrenos entalhados do complexo cristalino, de relevo mais íngreme, bem como regiões de várzeas, ainda sujeita aos processos geológicos acarretados pelas inundações (Boszczowski \& Borga, 1998).

A distribuição do material pertencente à Formação Guabirotuba e os aluviões formados nas regiões das várzeas dos rios podem ser visualizados na figura 2.2. Segundo Giusti (1989), o grande incremento da população de Curitiba se deu a partir dos anos 70, ocorrendo um descontrolado processo 
de "perifização" e ocupação do solo com avanço em direção aos municípios vizinhos, configurando uma complexa conurbação da RMC.

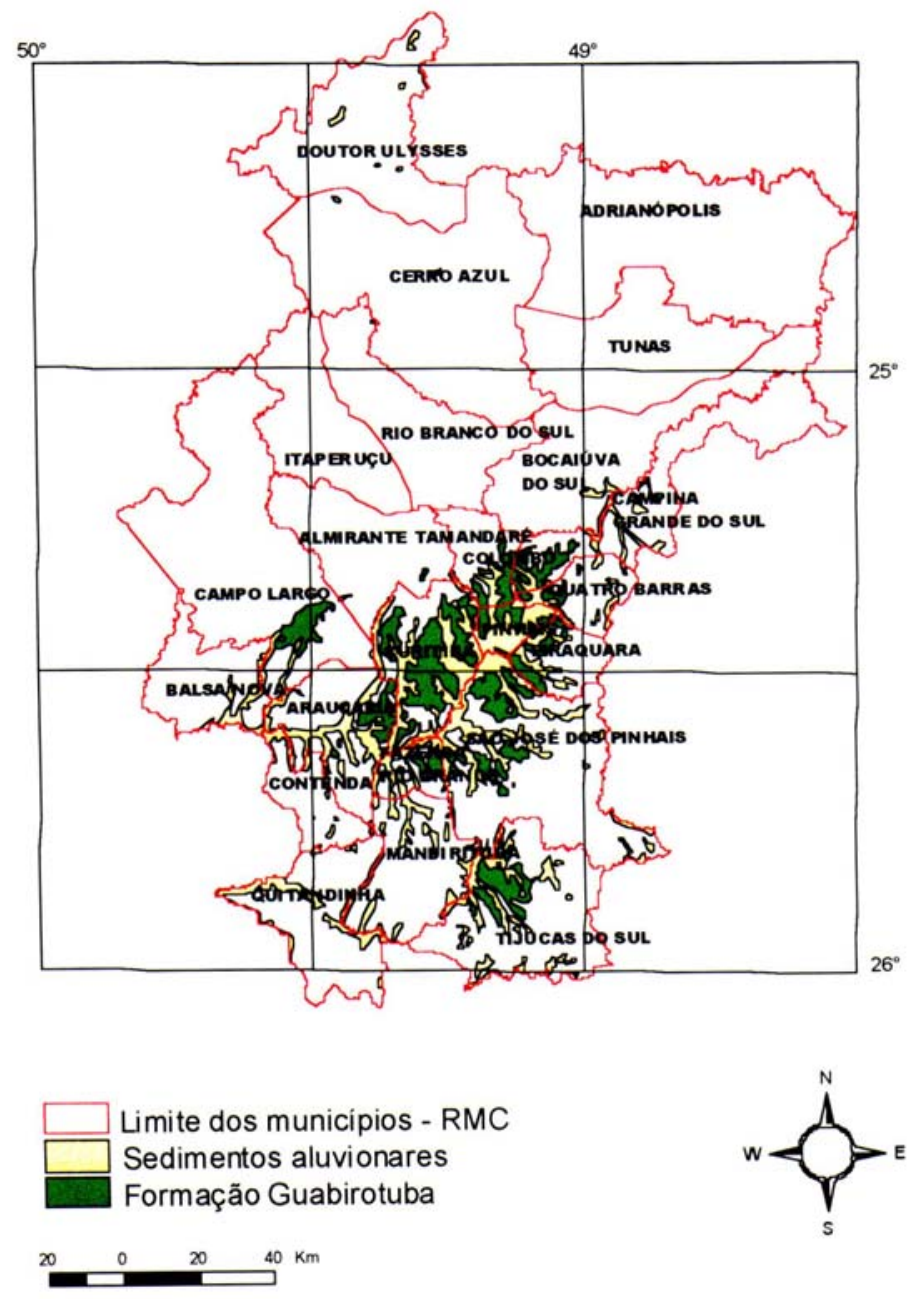

\section{Figura 2.2 - Distribuição da Formação Guabirotuba na RMC (DNPM/MINEROPAR, 1989 apud Felipe, 1998)}

Nos anos 80 verificou-se um reforço na tendência de expansão da malha urbana em direção aos municípios limítrofes, com ampliação e maior adensamento em relação à malha existente anteriormente. A ocorrência da expansão da malha urbana dos municípios restantes da Região, especialmente os limítrofes, caracterizou-se mais como uma continuidade da trama urbana de Curitiba do que um desenvolvimento dos próprio municípios. 
Segundo Schussel (1997), a RMC concentra respectivamente 25,34\% e 30,53\% das populações total e urbana do Estado do Paraná. A densidade demográfica da RMC é baixa, quando considerada no total (158 habitantes $\left./ \mathrm{km}^{2}\right)$. Na área urbana tem-se uma densidade de 1794 habitantes $/ \mathrm{km}^{2}$ na região e 3044 habitantes $/ \mathrm{km}^{2}$ em Curitiba.

Quanto à evolução da população urbana na região, para a atual década, mantendo-se esse ritmo de crescimento, haverá um acréscimo de 432.849 habitantes até o ano 2.000 e de 747.780 habitantes no período de 2.000 a 2.010, totalizando um acréscimo de 3.066.797 habitantes.

No município de Curitiba, nota-se que a população vem diminuindo seu ritmo de crescimento, enquanto nos demais municípios vem aumentando significativamente. Em 1.970 a população de Curitiba representava 88,48\% da RMC, baixando para 69,72\% em 91, e de acordo com projeções, chegará a 52,65\% em 2010. Curitiba e seus seis municípios limítrofes formam uma grande malha urbana contínua, que concentra $87 \%$ da população da RMC.

Este grande crescimento demográfico vem constituindo um importante agente modificador do meio ambiente, interferindo em seu equilíbrio, potencializando e acelerando diversos processos da dinâmica superficial. Estas interferências adquirem especial importância nas áreas de ocorrência da Formação Guabirotuba, devido a sua susceptibilidade natural a processos erosivos e aos movimentos gravitacionais de massa que são alguns de seus problemas mais comuns. A erosão e os movimentos de massa na região urbana estão associados à falta de planejamento adequado às condições sociais e econômicas do desenvolvimento em áreas urbanas (Felipe, 1998).

O desenvolvimento da cidade efetuou-se principalmente sobre as áreas ocupadas pelos Sedimentos Cenozóicos, onde se verifica uma grande concentração de obras de engenharia. Em alguns locais, onde há concentração de grandes edifícios, estão surgindo alguns problemas de recalques excessivos e desaprumos acentuados. Tais problemas podem ter 
sua origem devido ao uso abusivo do solo, superavaliação de características e/ ou conhecimento superficial do comportamento do "Sabão de Caboclo".

\subsection{ASPECTOS GEOLÓGICOS}

A geologia da Região Metropolitana de Curitiba (RMC) compreende três partes fundamentais. A primeira é representada pelos terrenos précambrianos formados respectivamente pelas rochas do Complexo Cristalino e dos Grupos Açungui e Setuva. A segunda é constituída pelas formações Camarinha e Guaratubinha e a terceira pelas formações cenozóicas (Formação Guabirotuba e seqüências mais recentes). O modelo digital elaborado por Salamuni (1998) ilustra as formações citadas (fig. 2.3).

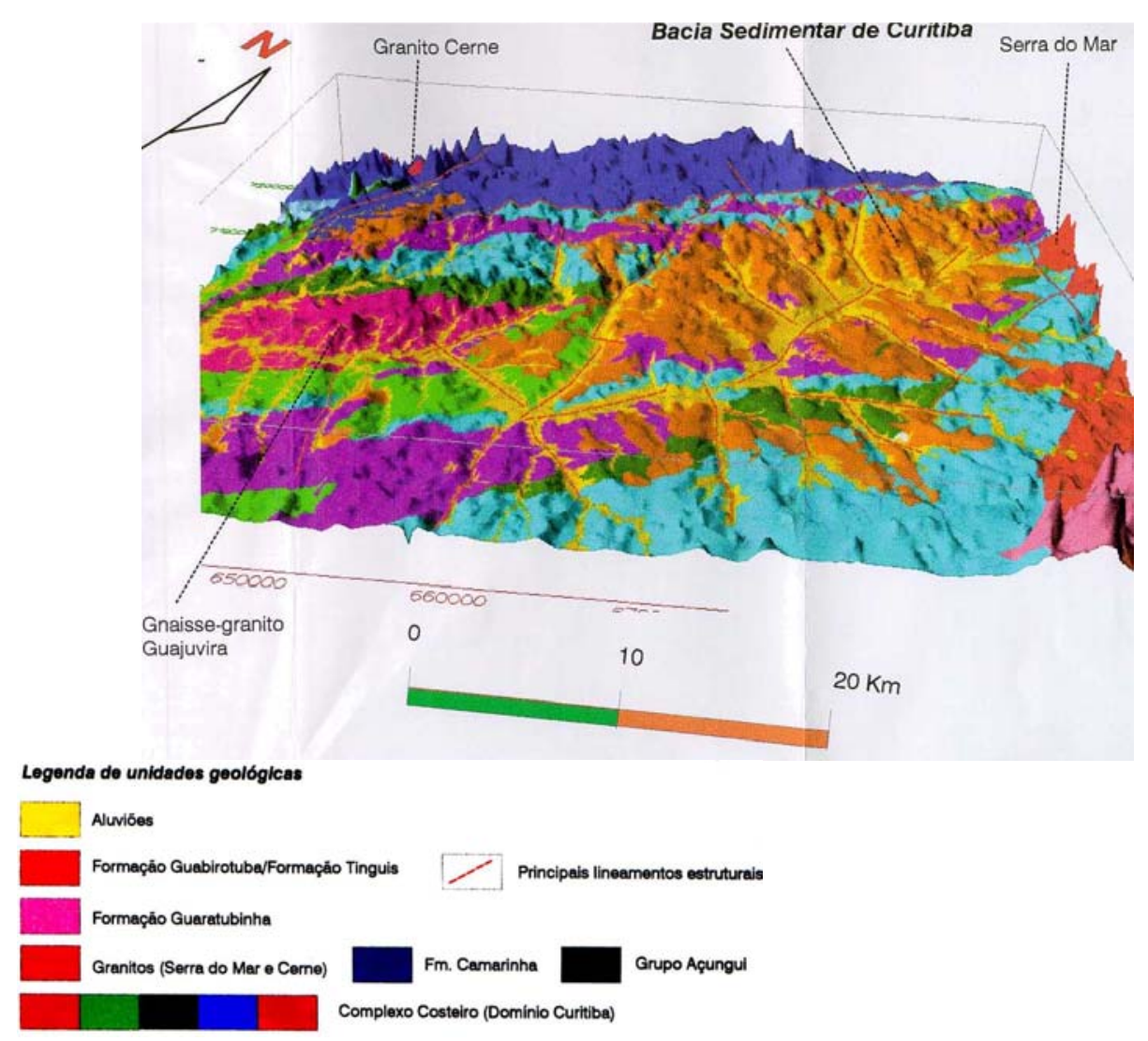

Figura 2.3 - Modelo digital do terreno visualizando os constituintes litológicos da área estudada (Salamuni, 1998). 
Devido ao fato deste trabalho apresentar maior enfoque à Formação Guabirotuba, serão enfatizadas as descrições da Bacia Sedimentar de Curitiba e das Formações Cenozóicas.

\subsubsection{Bacia Sedimentar de Curitiba}

Os depósitos cenozóicos da Bacia de Curitiba apresentam dificuldades para uma revisão estratigráfica, pela não existência de camadas guias. Tornase necessária a adoção de uma metodologia apropriada a este tipo de problema, a qual permita o estabelecimento de correlações e eventuais datações das camadas (Becker, 1982).

Os métodos geomorfológicos associados aos estratigráficos possibilitam uma melhor visão de conjunto dos fenômenos que ocorreram na bacia de sedimentação.

Azevedo (1981) sugere que pelo menos a porção superior da Formação Guabirotuba seja de idade pleistocênica. Tal idade é atribuída devido a ocorrência de microfósseis pertencentes ao grupo dos thecamoebianos encontrados nestas partes superiores e nas porções retrabalhadas dos sedimentos da própria formação.

Salamuni (1998) encontra em seu estudo pelo menos uma ocorrência fossilífera . Trata-se de bolsões de matéria orgânica, de coloração escura, em meio aos argilitos cinza-esverdeados, típicos do Guabirotuba (figura 2.4). 

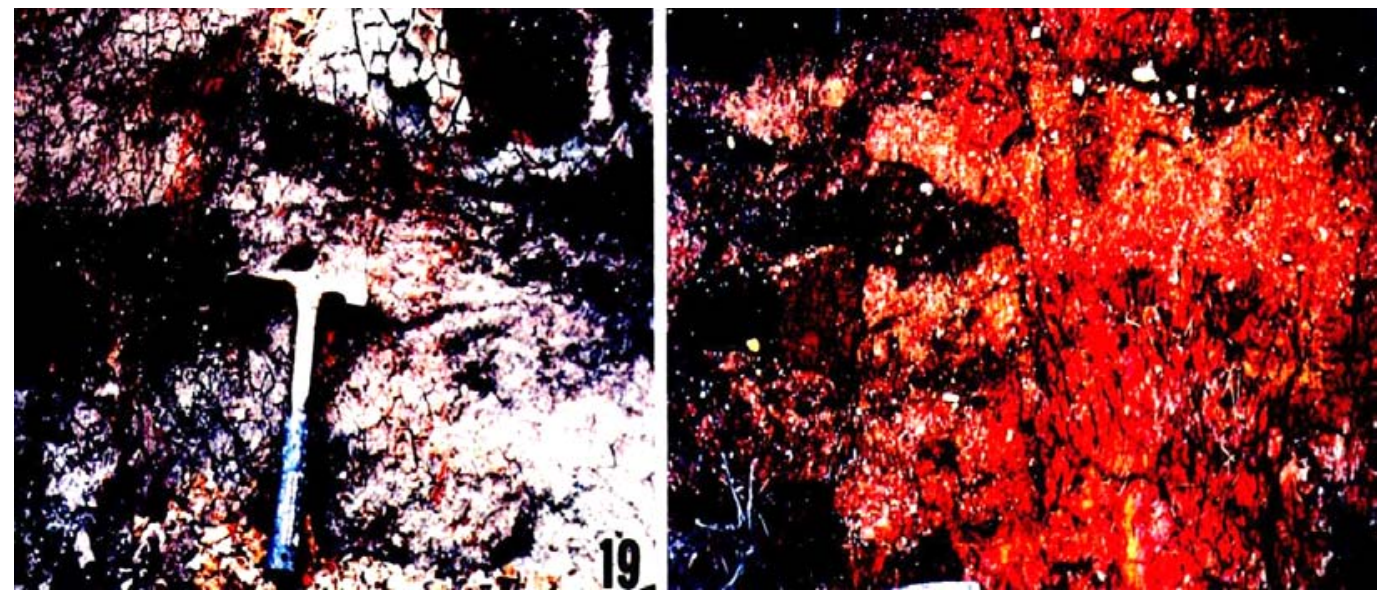

Figura 2.4 -Bolsões de materia orgânico que contém palinomorfor dentro de argilitos da Formação Guabirotuba (Salamuni, 1998).

Segundo Duarte (1986), a Bacia de Curitiba aproxima-se nos seus aspectos gerais e na morfologia superficial à Bacia Sedimentar de São Paulo, não obstante os trabalhos geológicos realizados ressaltarem as diferenças marcantes existentes entre as seqüências litográficas das duas bacias.

De acordo com Bigarella \& Salamuni (1962), a geologia da Bacia de Curitiba pode ser dividida em três agrupamentos distintos e perfeitamente diferenciados.

O primeiro, denominado Embasamento Cristalino é constituído por um complexo de rochas metamórficas do pré-cambriano (em geral, gnaisse e gnaisse-granito). Depositado sobre a superfície bastante irregular do citado embasamento, jazem os depósitos sedimentares do Terciário (depósitos cenozóicos), que são os constituintes essenciais da bacia em questão. Finalmente, depositados também sobre os gnaisses, em virtude da remoção parcial dos sedimentos mais antigos (cenozóicos), ocorrem os sedimentos mais recentes (holocênicos), depositados pelos rios e riachos que cortam a Bacia de Curitiba, constituindo assim, as várzeas.

A toda seqüência de Sedimentos Cenozóicos da Bacia de Curitiba foi atribuído o nome de Formação Guabirotuba por Bigarella et al. (1961) e Bigarella \& Salamuni (1962). 
Posteriormente, em pesquisas realizadas por Bigarella e colaboradores, revelou-se a existência de inconformidades erosivas no interior desta Formação. Tal fato permitiu reconhecer uma nova seqüência sedimentar. O que era antes considerado como uma porção intemperizada da Formação Guabirotuba, passou a ser definida como Formação Tinguis.

A subdivisão da bacia foi feita por vários autores cada qual com a sua interpretação.

Becker (1982) separa os depósitos da Bacia de Curitiba em três formações: 1) Formação Guabirotuba, depositada em ambientes de leques aluvionares durante a elaboração do pediplano $\mathrm{Pd}_{2}$, no Plioceno Inferior em épocas de semi aridez; 2) Formação Tinguis, que se depositou num ambiente de semi-aridez, mas em clima mais úmido que o da formação anterior, dissecando o terreno em vales mais amplos e suaves, elaborando o pediplano $\mathrm{Pd}_{1}$ durante o Plioceno superior e Pleistoceno inferior, 3) Formação Boqueirão, cuja sedimentação ocorreu durante o Pleistoceno superior e representa um ambiente de amplos vales com canais anastomosados, constituídos por depósitos arenáceos.

Giusti (1989) divide os sedimentos da bacia em Formação Guabirotuba, cujos sedimentos foram depositados em leques aluvionares coalescentes, e Formação Tinguis, separada da Formação Guabirotuba por discordância erosiva, depositada num clima de semi-aridez e constituída por sedimentos arenosos, arcosianos e síltico-argilosos e Depósitos Sedimentares Recentes, constituído por depósitos aluvionares.

Felipe et al. (1994), em trabalho executado pela MINEROPAR em convênio com a COMEC, dividiram os sedimentos da Bacia de Curitiba em sedimentos aluvionares recentes que se encontram nas várzeas e terraços que se localizam nas periferias dos sedimentos de várzea, e Formação Guabirotuba subdividida em duas subunidades: a primeira, encontrada em níveis topográficos inferiores e apresentando coloração cinza-esverdeada com ocorrência subordinadas de níveis de arcósios; a segunda, encontrada 
em níveis topográficos mais elevados e possuindo intercalações freqüentes de arcósio (fig. 2.5).

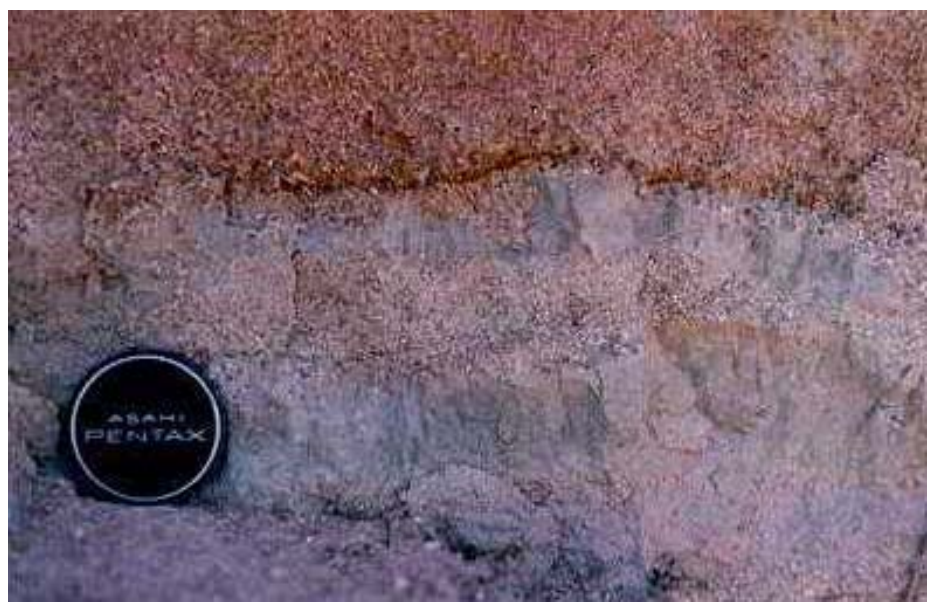

Figura 2.5 - Aspecto das alternâncias centimétricas de argilas e arcósios em sedimentos argilosos da Formação Guabirotuba (Felipe et al., 1994).

Coimbra et al. (1996) definem ainda a Formação Piraquara. Tantas subdivisões da Formação Guabirotuba em novas formações (Tinguis, Boqueirão e Piraquara) geram discussões a respeito da geologia local. Segundo Salamuni (1998), nenhuma destas três formações apresenta um documento cartográfico que delimite sua área de ocorrência. No caso da formação Tinguis, não se conhece a localização das seções pois as mesmas foram massacradas pela urbanização local. Soma-se a isto a ausência de registros documentais consistentes, tais como fotografias, desenhos e descrições mais detalhadas.

De acordo com o código estratigráfico, nenhuma destas unidades poderia receber a hierarquia de formação, com exceção, talvez, da "Formação" Tinguis. As "Formações" Boqueirão e Piraquara são semelhantes, pelo menos na sua porção conglomerática. Como a "Formação" Boqueirão está localizada em possíveis paleodrenagens, este fato poderia representar a situação pretérita episódica dos próprios depósitos de várzea, 
originados a partir do Holoceno. Sendo assim, ela não poderia estar dissociada, em termos evolutivos, dos aluviões atuais.

A unidade denominada "Formação" Piraquara necessita de melhor caracterização. De acordo com Salamuni (1998), pode-se tratar de mais de uma fácies, de deposição tardia, da Formação Guabirotuba, dominada por canais meandrantes, já ao final do seu ciclo de sedimentação. Ressalta-se que há manchas, em toda a Formação Guabirotuba de depósitos semelhantes àqueles descritos como "Formação" Piraquara, cujas relações de contato não são claras.

Devido ao fato acima apresentado, será feita menção neste trabalho apenas às Formações Guabirotuba e Tinguis, dando ênfase à primeira.

\subsubsection{Processo de Formação}

Segundo Becker (1982), o processo formativo das Formações Tinguis e Guabirotuba é o mesmo, porém ocorridos em épocas diferentes, razão pela qual a composição dos dois depósitos é distinta.

Na Era Cenozóica, nos períodos Plioceno e Pleistoceno ocorreram períodos de glaciação e degelo ocasionando alterações climáticas na região da atual Bacia. No período de glaciação, o clima era semi-árido enquanto que no período de degelo, o clima tornava-se úmido.

Durante a fase de clima úmido ocorreram os processos de decomposição das rochas do pré-cambriano resultando um manto de intemperismo (Regolito). Este manto não deveria diferir muito do que hoje em dia recobre a área correspondente ao Complexo Cristalino. Este material intemperizado constituiu a fonte inicial dos sedimentos (Duarte, 1986).

A erosão e transporte do material alterado quimicamente deu-se devido às chuvas concentradas e torrenciais que tornaram a cobertura vegetal ineficiente. O escoamento do lençol arrastava os sedimentos em direção aos vales, como verdadeiras torrentes de lama. Com isso, esses 
sedimentos depositaram-se de maneira aleatória sem que houvesse seleção dos sedimentos de acordo com o tamanho dos grãos.

A alternância ou oscilação climática foi sugerida por Bigarella \& Salamuni (1957 e 1962) e comprovada, em parte, pela constatação da existência dos Thecamoebianos, que se desenvolvem em clima úmido. Azevedo (1981) supõe que no Pleistoceno houve nova mudança climática com um ambiente propício ao desenvolvimento abundante de animais inferiores de modo que a ocorrência de esporos e pólens associados permitiria a correlação do clima daquela época ao clima atual.

Pode-se dizer que os sedimentos foram originados da decomposição química de rochas de clima úmido e transportados e depositados em clima semi-árido.

\subsubsection{Formação Tinguis}

A unidade superior do pacote de Sedimentos Cenozóicos, anteriormente considerada como produto do intemperismo sobre o material da Formação Guabirotuba foi redefinida por Becker (1982) e denominada Formação Tinguis. Esta unidade constitui uma seqüência sedimentar depositada em épocas de semi-aridez. Giusti (1989) afirma que esta seqüência, formada por sedimentos arenosos, arcosianos e síltico-argilosos, pode ser correlacionada com a Formação Riacho Morno do Grupo Barreiras e com a Formação Pariquera Açu do Vale do Ribeira.

A redefinição proposta por Becker (1982) baseou-se nas evidências encontradas de que o material desta Formação sofreu transporte. Um exemplo são as linhas de seixos e formações conglomeráticas na linha de contato entre as duas Formações. Este contato é, em geral, abrupto, na forma de uma superfície de erosão irregular. Apesar de não reconhecer o Tinguis como uma formação, Salazar Jr. (1996) identifica a existência de uma unidade 
distinta depositada sobre o Guabirotuba e separada por uma linha de seixos a qual denomina apenas de "material transportado" (fig. 2.6).

A coloração cinza-esverdeada caracteriza a unidade inferior (Guabirotuba) quando a mesma está isenta dos processos de intemperização devido à exposição ao tempo. Isto ocorre principalmente em taludes e cortes em rodovias onde se encontra tal formação com cores avermelhadas, como se observa na figura 2.6. Já na Formação Tinguis predominam os tons castanhos e avermelhados.

Os sedimentos da Formação Tinguis originaram-se do retrabalhamento das argilas e areias da Formação Guabirotuba, ocorrido durante nova inversão climática (para clima úmido) e sua posterior deposição ocorreu provavelmente em nova inversão climática, em períodos semi-áridos.

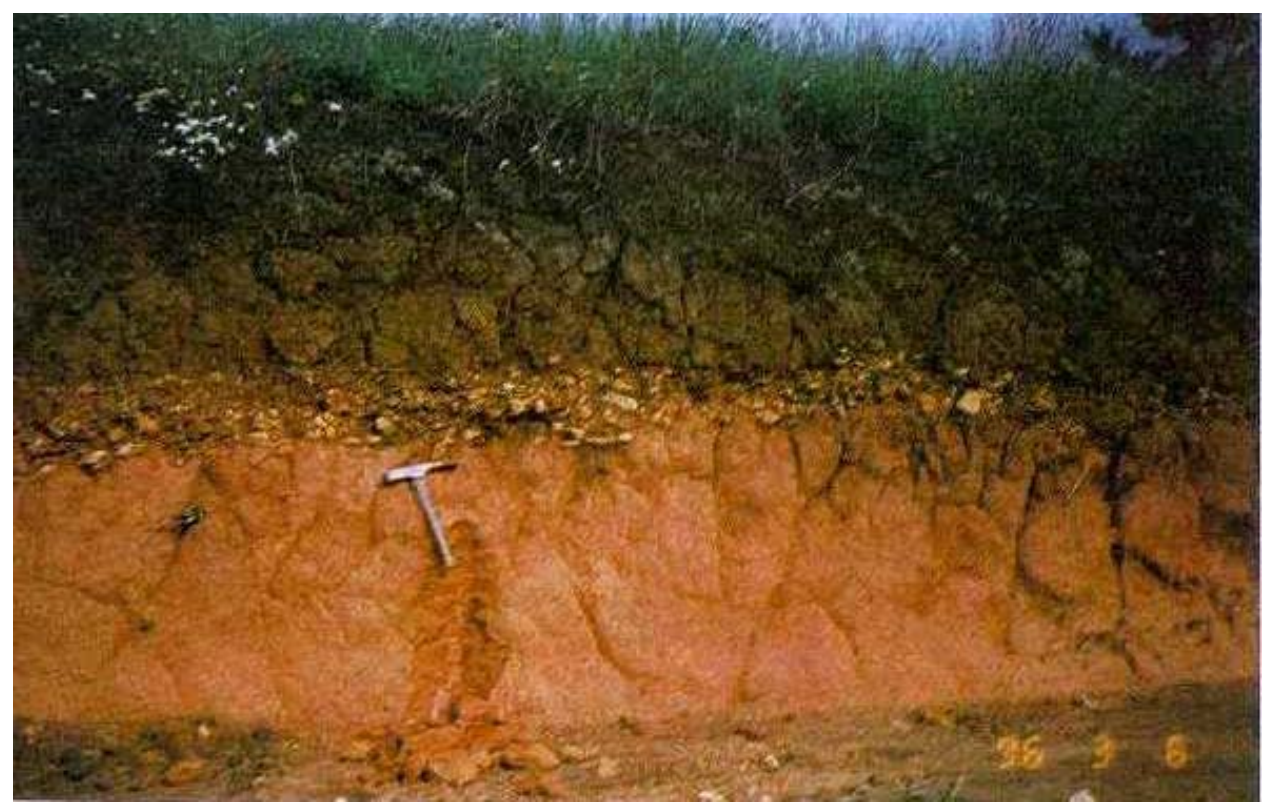

\section{Figura 2.6 - Solo transportado separado por uma linha de seixos da Formação Guabirotuba (Salazar Jr., 1996).}

A textura mais grossa e arenosa apresentada pela Formação Tinguis deve-se a este retrabalhamento e a deposição primária dos materiais mais grossos, pois os finos foram arrastados para as baixadas. 
Sendo mais grosso, e portanto mais permeável, este material permitiu escoamento intenso de água em seu interior, formando lençóis d'água suspensos, represados sobre a camada praticamente impermeável da Formação Guabirotuba, acarretando assim os processos de lixiviação, formação de óxido de ferro férrico e laterização característica dos solos bem drenados. Isto explica a coloração rósea ou avermelhada que diferencia este material daquele da Formação Guabirotuba (Duarte, 1986).

Embora ainda não tenham sido feitos trabalhos de mapeamento dos solos da Formação Tinguis, pode-se afirmar que a área de ocorrência desta formação é bem menos abrangente que a formação Guabirotuba. Além de uma área de recobrimento menor, sua espessura média é de $1 \mathrm{~m}$ a $3 \mathrm{~m}$ em consequiência da menor intensidade dos processos erosivos que a originaram.

\subsubsection{Formação Guabirotuba}

Muratori et al. (1982) concluem que a espessura dos sedimentos é variável, sendo maior na sua porção leste e central, tendo por referência a área do município. Os depósitos desta formação atingem espessuras máximas da ordem de $60 \mathrm{~m}$ a $80 \mathrm{~m}$ na porção central da Bacia de Curitiba. Tratam-se de depósitos que compreendem seqüências litológicas nas quais predominam principalmente as argilas rijas com presença de lentes arcosianas. Bigarella \& Salamuni (1962) classificam os sedimentos como argilitos e areias arcosianas. No âmbito da Mecânica dos Solos, esta denominação é modificada para "argilas rijas".

Estas argilas possuem textura extremamente fina, e as areias apresentam grãos de feldspato e quartzo de até $2 \mathrm{~mm}$ de diâmetro, o que indica a presença de processos de desagregação mecânica das rochas do complexo Cristalino de onde se originaram. Há evidências, segundo Duarte (1986), de que estes sedimentos sofreram profunda erosão após o preenchimento final da bacia, pois hoje estão separados em áreas geográficas 
distintas, intercalados com os depósitos Holocênicos (aluviões), que se assentam direto sobre as rochas do Complexo Cristalino.

Dependendo da espessura da camada, os aluviões podem estar assentados sobre os depósitos da Formação Guabirotuba. Sendo assim, pode haver regiões onde o perfil típico é formado pelo embasamento do Complexo Cristalino e, sobrejacente a ele, encontram-se os depósitos dos aluviões ou dos sedimentos da Formação Guabirotuba. Há regiões porém, em que o perfil típico é caracterizado pelo pacote embasamento Cristalino, sedimentos da Formação Guabirotuba e os aluviões.

A Formação Guabirotuba assenta discordantemente sobre o embasamento cristalino. A discordância entre os sedimentos da Formação Guabirotuba sobre o embasamento cristalino é caracterizada por Lopes (1966) como do tipo "non-conformity".

Salamuni (1998) elaborou o modelo digital apresentado na figura 2.7 indicando as principais litologias da Bacia Sedimentar de Curitiba.

Em muitos afloramentos encontram-se impregnações de carbonato de cálcio (caliche) anteriormente referidas como margas por Bigarella e Salamuni (1959). Essas formações carbonáticas contém minerais do grupo das terras raras como a lantanita mencionada por Coutinho (1955). As soluções contendo terras raras poderiam, de acordo com Becker (1982), ser provenientes tanto de rochas graníticas situadas a leste e nordeste da bacia, como também de áreas graníticas situadas a norte e nordeste, de corpos intrudidos tanto no Complexo Setuva quanto no Grupo Açungui. 


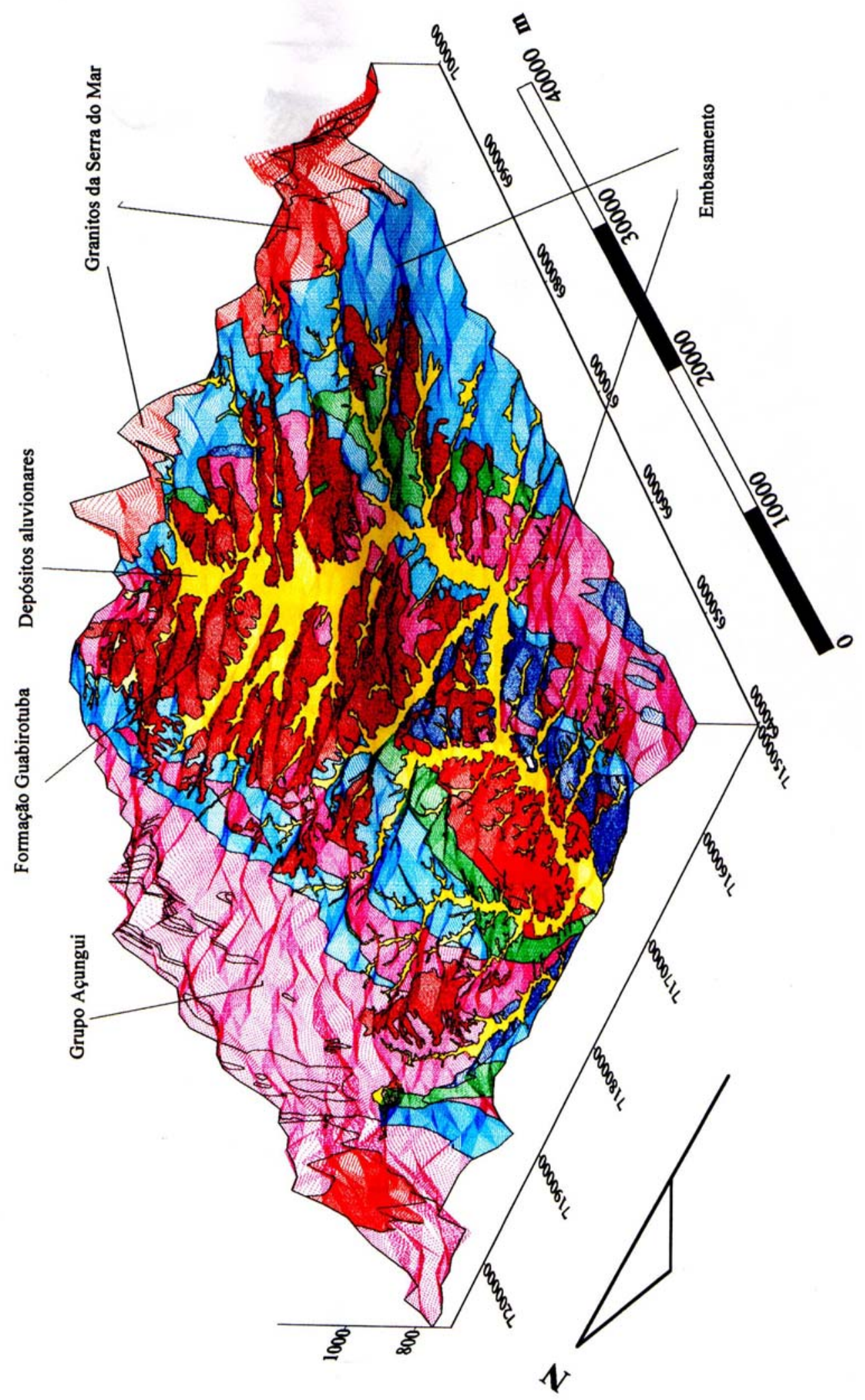

Figura 2.7 - Modelo digital de terreno com a sobreposição dos litotipos sedimentares da Bacia de Curitiba e do seu embasamento (Salamuni, 1998). 
Trescases et. al. (1986) descrevem com detalhes as terras raras da Formação Guabirotuba, definindo com detalhes como ocorrem as lantanitas nos sedimentos. Os carbonatos da bacia aparecem tanto como camadas margosas em meios argilitos como através de calcretes que estão em fissuras. Fortin (1989) e Fortin et al. (1989) aprofundam as pesquisas a respeito das lantanitas mostrando que as mesmas estão sempre próximas ao perfil genérico de alteração na superfície topográfica.

Os sedimentos arcosianos apresentam uma estratificação incipiente, às vezes entrecruzada. Os afloramentos examinados indicam uma tendência do transporte ter-se efetuado para o sul ou para o sudoeste, porém acredita-se na hipótese do transporte ter-se desenvolvido ou modificado durante a evolução da bacia. A configuração topográfica do embasamento cristalino mostra uma tendência para sudoeste e oeste a partir do centro (Giusti, 1989).

As argilas são os componentes litológicos mais abundantes na Formação Guabirotuba, preferencialmente acumulados em direção ao interior da bacia. Os fácies argilosos típicos apresentam variações de tonalidades do cinza. A natureza mineralógica é mista: esmectita, ilita e caulinita (Berg et al., 1973).

Os sedimentos desta Formação, segundo Polidoro (1997), são altamente erosivos por terem presença predominante de argilomineral do grupo das esmectitas (montmorilonita). Estas argilas apresentam retração e expansão muito grande pela perda ou absorção de água (argila higroscópica). Este fato, aliado à sua granulometria, faz com que estas argilas sejam facilmente transportadas. Portanto, a facilidade de transporte desta argila se dá mais pelo caráter físico-químico do que pela força dinâmica da água concentrada.

Em superfície, os sedimentos de características preferencialmente cauliníticas assumem coloração avermelhada, atribuída à presença de óxidos e hidróxidos de Fe. Os resultados analíticos obtidos por Fortin (1989) evidenciam a evolução da composição química da fração argilosa em direção 
ao horizonte superficial (avermelhado), traduzida pela diminuição progressiva da relação $\mathrm{SiO}_{2} / \mathrm{Al}_{2} \mathrm{O}_{3}$ e dos teores de $\mathrm{MgO}$ e $\mathrm{CaO}$. A diminuição do $\mathrm{K}_{2} \mathrm{O}$ porém é significativa somente no horizonte avermelhado. O processo de monossialitização se daria, portanto, a partir do horizonte cinza, enquanto que para a fração ilítica, a alteração se iniciaria a níveis mais superficiais.

\subsection{ASPECTOS GEOTÉCNICOS}

O solo da cidade de Curitiba e Região Metropolitana (RMC) caracteriza-se por ser argila-siltosa ou silte-argiloso com intercalações de lentes arenosas e arcosianas, de consistência elevada, variando de rija a dura. Apresenta-se nas cores cinza, cinza-esverdeada, marrom clara e avermelhada, conforme a localização e a formação a que se relaciona, sendo os tons de cinza mais comumente relacionados à Formação Guabirotuba e os tons avermelhados, à Formação Tinguis.

Este trabalho apresenta maior ênfase aos solos da Formação Guabirotuba, porém sempre que possível serão feitas comparações entre as duas formações. Quanto às características de campo, trata-se de um solo altamente plástico, de elevada expansibilidade tanto pela presença predominante de argilominerais do grupo das esmectitas quanto pelo fato de ser pré-adensado e que quando umedecido torna-se extremamente liso e pegajoso, motivo pelo qual é denominado popularmente de "sabão de caboclo" em sua região de ocorrência. Se exposto ao ar, sofre ressecamento e, na falta de cobertura vegetal, pode ocorrer o empastilhamento de sua superfície. Quando cortado ou desconfinado, apresenta superfície lisa e brilhante, porém não acusa direção predominante, ocorrendo aleatoriamente. Estruturas de origem tectônica, seguindo padrões definidos, também estão presentes (Salamuni, 1998). 


\subsubsection{Identificação de Campo}

Sondagens de simples reconhecimento com medidas de SPT realizadas na região de Araucária confirmaram a presença de uma camada de argila siltosa variegada, com predominância da cor vermelha, sobrejacente à argila siltosa plástica cinza clara (Fig. 2.8). A existência de camadas superficiais de cores variegadas é consequiência da intemperização da argila cinza clara (Massad et al., 1981).

Pode-se observar, na figura 2.8, que os valores de resistência à penetração nas camadas de argila siltosa vermelha ou variegada são da ordem de 3 a 6, enquanto que as camadas de argila siltosa cinza clara apresentam em geral resistência à penetração elevada, com SPT superior a 10 e aumentando com a profundidade.

Chamecki et al. (1998) detectaram também em ensaios de SPT realizados no Sítio Experimental de Geotecnia da UFPR, duas camadas distintas, sendo a mais superficial de coloração marrom e avermelhada e abaixo desta, um pacote típico da Formação Guabirotuba, composto por argilas rijas a duras, de coloração cinza e marrom. Nesta camada encontra-se um estrato de areia fina rica em feldspato. O nível d'água detectado apresenta-se superficial, em profundidades de 2,0 $\mathrm{m}$ a 2,5 m.

Também foram realizados ensaios do tipo Cone Penetration Test, com medida de pressão neutra (CPTU) e Penetrômetro Dinâmico Leve (DPL). Nos ensaios de CPTU, os valores de resistência de ponta na camada de argila marrom situaram-se em torno de $6 \mathrm{MPa}$, enquanto a razão de atrito oscilou em torno de $4 \%$, valor este típico para argilas (Fig. 2.9). 

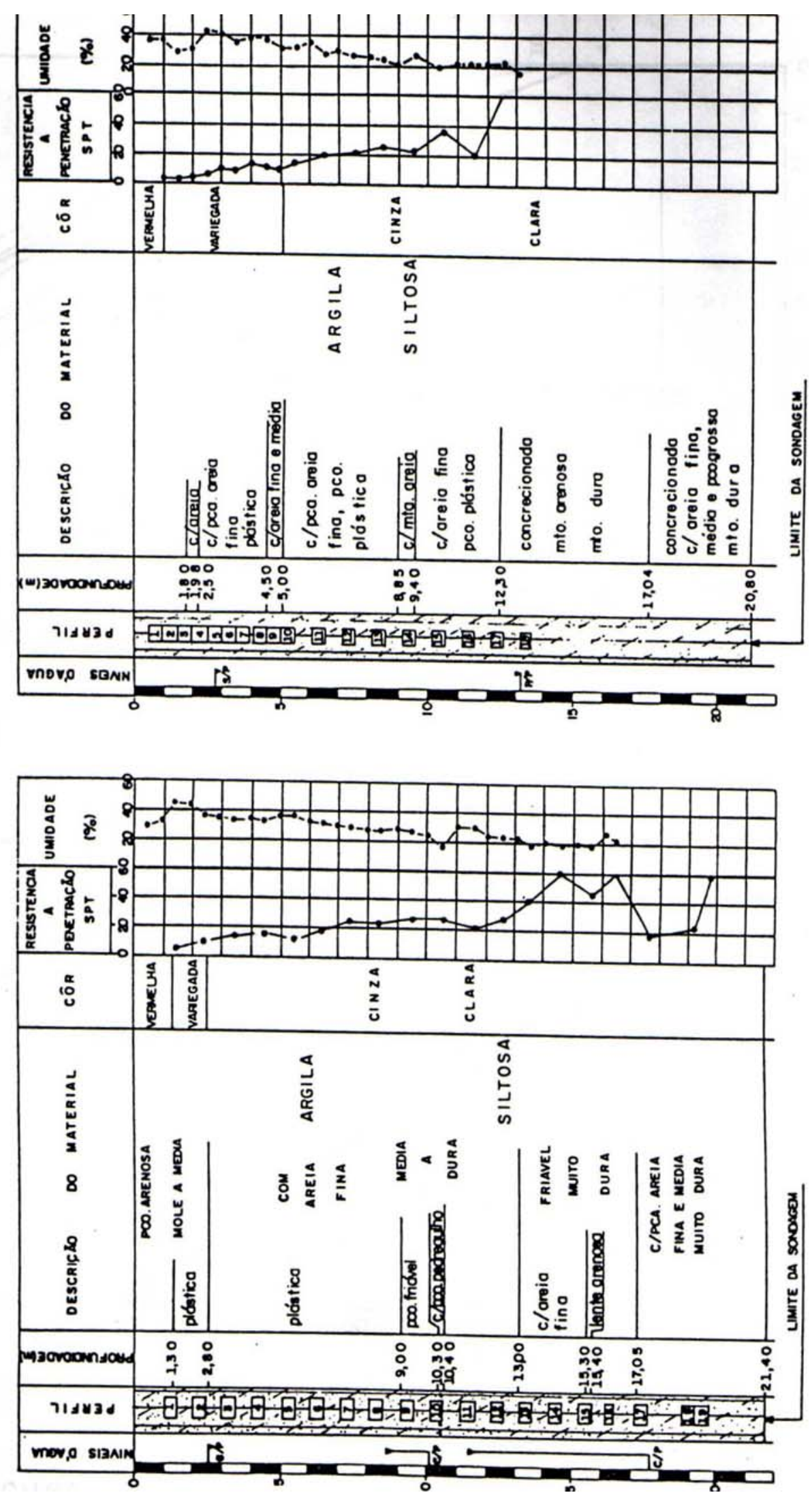

Figura 2.8 - Sondagens de simples reconhecimento na região de Araucária - PR (Massad et al., 1981). 
Estes ensaios apresentam maior dificuldade de execução, tornando muitas vezes impraticável seu prosseguimento devido à elevada consistência do material. Os resultados obtidos pelo DPL apresentaram boa concordância com os resultados do SPT. Apesar de alcançarem profundidade inferior, definem melhor a variação de resistência do perfil (Fig. 2.10).
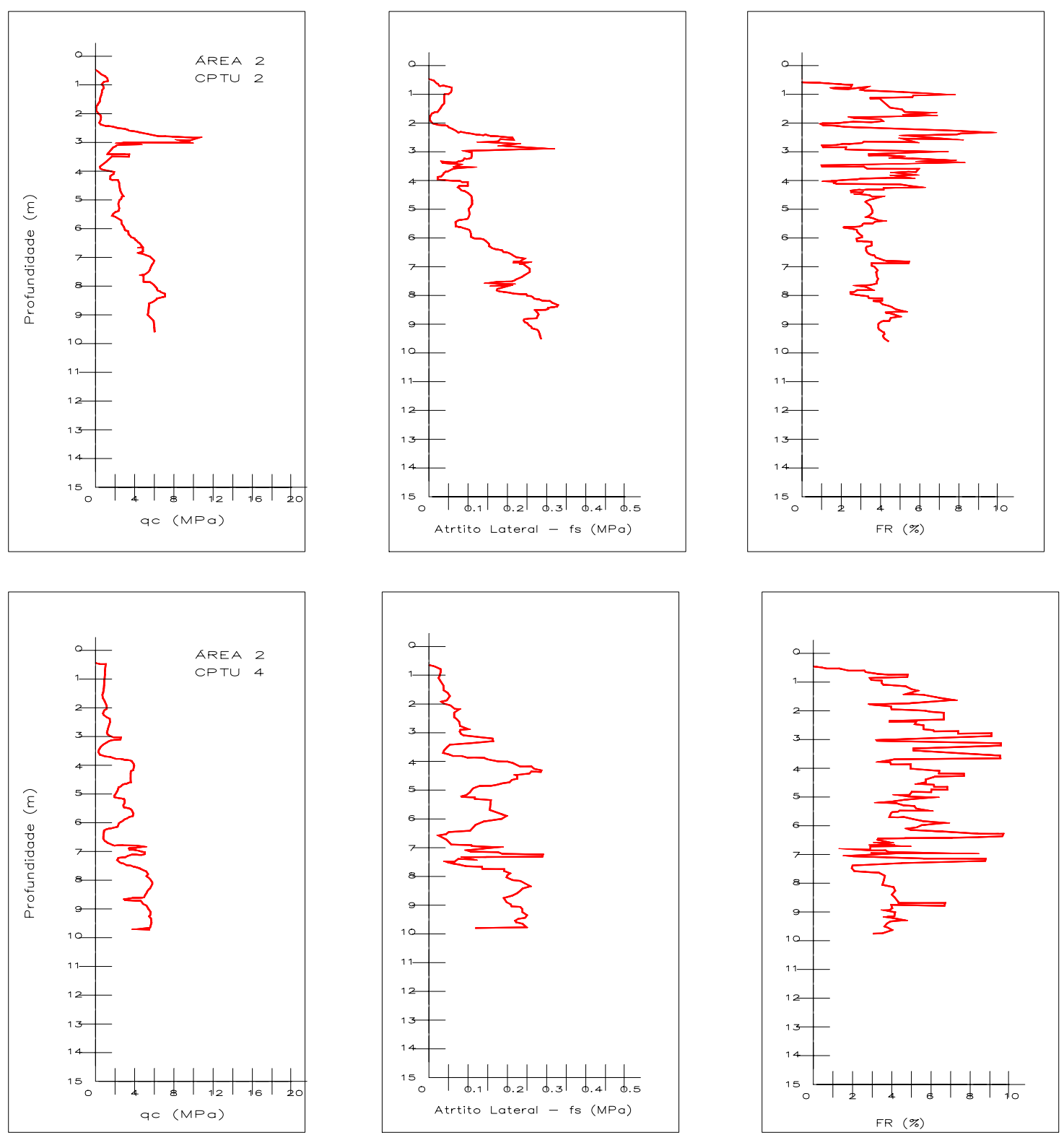

Figura 2.9- Dados de ensaios de CPTU em duas áreas de estudo (Chamecki et al., 1998). 

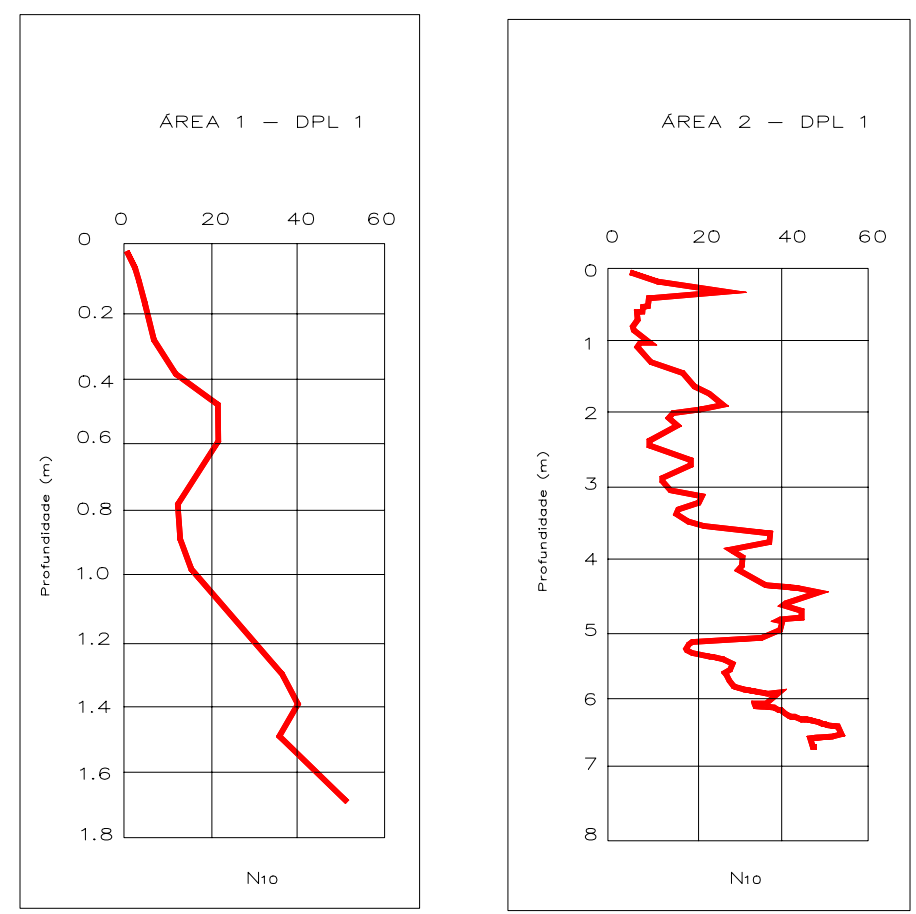

Figura 2.10 - Resultados do ensaio DPL em duas áreas de estudo (Chamecki et al., 1998).

O perfil esquemático obtido pelos autores pode ser observado na figura 2.11 abaixo:

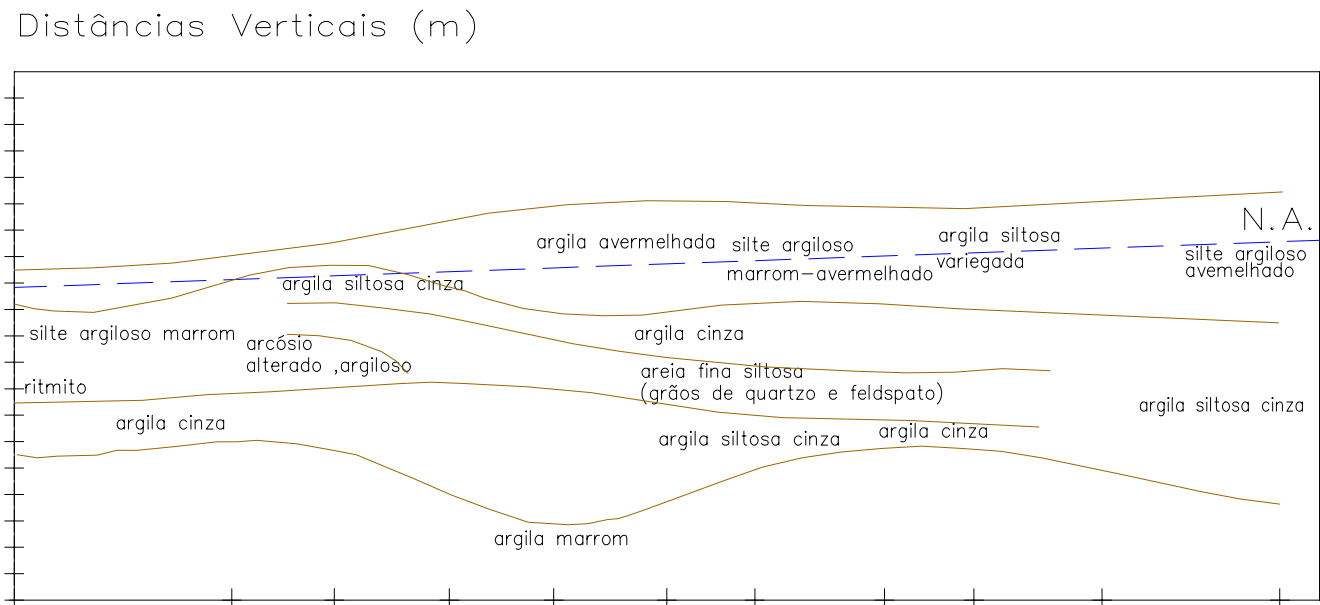

Distâncias Horizontais $(m)$

Figura 2.11 - Perfil esquemático (Chamecki et al., 1998). 
Pode-se visualizar mais claramente através deste perfil (Fig. 2.11) a distribuição das camadas conforme descrito pelas sondagens acima citadas.

Levantamentos sísmicos e elétricos foram realizados ao longo de aproximadamente $2.000 \mathrm{~m}$ em obra no município de Piraquara (RMC). Através do método da refração sísmica foram obtidas velocidades da ordem de 1.600 m/s e 2.000 m/s para a Formação Guabirotuba, enquanto que para os solos moles e topos rochosos estes valores correspondem a $200 \mathrm{~m} / \mathrm{s}$ e $2.000 \mathrm{~m} / \mathrm{s}$ a $5.600 \mathrm{~m} / \mathrm{s}$, respectivamente (Nascimento et al., 1994).

Para o caminhamento elétrico, ao autores utilizaram o arranjo de Wenner, sendo que nas sondagens verticais adotou-se a configuração Schlumberger. Os valores da resistividade aparente na Formação Guabirotuba variaram de 20 a 100 ohms. Os solos moles e a rocha sã compacta abaixo do nível piezométrico apresentaram resistividade de 150 a 400 ohms e 300 ohms, respectivamente.

Os autores poderiam, através dos resultados dos ensaios de sísmica, determinar o módulo de deformabilidade do material ( $\mathrm{E}_{50}$ ), porém limitaram-se apenas a apresentar os resultados. Outra verificação possível é o contraste entre camadas e a verificação do nível d'água, associando os ensaios ao conhecimento geológico proveniente da inspeção visual e de sondagens de simples reconhecimento.

\subsubsection{Ensaios de Caracterização Laboratorial}

Duarte (1986) realizou ensaios de granulometria utilizando amostras de solo da Formação Guabirotuba e da Formação Tinguis, retiradas do município de Araucária (RMC). Comparando-se as curvas granulométricas, nota-se a textura mais fina do solo da Formação Guabirotuba (Fig. 2.12), como já mencionado. 


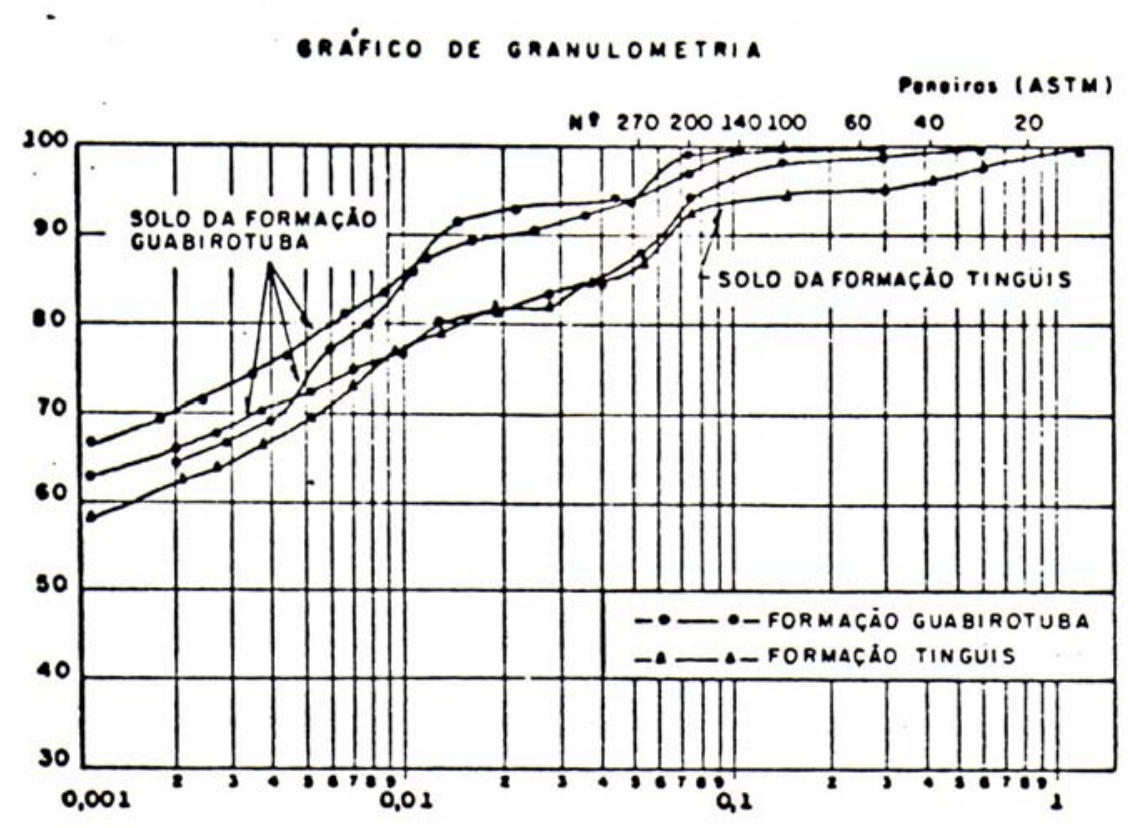

Figura 2.12 - Distribuição granulométrica (Duarte, 1986)

Os valores em termos percentuais podem ser melhor observados nas tabelas abaixo (Tab. 2.1 e Tab. 2.2).

Tabela 2.1 - Análise granulométrica para o solo da Formação Tinguis em termos percentuais (Duarte, 1986).

\begin{tabular}{|c||c|c|}
\hline \multicolumn{3}{|c|}{ Granulometria } \\
\hline Argila (\%) & Silte (\%) & Areia (\%) \\
\hline 62 & 31 & 7 \\
\hline
\end{tabular}

Tabela 2.2 - Análise granulométrica para o solo da Formação Guabirotuba em termos percentuais (Duarte, 1986).

\begin{tabular}{|c||c|c|}
\hline \multicolumn{3}{|c|}{ Granulometria } \\
\hline \hline Argila (\%) & Silte (\%) & Areia (\%) \\
\hline 67 & 30 & 3 \\
\hline
\end{tabular}


Pode-se observar que a fração argila corresponde à maior percentagem (50\%) para ambas as formações. Segundo Massad et al. (1981), as argilas cinza (Sabão de Caboclo) e as argilas intemperizadas são solos homogêneos, com predominância da fração de finos, que varia na faixa de 70 a $95 \%$ sendo a fração argila $(\%<5 \mu)$ superior a $50 \%$.

Ensaios de limites de consistência também foram realizados para estas amostras. Através da comparação dos resultados plotados na carta de plasticidade (Fig. 2.13), confirma-se o maior valor do índice de plasticidade para o solo da Formação Guabirotuba.

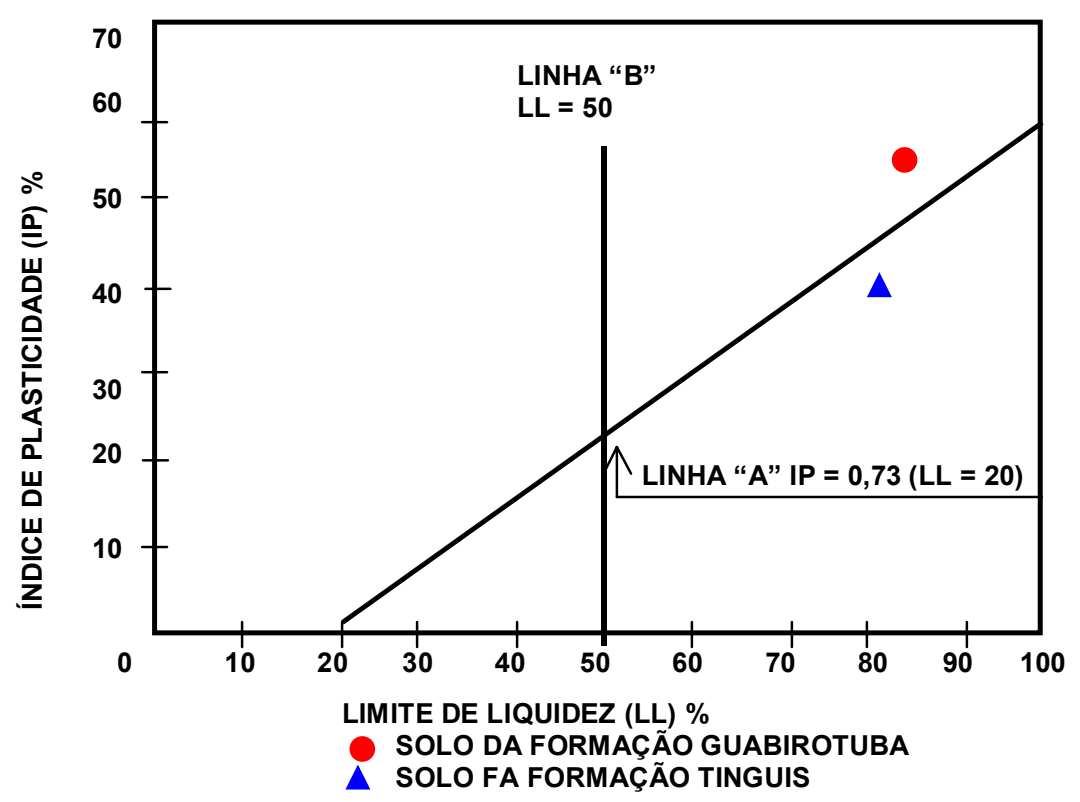

Figura 2.13 - Posição na carta de plasticidade (Duarte, 1986).

A tabela 2.3 apresenta o intervalo típico de variação dos valores de massa específica, massa específica dos sólidos, limite de liquidez, limite de plasticidade, índice de plasticidade, teor de umidade natural e índice de vazios para os solos das Formações Tinguis e Guabirotuba. Esses valores limites foram obtidos após interpretação dos resultados encontrados nos ensaios de caracterização realizados por Massad et al. (1981), Duarte (1986), 
Nascimento (1992), Nascimento et al. (1994), Chamecki et al. (1998) e Siedlecki (1998) em uma tentativa de diferenciar as formações.

Tabela 2.3 - Valores de $\rho, \rho_{\mathrm{s}}, \mathrm{w}_{\mathrm{L}}, \mathrm{w}_{\mathrm{p}}, \mathrm{IP}, \mathrm{w}_{\text {nat }}$ e e $\mathrm{e}_{\mathrm{o}}$ para os solos da Formação Tinguis e Formação Guabirotuba.

\begin{tabular}{|c|c|c|c|c|c|c|c||}
\hline FORMAÇÃO & $\rho\left(\mathbf{g} / \mathbf{c m}^{\mathbf{3}}\right)$ & $\rho_{\mathbf{s}}\left(\mathbf{g} / \mathbf{c m}^{\mathbf{3}}\right)$ & $\mathbf{W}_{\mathbf{L}}(\mathbf{\%})$ & $\mathbf{w}_{\mathbf{p}} \mathbf{( \% )}$ & IP (\%) & $\mathbf{W}_{\text {nat }} \mathbf{( \% )}$ & $\mathbf{E}_{\mathbf{o}}$ \\
\hline \hline Tinguis & $1,7-1,8$ & - & $30-50$ & $15-30$ & $15-30$ & $20-30$ & - \\
\hline Guabirotuba & $1,8-1,9$ & $2,7-2,8$ & $50-90$ & $25-45$ & $30-50$ & $20-35$ & $0,8-1,10$ \\
\hline
\end{tabular}

Os parâmetros de compactação obtidos por Massad et al. (1981) revelam valores de teor de umidade ótima na faixa de $25 \%$ a $30 \%$ e as densidades secas máximas variando entre 1,4 a 1,6 g/ $\mathrm{cm}^{3}$. Segundo Duarte (1986), os valores do grau de saturação para as amostras da Formação Guabirotuba mostraram-se bastante elevados, variando entre 90\% e 100\%.

Através de resultados obtidos em ensaios de caracterização, Nascimento (1992) classificou os solos pelos Sistema Unificado e HRBAASHO. Pelo primeiro, quase todas as amostras ensaiadas podem ser classificadas como $\mathrm{CH}$ (argila de alta plasticidade) e algumas poucas como CL (argilas de baixa plasticidade). Já pelo segundo, todas as amostras podem ser classificadas como solos argilosos (A-7-5 e A-7-6).

Recentemente, foram realizados ensaios de pressão de expansão e expansão livre por Pereira (1999). Tais ensaios seguiram os procedimentos da ISRM (1989) porém com algumas modificações necessárias devido às características do material. Os resultados obtidos para as amostras retiradas de uma região ao nordeste do município de Curitiba seguem nas tabelas 2.4 e 2.5: 
Tabela 2.4 - Resultados dos ensaios de expansão livre para amostras no estado natural e secas ao ar (Pereira, 1999).

\begin{tabular}{|c|c|c||}
\hline $\begin{array}{c}\text { Amostras com } \\
\text { umidade natural } \\
\text { Deformação (\%) }\end{array}$ & $\begin{array}{c}\text { Amostras com } \\
\text { umidade natural } \\
\text { em anel } \\
\text { metálico } \\
\text { Deformação (\%) }\end{array}$ & $\begin{array}{c}\text { Amostras secas } \\
\text { ao ar em anel } \\
\text { metálico } \\
\text { Deformação (\%) }\end{array}$ \\
\hline $0,70-1,40$ & $0,25-0,50$ & $30-50$ \\
\hline
\end{tabular}

Tabela 2.5 - Resultados dos ensaios de pressão de expansão (Pereira, 1999).

\begin{tabular}{|c|c|}
\hline $\begin{array}{c}\text { Amostras com umidade } \\
\text { natural }\end{array}$ & $\begin{array}{c}\text { Amostras secas ao ar } \\
\text { Pressão de Expansão } \\
\text { Pressão de Expansão (kPa) }\end{array}$ \\
\hline \hline $15-30$ & $1000-3700$ \\
\hline
\end{tabular}

Segundo a autora, as amostras utilizadas para o ensaio de expansão livre apresentaram uma contração significativa quando secas ao ar, o que refletiu diretamente nos ensaios de expansão livre e pressão de expansão, gerando resultados elevados se comparados com os materiais com umidade natural (tab. 2.6).

Tabela 2.6 - Contração das amostras secas ao ar retiradas para os ensaios de pressão de expansão (Pereira, 1999).

\begin{tabular}{|c|c|}
\hline \% Contração vertical & \% Contração lateral \\
\hline \hline $10-20$ & $10-15$ \\
\hline
\end{tabular}

Apesar de poucos ensaios terem sido realizados, observa-se que as amostras submetidas aos ensaios de pressão de expansão com umidade natural apresentam um expansão baixa em relação às secas ao ar, provavelmente por possuírem um grau de saturação elevado, superior a $80 \%$. Outro fator importante é o efeito da secagem pois este provocou um 
aumento significativo, tanto da expansão livre como da pressão de expansão. Devido a isto, no caso de obras civis que envolvam a escavação destas materiais, deve-se minimizar ao máximo as variações de umidade para evitar danos às obras, causados pela expansibilidade (Pereira, 1999).

\subsubsection{Parâmetros de Compressibilidade, Permeabilidade e Resistência}

Apesar da intensa utilização das Formações Tinguis e Guabirotuba como material natural de fundação, contenções, taludes, etc., pouco se sabe ainda sobre seus parâmetros geotécnicos, especialmente as propriedades de compressibilidade, permeabilidade, resistência e outras.

Em relação à compressibilidade do material, Duarte (1986) realizou ensaios de adensamento edométrico utilizando amostras indeformadas e remoldadas, determinando os índices de compressão $\left(C_{c}\right)$ e de expansão $\left(C_{e}\right)$, a pressão de pré-adensamento $\left(\sigma_{\mathrm{ad}}\right)$ e, a partir desta, a Razão de Préadensamento (RPA). O gráfico do ensaio em amostra indeformada pode ser visualizados na figura 2.14 .

A pressão de pré-adensamento obtida pelo método de Pacheco Silva corresponde a $1000 \mathrm{kPa}$ para a amostra indeformada. Os dados iniciais do ensaio bem como os demais coeficientes de compressibilidade são apresentados na tabela 2.7.

Tabela 2.7 - Dados iniciais do ensaio e coeficientes de compressibilidade do solo da Formação Guabirotuba (Duarte, 1986)

\begin{tabular}{|c|c|c||c|c||}
\cline { 2 - 5 } \multicolumn{1}{c|}{} & \multicolumn{2}{l||}{ DADOS INICIAIS } & \multicolumn{2}{c||}{ COMPRESSIBILIDAD } \\
\cline { 2 - 5 } \multicolumn{1}{c|}{} & $\mathbf{e}_{\mathbf{o}}$ & $\mathbf{S}_{\mathbf{o}} \mathbf{( \% )}$ & $\mathbf{C}_{\mathbf{c}}$ & $\mathbf{C}_{\mathbf{e}}$ \\
\hline Amostra indeformada & 0,917 & 98,6 & 0,313 & 0,090 \\
\hline Amostra remoldada & 2,062 & 99,5 & 0,404 & 0,108 \\
\hline
\end{tabular}




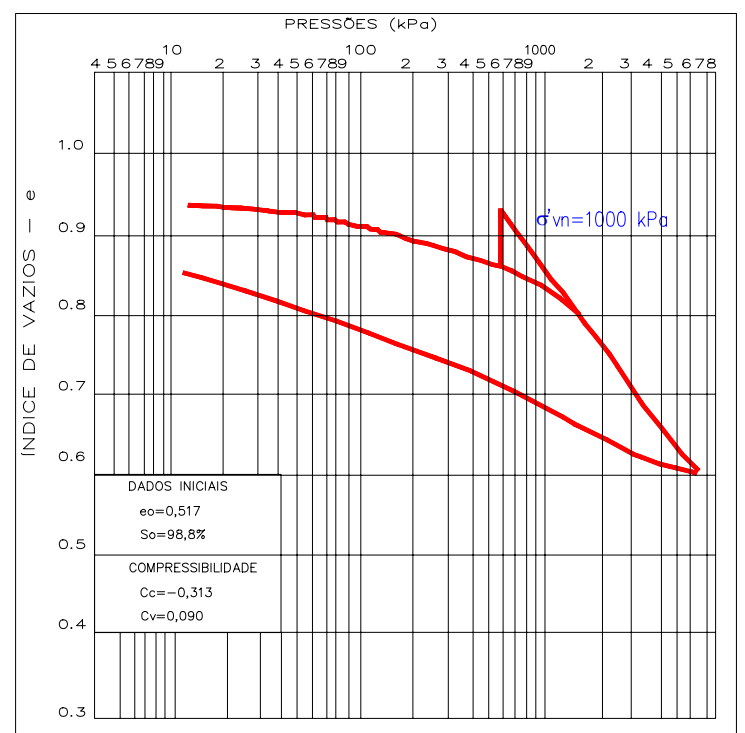

Figura 2.14 - Curvas de adensamento para ensaio sobre solo indeformado (Duarte, 1986).

Da curva recalque $x \log$ tempo (Fig. 2.15), o autor obteve também o coeficiente de adensamento $c_{v}$ e o módulo de deformabilidade confinado efetivo do solo ( $\left.\mathrm{E}_{\text {ed }}\right)$ e, a partir deste, calculou o coeficiente de permeabilidade k (tab. 2.8).

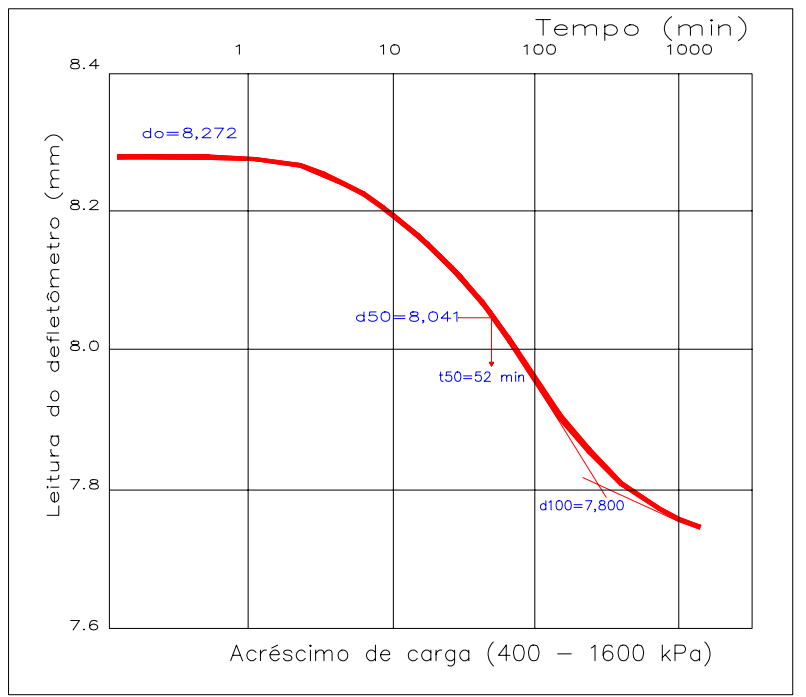

Figura 2.15 - Curva recalque $x \log$ tempo para ensaio sobre solo indeformado (Duarte, 1986). 
Tabela 2.8 - Valores de $c_{v}$, $E_{\text {ed }}$ e k estimados a partir das curvas recalque $x$ log tempo de ensaios edométricos (Duarte, 1986).

\begin{tabular}{|c|c|c|c|c|}
\hline AMOSTRA & $\begin{array}{c}\text { CARREGAMENTO } \\
(\mathbf{k P a})\end{array}$ & $\begin{array}{c}\mathrm{c}_{\mathrm{v}} \\
\left(\mathrm{cm}^{2} / \mathrm{s}\right)\end{array}$ & $\begin{array}{c}\mathrm{E}_{\mathrm{ed}} \\
\left(\mathrm{kN} / \mathrm{m}^{2}\right)\end{array}$ & $\begin{array}{c}\mathrm{K} \\
(\mathrm{cm} / \mathrm{s})\end{array}$ \\
\hline \multirow{4}{*}{ Indeformada } & 800 & $1,6 \times 10^{-4}$ & $3,2 \times 10^{4}$ & $5,0 \times 10^{-10}$ \\
\hline & 1600 & $5,7 \times 10^{-5}$ & $3,3 \times 10^{4}$ & $1,7 \times 10^{-10}$ \\
\hline & 3200 & $2,9 \times 10^{-5}$ & $3,1 \times 10^{4}$ & $9,3 \times 10^{-11}$ \\
\hline & 6400 & $2,6 \times 10^{-5}$ & $2,9 \times 10^{4}$ & $4,3 \times 10^{-11}$ \\
\hline \multirow{6}{*}{ Remoldada } & 5 & $2,0 \times 10^{-4}$ & $8,3 \times 10^{1}$ & $2,4 \times 10^{-7}$ \\
\hline & 25 & $2,7 \times 10^{-4}$ & $3,8 \times 10^{2}$ & $6,9 \times 10^{-8}$ \\
\hline & 100 & $2,8 \times 10^{-4}$ & $1,3 \times 10^{3}$ & $2,2 \times 10^{-8}$ \\
\hline & 400 & $1,9 \times 10^{-4}$ & $4,8 \times 10^{3}$ & $4,0 \times 10^{-9}$ \\
\hline & 800 & $1,1 \times 10^{-4}$ & $9,1 \times 10^{3}$ & $1,3 \times 10^{-9}$ \\
\hline & 3200 & $3,9 \times 10^{-5}$ & $3,3 \times 10^{4}$ & $1,1 \times 10^{-10}$ \\
\hline
\end{tabular}

Siedlecki (1998) realizou ensaios de permeabilidade a carga constante com amostras compactadas retiradas do distrito industrial de Campina Grande do Sul (RMC). Os valores obtidos são da ordem de $10^{-5}$ e 10-6 cm² / s. Pode-se notar que os valor estimados por Duarte (1986) são muito inferiores aos encontrados por Siedlecki (1998). Isto se deve ao fato de que a estimativa dos valores de permeabilidade depende da estimativa de outros fatores como $\mathrm{C}_{\mathrm{v}}$ e $\mathrm{E}_{\mathrm{ed}}$, tornando-a muito falha.

Quanto aos resultados dos ensaios edométricos, um valor que chama a atenção é a elevada pressão de pré-adensamento $(1000 \mathrm{kPa})$, e mais ainda a sua razão de sobreadensamento da ordem de 17, pois a amostra em questão foi retirada a profundidade de $2 \mathrm{~m}$ e sendo seu peso específico natural equivalente a $19 \mathrm{kN} / \mathrm{m}^{3}$, o peso de terra sobre a mesma seria da ordem de $40 \mathrm{kPa}$.

Valores desta grandeza são confirmados por Massad et al. (1981) e Nascimento (1992). O primeiro encontrou para o solo ensaiado um valor de 
pressão de pré-adensamento equivalente a $700 \mathrm{kPa}$, enquanto Nascimento (1992) obteve valores da ordem de $500 \mathrm{kPa}$ a $1000 \mathrm{kPa}$.

Tais valores reforçam o fato de que o elevado sobreadensamento não se deve somente ao alívio de tensões causado pela erosão de camadas superiores de solo, pois para tal seria necessária uma remoção de $50 \mathrm{~m}$ de sedimentos. Apesar de não haver estudos geológicos que mencionem o nível original de preenchimento da Bacia Sedimentar de Curitiba, é pouco provável que os sedimentos tenham atingido cotas tão elevadas (Becker,1985; apud Duarte, 1986).

Ao ensaiar uma amostra indeformada guardada em laboratório por aproximadamente 3 anos, parcialmente protegida, Nascimento (1992) mediu uma surpreendente expansão, equilibrada somente com pressão de $500 \mathrm{kPa}$, impossibilitando a seqüência normal do ensaio. Isto vem ao encontro da suposição de que os depósitos sedimentares da Bacia de Curitiba sejam, pelo menos em parte, spbreadensados por ressecamento.

Quanto às características de resistência, Nascimento (1992) realizou uma série de ensaios de cisalhamento direto e de compressão simples utilizando diversas amostras do solo sedimentar da bacia de Curitiba. Os valores obtidos para a coesão média e ângulo de atrito interno são próximos a $50 \mathrm{kPa}$ e $31^{\circ}$, respectivamente, para ensaios rápidos e inundados com velocidades de 0,0802 $\mathrm{mm} / \mathrm{min}$ e 0,182 mm/min. Um exemplo de envoltória segue na figura 2.16 . 


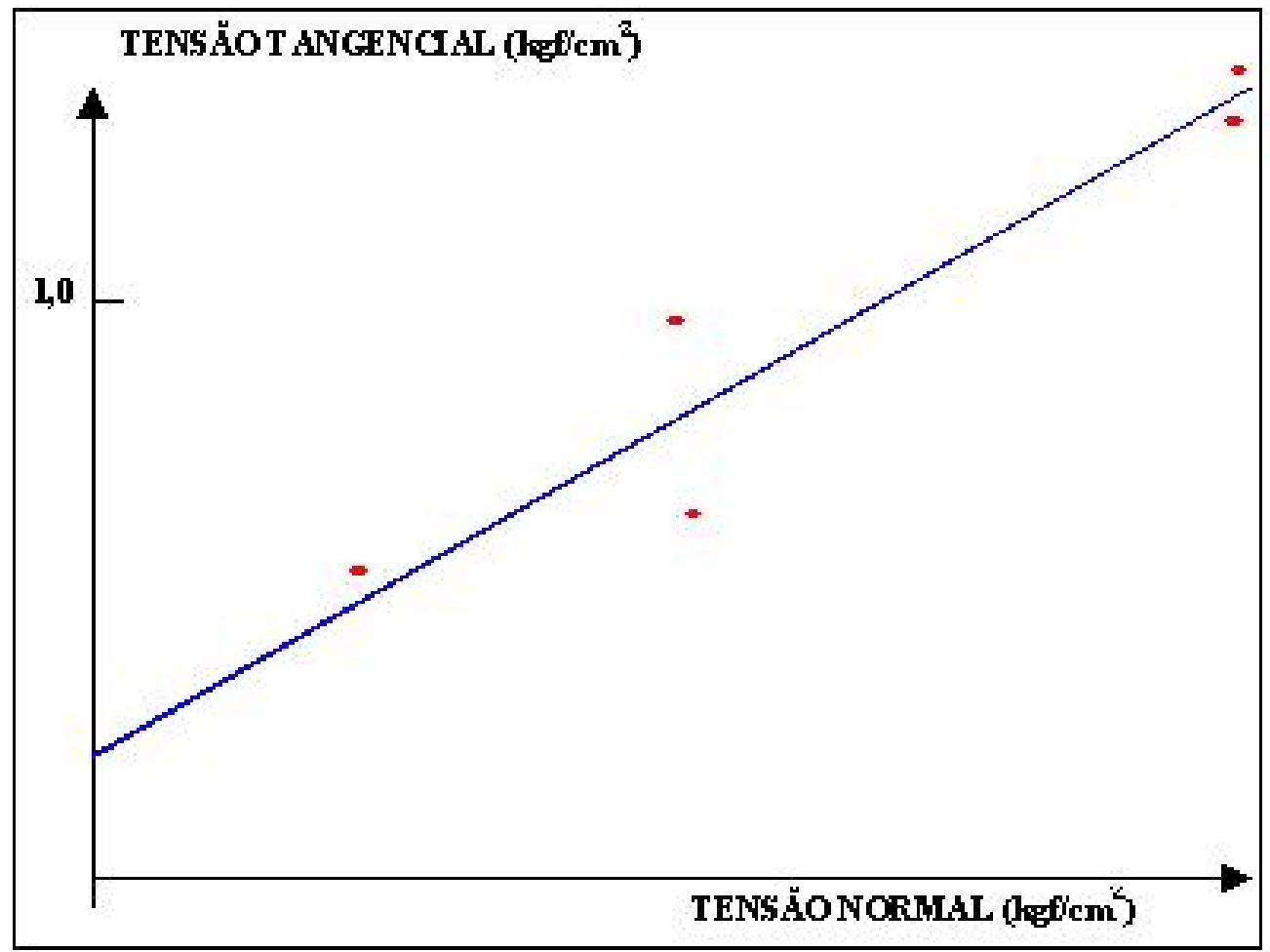

Figura 2.16 - Envoltória de resistência para o solo sedimentar da Bacia de Curitiba (Nascimento, 1992).

O autor analisou cuidadosamente o comportamento de cada amostra rompida na prensa de cisalhamento direto e observou um razoável desempenho tridimensional livre, ou seja, o corpo de prova é seccionado horizontalmente e pode comprimir e/ou expandir verticalmente, dependendo da pressão vertical utilizada. Esta situação, se comparada ao ensaio de compressão simples, por exemplo, é sem dúvida mais real. Outro fato constatado é a complementação da envoltória possibilitada pela resistência à compressão simples como na figura 2.17. 


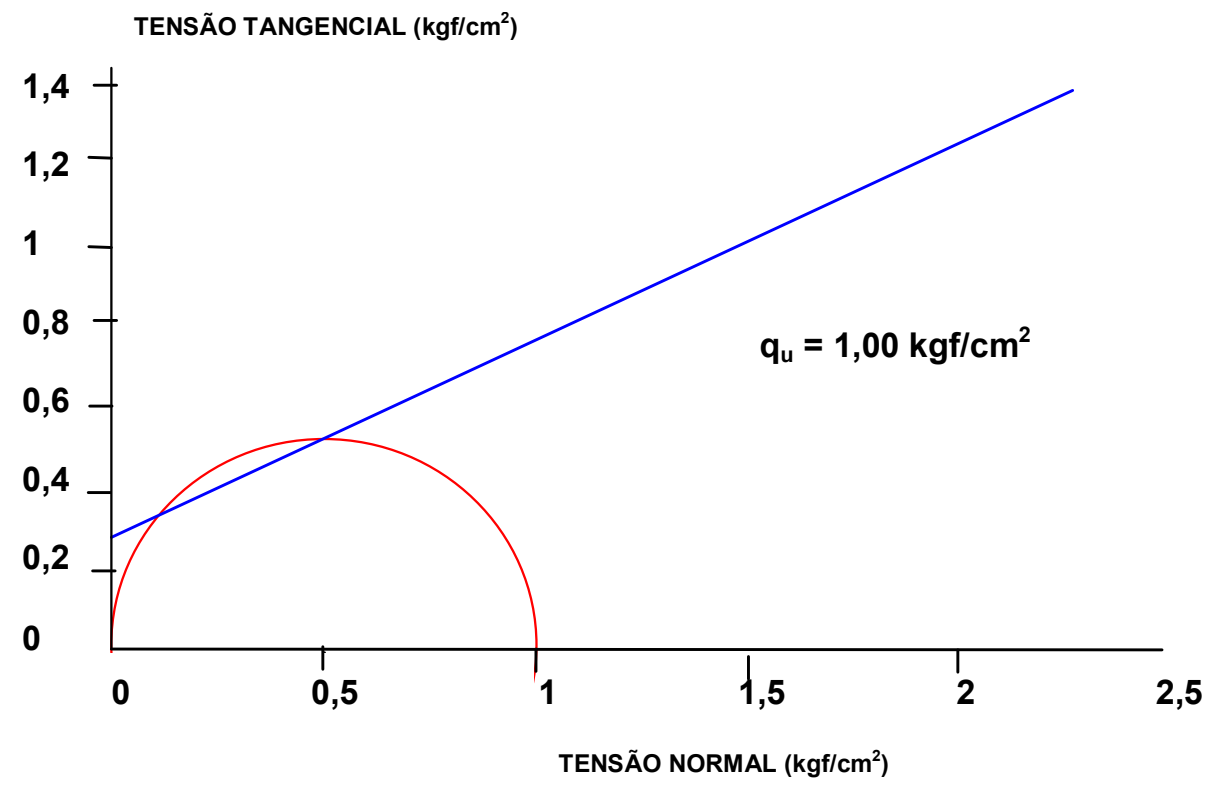

Figura 2.17 - Resistência à compressão simples e envoltória de cisalhamento direto para o solo sedimentar da Bacia de Curitiba (Nascimento, 1992).

Os ensaios realizados por Massad et al. (1981) foram do tipo compressão triaxial rápidos pré-adensados saturados por contrapressão. Os resultados obtidos são apresentados nas figuras 2.18 e 2.19 . 

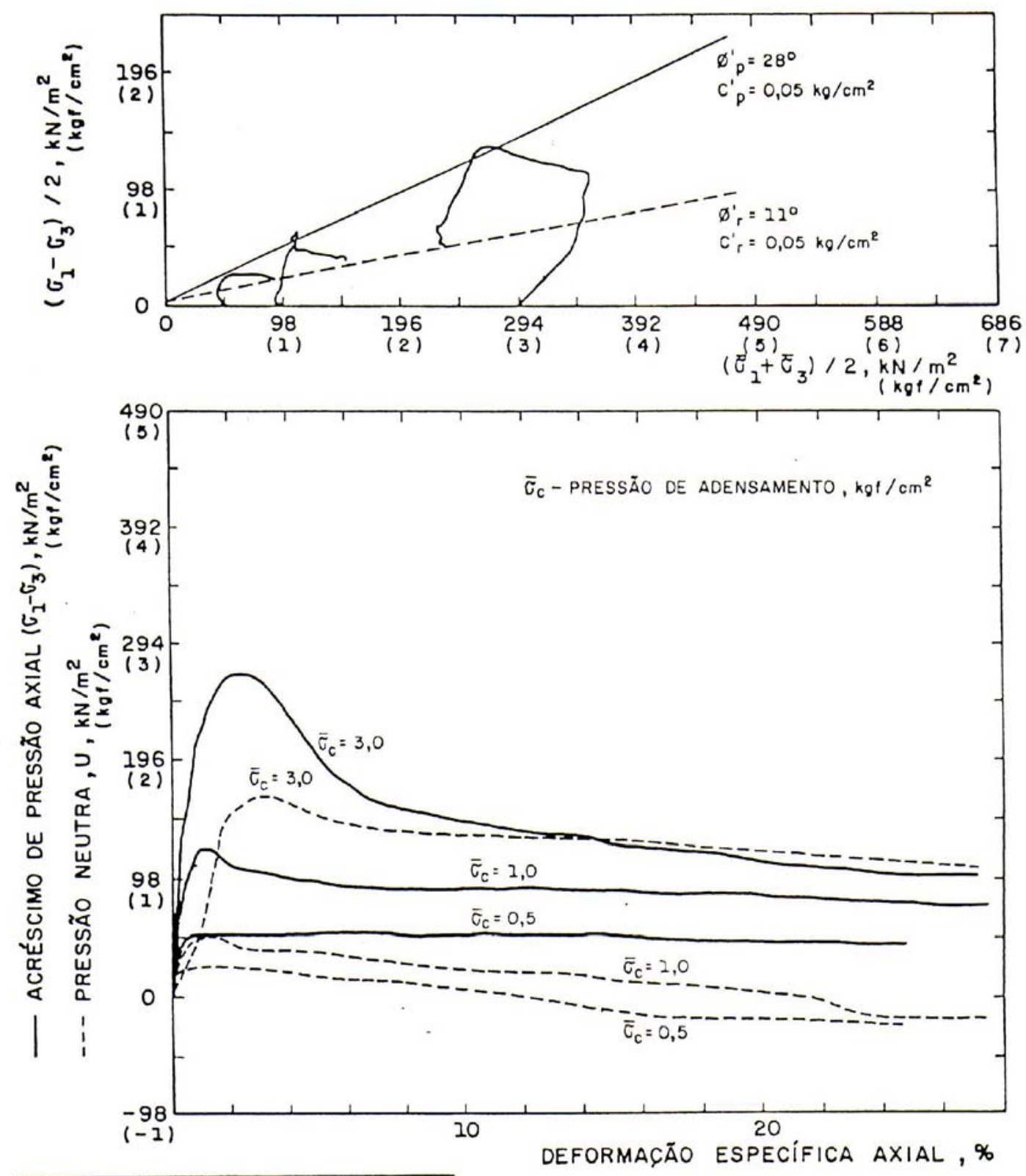

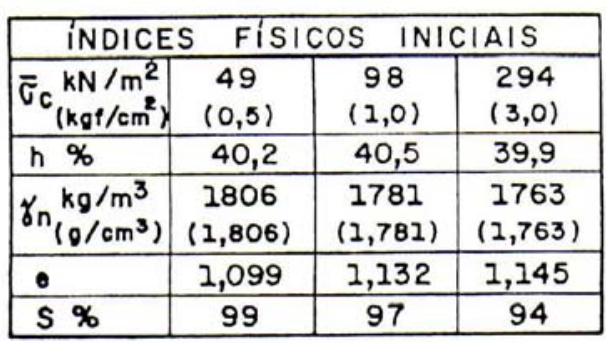

AMOSTRA : 6

POCO : 2

PROF. : 1,85 - 2,11 m

TALUDE NORTE

Figura 2.18 - Ensaio triaxial rápido pré-adensado saturado por contrapressão - argila cinza da Formação Guabirotuba (Massad et al., 1981). 

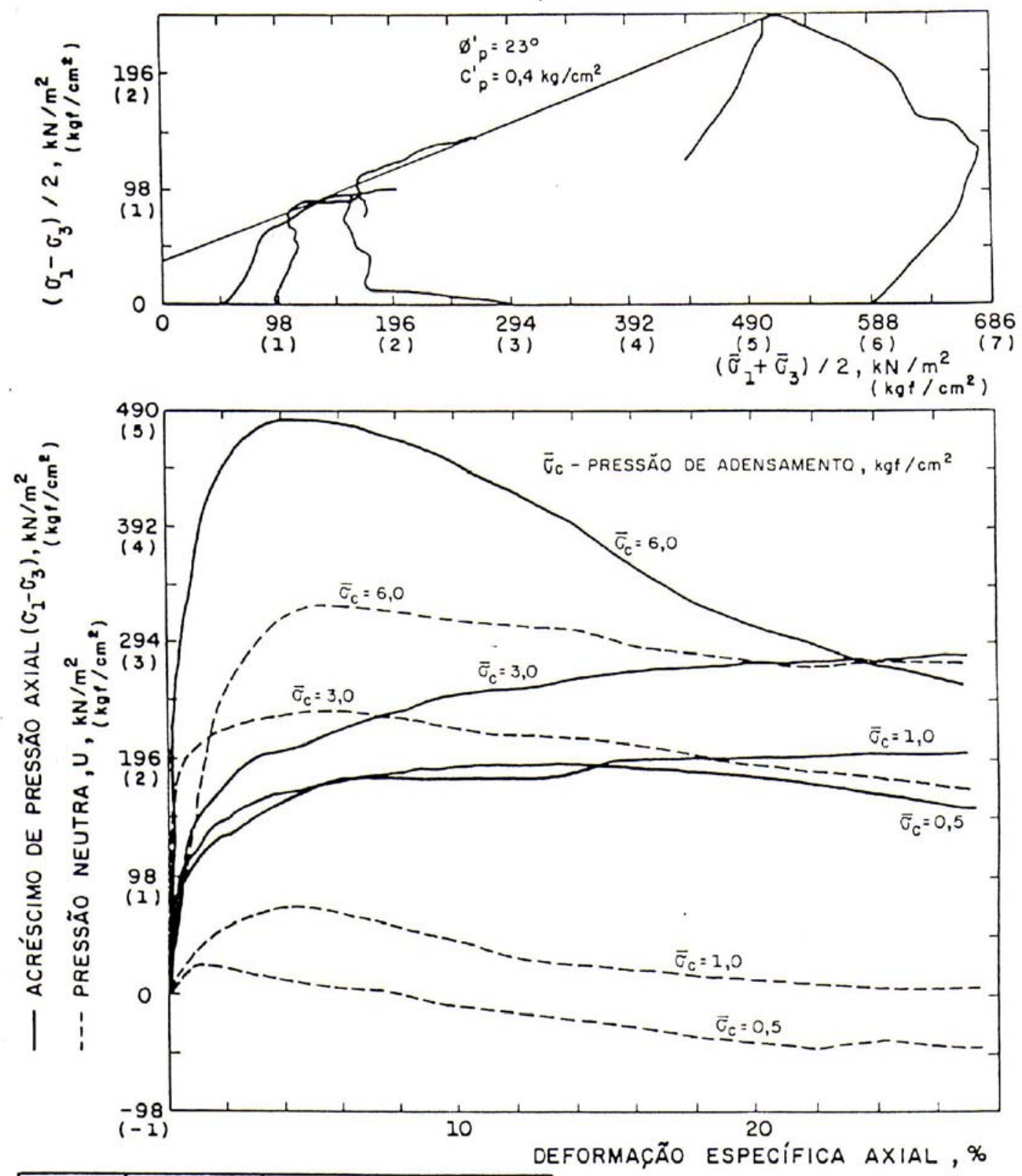

\begin{tabular}{|c|c|c|c|c|}
\hline \multicolumn{2}{|c|}{ ÍNDICES } & \multirow{2}{*}{ 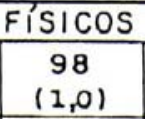 } & \multicolumn{2}{|c|}{$|N| C|A| S$} \\
\hline $\bar{\sigma}_{c}{ }_{\left(\mathrm{kgf} / \mathrm{cm}^{2}\right)}^{k N / \mathrm{m}^{2}}$ & $\begin{array}{c}49 \\
(0,5)\end{array}$ & & $\begin{array}{c}294 \\
(3,0)\end{array}$ & $\begin{array}{r}588 \\
(6,0)\end{array}$ \\
\hline$h \%$ & 30,2 & 30,7 & 30,3 & 30,1 \\
\hline$\gamma_{\mathrm{n}} \mathrm{kg} / \mathrm{m}^{3}$ & $\begin{array}{c}1926 \\
(1,926)\end{array}$ & $\begin{array}{c}1906 \\
(1,906)\end{array}$ & $\begin{array}{c}1891 \\
(1,891)\end{array}$ & $\begin{array}{c}1894 \\
(1,894)\end{array}$ \\
\hline - & 0,882 & 0,909 & 0,919 & 0,913 \\
\hline$S \%$ & 95 & 94 & 92 & 92 \\
\hline
\end{tabular}

AMOSTRA : 5

POÇO : 2

PROF. : $0,30-0,60 \mathrm{~m}$

TALUDE NORTE

Figura 2.19 - Ensaio triaxial rápido pré-adensado saturado por contrapressão - argila vermelha da Formação Tinguis (Massad et al., 1981). 
Nota-se que a argila cinza apresenta curva tensão $x$ deformação com pico bem acentuado, com parâmetros de resistência efetivos de $50 \mathrm{kPa}$ e $28^{\circ}$. Os valores residuais correspondentes foram $50 \mathrm{kPa}$ e $11^{\circ}$. Para as argilas vermelhas, a curva não apresenta um pico tão acentuado e o valor dos parâmetros efetivos correspondem a $40 \mathrm{kPa}$ e $23^{\circ}$. O critério de ruptura adotado foi o da máxima relação entre as tensões principais efetivas $\left(\overline{\sigma_{1}} / \overline{\sigma_{3}}\right)$, devido à tendência de diminuição das pressões neutras com o acréscimo de carga axial (comportamento de solos pré-adensados).

Sabe-se que para as argilas sobreadensadas, a diferença entre a resistência de pico e residual é significativa, pois ao efeito da reorientação das partículas lamelares no plano de ruptura (causa da queda de resistência pós-pico em argilas normalmente adensadas) vem somar-se o efeito da dilatância, que aumenta o teor de umidade na região cisalhada provocando uma queda adicional de resistência (Fig. 2.20).

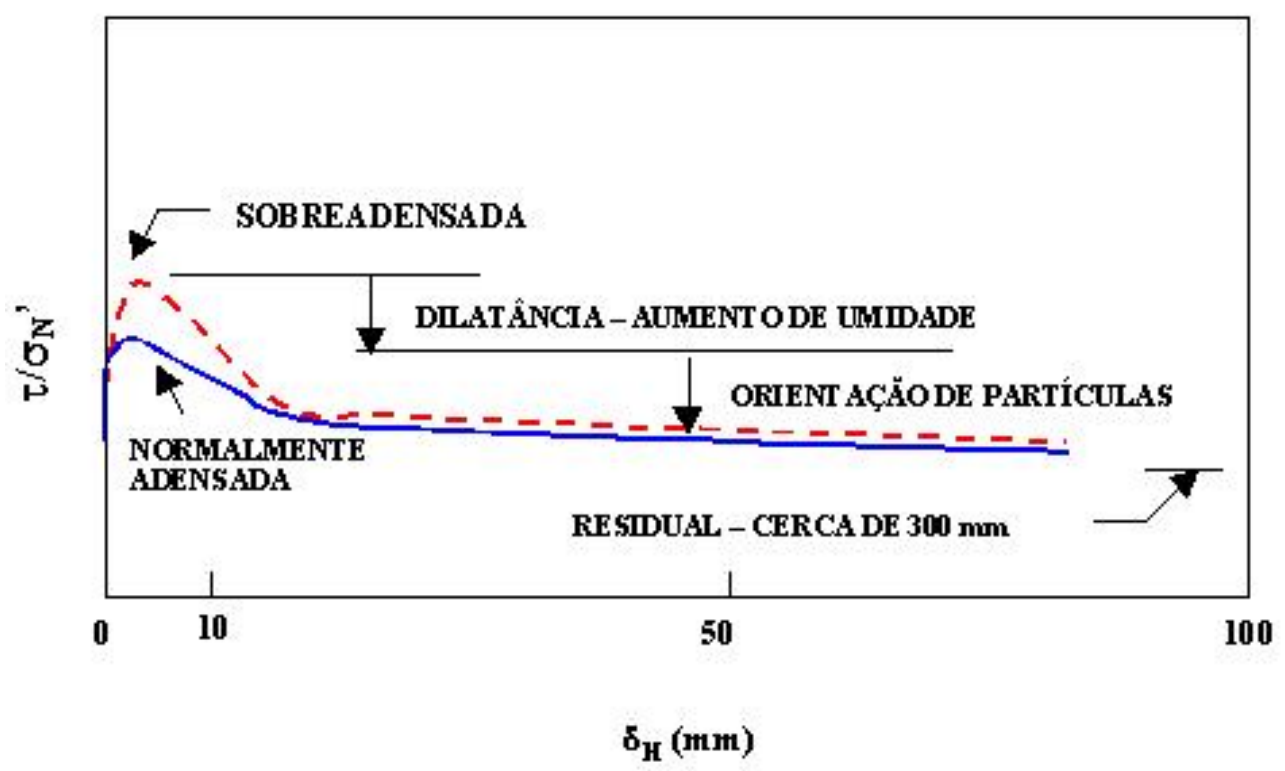

Figura 2.20 - Comparação simplificada entre comportamentos tensão $x$ deformação de argilas normalmente adensadas e sobreadensadas em condições drenadas (Duarte, 1986). 
Com o intuito de elucidar a questão da resistência residual, foram realizados ensaios de cisalhamento direto com grandes deformações por Massad et al. (1981) e posteriormente por Duarte (1986). O primeiro obteve para as argilas cinzas um valor para o ângulo de atrito efetivo residual da ordem de $10,4^{\circ}$, com coesão efetiva nula. Os correspondentes valores de pico foram $21^{\circ}$ e $10 \mathrm{kPa}$. Os dados relativos a estes ensaios são apresentados na tabela 2.9 e na figura 2.21 .

Tabela 2.9 - Índices físicos iniciais (Massad et al., 1981)

\begin{tabular}{|c|c|c|c|c|}
\hline \multicolumn{5}{|c|}{ ÍNDICES FÍSICOS INICIAIS } \\
\hline$\sigma_{\mathbf{N}} \mathbf{( k P a )}$ & $\mathbf{W} \mathbf{( \% )}$ & $\rho\left(\mathbf{g} / \mathbf{c m}^{\mathbf{3}}\right)$ & $\mathbf{e}_{\mathbf{o}}$ & $\mathbf{S}_{\mathbf{r}} \mathbf{( \% )}$ \\
\hline 49 & 39,2 & 1,794 & 1,151 & 92 \\
\hline 98 & 39,9 & 1,754 & 1,156 & 93 \\
\hline 294 & 39,5 & 1,744 & 1,162 & 92 \\
\hline
\end{tabular}




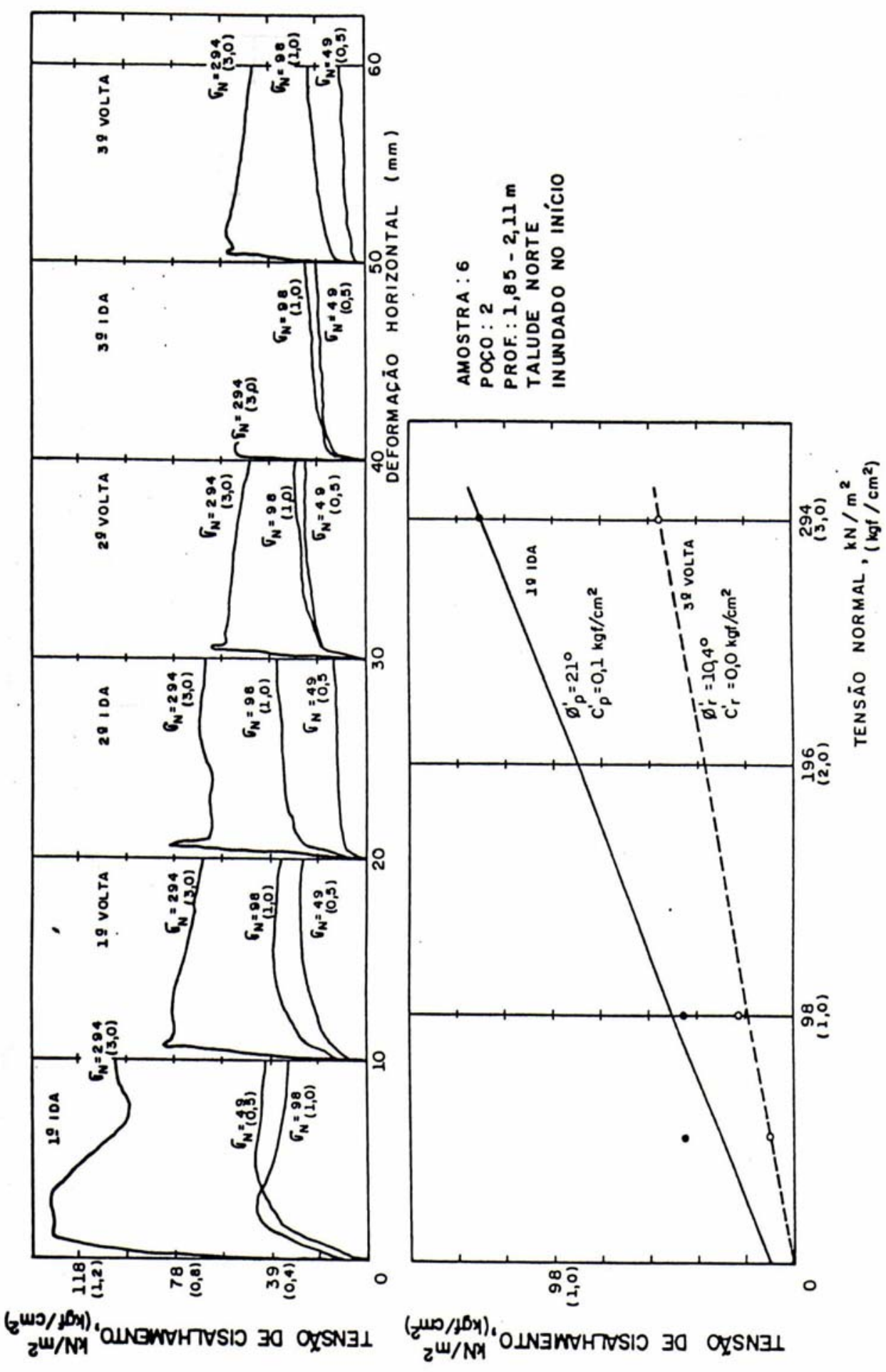

Figura 2.21 - Ensaio de cisalhamento direto com grandes deformações para a argila cinza da Formação Guabirotuba (Massad et al., 1981). 
Duarte (1986) realizou diversos ensaios de cisalhamento direto com reversão múltipla para amostras também da região de Araucária e obteve as envoltórias de resistência de pico e residual apresentadas na figura 2.22:

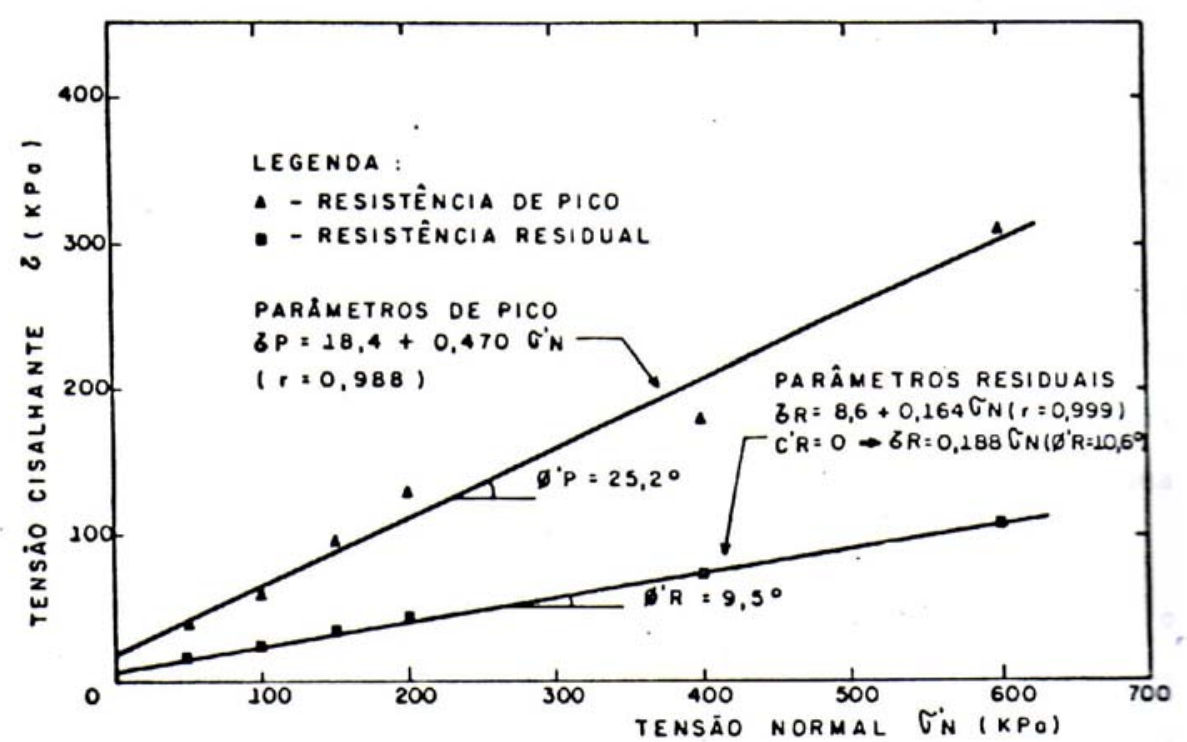

Figura 2.22 - Envoltórias de resistência, em termos de tensões efetivas para o solo da Formação Guabirotuba, obtidas através de ensaios de cisalhamento direto com reversão múltipla (Duarte, 1986)

Pode-se atribuir o baixo valor da resistência residual ao elevado conteúdo de esmectitas (montmorilonitas), cujas partículas lamelares extremamente pequenas e delgadas implicam um reduzido valor do ângulo de atrito intrínseco $\left(\phi_{\mu}\right)$, e portanto do ângulo de atrito residual $\left(\phi_{\mathrm{R}}\right)$.

\subsubsection{Problemas esperados}

A prática regional de engenharia geotécnica recomenda cuidados especiais ao se trabalhar neste solo. Estruturas leves, como pavimentos, sugerem a execução de drenagem superficial e profunda, além de isolamento do solo expansivo através de selos de argila, evitando grandes mudanças do teor de umidade, e por conseguinte, expansão (Nascimento et al., 1994). 
Em relação à execução de fundação superficial ou profunda neste tipo de solo, um dos pontos mais importantes é a boa organização do serviço na obra, especialmente no sentido de agilizar o lançamento do lastro de concreto magro, no caso de sapatas, e do concreto estrutural em estacas escavadas e tubulões. Tal serviço deve ser realizado imediatamente após inspeção e liberação da fiscalização da obra com o intuito de evitar a perda ou absorção de água que pode ocasionar sérios problemas como fechamento do fuste.

O caso de tubulões com base alargada é normalmente crítico e, se houver presença do nível d'água, torna-se altamente desejável a perfuração mecânica do fuste. Recomenda-se ainda que cada tubulão seja concretado o quanto antes e no mesmo dia da escavação, sob risco de desmoronamento (Nascimento, 1992).

Acidentes também têm ocorrido em obras de escavações e contenções nos solos da Formação Guabirotuba, bem como comportamentos inesperados em contenções, fundações e taludes de diversas inclinações que apresentam problemas de instabilidade, provavelmente relacionados à expansividade e à existência das superfícies lisas e brilhantes que se desenvolvem aleatoriamente na massa de solo.

Salazar Jr. et al. (1996) apresentam também diversos problemas relacionados à erodibilidade destes materiais. Como exemplo, a ação atrópica nas obras de construção de estradas, implantação de loteamentos, cortes em lotes para construção de casas, terraplanagem, etc., em que normalmente é retirado o solo superficial estável, de pouca espessura, deixando expostas as argilas da Formação Guabirotuba.

Nestas condições, os sedimentos perdem a umidade natural e em função das características físico-químicas, retraem-se (empastilhamento) e com a água da chuva se re-hidratam e se expandem formando uma lama que é facilmente transportada mesmo com pequenos gradientes, necessitando apenas que haja escoamento de água formada ou erosão laminar ou concentrada. Quanto maior a declividade, mais acelerado será o processo de 
formação de ravinas que atingem grandes dimensões causando grandes danos em áreas rurais e urbanas (Fig. 2.23).

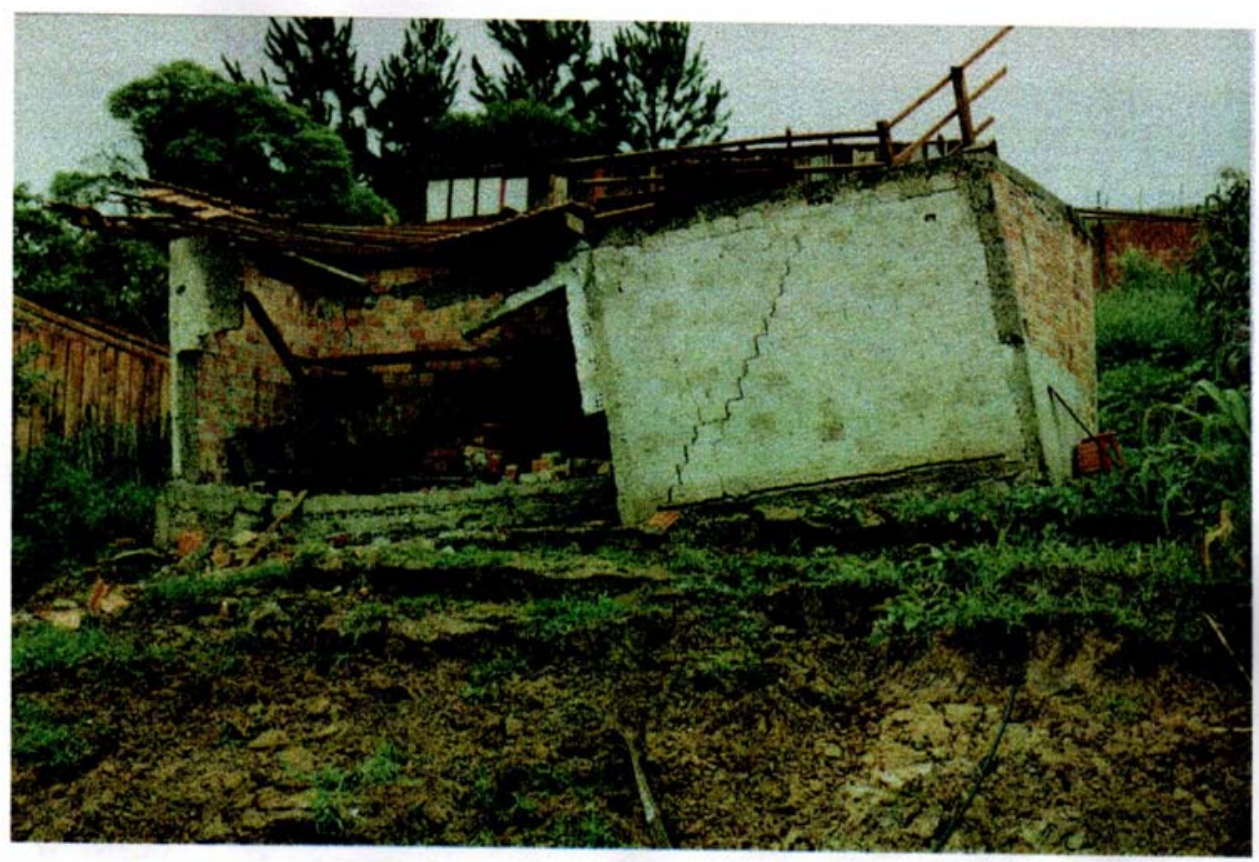

Figura 2.23 - Movimento de massa gravitacional "rastejo" e suas conseqüências no loteamento Santa Rosa em campina Grande do Sul (RMC) (Felipe, 1998)

Oliveira et al. (1997) apresentam situações de riscos de escorregamento oferecidas por alterações introduzidas pelo próprio uso do solo, em função de problemas ligados à variação volumétrica dos sedimentos pela presença de argilo-minerais expansivos. Essas alterações resultam da exposição do sedimentos argilosos a ciclos de umedecimento e ressecamento, em taludes, cortes e mesmo terraplanagens, gerando fenômenos de empastilhamento (Fig. 2.24). 


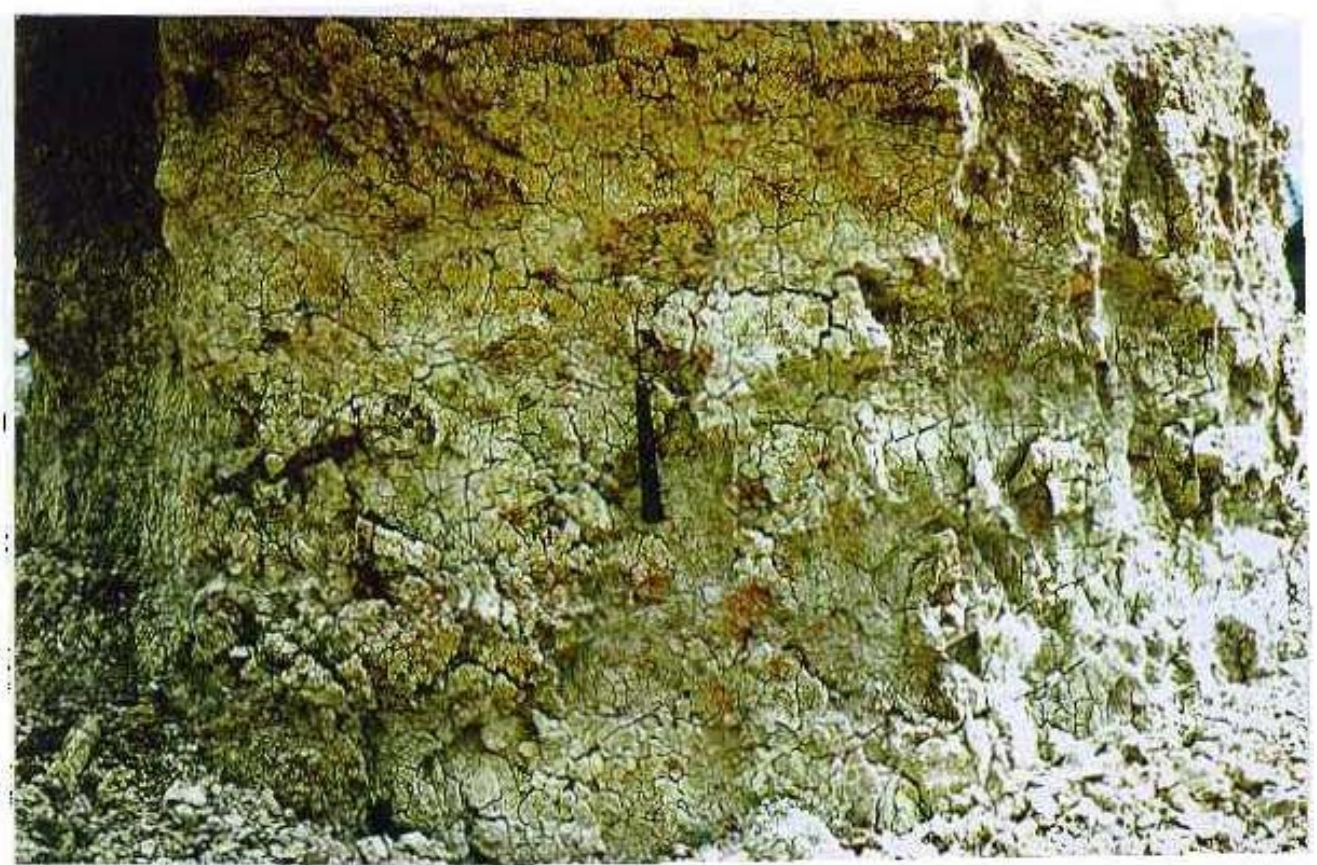

Figura 2.24 - Aspecto do empastilhamento e trincas causados pela retração nas argilas cinza-esverdeadas da Formação Guabirotuba (Felipe et al., 1994)

A existência de fraturamento conchoidal favorece a formação de superfície de ruptura, potencializando a movimentação de fatias do terreno (Fig. 2.25). As áreas que oferecem maior risco têm declividade superior a $20 \%$ e são desprovidas do solo de cobertura e vegetação (Hach-Hach, 1998 e Hach-Hach et al., 1998). 


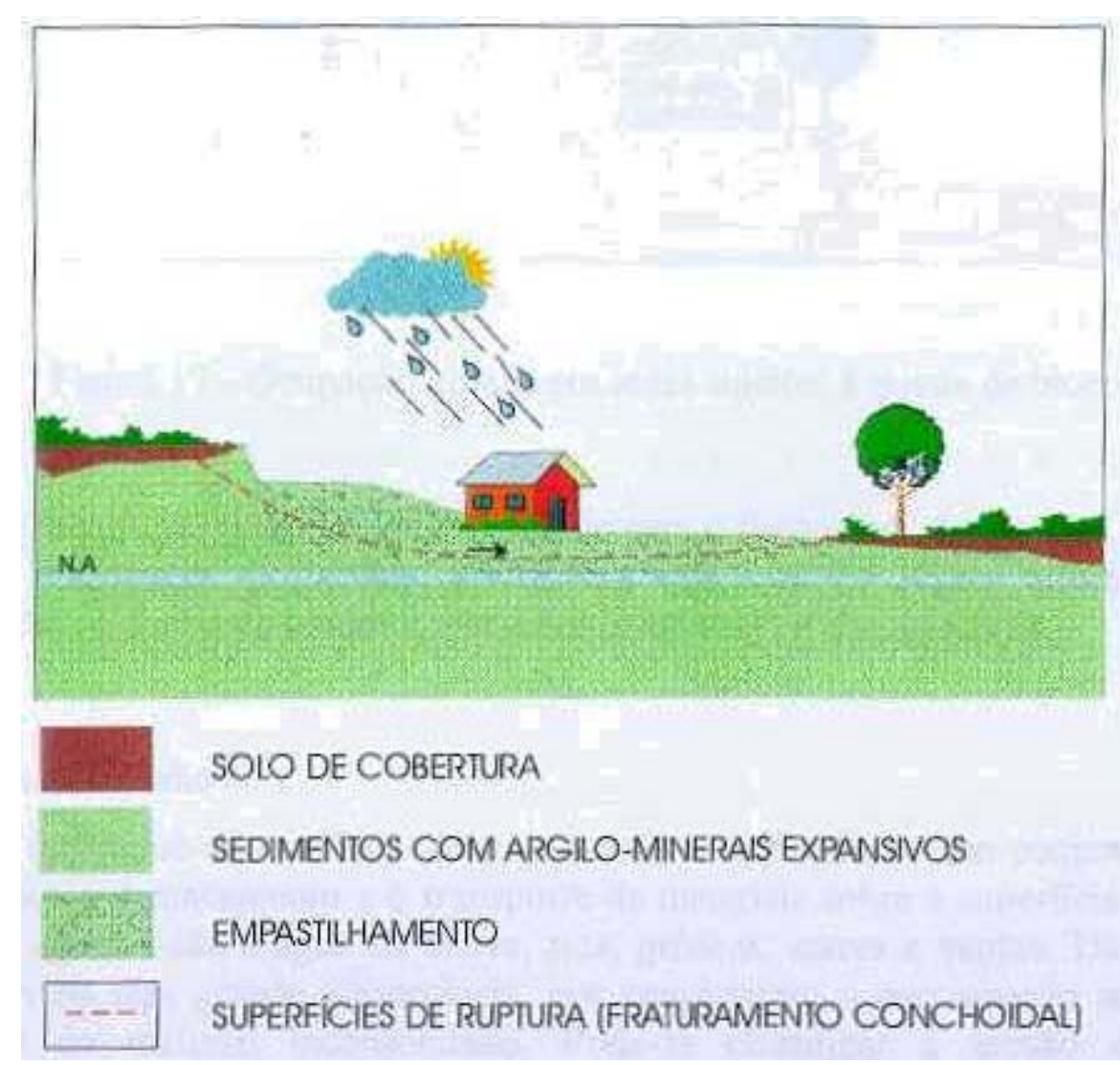

Figura 2.25 - Risco de escorregamento em sedimentos da Formação Guabirotuba, desprovidos de solo e cobertura vegetal (Oliveira et al., 1997).

\subsection{PREVISÃO DA CAPACIDADE DE CARGA E INTERPRETAÇÃO DA CURVA CARGA - RECALQUE}

\subsubsection{Capacidade de carga}

O estudo da capacidade de carga, em estacas cravadas em solos argilosos, assume especial importância quando se considera a grande ocorrência de tais tipos de solo nas bacias sedimentares em que estão instalados grandes centros urbanos e industriais do sul do país, que é o caso da Região Metropolitana de Curitiba. 
Entretanto, contrastando com a enorme quantidade de dados e a volumosa bibliografia existente a propósito do assunto, em solos de São Paulo, por exemplo, de quase nada se dispõe a respeito dos solos de Curitiba (Amaral, 1982). A situação atual é diferente de 1982, pois já existe uma bibliografia disponível, mas ainda pode ser considerada insuficiente. Pesquisas do ponto de vista geológico vêm sendo realizadas, mas o comportamento do material do ponto de vista geotécnico ainda precisa ser estudado e compreendido.

A partir de dados fornecidos por sondagens, especialmente os de caracterização do solo e os resultados dos ensaios penetrométricos SPT, Amaral (1982) elaborou um método de cálculo para estimativa da capacidade de carga de estacas pré-moldadas ajustado aos solos argilosos da Formação Guabirotuba. Este método foi aprimorado pelo autor em 1999.

Para elaboração de algumas formulações de origem semi-empírica relativas à capacidade de carga de estacas à compressão, parte-se de um valor da carga de ruptura obtido por algum critério, designa-se a parcela de ponta e por subtração obtém-se a parcela lateral. Isto traz uma imprecisão a este valor que não existiria em processo que separasse os componentes lateral e de ponta através de evidências físicas dessa transição que pudessem ser matematicamente formuladas (Amaral, 1999).

De acordo com Amaral (1982), para a Formação Guabirotuba a carga lateralmente resistida em estacas pré-moldadas corresponde em média a $88 \%$ da carga de ruptura. Sendo assim, a precisão do cálculo da resistência lateral é mais importante que aquela de ponta, sendo conveniente inverter a subtração, calculando-se primeiramente a resistência lateral por formulações algébricas advindas de evidências físicas e depois obtendo-se a resistência de ponta por subtração.

Para elaboração do método, o autor procurou determinar a expressão matemática da curva carga - recalque, partindo da proposta de Van der Veen (1953), ligeiramente modificada para se adequar melhor aos últimos pontos 
da curva. Foram obtidos então, os valores da carga de ruptura $\mathrm{R}$ através da equação

$$
\mathrm{P}=\mathrm{P}_{\mathrm{u}}\left(1-\mathrm{ae} \mathrm{e}^{\mathrm{b} \rho}\right)
$$

Derivando-se essa a equação em relação a r, obtém-se:

$$
\frac{\mathrm{dP}}{\mathrm{d} \rho}=-\left[\mathrm{P}_{\mathrm{u}} \text { bae } \mathrm{e}^{\mathrm{b} \rho}\right]
$$

mas de acordo com (1)

$$
\mathrm{P}-\mathrm{P}_{\mathrm{u}}=-\mathrm{P}_{\mathrm{u}} \mathrm{ae}
$$

então

$$
\frac{d P}{d \rho}=b\left(P_{u}-P\right)
$$

De acordo com a figura 2.26, $\mathrm{dP} / \mathrm{d} \rho$ é a tangente do ângulo $\varepsilon$ 


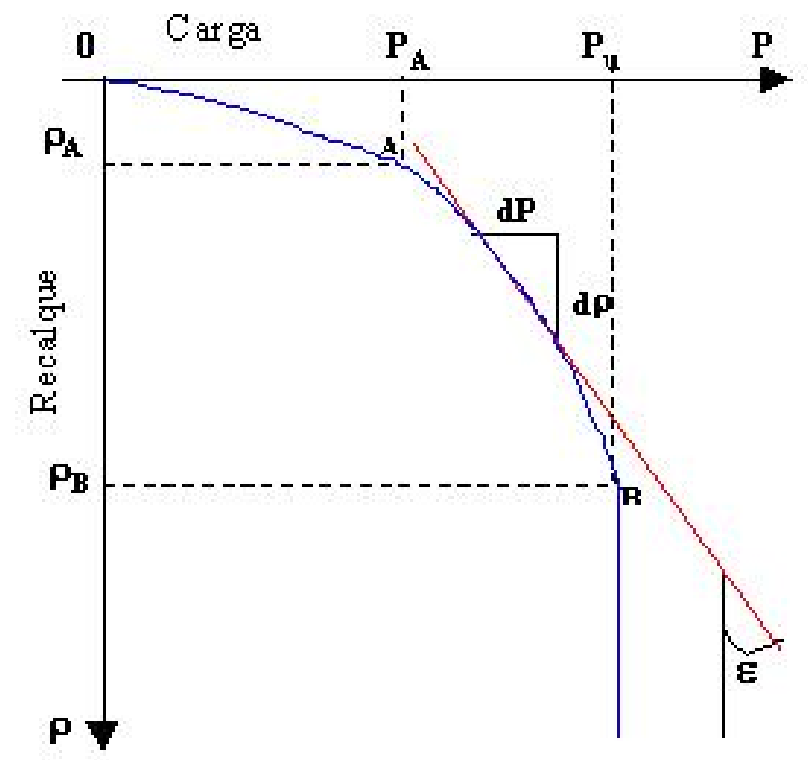

Figura 2.26 - Curva carga x recalque genérica (Amaral et al., 1999). então

$$
\begin{aligned}
& \operatorname{tg} \varepsilon=-b(P u-P) . \\
& \frac{\operatorname{tg} \varepsilon}{\mathrm{Pu}}=-\mathrm{b}\left(1-\frac{\mathrm{P}}{\mathrm{Pu}}\right)
\end{aligned}
$$

Para

$$
\begin{array}{ll}
\mathrm{P}=0 & \frac{\operatorname{tg} \varepsilon}{\mathrm{Pu}}=-\mathrm{b} \\
\mathrm{P}=\mathrm{Pu} & \frac{\operatorname{tg} \varepsilon}{\mathrm{Pu}}=0 \ldots
\end{array}
$$

A figura 2.26 mostra uma curva carga - recalque cujo ponto A corresponde ao ponto em que a resistência por atrito está totalmente mobilizada. Este ponto deve satisfazer a condição $5 \leq \rho_{\mathrm{A}} \leq 10 \mathrm{~mm}$. Para cada prova de carga deve haver um valor de tge correspondente ao ponto A.

O fator de adesão $\alpha$ é definido como sendo a resistência lateral unitária dividida pelo NSPT médio ao longo do fuste como mostra a equação (8). 


$$
\alpha=\frac{\mathrm{f} \ell}{\mathrm{N} \ell}
$$

Adotando-se provisoriamente um valor de tge/ Pu (em que $5 \leq \rho \leq 10$ $\mathrm{mm}$ ) para o ponto A, calcula-se o valor de $\alpha$ e $\mathrm{N}_{\ell}$ para todas as curvas que pertençam ao universo a ser estudado estatisticamente. Analisados os dados, o autor chegou ao seguinte valor:

$$
\frac{\operatorname{tg} \varepsilon}{\mathrm{Pu}}=(0,005)^{-1}
$$

A maior parte das amostras estudadas por Amaral (1999) faz parte da Formação Guabirotuba. Apenas quando foram necessárias amostras em solos de granulometria predominantemente inexistentes nessa Formação, como solos arenosos, foram usadas amostras de outras formações geológicas. As amostras foram divididas em três universos:
a) amostras predominantemente argilosas;
b) amostras predominantemente siltosas;
c) amostras predominantemente arenosas.

Adotando-se a equação (9), e analisando-se cada uma das curvas carga $\mathrm{x}$ recalque neste ponto, obtiveram-se as seguintes funções:

$$
\begin{array}{cc}
\alpha=0,032 \mathrm{~N}_{\ell}^{-0,74} & \text { (argilas).... } \\
\alpha=0,014 \mathrm{~N}_{\ell}^{-0,35} & \text { (siltes).... } \\
\alpha=0,016 \mathrm{~N}_{\ell}^{-0,35} & \text { (areias)... }
\end{array}
$$

e a parcela de resistência lateral pode ser escrita como: 


$$
\mathrm{R}_{\ell}=\alpha \mathrm{N}_{\ell} S_{\ell}
$$

A parcela de resistência de ponta pode ser escrita como:

$$
\mathrm{R}_{\mathrm{p}}=\mathrm{KN}_{\mathrm{p}} \mathrm{A}_{\mathrm{p}}
$$

e os valores de K estão apresentados na tabela 2.10.

Tabela 2.10 - Valores do coeficiente K

\begin{tabular}{cc}
\hline Solo & K \\
\hline Argila & 0,16 \\
Silte & 0,31 \\
Areia & 0,44 \\
\hline
\end{tabular}

Obs.: Para valores de $S_{\ell}$ e $A_{p}$ em m², obtém-se valores de $\mathrm{P}$ em 10-1 kN.

\subsubsection{Diagnóstico da Condição da Estaca}

Chin (1978) apresenta um método no qual a condição estrutural de uma estaca pode ser diagnosticada simplesmente pela observação dos resultados da curva carga $x$ recalque, sem necessidade da extração da estaca para fazer-se a verificação. Este método é baseado na relação tensão $x$ deformação do material da estaca e do solo no qual ela está inserida.

Geralmente, quando uma carga P é aplicada na cabeça de uma estaca, a compressão elástica do material da estaca é relativamente pequena quando comparada com a deformação do solo. Consequentemente, a relação entre o recalque $\rho$ e a carga P na cabeça da estaca será aproximadamente hiperbólica como mostra a equação (16), idealizada por Chin (1970): 


$$
\frac{\rho}{P}=m \rho+C
$$

onde m e c são constantes.

Quando plotado $\rho / \mathrm{P}$ versus $\rho$, obtém-se uma relação linear. Para uma estaca em que a capacidade de carga é suportada substancialmente pela resistência lateral, ou se o limite da prova de carga corresponde ao valor último do atrito lateral, o gráfico $\rho / p \times \rho$ resulta em uma única linha reta. Se as condições são tais que a capacidade de carga da estaca é suportada pela resistência de ponta, o gráfico também resulta em uma única linha reta (figura 2.27). $\mathrm{O}$ inverso do coeficiente angular fornece a carga última extrapolada (Chin, 1970).

A resistência de ponta requer deslocamentos relativamente grandes para ser mobilizada quando comparada com os deslocamentos necessários para mobilizar o atrito lateral na compressão.

Quando o diagrama $\rho / \mathrm{P} \times \rho$ resulta em dois trechos de reta (figura 2.28), o inverso do coeficiente angular do primeiro trecho (PQ) fornece a parcela de atrito lateral e o inverso do coeficiente angular do segundo trecho (RS) fornece a carga última extrapolada (Chin, 1970).

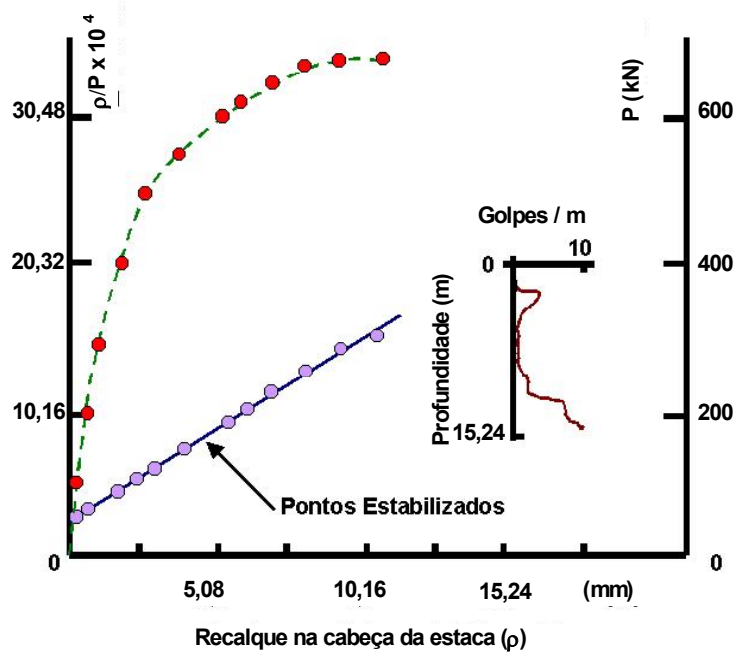

Figura 2.27 - Gráfico $\rho / p \times \rho$ para uma estaca de ponta (Chin, 1978). 


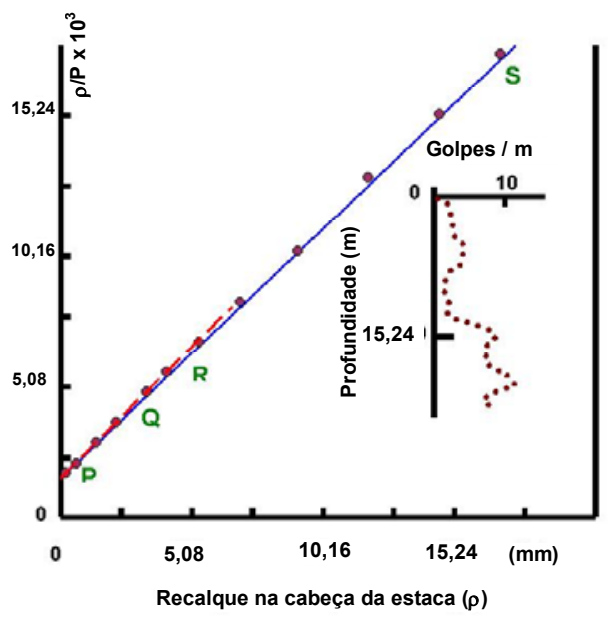

Figura 2.28 - Gráfico $\rho / p \times \rho$ para uma estaca que trabalha pela ponta e por atrito lateral (Chin, 1978).

O gráfico $\rho / \mathrm{P} \times \rho$ possibilita ainda analisar a condição estrutural de uma estaca como mostra as figuras 2.29 e 2.30. Nestes casos, os pontos não se encaixam em nenhum dos casos acima citados indicando a existência de alguma anomalia proveniente de algum dano estrutural da estaca que não é possível de ser detectado apenas observando-se a curva carga x recalque. Chin (1978) comprova tal fato através da extração das estacas.

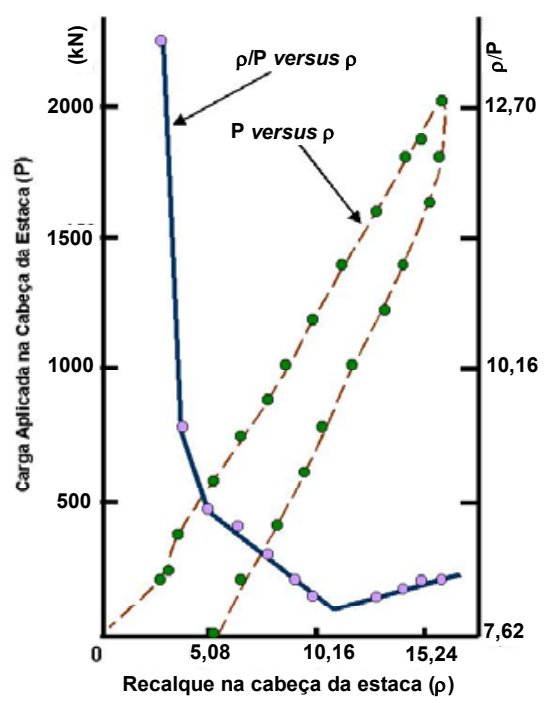

Figura 2.29 - Gráfico $\rho / p \times \rho$ para uma estaca que sofreu danos estruturais durante a cravação (Chin, 1978). 


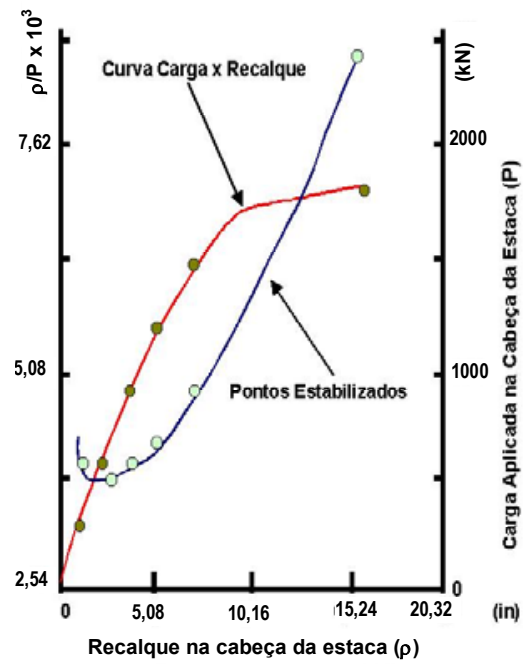

Figura 2.30 - Gráfico $\rho / p \times \rho$ para uma estaca que sofreu sérios danos na ponta (Chin, 1978). 


\section{MÉTODOS DE PREVISÃO DA CAPACIDADE DE CARGA}

Dentre os inúmeros métodos existentes para previsão da capacidade de carga $(\mathrm{R})$ de um elemento isolado de fundação, foram escolhidos para este estudo os métodos semi-empíricos propostos por Aoki - Velloso (1975), Décourt - Quaresma (1978) e Amaral (1982, 1999). Os dois primeiros foram escolhidos por serem amplamente utilizados no Brasil e o último, por ser desenvolvido para estacas cravadas na Formação Guabirotuba.

Esses métodos foram aplicados ao conjunto de 34 provas de carga estática, das quais 30 não atingiram a ruptura, sendo necessário extrapolar as curvas carga $x$ recalque para obtenção dos valores da carga última $(\mathrm{Pu})$. Os valores obtidos pelos métodos semi-empíricos para a capacidade de carga (R), bem como os valores extrapolados da carga última $(\mathrm{Pu})$, estão apresentados no anexo 2. A comparação dos valores da capacidade de carga obtidos pelos métodos Aoki - Velloso, Décourt - Quaresma e Amaral, com os valores da carga última de Van der Veen (1953), está representada nas figuras 3.1a, 3.1b e 3.1c, respectivamente. 


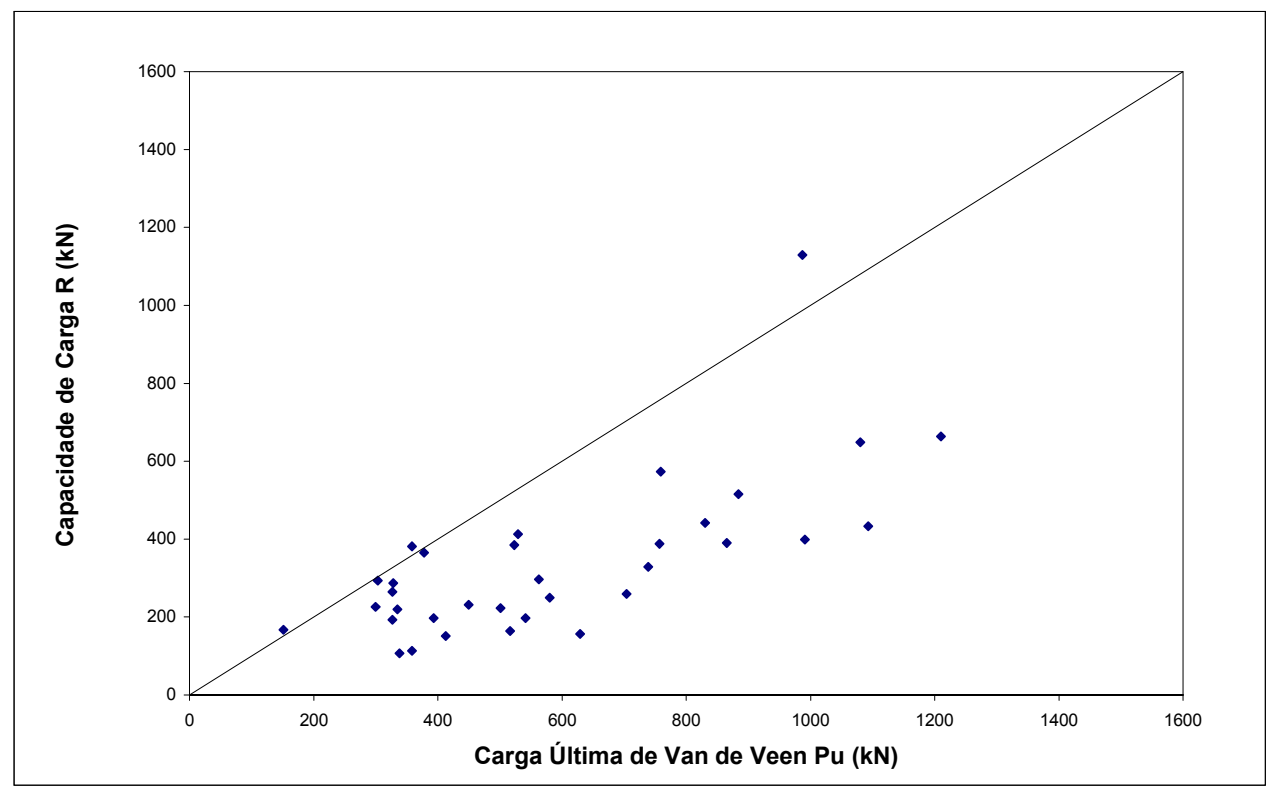

Figura 3.1a - Comparação do método Aoki - Velloso com a carga última de Van der Veen.

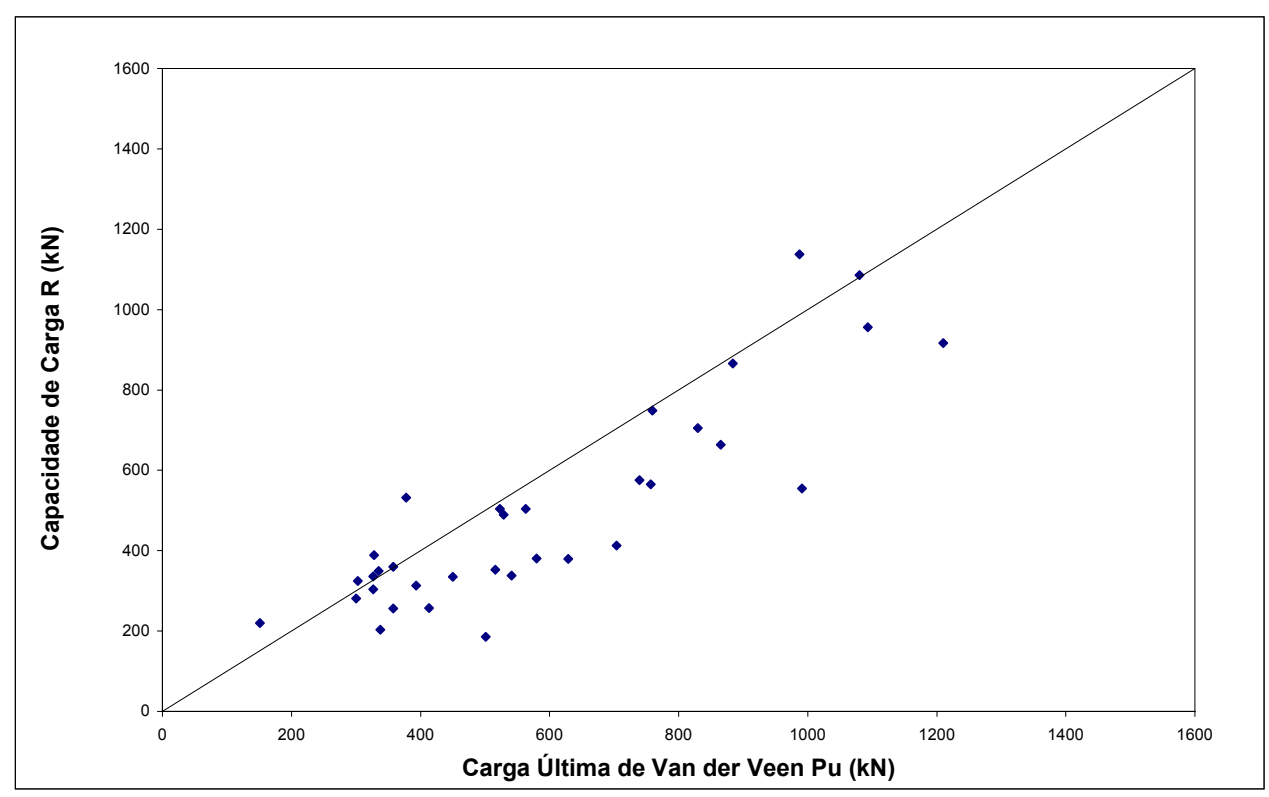

Figura 3.1b - Comparação do método Décourt - Quaresma com a carga última de Van der Veen. 


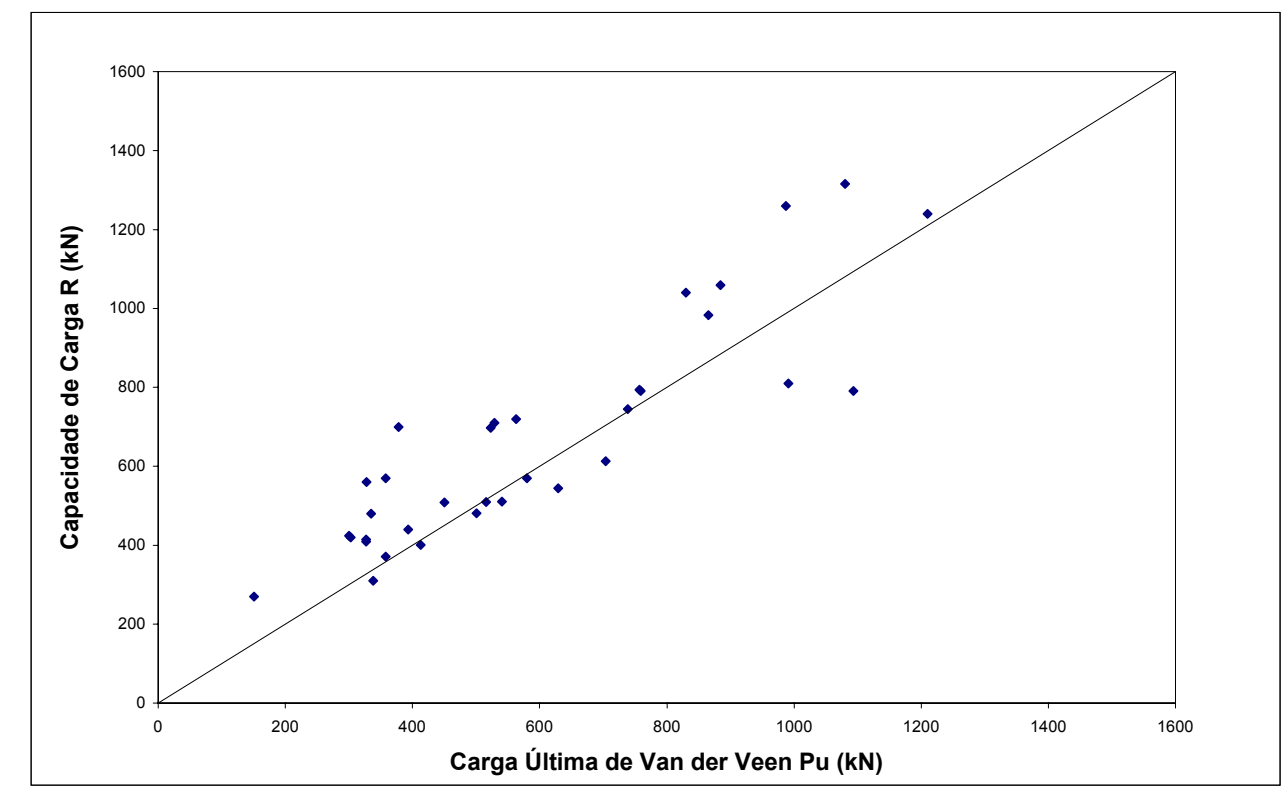

Figura 3.1c - Comparação do método Amaral com a carga última de Van der Veen.

Observa-se que o método Aoki - Velloso apresenta-se muito conservador, enquanto que o método Amaral apresenta valores mais ousados, às vezes indo contra a segurança. O método Décourt - Quaresma apresenta valores intermediários.

Para quantificar a dispersão dos valores de $\mathrm{R}$ em relação a $\mathrm{Pu}$, calculou-se a relação $\mathrm{R} / \mathrm{Pu}$ para cada elemento de fundação, assim como o valor médio, desvio padrão e coeficiente de variação (tabela 3.1). Desta tabela, observa-se que o valor médio de $\mathrm{R} / \mathrm{Pu}$ do método Aoki - Velloso é $42 \%$ inferior ao valor unitário (esperado), enquanto os métodos Décourt - Quaresma e Amaral aproximam-se mais do valor unitário: $-17 \%$ e $+23 \%$, respectivamente. 
Tabela 3.1 - Valores da média, desvio padrão e coeficiente de variação da relação R/Pu para cada método.

\begin{tabular}{cccc} 
& Aoki - Velloso & Décourt - Quaresma & Amaral \\
\hline Média & 0,583 & 0,834 & 1,181 \\
Desvio Padrão & 0,225 & 0,245 & 0,273 \\
Coef. Variação & 0,387 & 0,294 & 0,231 \\
\hline
\end{tabular}

Em seguida, procurou-se adaptar cada um dos métodos analisados, de forma a tornar o valor da capacidade de carga mais próxima da carga última, através da introdução de fatores de correção.

Para este estudo, foram utilizadas apenas as quatro provas de carga que atingiram a ruptura, cujas características referentes ao diâmetro (D), comprimento $(\mathrm{L})$, carga nominal $(\overline{\mathrm{P}})$ e carga última $(\mathrm{Pu})$ obtida no ensaio, estão apresentadas na tabela 3.2.

Tabela 3.2 - Características das estacas ensaiadas até a ruptura.

\begin{tabular}{lllll}
\hline Estaca & $\mathrm{D}(\mathrm{m})$ & $\mathrm{L}(\mathrm{m})$ & $\overline{\mathrm{P}}(\mathrm{kN})$ & $\mathrm{Pu}(\mathrm{kN})$ \\
\hline 05 & 0,38 & 9,6 & 700 & 1080 \\
11 & 0,20 & 12,0 & 200 & 300 \\
21 & 0,25 & 11,5 & 300 & 450 \\
30 & 0,28 & 10,6 & 400 & 580 \\
\hline
\end{tabular}

\subsection{Método Aoki - Velloso (1975)}

Neste método, as parcelas de resistência de ponta $\left(R_{\mathrm{p}}\right)$ e de resistência lateral $\left(\mathrm{R}_{\ell}\right)$ que compõem a capacidade de carga $(\mathrm{R})$ são obtidas a partir da 
resistência de ponta $\left(\mathrm{q}_{\mathrm{c}}\right)$ e do atrito lateral unitário $\left(\mathrm{f}_{\mathrm{c}}\right)$ medidos em ensaios de penetração estática CPT,

$$
\begin{aligned}
& \mathrm{R}_{\mathrm{p}}=\frac{\mathrm{q}_{\mathrm{c}}}{\mathrm{F}_{1}} \times \mathrm{A}_{\mathrm{p}} \\
& \mathrm{R}_{\ell}=\frac{\mathrm{f}_{\mathrm{C}}}{\mathrm{F}_{2}} \times \mathrm{S}_{\ell} \ldots
\end{aligned}
$$

onde: $A_{p}$ e $S_{\ell}$ correspondem a área da seção transversal da ponta e a área lateral do elemento estrutural de fundação respectivamente;

$F_{1}$ e $F_{2}$ são coeficientes de transformação que englobam o tipo de estaca e o efeito escala entre a estaca (protótipo) e o cone do CPT (modelo) cujos valores para estacas pré-moldadas de concreto correspondem a 1,75 e 3,5, respectivamente.

Para estacas de pequeno diâmetro, Aoki (1985) avalia que $F_{1}=1,75$ mostrou-se muito conservador e, por isso, propõe a seguinte expressão para estacas pré-moldadas de concreto:

$$
\mathrm{F}_{1}=1+\frac{\mathrm{D}}{0,80} \quad(\mathrm{D} \text { em metros}) .
$$

em que $D$ é o diâmetro ou lado do fuste da estaca, mantendo a relação $F_{2}=2 F_{1}$. Vale salientar que o coeficiente $F_{2}$ pode variar entre uma e duas vezes o valor de $F_{1}$ e que, portanto $F_{2}=2 F_{1}$ é a hipótese mais conservadora (Aoki,1996).

Com esta proposição para $F_{1}$ e, consequentemente para $F_{2}$, calculou-se novamente a capacidade de carga $\left(R^{*}\right)$ para cada elemento isolado de fundação (anexo 2). 
A figura 3.2 mostra a comparação dos valores da capacidade de carga obtidos pelo método adaptado $\left(\mathrm{R}^{*}\right)$ com os valores da carga última de Van der Veen $(\mathrm{Pu})$, reapresentando-se os valores obtidos pelo método original (R).

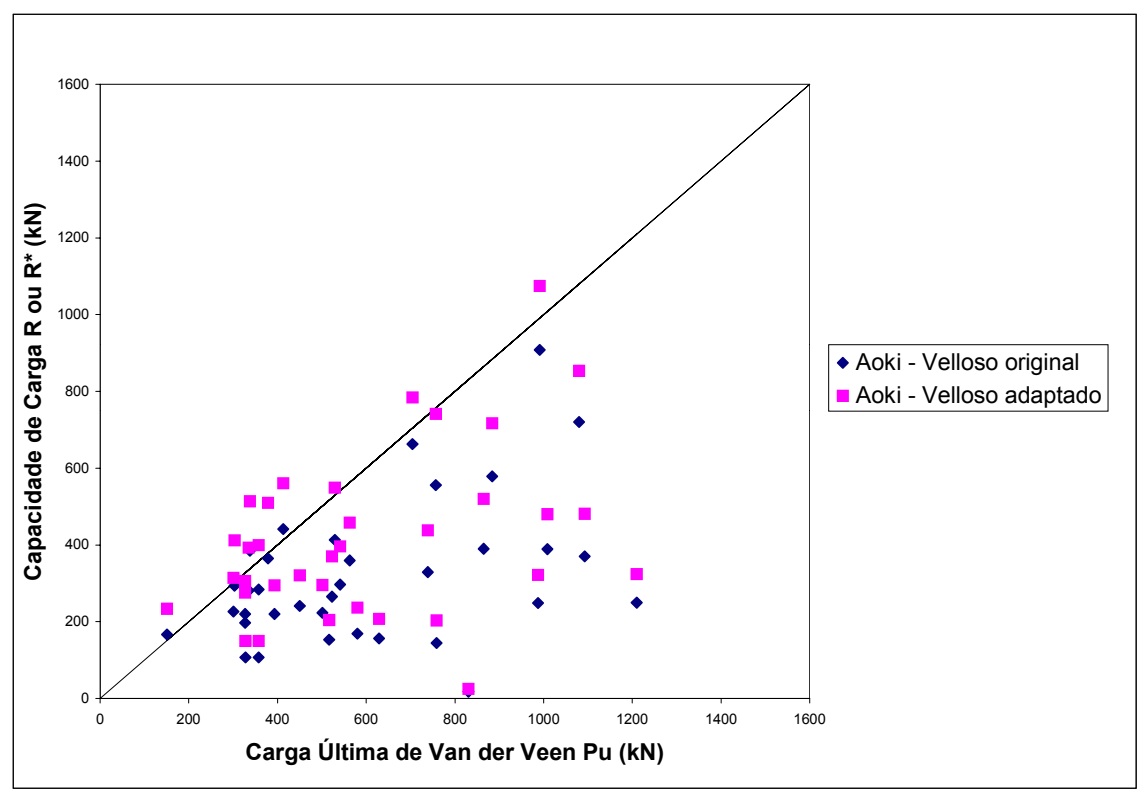

Figura 3.2 - Comparação do método Aoki - Velloso original e adaptado com os valores da carga última de Van der Veen.

A relação $\mathrm{R}^{*} / \mathrm{Pu}$ foi calculada para cada elemento isolado de fundação e os valores da média, desvio padrão e coeficiente de variação estão apresentados na tabela 3.3, reapresentando-se os valores referentes à relação $\mathrm{R} / \mathrm{Pu}$.

Tabela 3.3 - Valores da média, desvio padrão e coeficiente de variação das relações R/Pu e R*/Pu para o método Aoki - Velloso.

\begin{tabular}{ccc} 
& $\mathrm{R} / \mathrm{Pu}$ & $\mathrm{R}^{*} / \mathrm{Pu}$ \\
\hline Média & 0,583 & 0,778 \\
Desvio Padrão & 0,225 & 0,314 \\
Coef. Variação & 0,387 & 0,404 \\
\hline
\end{tabular}


Observa-se que o método adaptado apresenta um valor médio da relação $\mathrm{R}^{*} / \mathrm{Pu} 33 \%$ superior ao de $\mathrm{R} / \mathrm{Pu}$, mas ainda permanece razoavelmente conservador.

Por isso, optou-se por introduzir um fator de correção, conforme exposto a seguir.

\subsubsection{Fator de correção global}

Para obter um fator de correção ao método adaptado de Aoki - Velloso, consideraram-se as quatro provas de carga conduzidas até a ruptura (tabela 3.2), cujos valores de capacidade de carga são experimentais.

A aplicação do método Aoki - Velloso adaptado a essas quatro estacas resulta nos valores de resistência de ponta $\left(R_{p}^{*}\right)$, resistência lateral $\left(R_{\ell}^{*}\right)$ e capacidade de carga $\left(R^{*}\right)$ mostrados na tabela 3.4.

Tabela 3.4 - Valores das resistências de ponta, lateral e de ruptura obtidos pelo método Aoki - Velloso adaptado.

\begin{tabular}{cccc}
\hline Estaca & $\mathrm{R}_{\mathrm{p}}^{*}(\mathrm{kN})$ & $\mathrm{R}_{\ell}^{*}(\mathrm{kN})$ & $\mathrm{R}^{*}(\mathrm{kN})$ \\
\hline 5 & 477 & 376 & 853 \\
11 & 165 & 150 & 315 \\
21 & 87 & 208 & 295 \\
30 & 131 & 193 & 324 \\
\hline
\end{tabular}

Em seguida calculou-se a relação $\mathrm{R}^{*} / \mathrm{Pu}$ para cada prova de carga e os respectivos valores da média, desvio padrão e coeficiente de variação (tabela 3.5). 
Tabela 3.5 - Valores da média, desvio padrão e coeficiente de variação da relação $R^{*} / \mathrm{Pu}$ para as provas que atingiram a ruptura.

\begin{tabular}{cccc}
\hline Estaca & $\mathrm{R}^{*}(\mathrm{kN})$ & $\mathrm{Pu}(\mathrm{kN})$ & $\mathrm{R}^{*} / \mathrm{Pu}$ \\
\hline 05 & 853 & 1080 & 0,790 \\
11 & 315 & 300 & 1,050 \\
21 & 295 & 450 & 0,655 \\
30 & 324 & 580 & 0,559 \\
\hline & & Média & 0,763 \\
& & Desvio Padrão & 0,213 \\
& & Coef. Variação & 0,279 \\
\cline { 3 - 4 } & & &
\end{tabular}

Finalmente o fator de correção global foi determinado como o inverso do valor médio da relação $\mathrm{R}^{*} / \mathrm{Pu}$, que e corresponde a 1,3. Este fator multiplicador foi aplicado ao valor de $\mathrm{R}^{*}$ obtido pelo método Aoki - Velloso adaptado, encontrando-se o correspondente valor corrigido de $\mathrm{R}^{\prime}$, para os 34 elementos isolados de fundação (anexo 2).

A figura 3.3 mostra a comparação dos valores da capacidade de carga $\left(\mathrm{R}^{\prime}\right)$ obtidos pelo método adaptado e corrigido com o fator global com os valores da carga última de Van der Veen $(\mathrm{Pu})$, reapresentando-se também os valores de capacidade de carga pelo método adaptado $\left(R^{*}\right)$. 


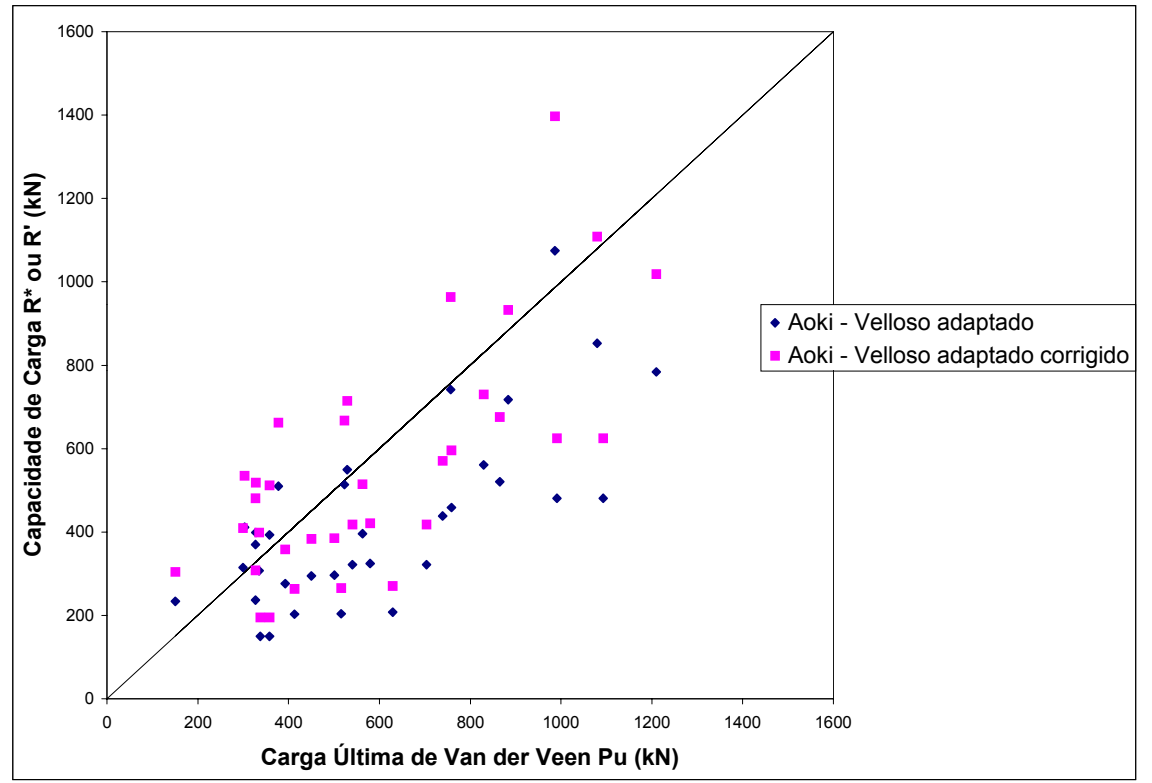

Figura 3.3 - Comparação do método Aoki - Velloso adaptado ( $\left.R^{*}\right)$ e do método corrigido com o fator global $\left(\mathbf{R}^{\prime}\right)$ com a carga última de Van der Veen.

Os valores da média, desvio padrão e coeficiente de variação das relações $\mathrm{R}^{*} / \mathrm{Pu}$ e $\mathrm{R}^{\prime} / \mathrm{Pu}$ estão apresentados na tabela 3.6.

Tabela 3.6 - Valores da média, desvio padrão e coeficiente de variação das relações $\mathbf{R}^{*} / \mathbf{P u}$ e $\mathbf{R}^{\prime} / \mathbf{P u}$.

\begin{tabular}{ccc}
\cline { 2 - 3 } & $\mathrm{R}^{*} / \mathrm{Pu}$ & $\mathrm{R}^{\prime} / \mathrm{Pu}$ \\
\hline Média & 0,778 & 1,012 \\
Desvio Padrão & 0,314 & 0,408 \\
Coef. Variação & 0,404 & 0,404 \\
\hline
\end{tabular}

Observa-se, portanto, que é vantajosa a introdução do fator de correção global ao valor de capacidade de carga obtido pelo método adaptado. 


\subsubsection{Fator de correção parcial}

Em outra análise, procurou-se obter um fator de correção apenas para a parcela de resistência lateral uma vez que para essa parcela existe o conservadorismo da hipótese $\mathrm{F}_{2}=2 \mathrm{~F}_{1}$.

Para as quatro provas de carga que atingiram a ruptura, foram mantidos os valores de $\mathrm{Pu}$ e de $\mathrm{R}_{\mathrm{p}}^{*}$, encontrando-se um novo valor para a resistência lateral $\left(\mathrm{R}^{\prime \prime}\right)$, tal que

$$
\mathrm{R}_{\ell}^{\prime \prime}=\mathrm{Pu}-\mathrm{R}_{\mathrm{p}}^{*}
$$

Em seguida, calculou-se a relação $R_{\ell}^{\prime \prime} / R_{\ell}^{*}$ para cada um dos quatro ensaios, bem como a média, desvio padrão e coeficiente de variação (tabela 3.7). O inverso deste valor médio , 1,46 arredondado para 1,5, foi tomado como fator multiplicador para correção da parcela de resistência lateral.

Tabela 3.7 - Valores da média, desvio padrão e coeficiente de variação da relação $\mathbf{R}_{\ell}^{\prime \prime} / \mathbf{R}_{\ell}^{*}$ para as provas que atingiram a ruptura.

\begin{tabular}{cccc}
\hline Prova & $\mathrm{R}_{\ell}^{*}(\mathrm{kN})$ & $\mathrm{R}_{\ell}^{\prime \prime}(\mathrm{kN})$ & $\mathrm{R}_{\ell}^{\prime \prime} / \mathrm{R}_{\ell}^{*}$ \\
\hline 05 & 376 & 603 & 0,624 \\
11 & 150 & 135 & 1,111 \\
21 & 208 & 363 & 0,572 \\
30 & 193 & 449 & 0,430 \\
\hline & & Média & 0,684 \\
& & Desvio Padrão & 0,296 \\
& & Coef. Variação & 0,433 \\
\cline { 3 - 4 }
\end{tabular}


Com esta correção, foram obtidos novos valores de capacidade de carga $\left(\mathrm{R}^{\prime \prime}\right)$ para as 34 estacas (anexo 2). A figura figura 3.4 mostra a comparação dos valores da capacidade de carga $\left(\mathrm{R}^{\prime \prime}\right)$ obtidos pelo método adaptado e corrigido com o fator parcial com os valores da carga última de Van der Veen $(\mathrm{Pu})$, reapresentando-se os valores de capacidade de carga $\left(R^{*}\right)$ do método adaptado.

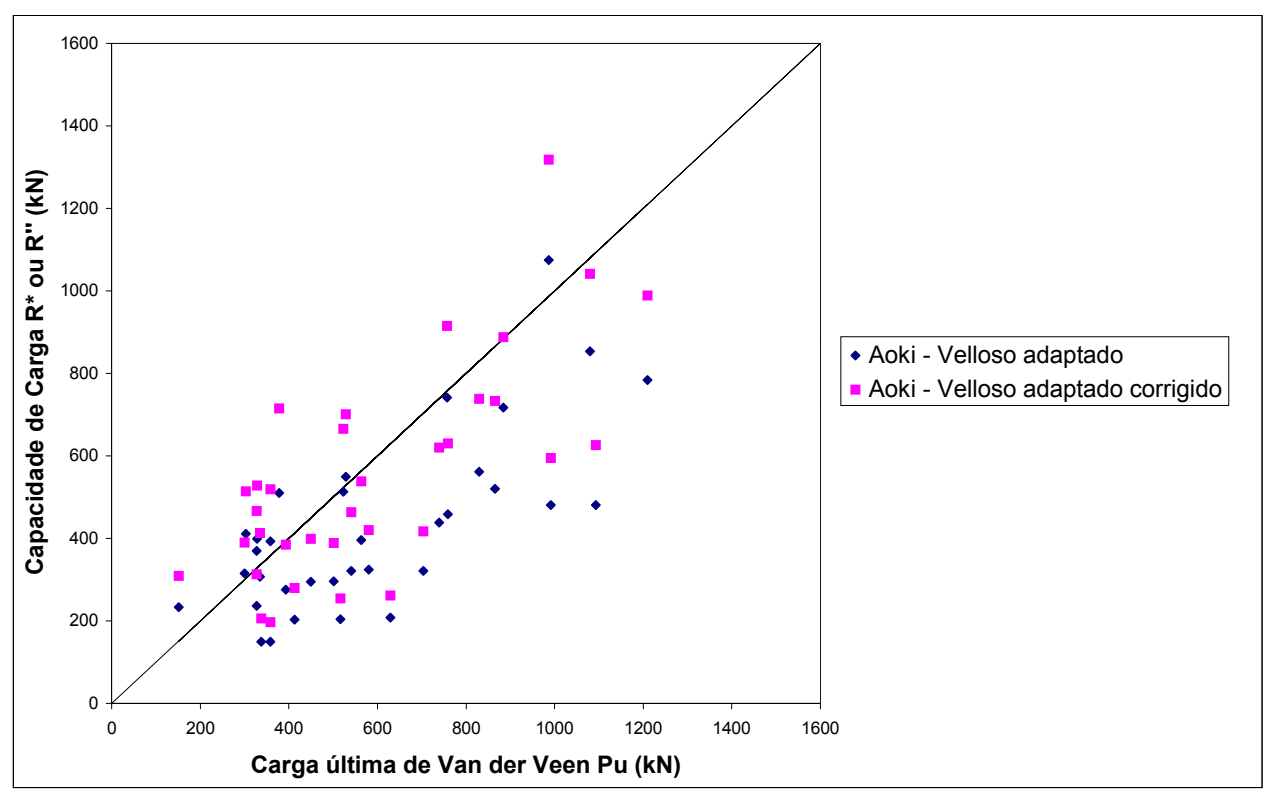

Figura 3.4 - Comparação do método Aoki - Velloso adaptado ( $\left.\mathbf{R}^{*}\right)$ e do método Aoki - Velloso adaptado e corrigido com o fator parcial $\left(\mathbf{R}^{\prime \prime}\right)$ com a carga última de Van der Veen.

Os valores da média, desvio padrão e coeficiente de variação da relação $\mathrm{R}^{\prime \prime} / \mathrm{Pu}$ são apresentados na tabela 3.8 , reapresentando-se os valores referentes à relação $\mathrm{R}^{*} / \mathrm{Pu}$. 
Tabela 3.8 - Valores da média, desvio padrão e coeficiente de variação da relação $R^{*} / \mathbf{P u}$ e $\mathbf{R}^{\prime \prime} / \mathbf{P u}$.

\begin{tabular}{ccc} 
& $\mathrm{R}^{*} / \mathrm{Pu}$ & $\mathrm{R}^{\prime \prime} / \mathrm{Pu}$ \\
\hline Média & 0,778 & 1,019 \\
Desvio Padrão & 0,314 & 0,406 \\
Coef. Variação & 0,404 & 0,399 \\
\hline
\end{tabular}

Observa-se que é interessante a aplicação do fator de correção parcial ao valor de capacidade de carga obtido pelo método adaptado. Da comparação das tabelas 3.6 e 3.8, conclui-se que não há diferenças significativas na utilização dos coeficientes de correção global ou parcial.

É importante notar que o fator de correção parcial encontrado equivale a uma relação $F_{2}=1,35 F_{1}$.

\subsection{Método Décourt - Quaresma}

Para o cálculo do fator de correção a ser aplicado neste método novamente foram utilizadas as provas de carga rompidas (tabela 3.2). Aplicando-se o método Décourt - Quaresma (1978) na versão de Décourt (1982), encontram-se os valores da resistência de ponta $\left(R_{p}\right)$, resistência lateral $\left(R_{\ell}\right)$ e capacidade de carga (R) constantes da tabela 3.9. 
Tabela 3.9 - Valores das resistências de ponta, lateral e de ruptura obtidos pelo método Décourt - Quaresma.

\begin{tabular}{cccc}
\hline Estaca & $\mathrm{R}_{\mathrm{p}}(\mathrm{Kn})$ & $\mathrm{R}_{\ell}(\mathrm{kN})$ & $\mathrm{R}(\mathrm{kN})$ \\
\hline 5 & 680 & 406 & 1086 \\
11 & 210 & 70 & 281 \\
21 & 45 & 272 & 317 \\
30 & 79 & 311 & 390 \\
\hline
\end{tabular}

\subsubsection{Fator de correção global}

A relação $\mathrm{R} / \mathrm{Pu}$ foi calculada para cada um dos quatro ensaios e os valores da média, desvio padrão e coeficiente de variação estão apresentados na tabela 3.10.

Tabela 3.10 - Valores da média, desvio padrão e coeficiente de variação da relação $\mathrm{R} / \mathrm{Pu}$ para as provas que atingiram a ruptura.

\begin{tabular}{cccc}
\hline Estaca & $\mathrm{R}(\mathrm{kN})$ & $\mathrm{Pu}(\mathrm{kN})$ & $\mathrm{R} / \mathrm{Pu}$ \\
\hline 05 & 1086 & 1080 & 1,006 \\
11 & 281 & 300 & 0,937 \\
21 & 317 & 450 & 0,704 \\
30 & 390 & 580 & 0,672 \\
\hline & & Média & 0,830 \\
& & Desvio Padrão & 0,166 \\
& & Coef. Variação & 0,200 \\
\cline { 3 - 4 } & &
\end{tabular}

O inverso do valor médio corresponde ao fator de correção global aplicado diretamente na capacidade de carga. Este fator de 1,2 foi multiplicado 
ao valor da capacidade de carga $(\mathrm{R})$ do método original, obtendo-se os valores corrigidos ( $R^{\prime}$ ) dos 34 elementos isolados de fundação (anexo 2).

A comparação entre os valores da capacidade de carga corrigidos pelo fator de correção global $\left(\mathrm{R}^{\prime}\right)$ com os valores da carga última de Van der Veen $(\mathrm{Pu})$ é apresentado na figura 3.5, reapresentando-se os valores da capacidade de carga (R).

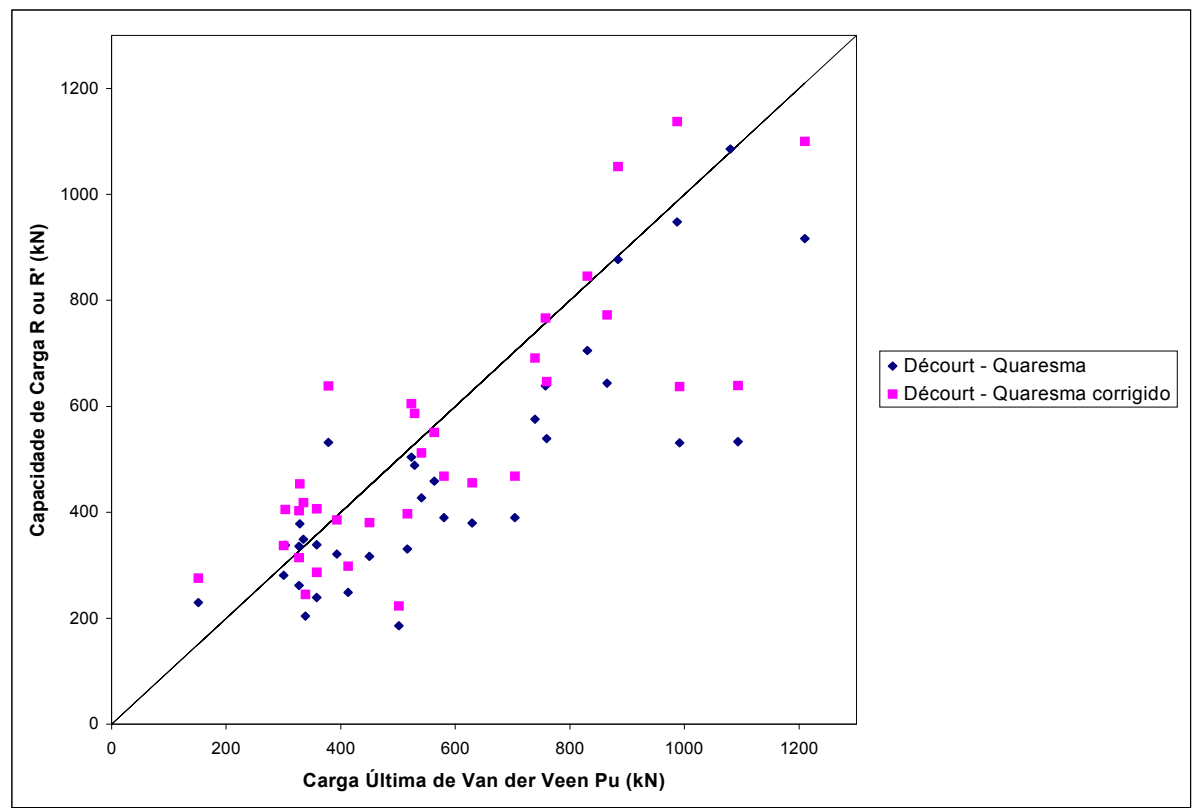

Figura 3.5 - Comparação do método Décourt - Quaresma original e do corrigido como fator global com os valores da carga última de Van der Veen.

A relação $\mathrm{R} / \mathrm{Pu}$ e R' / Pu foi calculada para cada elemento de fundação e os valores da média, desvio padrão e coeficiente de variação estão apresentados na tabela 3.11,reapresentando-se os valores referentes à relação $\mathrm{R} / \mathrm{Pu}$. 
Tabela 3.11 - Valores da média, desvio padrão e coeficiente de variação da relação $\mathbf{R} / \mathbf{P u}$ e $\mathbf{R}^{\prime} / \mathbf{P u}$.

\begin{tabular}{ccc}
\cline { 2 - 3 } & $\mathrm{R} / \mathrm{Pu}$ & $\mathrm{R}^{\prime} / \mathrm{Pu}$ \\
\hline Média & 0,834 & 1,001 \\
Desvio Padrão & 0,245 & 0,295 \\
Coef. Variação & 0,294 & 0,294 \\
\hline
\end{tabular}

Observa-se a eficiência da utilização do fator de correção global.

\subsubsection{Fator de correção parcial}

Procurou-se obter um fator de correção apenas para a parcela de resistência de ponta, pois pode-se considerar que a parcela de resistência lateral calculada pelo método original resulta em valores razoáveis.

Recalculou-se então a parcela de resistência de ponta, como sendo a diferença entre a carga última obtida experimentalmente e a resistência lateral dada pelo método original.

Para as quatro provas de carga que atingiram a ruptura, os resultados são apresentados na tabela 3.12 .

Tabela 3.12 - Valores recalculados da resistência de ponta.

\begin{tabular}{cccc}
\hline Estaca & $\mathrm{R}_{\ell}(\mathrm{kN})$ & $\mathrm{Pu}(\mathrm{kN})$ & $\mathrm{R}_{\mathrm{p}}^{\prime \prime}(\mathrm{kN})$ \\
\hline 05 & 406 & 1080 & 674 \\
11 & 210 & 300 & 90 \\
21 & 272 & 450 & 178 \\
30 & 311 & 580 & 169 \\
\hline
\end{tabular}


Em seguida, calculou-se a relação $R_{p}^{\prime \prime} / R_{p}$ para cada um dos quatro elementos isolados de fundação, bem como a média, desvio padrão e coeficiente de variação (tabela 3.13).

Tabela 3.13 - Valores da média, desvio padrão e coeficiente de variação da relação $R_{p}^{\prime \prime} / R_{p}$ para as provas que atingiram a ruptura.

\begin{tabular}{cccc}
\hline Estaca & $\mathrm{R}_{\mathrm{p}}(\mathrm{kN})$ & $\mathrm{R}_{\mathrm{p}}^{\prime \prime}(\mathrm{kN})$ & $\mathrm{R}_{\mathrm{p}}^{\prime \prime} / \mathrm{R}_{\mathrm{p}}$ \\
\hline 05 & 680 & 603 & 1,009 \\
11 & 70 & 135 & 0,778 \\
21 & 45 & 363 & 0,253 \\
30 & 79 & 449 & 0,294 \\
\hline & & Média & 0,583 \\
& & Desvio Padrão & 0,371 \\
& & Coef. Variação & 0,635 \\
\cline { 3 - 4 } & & &
\end{tabular}

O inverso deste valor médio foi tomado como fator multiplicador para correção da parcela de resistência de ponta. Multiplicou-se, então, por 1,7 os valores de $R_{p}$ dos 34 elementos isolados de fundação, obtendo-se os valores $R^{\prime \prime}$ de capacidade de carga com fator de correção parcial (Anexo 2).

A figura 3.6 mostra a comparação dos valores da capacidade de carga $\mathrm{R}^{\prime \prime}$ corrigidos com o fator de correção parcial com os valores da carga última de Van der Veen $(\mathrm{Pu})$, representando-se os valores originais $(\mathrm{R})$. 


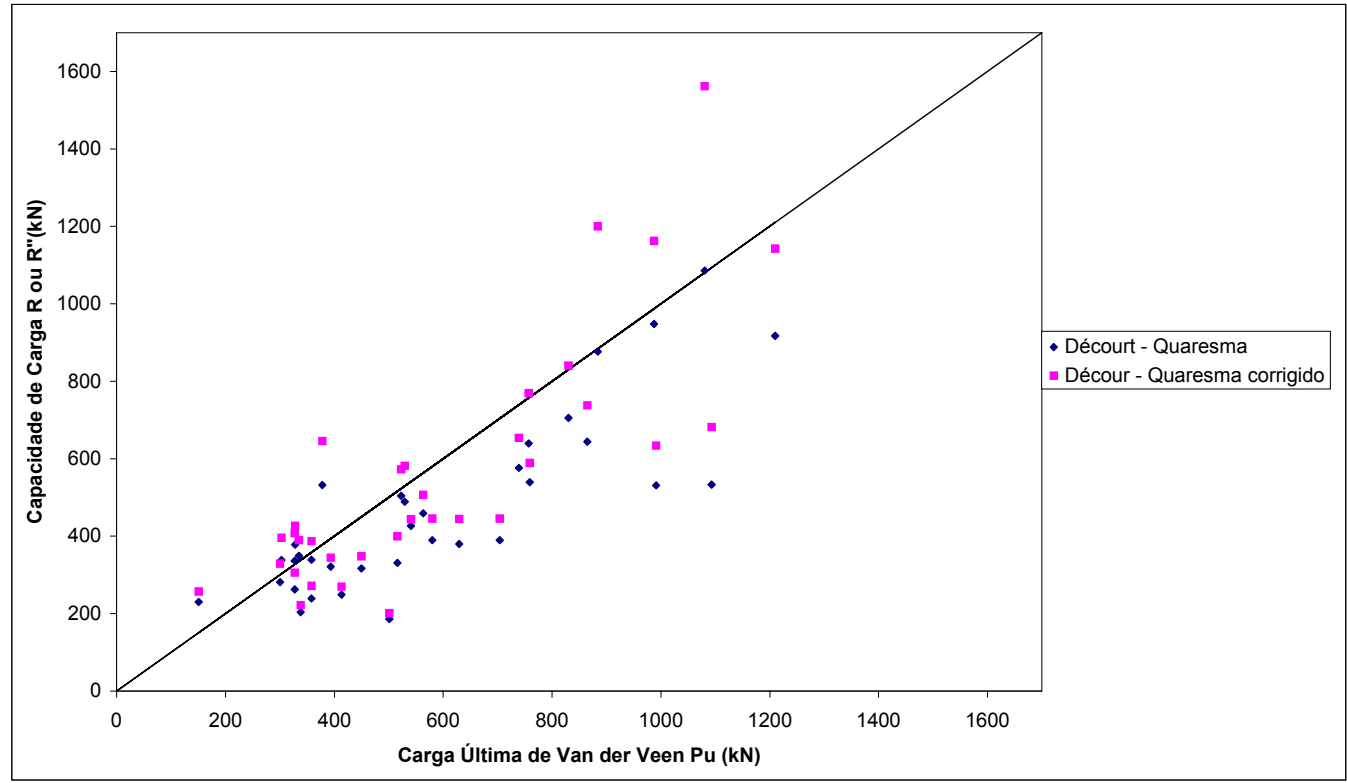

Figura 3.6 - Comparação do método Décourt - Quaresma original e do corrigido com fator parcial com carga última de Van der Veen.

A relação $\mathrm{R}^{\prime \prime} / \mathrm{Pu}$ foi calculada para cada elemento de fundação e os valores da média, desvio padrão e coeficiente de variação estão apresentados na tabela 3.14, representando-se os correspondentes valores para a relação R/Pu.

Tabela 3.14 - Valores da média, desvio padrão e coeficiente de variação da relações $\mathbf{R} / \mathbf{P u}$ e $\mathbf{R}^{\prime \prime} / \mathbf{P u}$.

\begin{tabular}{ccc}
\cline { 2 - 3 } & $\mathrm{R} / \mathrm{Pu}$ & $\mathrm{R}^{\prime \prime} / \mathrm{Pu}$ \\
\hline Média & 0,834 & 0,976 \\
Desvio Padrão & 0,245 & 0,306 \\
Coef. Variação & 0,294 & 0,314 \\
\hline
\end{tabular}

Observa-se que é eficiente a correção com o fator parcial. Das tabelas 3.11 e 3.14 conclui-se que não há diferenças significativas da utilização do fator global de correção de capacidade de carga ou do fator parcial, aplicado somente na parcela de resistência de ponta. 


\subsection{Método Amaral}

Para o cálculo do fator de correção a ser aplicado neste método foram novamente utilizadas as provas de carga rompidas (tabela 3.2). Aplicando-se o método Amaral $(1982,1999)$ encontram-se os valores da resistência de ponta $\left(R_{\mathrm{p}}\right)$, resistência lateral $\left(\mathrm{R}_{\ell}\right)$ e capacidade de carga $(\mathrm{R})$ constantes na tabela 3.15.

Tabela 3.15 - Valores da resistência de ponta, lateral e de ruptura do método Amaral.

\begin{tabular}{cccc}
\hline Estaca & $\mathrm{R}_{\mathrm{p}}(\mathrm{kN})$ & $\mathrm{R}_{\ell}(\mathrm{kN})$ & $\mathrm{R}(\mathrm{kN})$ \\
\hline 5 & 903 & 413 & 1316 \\
11 & 83 & 341 & 424 \\
21 & 57 & 451 & 508 \\
30 & 101 & 469 & 570 \\
\hline
\end{tabular}

A relação $\mathrm{R} / \mathrm{Pu}$ foi calculada para cada um dos quatro elementos isolados de fundação e os valores da média, desvio padrão e coeficiente de variação estão apresentados na tabela 3.16 .

Tabela 3.16 - Valores da média, desvio padrão e coeficiente de variação da relação $\mathrm{R} / \mathrm{Pu}$ para as provas que atingiram a ruptura.

\begin{tabular}{cccc}
\hline Prova & $\mathrm{R}(\mathrm{kN})$ & $\mathrm{Pu}(\mathrm{kN})$ & $\mathrm{R} / \mathrm{Pu}$ \\
\hline 05 & 1316 & 1080 & 1,219 \\
11 & 424 & 300 & 1,413 \\
21 & 508 & 450 & 1,129 \\
30 & 570 & 580 & 0,983 \\
\hline & & Média & 1,186 \\
& & Desvio Padrão & 0,180 \\
& & Coef. Variação & 0,152 \\
\cline { 3 - 4 } & & &
\end{tabular}


O inverso do valor médio corresponde ao fator de correção global. Este fator de 0,85 foi aplicado aos 34 elementos isolados de fundação, obtendo-se os valores corrigidos de $\mathrm{R}^{\prime}$ de capacidade de carga (Anexo 2).

A figura 3.7 apresenta a comparação entre os valores da capacidade de carga corrigidos com o fator global (R) com os valores da carga última de Van der Veen $(\mathrm{Pu})$, representando-se os valores originais $(\mathrm{R})$.

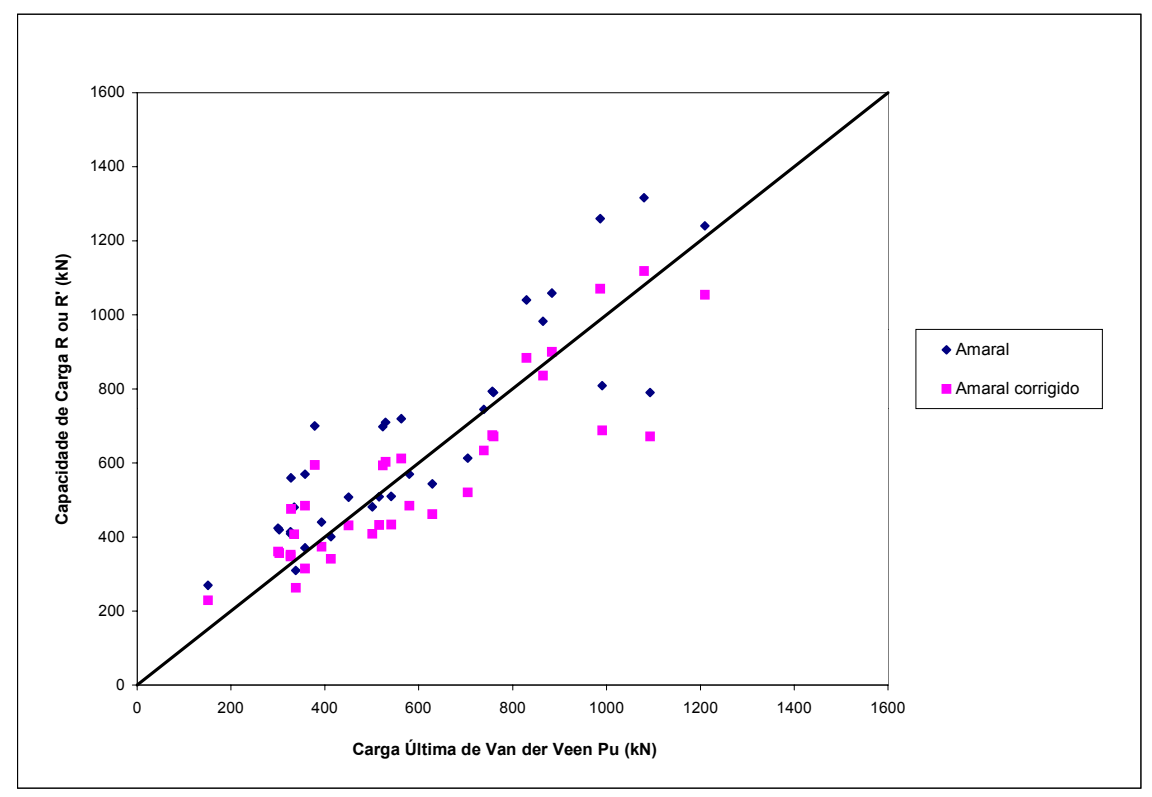

Figura 3.7 - Comparação do método Amaral original e do corrigido com fator global com os valores da carga última de Van der Veen.

As relações $\mathrm{R}_{1} / \mathrm{Pu}$ e $\mathrm{R}^{\prime}$ / $\mathrm{Pu}$ foram calculadas para os 34 elemento isolados de fundação e os valores da média, desvio padrão e coeficiente de variação estão apresentados na tabela 3.17. 
Tabela 3.17 - Valores da média, desvio padrão e coeficiente de variação das relações $\mathbf{R} / \mathbf{P u}$ e $\mathbf{R}^{\prime} / \mathbf{P u}$.

\begin{tabular}{ccc} 
& $\mathrm{R} / \mathrm{Pu}$ & $\mathrm{R}^{\prime} / \mathrm{Pu}$ \\
\hline Média & 1,181 & 1,004 \\
Desvio Padrão & 0,273 & 0,232 \\
Coef. Variação & 0,231 & 0,231 \\
\hline
\end{tabular}

Observa-se que é válida a utilização do fator de correção global.

\subsection{Método "Composto"}

Finalmente, optou-se por calcular a capacidade de carga somando-se a parcela de resistência lateral do método Décourt-Quaresma com a resistência de ponta do método Aoki-Velloso. Os valores de R obtidos para os 34 elementos isolados de fundação são apresentados no Anexo 2.

A figura 3.8 apresenta a comparação dos valores da capacidade de carga obtida por esse método "composto" com os valores da carga última de Van der Veen. 


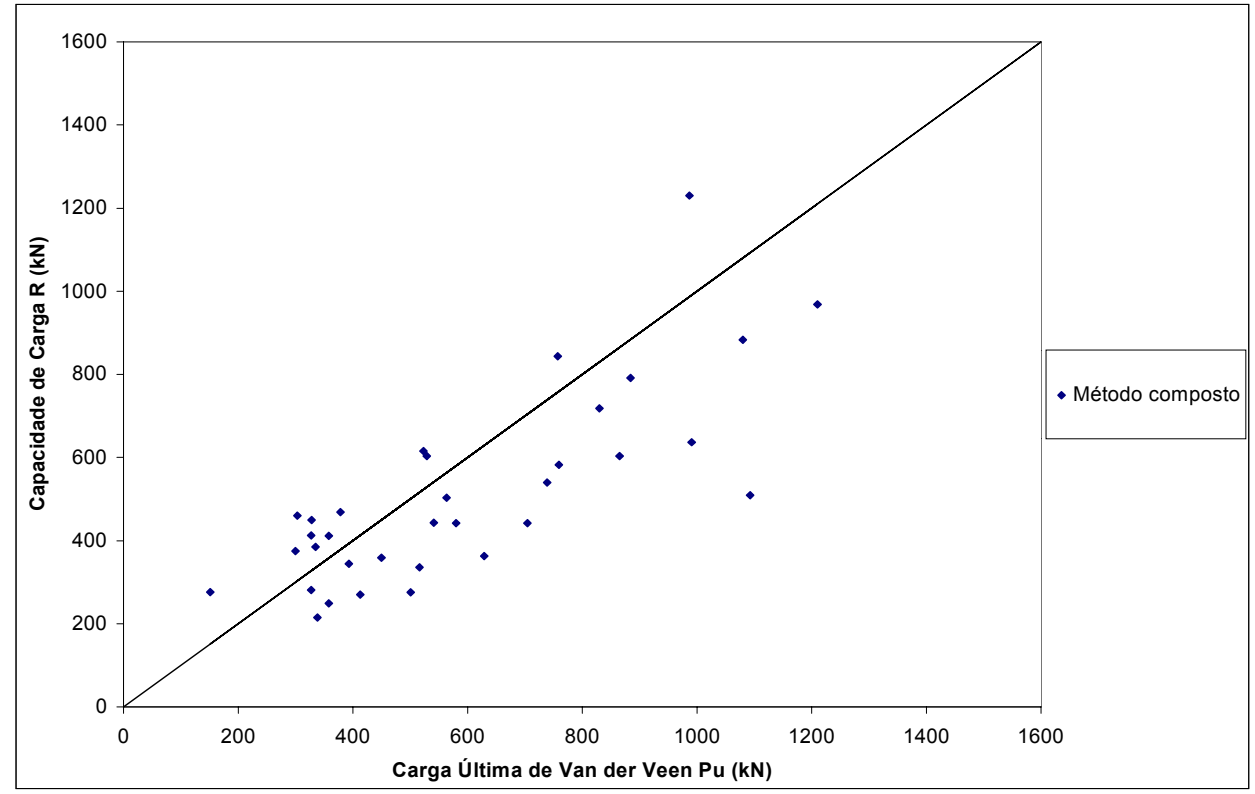

Figura 3.8 - Comparação do método composto com os valores da carga última de Van der Veen.

A relação $\mathrm{R} / \mathrm{Pu}$ foi calculada para os 34 elementos de fundação e os valores da média, desvio padrão e coeficiente de variação são apresentados na tabela 3.18.

Tabela 3.18 - Valores da média, desvio padrão e coeficiente de variação da relação $\mathrm{R} / \mathrm{Pu}$.

\begin{tabular}{cc}
\cline { 2 - 2 } & $\mathrm{R} / \mathrm{Pu}$ \\
\hline Média & 0,927 \\
Desvio Padrão & 0,310 \\
Coef. Variação & 0,334 \\
\hline
\end{tabular}

Comparando-se as tabelas 3.1 e 3.19, observa-se que curiosamente esse método "composto" apresenta valores de capacidade de carga melhores do que os três métodos originais analisados. 


\section{INTERPRETAÇÃO DA CURVA CARGA - RECALQUE}

\subsection{Método de Van der Veen (1953)}

A expressão proposta por Van der Veen (1953) para representar a curva carga $x$ recalque tem sido amplamente utilizada no Brasil para extrapolação de curvas obtidas em provas de carga que não foram levadas à ruptura. $\mathrm{O}$ procedimento de extrapolar a curva para se avaliar a carga de ruptura, quando o ensaio da estaca não indicar uma ruptura nítida, é legitimado pela NBR 6122/96 (item 7.2.2.3). Porém tem-se feito um uso quase indiscriminado desse método sem a preocupação com sua aplicabilidade.

Quando se discute o problema dos ensaios encerrados prematuramente, ainda no trecho praticamente linear da curva carga $x$ recalque, cabem alertas do tipo: o critério de Van der Veen é aplicável somente se o ensaio atingiu pelo menos dois terços da carga de ruptura (Décourt \& Niyama, 1994). Entretanto, não há meio de assegurar, para uma prova de carga não rompida, qual a proporção da carga de ruptura teria sido atingida.

Além disso, é preciso considerar que o método de Van der Veen tem duas hipóteses básicas: $1^{\mathrm{a}}$ ) a forma da curva carga $\mathrm{x}$ recalque é do tipo exponencial; 
$2^{a}$ ) o modo de ruptura é do tipo ruptura física, correspondendo a recalques teoricamente infinitos. Portanto nos casos em que a curva real não for do tipo exponencial adotado por Van der Veen (ou a carga máxima atingida no ensaio não for suficiente para evidenciar a forma da curva) ou ainda quando o modo de ruptura não for o de ruptura física é de se esperar que este método não forneça resultados satisfatórios.

Para a verificação da validade deste procedimento de extrapolação, foram utilizadas as quatro provas de carga conduzidas até a ruptura (tabela 3.2). Essas provas de carga foram realizadas em estágios correspondentes a $20 \%$ da carga nominal $\left(\overline{\mathrm{P}_{\mathrm{e}}}\right)$ e atingiram a ruptura no 80 estágio. Os valores experimentais da carga última Pu coincidem com os determinados pelo método de Van der Veen, considerando todos os estágios das provas de carga, o que demostra que os ensaios atingiram a ruptura.

Utilizou-se a expressão matemática de Van der Veen (1953), modificada por Aoki (1976), para não impor que a curva carga x recalque ajustada passe pela origem:

$$
\mathrm{P}=\mathrm{Pu}\left[1-\mathrm{e}^{-(\mathrm{a} \rho+\mathrm{b})}\right]
$$

onde

- P é a carga correspondente a um recalque $\rho$;

- Pu é a carga última (ruptura física);

- a é o coeficiente de forma da curva;

- b é o intercepto no eixo dos recalques.

O método de Van der Veen foi aplicado considerando-se que os ensaios tivessem sido interrompidos, em diferentes estágios, com o objetivo de verificar 
se os valores obtidos para a carga última através da extrapolação aproximam-se dos valores experimentais.

Este procedimento foi aplicado, para cada ensaio, a partir do quarto estágio, obtendo-se os valores apresentados na tabela 4.1. O ponto correspondente à origem foi considerado nas estacas 11, 21 e 30. Para a estaca 05 não considerou-se tal ponto por não estar "alinhado" com o restante da curva carga $\times$ recalque.

\section{Tabela 4.1 - Carga última de Van der Veen $(\mathrm{Pu}, \mathrm{em} \mathrm{kN})$ com o avanço do ensaio.}

\begin{tabular}{c|ccccc}
\hline \multirow{2}{*}{ Estaca } & \multicolumn{5}{|c}{ Estágio } \\
\cline { 2 - 6 } & $4^{\mathrm{o}}$ & $5^{\mathrm{o}}$ & $6^{\mathrm{o}}$ & $7^{\mathrm{O}}$ & $8^{\mathrm{o}}$ \\
\hline 05 & 730 & 950 & 1060 & 1260 & 1080 \\
11 & 280 & 230 & 260 & 280 & 300 \\
21 & 470 & 480 & 470 & 500 & 450 \\
30 & 370 & 480 & 530 & 580 & 580 \\
\hline
\end{tabular}

A análise desses resultados mostra que a carga última de Van der Veen varia com o andamento do ensaio. Esta variação pode ser mais "comportada", no caso das estacas 11, 21 e 30 ou um tanto quanto "aleatória" como no caso da estaca 05. Aliás, para esta estaca, o valor de Pu obtido no penúltimo estágio é $17 \%$ superior ao valor experimental $(1080 \mathrm{kN})$.

Para quantificar essa variação da carga última, os valores absolutos da Tabela 4.1 foram transformados em variação percentual em relação ao estágio anterior (Tabela 4.2). 
Tabela 4.2 - Variação (em \%) da carga última de Van der Veen em relação ao estágio anterior.

\begin{tabular}{c|cccc}
\hline \multirow{2}{*}{ Estaca } & \multicolumn{4}{|c}{ Estágio } \\
\cline { 2 - 5 } & $5^{\mathrm{o}}$ & $6^{\mathrm{o}}$ & $7^{\mathrm{o}}$ & $8^{\mathrm{o}}$ \\
\hline 05 & $+30 \%$ & $+12 \%$ & $+19 \%$ & $-14 \%$ \\
11 & $-18 \%$ & $+13 \%$ & $+8 \%$ & $+7 \%$ \\
21 & $+2 \%$ & $-2 \%$ & $+6 \%$ & $-10 \%$ \\
30 & $+30 \%$ & $+10 \%$ & $+9 \%$ & 0 \\
\hline
\end{tabular}

A partir dos valores da Tabela 4.1, também se pode calcular o erro da carga última de Van der Veen, para cada estágio, em relação ao valor experimental, obtendo-se os valores mostrados na Tabela 4.3.

Tabela 4.3 - Erro (em \%) na carga última em cada estágio em relação ao valor experimental.

\begin{tabular}{c|cccc}
\hline \multirow{2}{*}{ Estaca } & \multicolumn{4}{|c}{ Estágio } \\
\cline { 2 - 5 } & $4^{\mathrm{o}}$ & $5^{\mathrm{o}}$ & $6^{\mathrm{o}}$ & $7^{\mathrm{o}}$ \\
\hline 05 & $-32 \%$ & $-12 \%$ & $-2 \%$ & $+17 \%$ \\
11 & $-7 \%$ & $-23 \%$ & $-13 \%$ & $-7 \%$ \\
21 & $+4 \%$ & $+7 \%$ & $+4 \%$ & $+11 \%$ \\
30 & $-36 \%$ & $-22 \%$ & $-9 \%$ & 0 \\
\hline
\end{tabular}

Da observação conjunta das tabelas 4.2 e 4.3 deduz-se que, a partir do $5 \underline{0}$ estágio, correspondente a carga nominal, a variação máxima de 10\% (em 
módulo) nos valores da carga última de Van der Veen (tabela 4.2), garante um erro máximo de 11\% (em módulo) em relação ao valor experimental (tabela 4.3).

A aplicação desse critério, às quatro provas de carga analisadas resultaria nos seguintes resultados:

a) A curva da prova de carga da estaca 21 pode ser extrapolada a partir do $5^{\circ}$ estágio, com $\mathrm{Pu}=480 \mathrm{kN}$ (erro de $+7 \%$ ); a partir do $6^{\circ}$ estágio, com $\mathrm{Pu}=470$ $\mathrm{kN}($ erro de $+4 \%)$; ou a partir do $7^{\circ}$ estágio, com Pu $=500 \mathrm{kN}$ (erro de+11\%);

b) A curva da prova de carga da estaca 30 pode ser extrapolada a partir do $6^{\circ}$ estágio, com $\mathrm{Pu}=530 \mathrm{kN}$ (erro de $-9 \%$ ) ou a partir do $7^{\circ}$ estágio, $c 0 m \mathrm{Pu}=$ $580 \mathrm{kN}$ (erro nulo);

c) A curva da prova de carga da estaca 11 pode ser extrapolada a partir do $7^{\circ}$ estágio, com $\mathrm{Pu}=280 \mathrm{kN}$ (erro de $-7 \%$ );

d) A curva da prova de carga da estaca 05 não pode ser extrapolada nem mesmo se interrompida no penúltimo estágio.

Para as demais 30 provas de carga analisadas, calculou-se a variação da carga última de Van der Veen $(\Delta \mathrm{Pu})$ entre os dois últimos estágios. Constatou-se que em apenas 15 ensaios (tabela 4.4a), essa variação é de no máximo 10\% em módulo, o que garantiria uma boa extrapolação da curva por Van der Veen (erro máximo de $11 \%$ na carga última).

Mas em outros 15 ensaios (tabela 4.4b), a variação da carga última de Van der Veen nos dois últimos estágios é superior a 10\%, em módulo, o que não garante uma extrapolação razoável da curva 
Tabela 4.4a - Variação da carga última de Van der Veen entre os dois últimos estágios $(|\Delta \mathrm{Pu}| \leq \mathbf{1 0} \%)$.

\begin{tabular}{c|cc|cc|c}
\hline \multirow{2}{*}{ Estaca } & \multicolumn{2}{|c|}{ Penúltimo estágio } & \multicolumn{2}{|c|}{ Último estágio } & \multirow{2}{*}{$\Delta \mathrm{Pu}$} \\
\cline { 2 - 4 } & $\mathrm{P}-$ ensaio & Pu - Van der & $\mathrm{P}-$ ensaio & Pu - Van der & $(\%)$ \\
& $(\mathrm{kN})$ & Veen $(\mathrm{kN})$ & $(\mathrm{kN})$ & Veen $(\mathrm{kN})$ & \\
\hline 03 & 420 & 500 & 450 & 516 & $+3,2 \%$ \\
04 & 700 & 822 & 750 & 884 & $+7,5 \%$ \\
06 & 550 & 994 & 600 & 1093 & $+10,0 \%$ \\
10 & 540 & 821 & 600 & 739 & $-10,0 \%$ \\
13 & 160 & 274 & 200 & 302 & $+10,0 \%$ \\
15 & 420 & 513 & 450 & 501 & $-2,3 \%$ \\
17 & 280 & 570 & 300 & 549 & $-3,7 \%$ \\
20 & 420 & 549 & 450 & 541 & $-1,5 \%$ \\
22 & 280 & 402 & 300 & 393 & $-2,2 \%$ \\
23 & 280 & 341 & 300 & 327 & $-4,1 \%$ \\
25 & 280 & 346 & 300 & 338 & $-2,3 \%$ \\
26 & 280 & 374 & 300 & 367 & $-1,9 \%$ \\
31 & 820 & 1315 & 900 & 1210 & $-8,0 \%$ \\
33 & 820 & 1040 & 900 & 998 & $-4,0 \%$ \\
34 & 840 & 953 & 900 & 991 & $+4,0 \%$ \\
\hline
\end{tabular}


Tabela 4.4b - Variação da carga última de Van der Veen entre os dois últimos estágios $(|\Delta \mathrm{Pu}|>10 \%)$.

\begin{tabular}{c|cc|cc|c}
\hline \multirow{2}{*}{ Estaca } & \multicolumn{2}{|c|}{ Penúltimo estágio } & \multicolumn{2}{|c|}{ Último estágio } & $\Delta \mathrm{Pu}$ \\
\cline { 2 - 4 } & $\mathrm{P}-$ ensaio & $\mathrm{Pu}-$ Van der & $\mathrm{P}-$ ensaio & $\mathrm{Pu}-$ Van der & $(\%)$ \\
& $(\mathrm{kN})$ & Veen $(\mathrm{kN})$ & $(\mathrm{kN})$ & Veen $(\mathrm{kN})$ & \\
\hline 01 & 420 & 1294 & 450 & 629 & $+51,4 \%$ \\
02 & 280 & 455 & 300 & 358 & $-21,3 \%$ \\
07 & 450 & 1049 & 500 & 757 & $-27,8 \%$ \\
08 & 280 & 895 & 300 & 378 & $-57,8 \%$ \\
09 & 540 & 1392 & 600 & 865 & $-37,9 \%$ \\
12 & 420 & 636 & 450 & 529 & $-16,8 \%$ \\
14 & 80 & 151 & 123 & 288 & $+90,7 \%$ \\
16 & 560 & 1289 & 600 & 830 & $-35,6 \%$ \\
18 & 560 & 985 & 600 & 759 & $-22,9 \%$ \\
19 & 420 & 833 & 450 & 563 & $-32,4 \%$ \\
24 & 420 & 644 & 450 & 523 & $-18,8 \%$ \\
27 & 280 & 1152 & 300 & 358 & $-68,9 \%$ \\
28 & 280 & 402 & 300 & 335 & $-16,6 \%$ \\
29 & 280 & 419 & 300 & 327 & $-22,0$ \\
32 & 560 & 921 & 600 & 704 & $-23,6 \%$ \\
\hline
\end{tabular}

Nas curvas em que este critério não se aplica pode-se deduzir que a prova de carga deveria ter continuado em pelo menos um estágio adicional, ou que essas curvas carga $x$ recalque talvez não sigam o modelo proposto por Van der Veen (1953).

Em princípio, essas conclusões devem ser consideradas apenas para a região estudada e, ainda assim, como preliminares. Seria desejável a análise de 
um número maior de provas de carga conduzidas até a ruptura para aprimorar o critério.

\subsection{Método de Chin (1978)}

Para aplicação do método de Chin (1978) desenhou-se o diagrama $\rho / \mathrm{P} \times \rho$ para as 34 provas de carga (anexo 3). Da observação destes diagramas podem-se identificar três subconjuntos.

No primeiro subconjunto os pontos constituem uma única reta, para o qual o inverso do coeficiente angular fornece a carga última extrapolada (Chin, 1970). De acordo com Chin (1978), este caso corresponde a estacas que trabalham substancialmente pela ponta. No segundo subconjunto, o diagrama mostra dois trechos de reta: o inverso do coeficiente do trecho inicial dá a parcela de atrito lateral e o inverso do coeficiente angular do trecho final caracteriza a capacidade de carga (ponta e atrito). No terceiro subconjunto, os pontos indicam uma anomalia proveniente de algum dano estrutural da estaca.

Entretanto essas deduções não tem comprovação para o conjunto de provas de cargas analisadas por ausência de instrumentação e de ensaios de integridade.

Em trabalhos futuros será interessante analisar a eficácia deste método. 


\section{ESTIMATIVA DE RECALQUE E PREVISÃO DA CURVA CARGA X RECALQUE}

Para a estimativa dos recalques, utilizaram-se as 18 provas de carga listadas na tabela 4.4a, as quais satisfazem o critério de extrapolação. A estaca de número 4 não foi utilizada porque não há valores de $\mathrm{N}_{\mathrm{SPT}}$ abaixo da ponta da estaca.

Primeiramente calculou-se o recalque para três níveis de carga em cada estaca: a carga equivalente à resistência lateral $\left(\mathrm{P}_{1}=\mathrm{R}_{\ell}\right)$, a carga máxima do ensaio $\left(\mathrm{P}_{3}=\mathrm{P}_{\text {máx }}\right)$ e a carga média $\left(\mathrm{P}_{2}\right)$ dada pela média entre $\mathrm{P}_{1} \mathrm{e}$ $P_{3}$. Para as estacas de número 13, 22 e 26 preferiu-se não calcular os recalques porque o valor do atrito lateral $\left(\mathrm{R}_{\ell}\right)$ é maior que o valor da carga máxima do ensaio.

Para o valor de $\mathrm{P}_{1}$ considerou-se a resistência lateral obtida pelo método Aoki - Velloso adaptado e corrigido com o fator de correção parcial (item 3.1.2).

Para as estacas que atingiram a ruptura $(11,21$ e 30) utilizou-se em vez da carga máxima do ensaio, a carga equivalente a $\mathrm{P}_{3}=1,4 \overline{\mathrm{P}}_{\mathrm{e}}$. Os valores de $\mathrm{P}_{1}, \mathrm{P}_{2}$ e $\mathrm{P}_{3}$ para as 18 estacas analisadas estão no anexo 4. 


\subsection{Estimativa do Recalque}

O recalque $\rho$ do topo da estaca para os níveis de carregamento mencionados podem ser estimados pela equação (1) proposta por Vésic (19??).

$$
\rho=\rho e+\rho_{\mathrm{S}}
$$

onde

- $\rho_{e}$ corresponde ao encurtamento elástico do fuste;

- $\rho_{\mathrm{s}}$ corresponde a parcela do recalque, devida à ação das cargas transmitidas ao longo do fuste e pela ponta.

\subsubsection{Parâmetros Elásticos do Terreno}

O módulo de deformabilidade das camadas abaixo da ponta da estaca foi estimado pela proposição de Janbu (1963),

$$
\mathrm{E}=\mathrm{E}_{0} \times(\Delta \sigma)^{\mathrm{n}}
$$

onde:

- n é o expoente que depende da natureza do solo e que varia de 0,5 a 1,0 ;

- $\Delta \sigma$ é o acréscimo tensões;

- $E_{0}$ é o módulo de deformabilidade correspondente ao solo natural, que pode ser obtido, por exemplo pela equação (Aoki, 1985);

$$
\mathrm{E}_{0}=6 \mathrm{KN}
$$


- K é o coeficiente de Aoki - Velloso;

- N é o SPT médio da camada.

Adotou-se para n o valor médio de 0,75 .

\subsubsection{Diagrama de Transferência de Carga}

Para obter o diagrama de transferência de carga pode-se considerar que inicialmente são mobilizadas apenas as parcelas de resistência lateral e que somente para níveis de carregamento superiores ao valor do máximo atrito lateral disponível $\left(\mathrm{R}_{\ell}\right)$, a carga excedente a este valor é transferida para a ponta da estaca. Essa condição é ilustrada pela figura 5.1, para o caso de três camadas distintas de solo ao longo do fuste, sendo que:

$\mathrm{R}_{\ell_{\mathrm{i}}}$ representa a parcela de atrito lateral da camada $\mathrm{i}\left(\mathrm{R}_{\ell}=\sum \mathrm{R}_{\ell_{\mathrm{i}}}\right)$;

P é a carga aplicada no topo da estaca;

$\mathrm{R}_{\mathrm{p}, \mathrm{m}}$ é a resistência de ponta mobilizada $\left(\mathrm{R}_{\mathrm{p}, \mathrm{m}}=\mathrm{P}-\mathrm{R}_{\ell}\right)$;

$\mathrm{Q}_{\mathrm{i}}$ representa o esforço normal na estaca na cota correspondente ao topo da camada i.

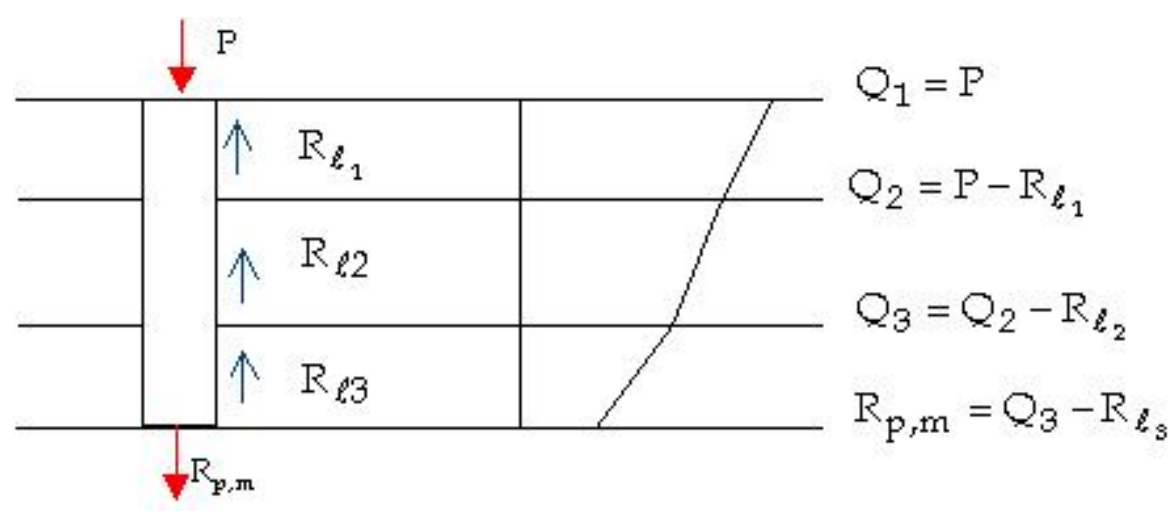

Figura 5.1 - Diagrama de transferência de carga.

\subsubsection{Encurtamento Elástico do Fuste}


Para o cálculo do encurtamento elástico do fuste tem-se a equação

$$
\rho_{\mathrm{e}}=\sum_{\mathrm{i}=1}^{\mathrm{h}} \frac{\left(\mathrm{Q}_{\mathrm{i}}+\mathrm{Q}_{\mathrm{i}+1}\right) / 2}{\mathrm{~A}_{\mathrm{p}} \mathrm{E}_{\mathrm{c}}} \times \Delta \ell_{\mathrm{i}}
$$

onde

- $\Delta \ell_{\mathrm{i}}$ é a espessura da camada i;

- $\mathrm{A}_{\mathrm{p}}$ á a área da ponta da estaca;

- $\mathrm{E}_{\mathrm{c}}$ é o módulo de elasticidade da estaca.

Para $\mathrm{E}_{\mathrm{c}}$, adotou-se o valor de $25000 \mathrm{MPa}$.

\subsubsection{Acréscimo de Tensões}

$\mathrm{O}$ acréscimo médio de tensão vertical $\left(\Delta \sigma_{\mathrm{j}}\right)$ na camada $\mathrm{j}$ abaixo da ponta da estaca, devido à reação às parcelas de resistência lateral $R_{\ell_{\mathrm{i}}}$ e de ponta $R_{p, m}$ pode ser calculada pela consideração de que ocorra um espraiamento de tensões de 2:1,. conforme mostra a figura 5.2 e a equação (5).

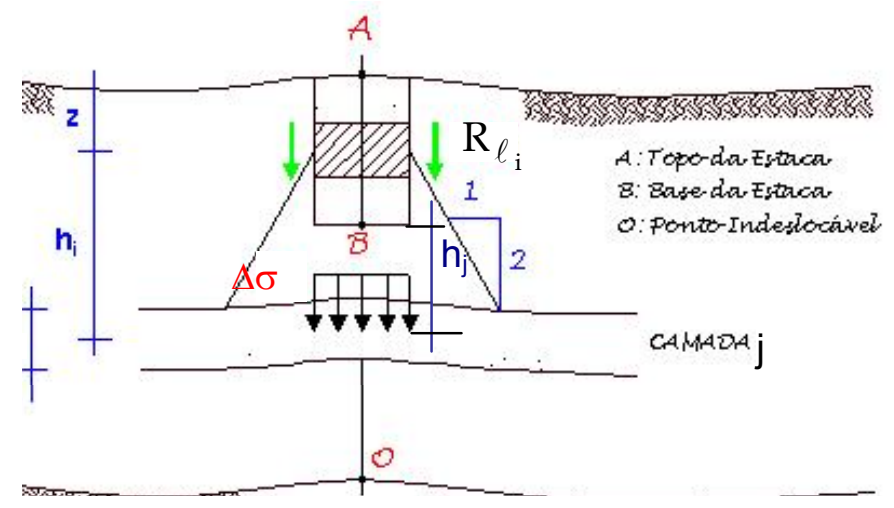

Figura 5.2 - Distribuição de pressões (Aoki, 1985). 


$$
\Delta \sigma_{j}=\left(\sum_{i=1}^{h} \frac{4 \times R_{\ell_{i}}}{\pi\left(h_{i}+D\right)^{2}}\right)+\frac{4 R_{p, m}}{\pi\left(h j+D^{2}\right)}
$$

onde

- D corresponde ao diâmetro da estaca;

- $h_{i}$ corresponde a distância entre o centro da camada i, ao longo do fuste, e o centro da camada $\mathrm{j}$ abaixo da ponta da estaca;

- $h_{j}$ é a distância entre a ponta da estaca e o centro da camada j.

assim, a parcela de recalque $\rho_{\mathrm{sj}}$ de cada camada $\mathrm{j}$ pode ser calculada pela expressão

$$
\rho_{\mathrm{s}, \mathrm{j}}=\frac{1}{E_{\mathrm{s}}}\left[\Delta \sigma_{j} \mathrm{~d}_{\mathrm{j}}\right]
$$

Evidentemente são considerados os recalques de todas as camadas situadas abaixo da ponta da estaca, até o indeformável, admitido como sendo a cota correspondente ao impenetrável pelo amostrador na sondagem SPT.

Para os três níveis de carga $P_{1}, P_{2}$ e $P_{3}$, calcularam-se os correspondentes valores de recalque $\rho_{1}, \rho_{2}$ e $\rho_{3}$. Para cada estaca analisada esses valores juntamente com o recalque medido no ensaio estão apresentados no anexo 4.

A tabela 5.1 apresenta a relação $\rho_{\mathrm{c}} / \rho_{\mathrm{m}}$ (recalque calculado pelo recalque medido) para as cargas $\mathrm{P}_{1}, \mathrm{P}_{2}$ e $\mathrm{P}_{3}$ de cada estaca. Os valores da média, desvio padrão e coeficiente de variação também são apresentados nesta tabela. 
Tabela 5.1 - Valores da relação $\rho_{c} / \rho_{m}$ para as cargas $P_{1}, P_{2}$ e $P_{3}$.

\begin{tabular}{cccc}
\hline Prova & $\mathrm{P}_{1}$ & $\mathrm{P}_{2}$ & $\mathrm{P}_{3}$ \\
\hline 03 & 0,917 & 1,349 & 0,764 \\
06 & 0,521 & 0,478 & 0,491 \\
10 & 0,709 & 0,748 & 0,663 \\
11 & 0,535 & 0,526 & 0,402 \\
15 & 1,176 & 1,208 & 0,914 \\
17 & 1,667 & 2,544 & 2,384 \\
20 & 0,683 & 0,749 & 0,735 \\
21 & 0,803 & 0,81 & 0,705 \\
23 & 1,189 & 1,167 & 0,904 \\
25 & 1,475 & 1,682 & 1,239 \\
30 & 1,556 & 1,461 & 0,453 \\
31 & 0,561 & 0,597 & 0,534 \\
33 & 0,648 & 0,771 & 0,596 \\
34 & 1,638 & 1,392 & 0,843 \\
\hline Média & 1.006 & 1.106 & 0.831 \\
Desvio Padrão & 0.434 & 0.563 & 0.499 \\
Coef. Variação & 0.431 & 0.509 & 0.601 \\
\hline
\end{tabular}

Observa-se que para a carga $P_{1}$ têm-se um valor médio mais próximo do valor unitário $(+0,6 \%)$. $O$ coeficiente de variação também apresenta o menor valor.

\subsection{Previsão da Curva Carga $x$ Recalque}

Para cada um dor três pares de valores $\left(P_{i} ; \rho_{i}\right)$ obteve-se uma curva de Van der Veen.

Além disso, ajustou-se uma única curva para os três pontos, para cada estaca analisada. As figuras 5.3 a 5.16 mostram, para cada estaca, a comparação da curva experimental com as quatro curvas obtidas. 


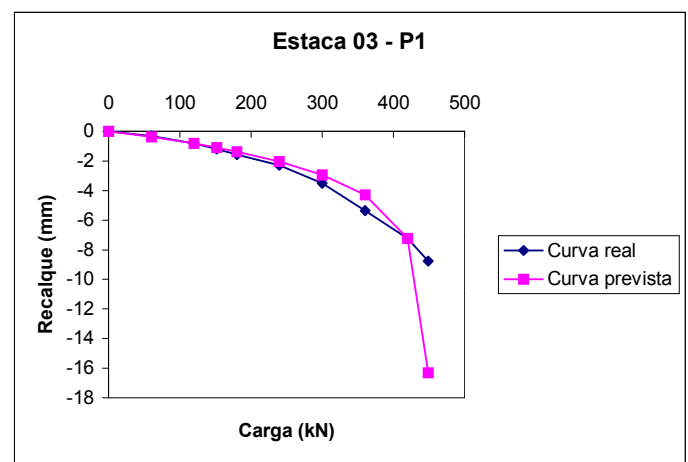

Figura 5.3a - Comparação entre a curva prevista da estaca 03 para a carga $P_{1}$ e a curva experimental.

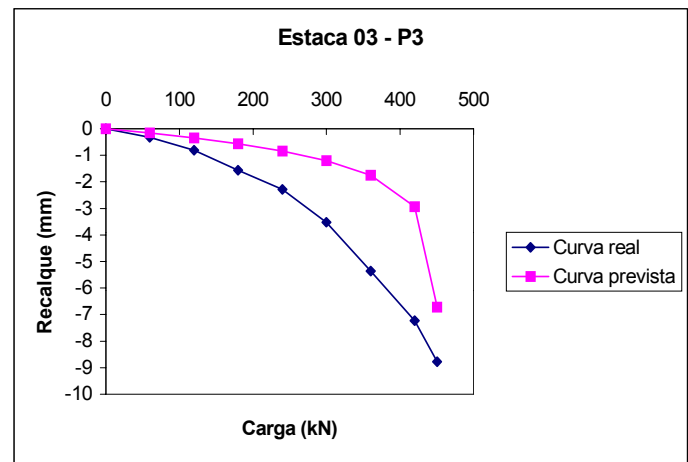

Figura 5.3c - Comparação entre a curva prevista da estaca 03 para carga $P_{3}$ e a curva experimental.

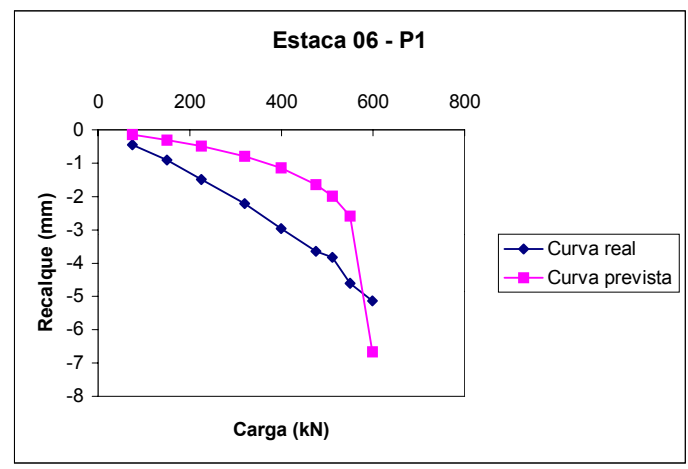

Figura 5.4a - Comparação entre a curva prevista da estaca 06 para carga $P_{1}$ e a curva experimental.

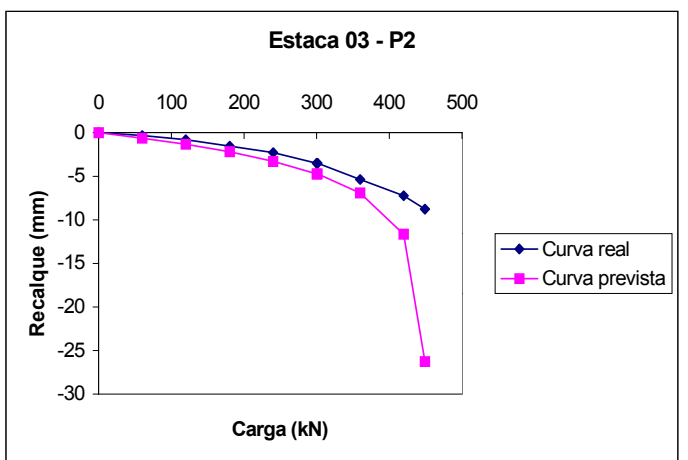

Figura 5.3b - Comparação entre a curva prevista da estaca 03 para a carga $\mathrm{P}_{2}$ e a curva experimental.

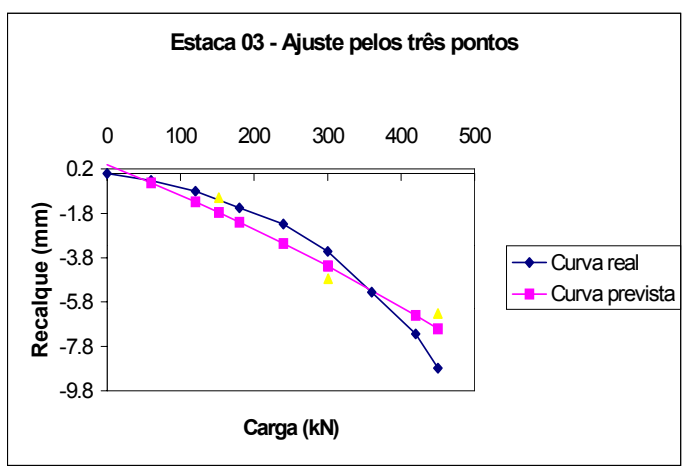

Figura 5.3d - Comparação entre a curva ajustada pelos três pontos da estaca 03 e a curva experimental.

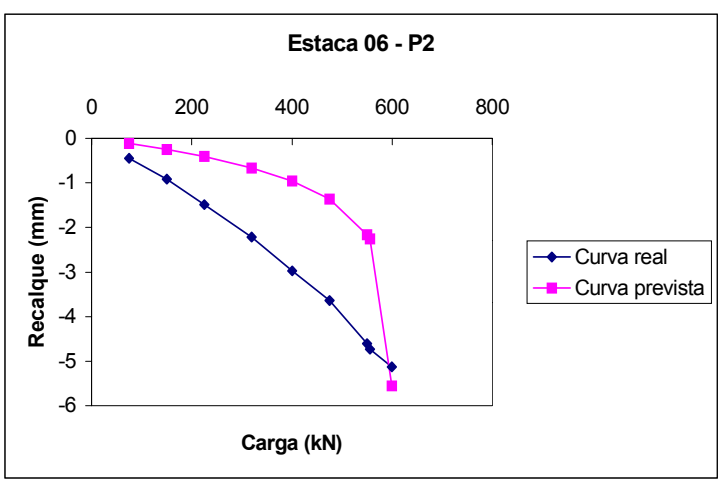

Figura 5.4b - - Comparação entre a curva prevista da estaca 06 para carga $\mathrm{P}_{2}$ e a curva experimental. 


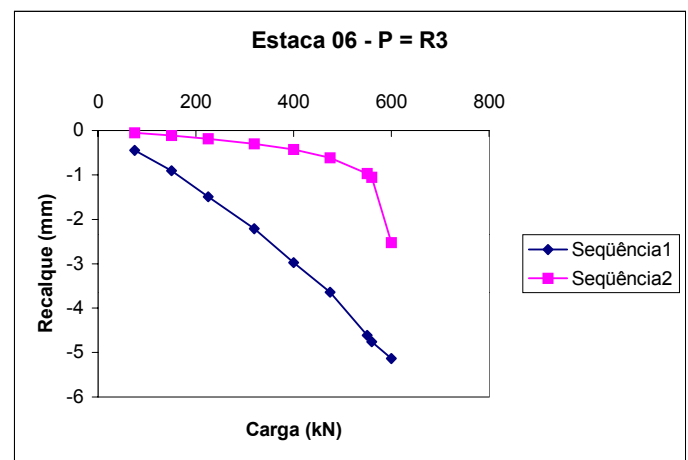

Figura 5.4c - Comparação entre a curva prevista da estaca 06 para carga $\mathrm{P}_{3}$ e a carga experimental.

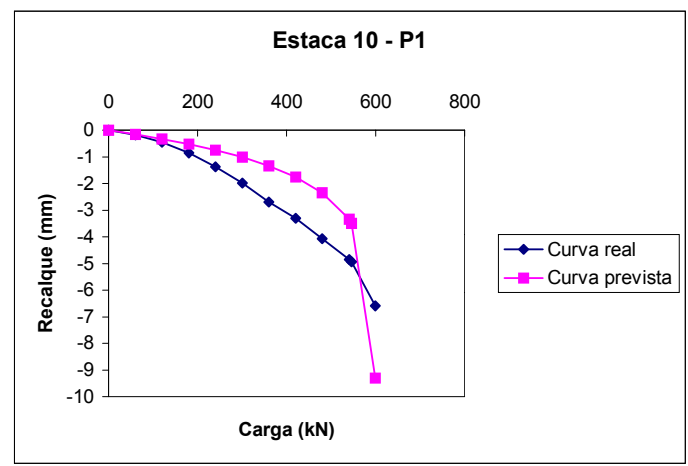

Figura 5.5a - Comparação entre a curva prevista da estaca 10 para a carga $P_{1}$ e a curva experimental.

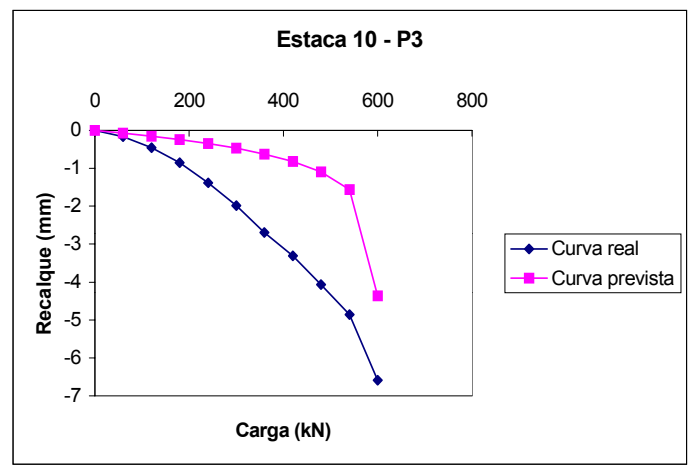

Figura 5.5c - Comparação entre a curva prevista da estaca 10 para a carga $P_{3}$ e a curva experimental.

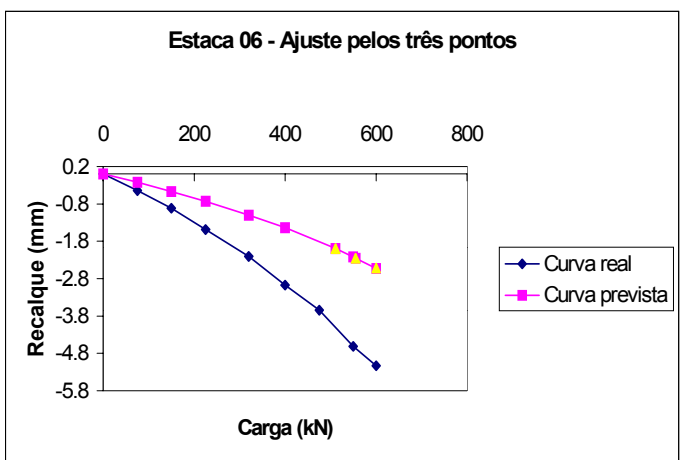

Figura 5.4d - Comparação entre a curva ajustada pelos três pontos da estaca 06 e a curva experimental.

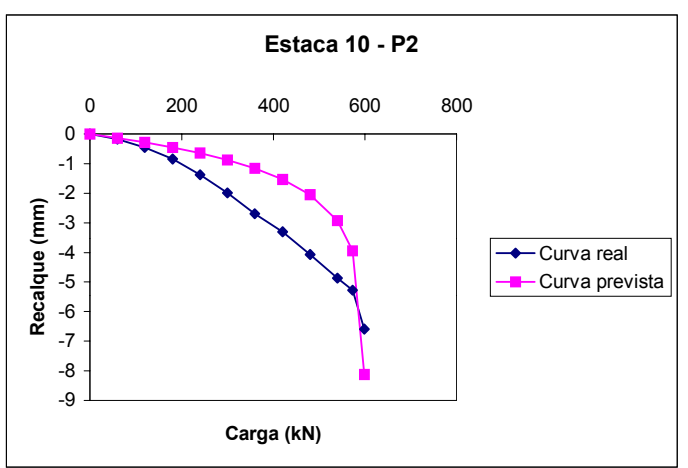

Figura 5.5b - Comparação entre a curva prevista da estaca 10 para a carga $\mathrm{P}_{2}$ e a curva experimental.

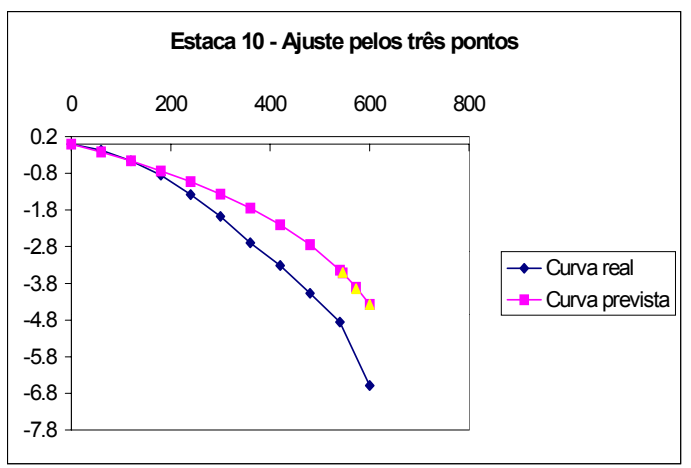

Figura 5.5d - Comparação entre a curva ajustada pelos três pontos da estaca 10 e a curva experimental. 


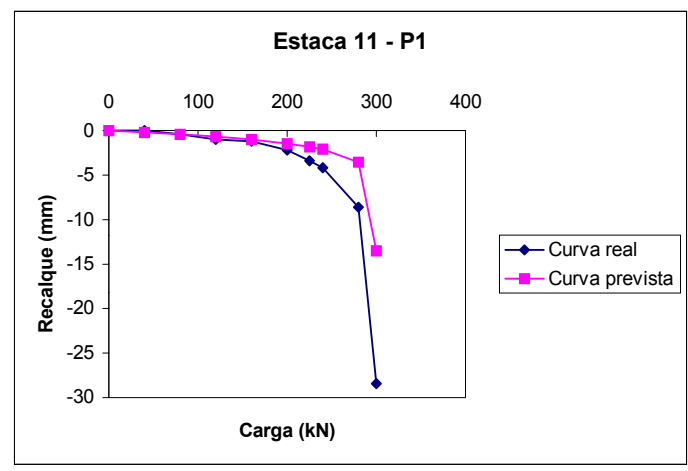

Figura 5.6a - Comparação entre a curva prevista da estaca 11 para a carga $P_{1}$ e a curva experimental.

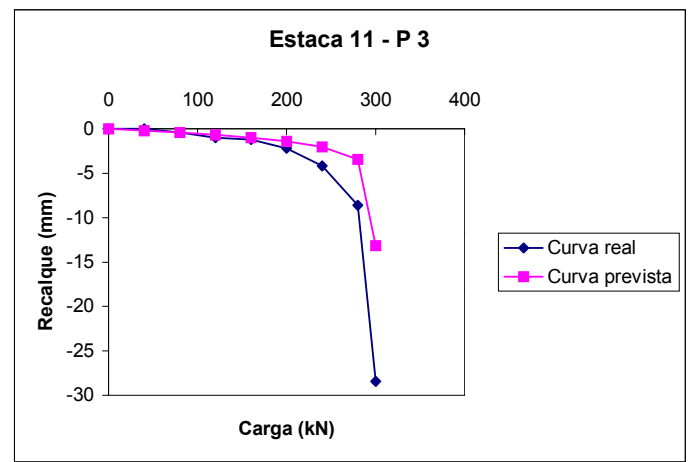

Figura 5.6c - Comparação entre a curva prevista da estaca 11 para a carga $\mathrm{P}_{3}$ e a curva experimental.

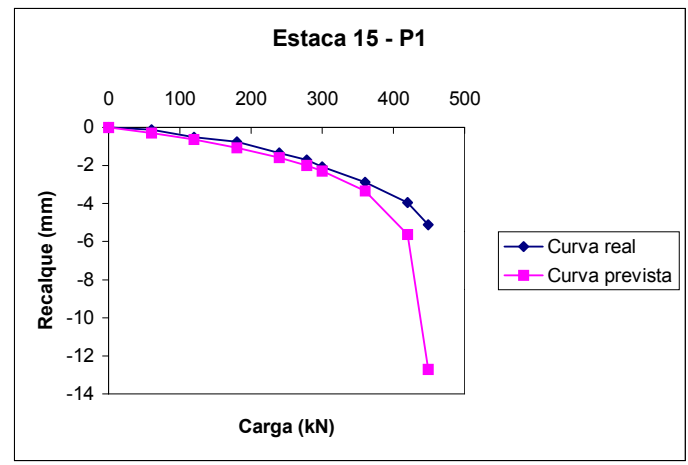

Figura 5.7a - Comparação entre a curva prevista da estaca 15 para a carga $P_{1}$ e a curva experimental.

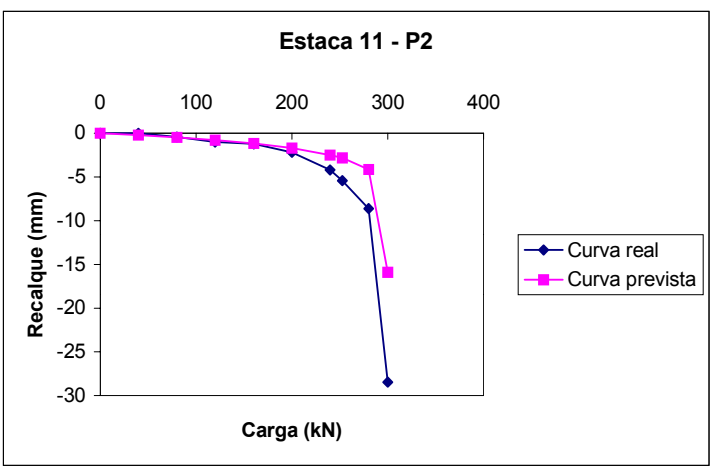

Figura 5.6b - Comparação entre a curva prevista da estaca 11 para a carga $\mathrm{P}_{2}$ e a curva experimental.

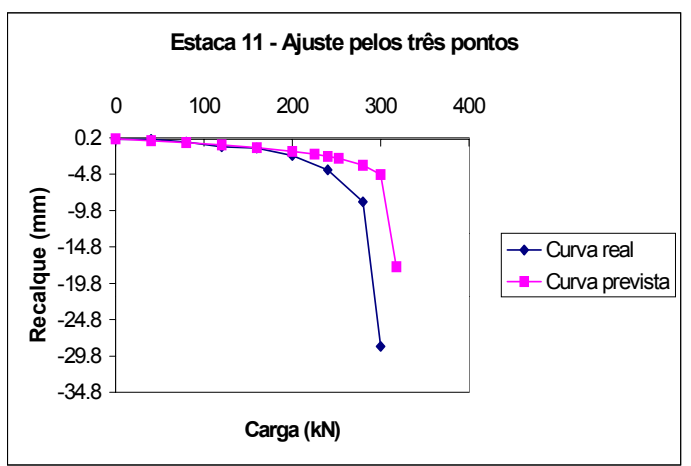

Figura 5.6d - Comparação entre a curva ajustada pelos três pontos da estaca 11 e a curva experimental.

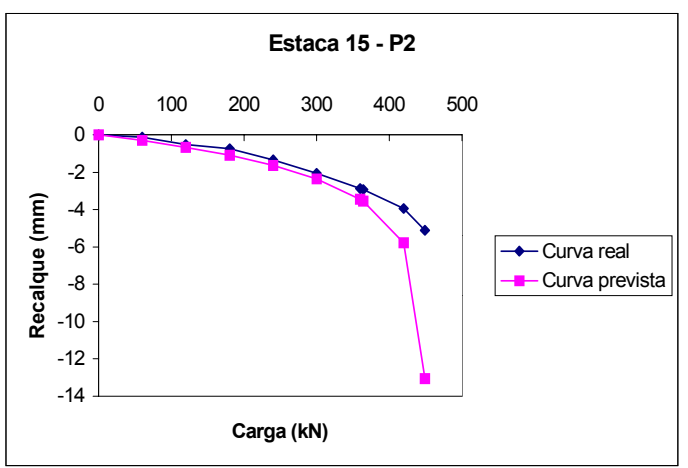

Figura 5.7b - Comparação entre a curva prevista da estaca 15 para a carga $\mathrm{P}_{2}$ e a curva experimental. 


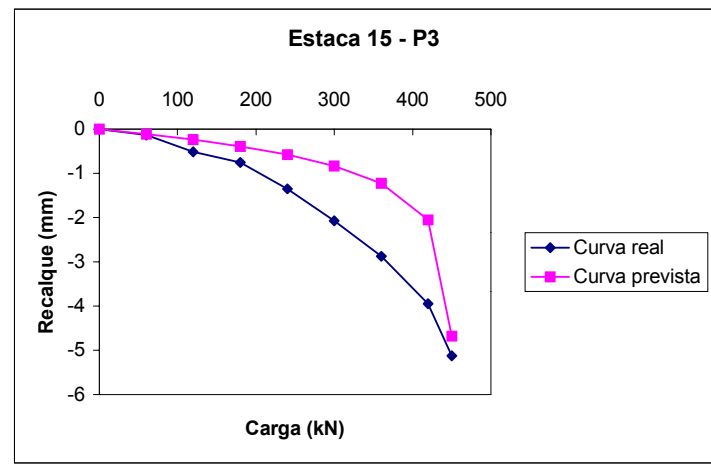

Figura 5.7c - Comparação entre a curva prevista da estaca 15 para a carga $P_{3}$ e a curva experimental.

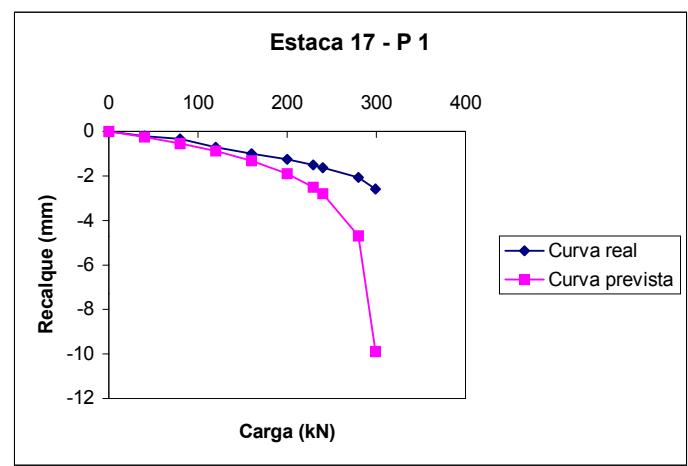

Figura 5.8a - Comparação entre a curva prevista da estaca 17 para a carga $P_{1}$ e a curva experimental.

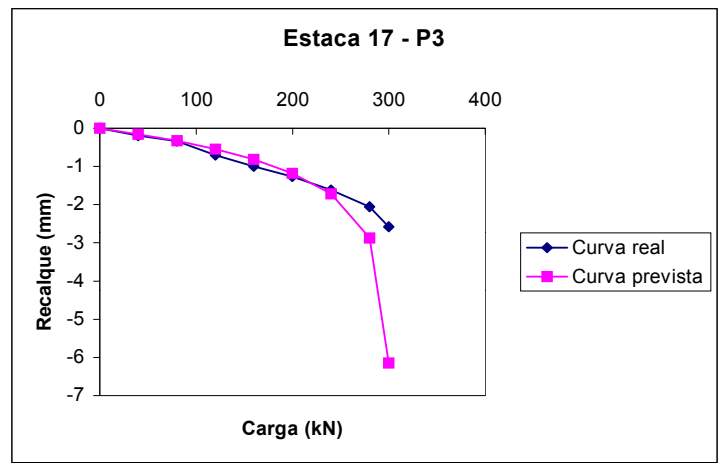

Figura 5.8c - Comparação entre a curva prevista da estaca 17 para a carga $P_{3}$ e a curva experimental.

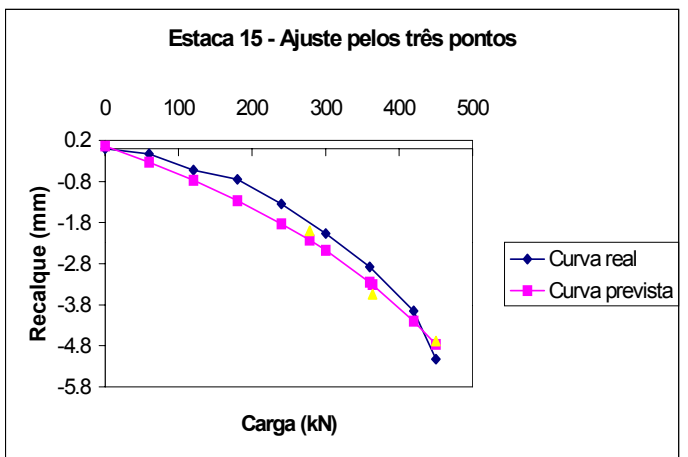

Figura 5.7d - Comparação entre a curva ajustada pelos três pontos da estaca 15 e a curva experimental.

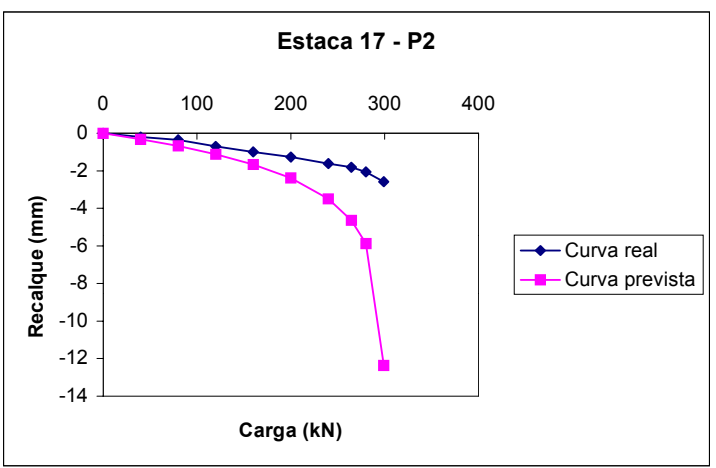

Figura 5.8b - Comparação entre a curva prevista da estaca 17 para a carga $\mathrm{P}_{2}$ e a curva experimental.

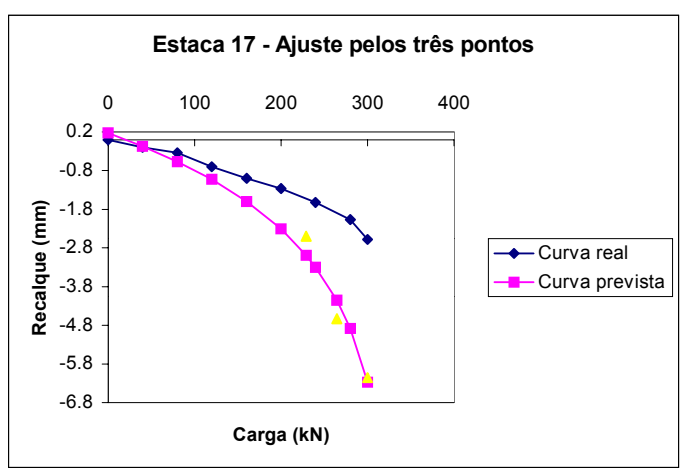

Figura 5.8d - Comparação entre a curva ajustada pelos três pontos da estaca 17 e a curva experimental. 


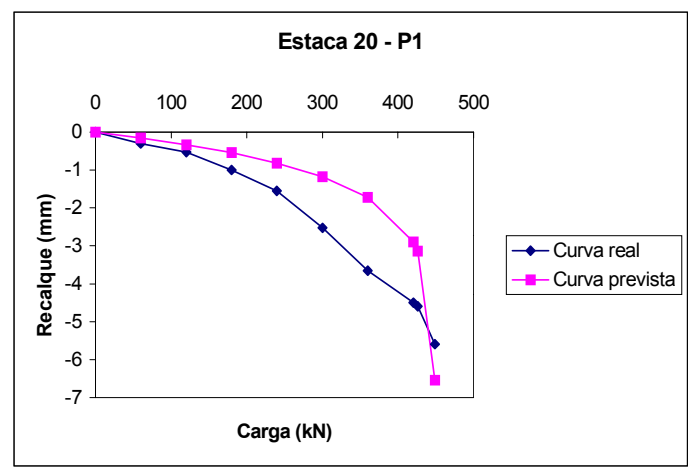

Figura 5.9a - Comparação entre a curva prevista da estaca 20 para a carga $P_{1}$ e a curva experimental.

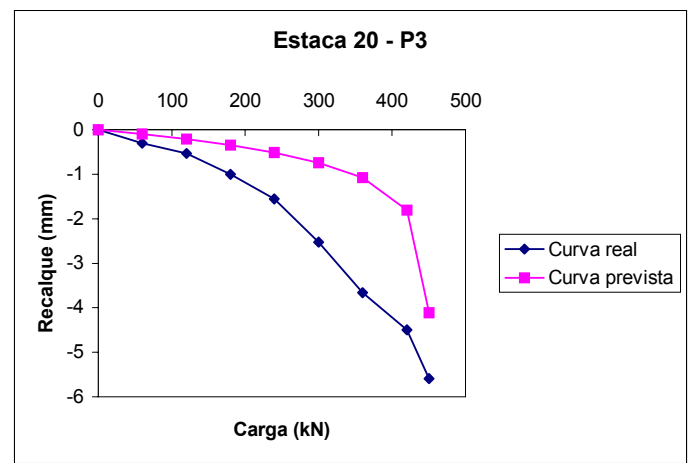

Figura 5.9c - Comparação entre a curva prevista da estaca 20 para a carga $\mathrm{P}_{3}$ e a curva experimental.

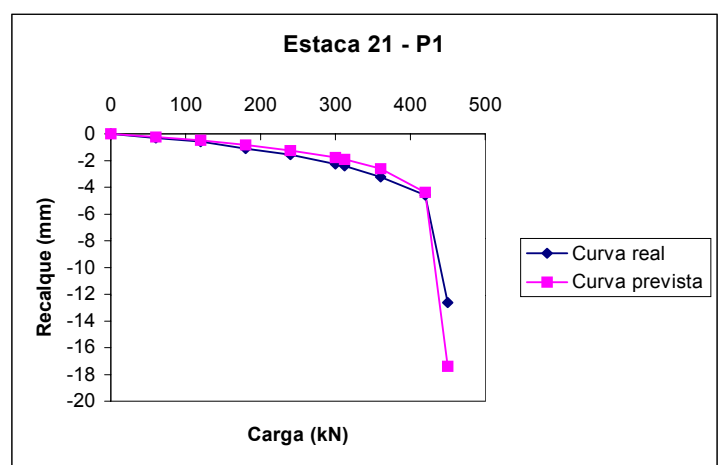

Figura 5.10a - Comparação entre a curva prevista da estaca 21 para a carga $P_{1}$ e a curva experimental.

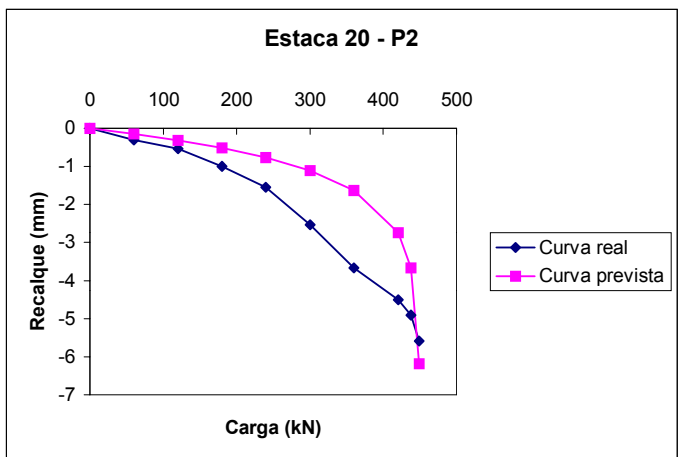

Figura 5.9b - Comparação entre a curva prevista da estaca 20 para a carga $P_{2}$ e a curva experimental.

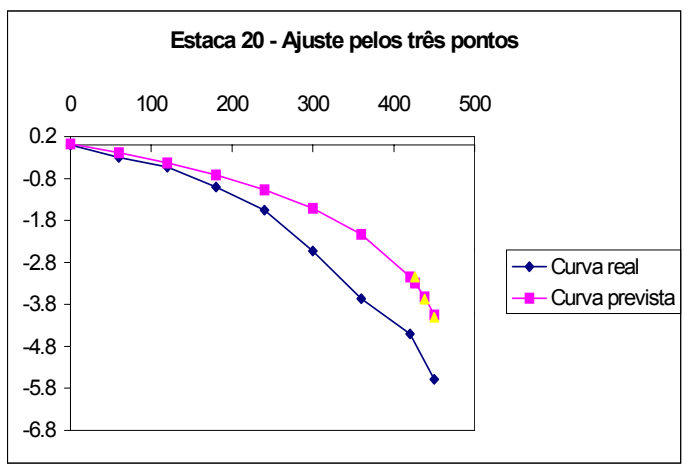

Figura 5.9d - Comparação entre a curva ajustada pelos três pontos da estaca 20 e a curva experimental.

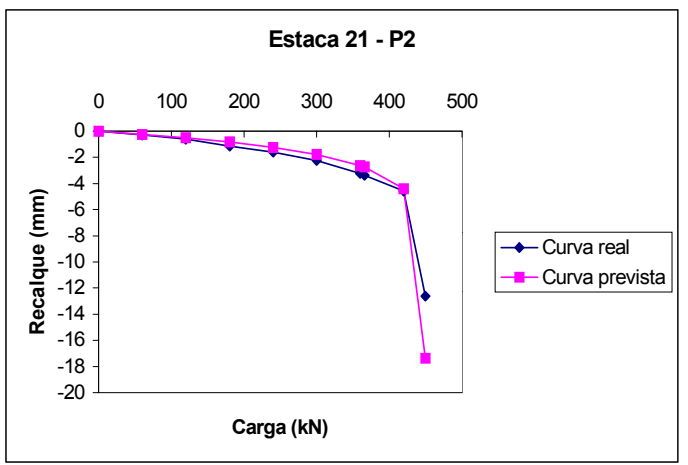

Figura 5.10b - Comparação entre a curva prevista da estaca 21 para a carga $\mathrm{P}_{2}$ e a curva experimental. 


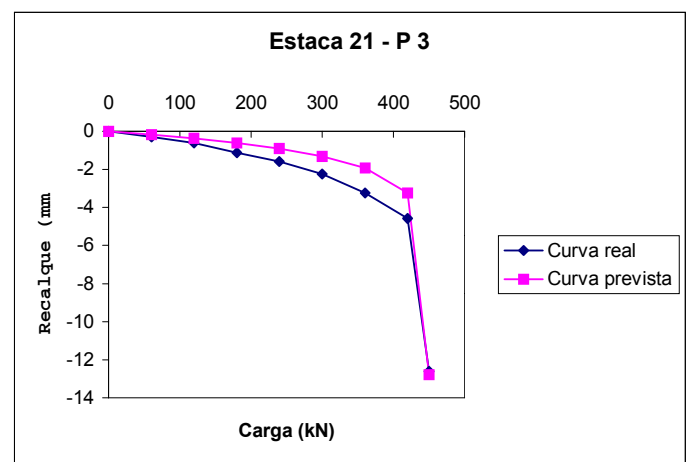

Figura 5.10c - Comparação entre a curva prevista da estaca 21 para a carga $P_{3}$ e a curva experimental.

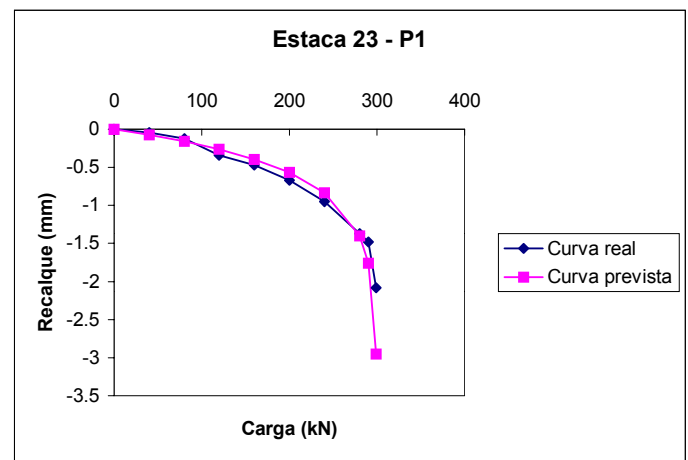

Figura 5.11a - Comparação entre a curva prevista da estaca 23 para a carga $P_{1}$ e a curva experimental.

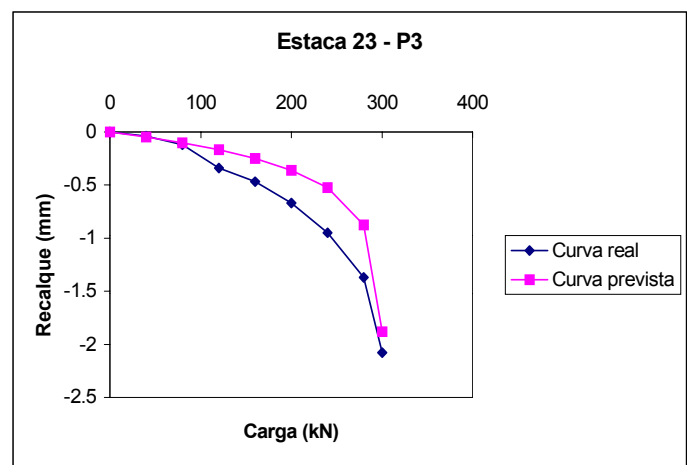

Figura 5.11c - Comparação entre a curva prevista da estaca 23 para a carga $\mathrm{P}_{3}$ e a curva experimental.

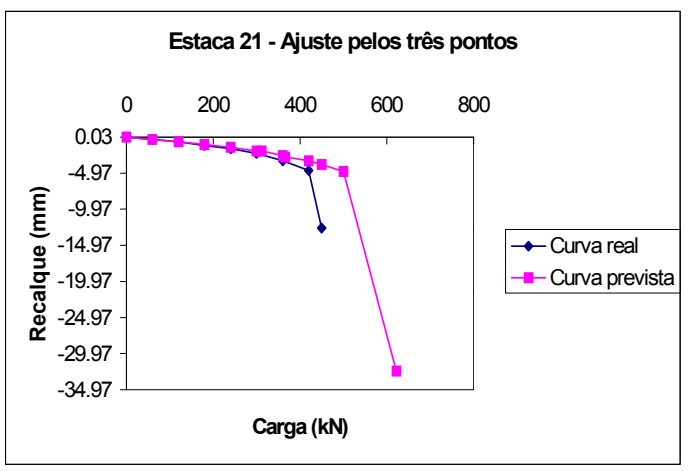

Figura 5.10d - Comparação entre a curva ajustada pelos três pontos da estaca 21 e a curva experimental.

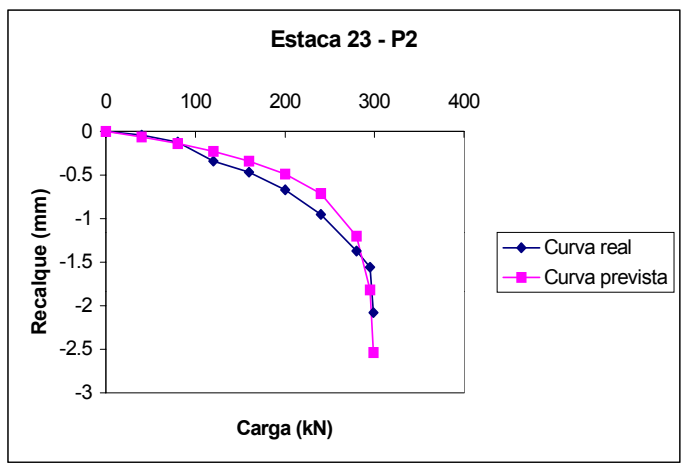

Figura 5.11b - Comparação entre a curva prevista da estaca 23 para a carga $\mathrm{P}_{2}$ e a curva experimental.

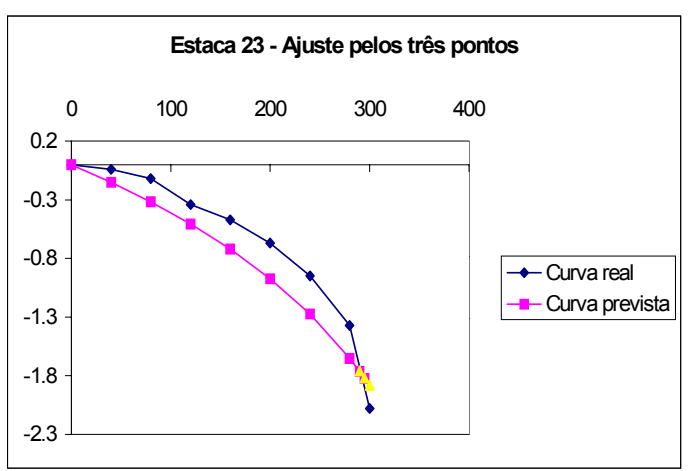

Figura 5.11d - Comparação entre a curva ajustada pelos três pontos da estaca 23 e a curva experimental. 


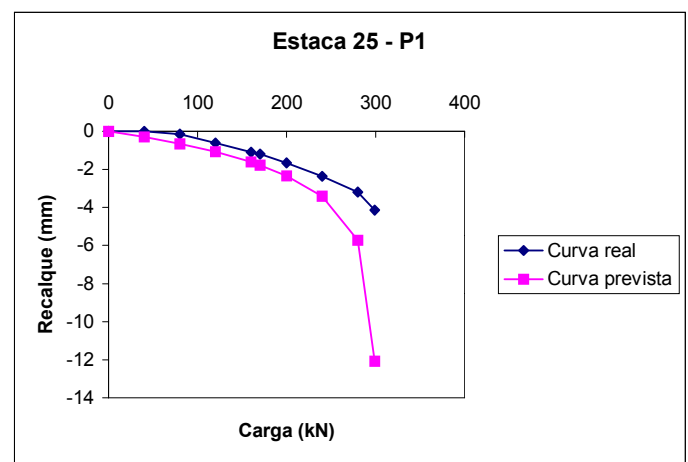

Figura 5.12a - Comparação entre a curva prevista da estaca 25 para a carga $P_{1}$ e a curva experimental.

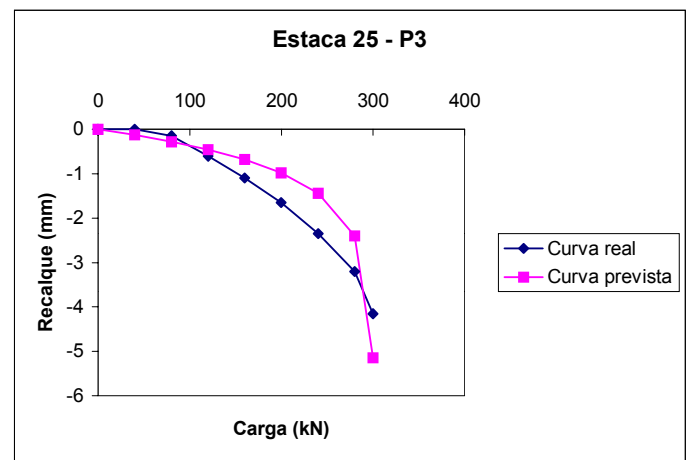

Figura 5.12c - Comparação entre a curva prevista da estaca 25 para a carga $\mathrm{P}_{3}$ e a curva experimental.

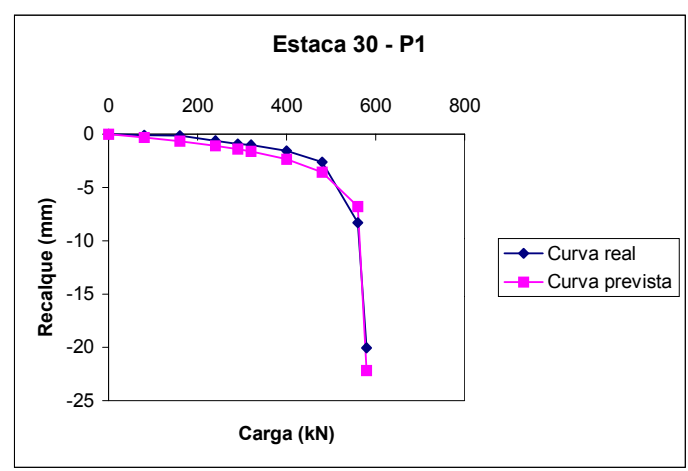

Figura 5.13a - Comparação entre a curva prevista da estaca 30 para a carga $\mathrm{P}_{3}$ e a curva experimental.

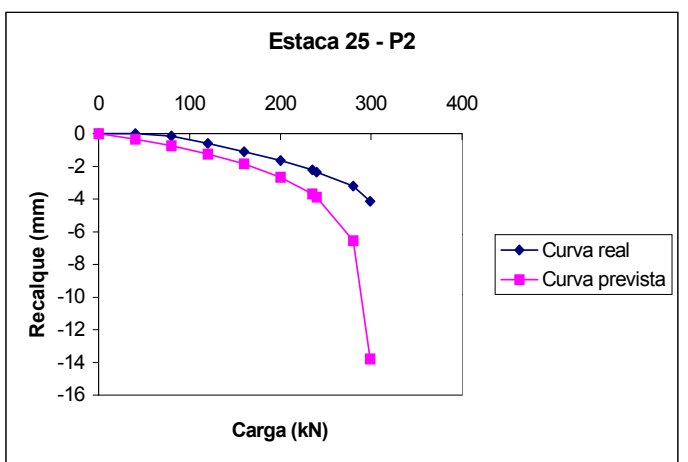

Figura 5.12b - Comparação entre a curva prevista da estaca 25 para a carga $\mathrm{P}_{2}$ e a curva experimental.

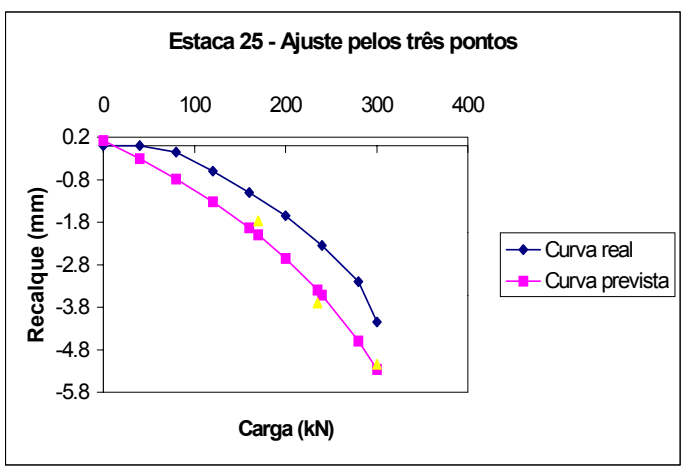

Figura 5.12d - Comparação entre a curva ajustada pelos três pontos da estaca 25 e a curva experimental.

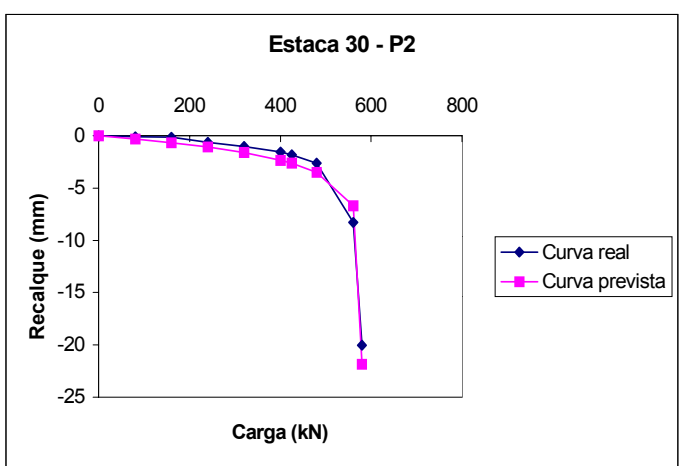

Figura 5.13b - Comparação entre a curva prevista da estaca 30 para a carga $P_{3}$ e a curva experimental. 


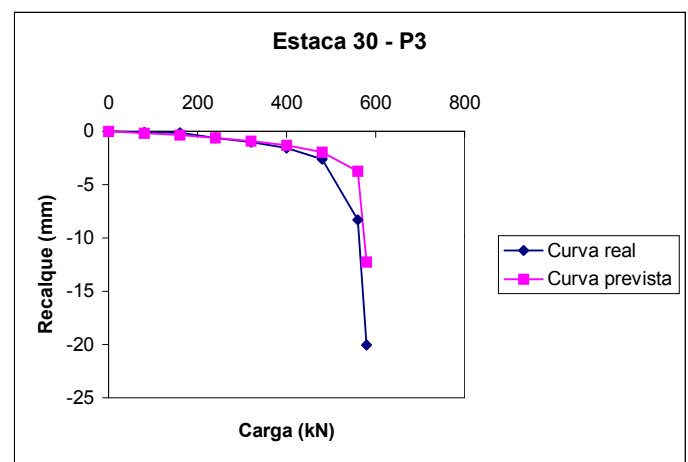

Figura 5.13c - Comparação entre a curva prevista da estaca 30 para a carga $P_{3}$ e a curva experimental.

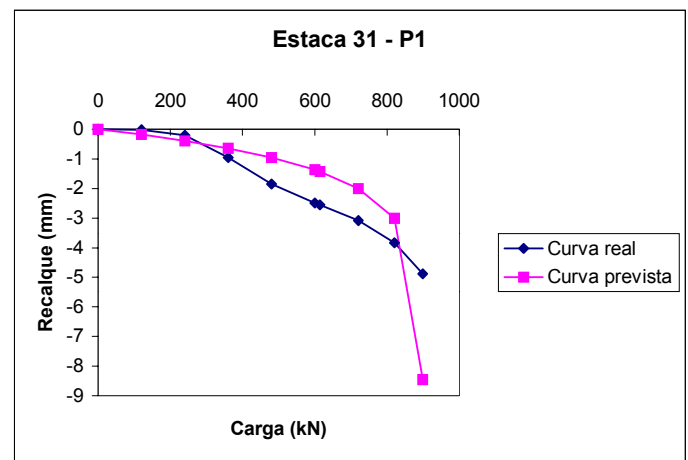

Figura 5.14a - Comparação entre a curva prevista da estaca 31 para a carga $P_{1}$ e a curva experimental.

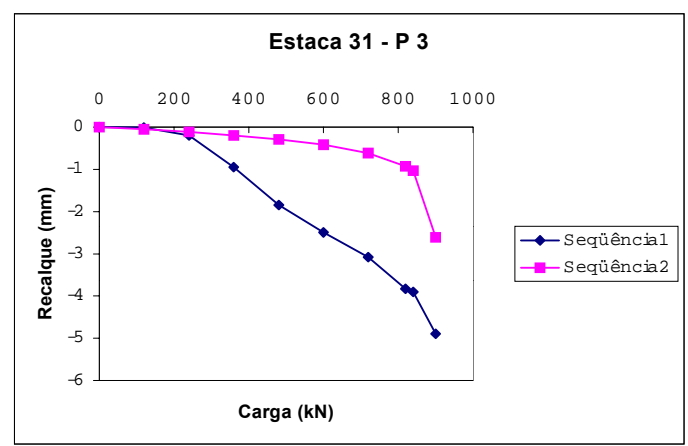

Figura 5.14c - Comparação entre a curva prevista da estaca 31 para a carga $\mathrm{P}_{3}$ e a curva experimental.

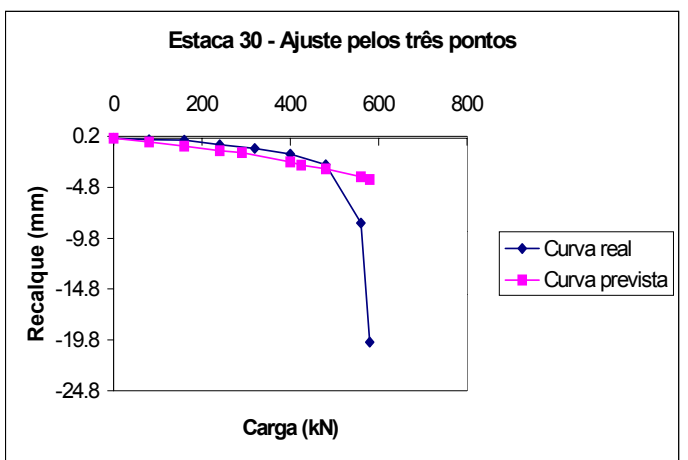

Figura 5.13d - Comparação entre a curva ajustada pelos três pontos da estaca 30 e a curva experimental.

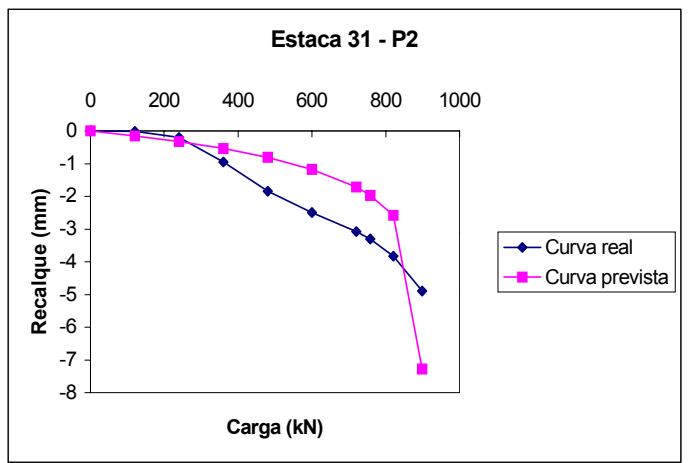

Figura 5.14b - Comparação entre a curva prevista da estaca 31 para a carga $\mathrm{P}_{2}$ e a curva experimental.

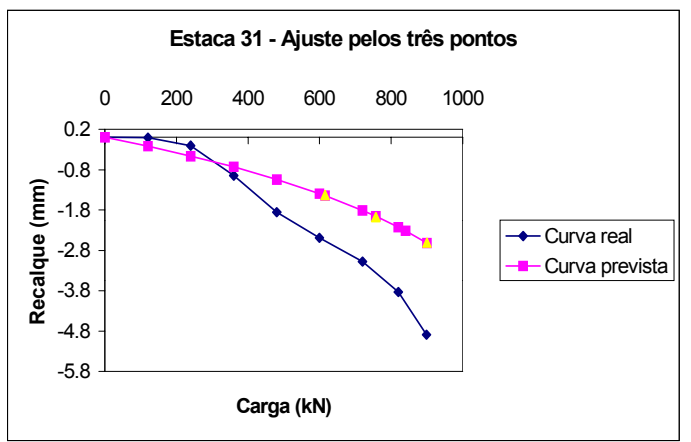

Figura 5.14d - Comparação entre a curva ajustada pelos três pontos da estaca 31 e a curva experimental. 


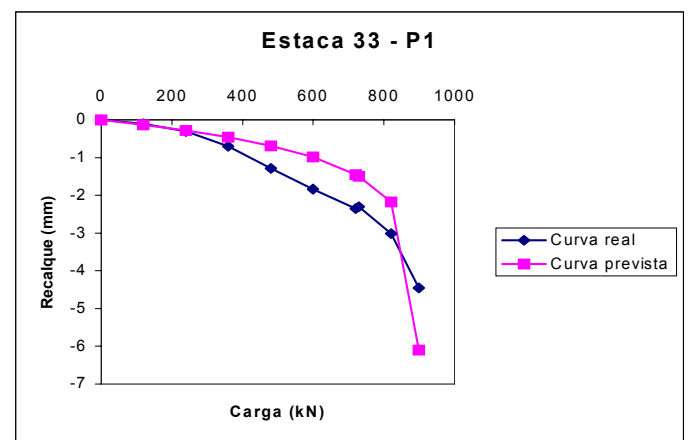

Figura 5.15a - Comparação entre a curva prevista da estaca 33 para a carga $P_{1}$ e a curva experimental.

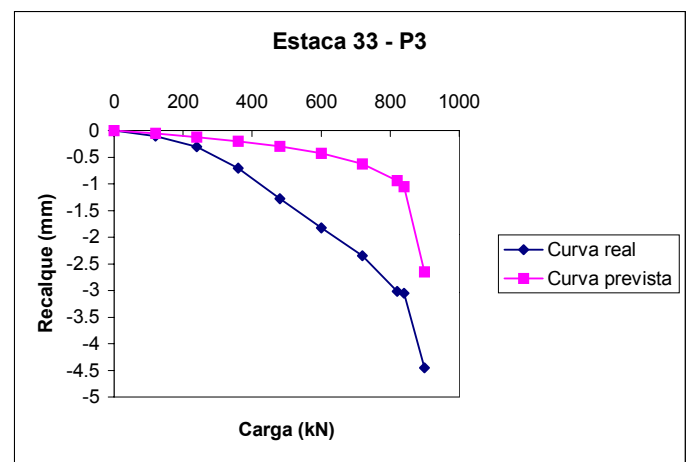

Figura 5.15c - Comparação entre a curva prevista da estaca 33 para a carga $P_{3}$ e a curva experimental.

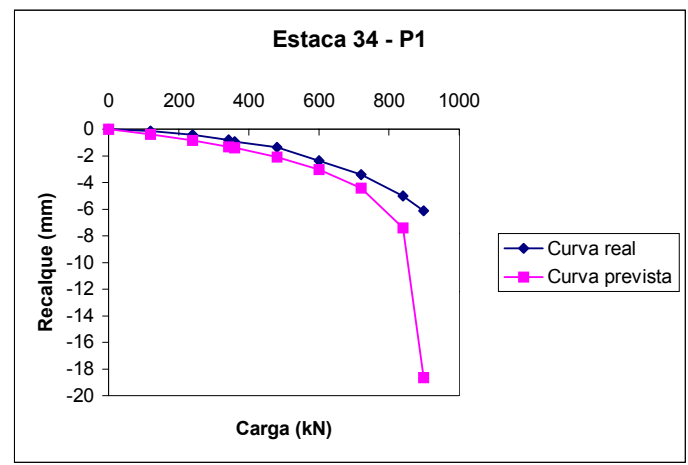

Figura 5.16a - Comparação entre a curva prevista da estaca 34 para a carga $P_{1}$ e a curva experimental.

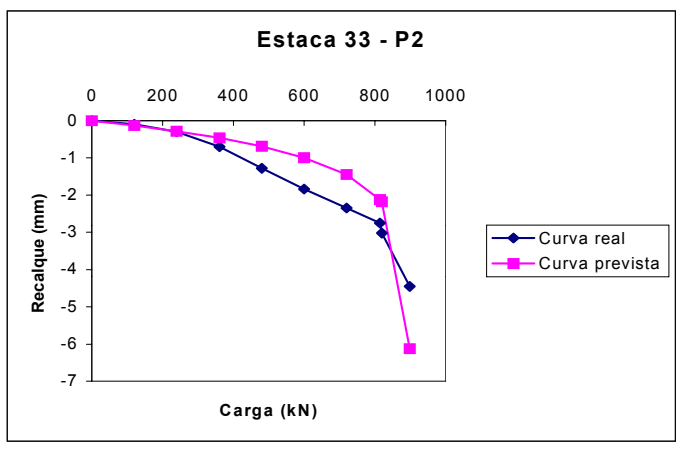

Figura 5.15b - Comparação entre a curva prevista da estaca 33 para a carga $P_{2}$ e a curva experimental.

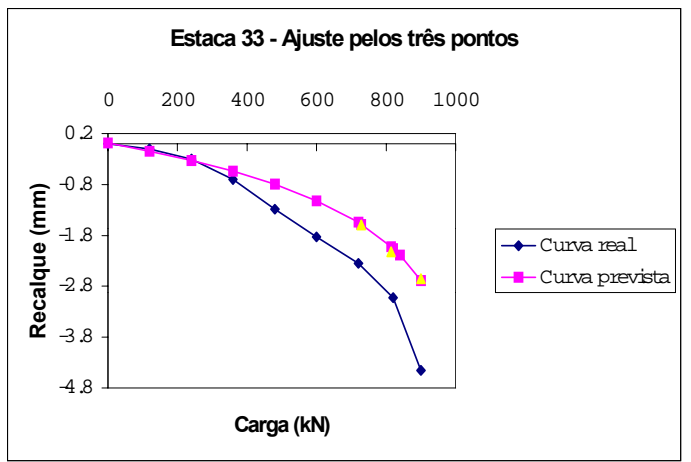

Figura 5.15d - Comparação entre a curva ajustada pelos três pontos da estaca 33 e a curva experimental.

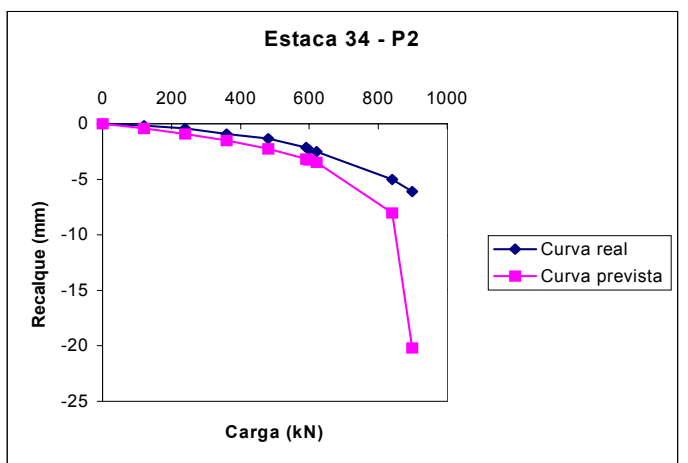

Figura 5.16b - Comparação entre a curva prevista da estaca 34 para a carga $P_{2}$ e a curva experimental. 


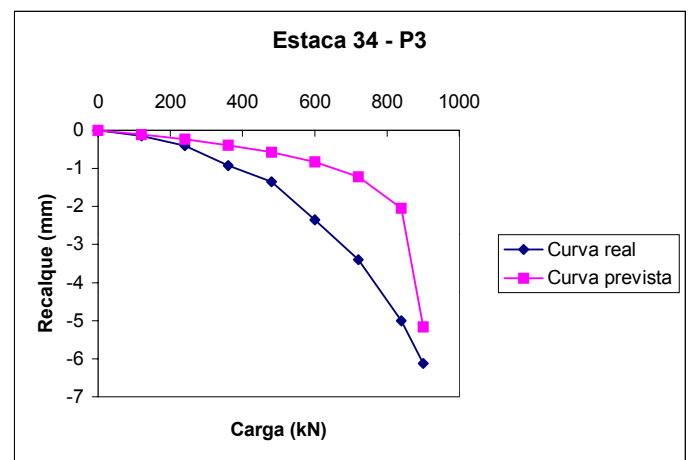

Figura 5.16c - Comparação entre a curva prevista da estaca 34 para a carga $\mathrm{P}_{3}$ e a curva experimental.

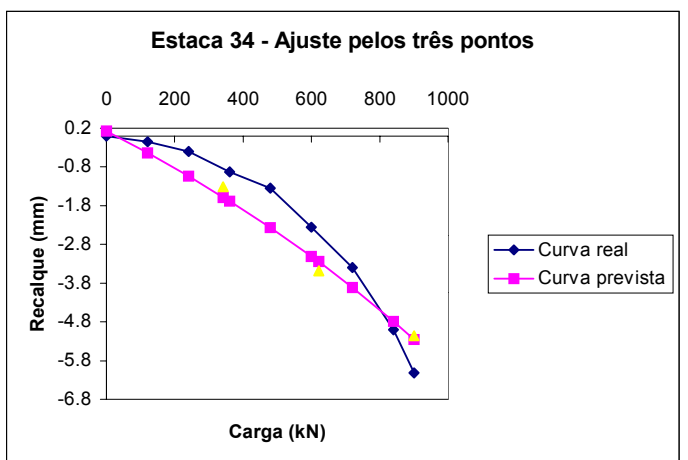

Figura 5.16d - Comparação entre a curva ajustada pelos três pontos da estaca 34 e a curva experimental. 
Observa-se que, em alguns casos, apesar da relação $\rho_{\mathrm{c}} / \rho_{\mathrm{m}}$ não estar muito próxima do valor unitário, a curva carga $\mathrm{x}$ recalque prevista apresenta uma boa coincidência com a curva experimental, como por exemplo, as estacas 21, 23, 30 (para os três valores de $P_{i}$ ).

Em outros casos, a curva apresenta uma boa concordância em todo o trecho inicial, havendo entretanto uma diferença significativa dos resultados no trecho próximo à carga máxima do ensaio. Isto é notado nas estacas de número 3 (para $\mathrm{P}_{1}$ e $\mathrm{P}_{2}$ ), 11 (para os três valores de $\mathrm{P}_{\mathrm{i}}$ ), 15 (para $\mathrm{P}_{1}$ e $\mathrm{P}_{2}$ ), 17 (para os três valores de $P_{i}$ ), 25 (para os três valores de $P_{i}$ ), 30 (para $P_{1}$ e $P_{2}$ ),, 33 (para $\mathrm{P}_{1}$ ), 34 (para $\mathrm{P}_{1}$ e $\mathrm{P}_{2}$ ).

Nos casos em que a distância da ponta da estaca até a profundidade limite inferior da sondagem (tabela 5.3) é pequena (inferior a 6 m), não houve boa concordância, entre a curva prevista e experimental, como as estacas 6 e 31.

Tabela 5.2 - Distância entre a ponta da estaca e o limite inferior da sondagem (h).

\begin{tabular}{cc}
\hline Estaca & $\mathrm{h}(\mathrm{m})$ \\
\hline 03 & 6,37 \\
06 & 1,00 \\
10 & 8,55 \\
11 & 6,45 \\
15 & 9,45 \\
17 & 11,45 \\
20 & 6,00 \\
21 & 11,00 \\
23 & 1,00 \\
25 & 8,25 \\
30 & 11,45 \\
31 & 3,45 \\
33 & 6,45 \\
34 & 9,45 \\
\hline
\end{tabular}


Nos casos das estacas 10 e 20, que apresentam h maior que $6 \mathrm{~m}$, podese justificar os resultados obtidos provavelmente pelo baixo valor do NSPT na ponta da estaca (8 e 3 golpes).

Para os demais casos, notou-se que para determinadas estacas, os resultados nem sempre são satisfatórios para todos os níveis de carregamento analisados. Utilizando-se $\mathrm{P}=\mathrm{R}_{\ell}$ obteve-se a maioria das melhores concordâncias entre curvas. Isto também pode ser visto quando se analisa a tabela 5.1, que além de apresentar o valor médio mais próximo do valor unitário, apresentou o menor desvio padrão.

Já as curvas ajustadas por três pontos, pode-se dizer que no caso das estacas $03,11,15,21,23,30$ e 34 houve boa concordância com a curva experimental apesar de que para as estacas $03,15,21,23,30$ e 34, o valor da carga última de Van der Veen tornou-se divergente.

As curvas das estacas 06, 10, 17,20, 25, 31 e 33 não apresentaram boa concordância com as curvas experimental, porém para as estacas de número 06, 10, 31 e 33 a carga última apresentou valores convergentes (diferença menor que $10 \%)$. 


\section{CONCLUSÕES}

$\mathrm{Na}$ bibliografia consultada foi possível observar a crescente necessidade de se conhecer melhor a formação em questão. Estudos geológicos a respeito do assunto vêm sendo desenvolvidos. Do ponto de vista geotécnico porém, há a necessidade de melhor compreensão do comportamento do material a fim de que haja uma melhoria da qualidade das obras de engenharia.

Tendo em vista tal fato, analisou-se neste trabalho, um conjunto de 34 provas de carga estática realizadas em estacas pré-moldadas de concreto cravadas na cidade de Curitiba e Região Metropolitana sendo a maioria situada na Formação Guabirotuba.

Primeiramente estudaram-se três métodos de previsão de capacidade de carga: Aoki - Velloso (1975), Décourt - Quaresma (1978) e Amaral $(1982,1999)$. Estes métodos foram aplicados ao conjunto de estacas comparando os valores calculados da capacidade de carga (R) com os valores da carga última de Van der Veen $(\mathrm{Pu})$. Observou-se que o método Aoki Velloso é bastante conservador (valores de $\mathrm{R}$ cerca de $40 \%$ inferiores a $\mathrm{Pu}$ ) enquanto que o método de Amaral apresenta valores bastante ousados ( $R$ $20 \%$ superior a Pu). Já o método Décourt - Quaresma (R 20\% inferior a Pu) apresenta valores intermediários. 
Para cada um dos métodos citados buscou-se um fator de correção de modo a tornar a relação $\mathrm{R} / \mathrm{Pu}$ a mais próxima do valor unitário. No caso do método Aoki - Velloso, analisou-se primeiramente a adaptação do método de acordo com Aoki (1985). Constatou-se que os resultados de $R$ apresentaram uma melhoria pois a relação $\mathrm{R} / \mathrm{Pu}$ é apenas $24 \%$ inferior ao valor unitário. Os fatores de correção então foram calculados para esta versão do método. Aplicando-se o fator global na capacidade de carga (R), os valores resultantes são 1,2 \% superiores ao valor unitário. Já para o fator de correção parcial, multiplicado pela parcela de atrito lateral $\left(\mathrm{R}_{\ell}\right)$, os valores da capacidade de carga $\mathrm{R}$ resultaram em 1,9\% acima do valor unitário.

Para o método Décourt - Quaresma (1978) o valor do coeficiente de correção global, aplicado na capacidade de carga, resulta valores da $\mathrm{R} / \mathrm{Pu}$ praticamente igual ao valor unitário $(+1 \%)$ enquanto que para o coeficiente de correção parcial, aplicado na parcela de resistência de ponta $\left(R_{\mathrm{p}}\right)$, a relação $\mathrm{R} / \mathrm{Pu}$ resultou $0,9 \%$ superior ao valor unitário.

No caso do método Amaral, trabalhou-se apenas com o coeficiente global aplicado na capacidade de carga (R) que resulta numa relação $\mathrm{R} / \mathrm{Pu}$ $0,4 \%$ acima do valor unitário.

Uma outra análise foi feita somando-se as parcelas de resistência de ponta $\left(R_{\mathrm{p}}\right)$ do método Aoki - Velloso (1975, adaptado por Aoki em 1985) e resistência lateral $\left(R_{\ell}\right)$ do método Décourt - Quaresma (1978). Os valores resultantes de $\mathrm{R}$ mostraram-se bastante satisfatórios, sendo a relação $\mathrm{R} / \mathrm{Pu}$ (cerca de 7\% inferior ao valor unitário).

Todos os métodos, após a utilização dos fatores de correção, apresentaram uma melhoria significativa dos resultados. Os coeficientes de variação também apresentam uma diferença pequena. Os métodos Décourt Quaresma e Amaral apresentam os menores valores (0,294 e 0,231 respectivamente) enquanto que para o método Aoki - Velloso este valor corresponde a 0,404. 
O método de Van der Veen (1953) foi aplicado a quatro provas de carga conduzidas à ruptura, para dedução de um critério que garantisse uma boa extrapolação das curvas carga x recalque.

A partir do quarto estágio, aplicou-se o método de Van der Veen para cada estágio, considerando somente os pontos obtidos até esse estágio. Determinou-se assim a variação da carga última de Van der Veen com o prosseguimento do ensaio.

Deduziu-se o seguinte critério para garantir uma boa extrapolação da curva: uma variação máxima de 10\% (em módulo) nos valores da carga última de Van der Veen obtidos em dois estágios consecutivos garante um erro máximo de 11\% (em módulo) em relação ao valor experimental da carga última.

A aplicação deste critério a três provas de carga levadas até a ruptura conduziu a erros aceitáveis de $-9 \%$ a $+7 \%$ em relação a carga última obtida experimentalmente. Por outro lado, este critério não se aplicou a uma das provas de carga rompidas, o que demonstra a existência de casos em que a extrapolação por Van der Veen conduz a discrepâncias. Neste caso específico, a interrupção da prova de carga no penúltimo estágio teria resultado uma carga última extrapolada de $17 \%$ acima do valor experimental (contra a segurança).

Também se aplicou o critério proposto a 30 provas de carga sem ruptura: em apenas 15 delas pode-se garantir uma boa extrapolação da curva carga x recalque. Nas curvas em que o critério não se aplica pode-se deduzir que a prova de carga deveria ter continuado em pelo menos um estágio adicional, ou que essas curvas carga $x$ recalque talvez não sigam o modelo proposto por Van der Veen (1953).

Em princípio, essas conclusões devem ser consideradas apenas para a região estudada e, ainda assim como preliminares. Seria desejável a análise de um número maior de provas de carga conduzidas até a ruptura para aprimorar o critério. 
Finalmente para estimativa dos recalques, utilizaram-se as 18 provas de carga nas quais o critério apresentado anteriormente se aplica. O recalque foi calculado para três níveis de carregamento diferentes. Estes valores correspondem a parcela de atrito lateral, à carga máxima do ensaio e ao valor médio dos dois anteriores. $\mathrm{O}$ valor utilizado para o atrito lateral foi o calculado pelo método Aoki - Velloso adaptado e corrigido com o fator de correção parcial.

Os recalques calculados $\left(\rho_{c}\right)$ foram comparados aos recalques medidos $\left(\rho_{\mathrm{m}}\right)$ e a relação $\rho_{\mathrm{c}} / \rho_{\mathrm{m}}$ foi obtida para cada um dos níveis de carregamento. Os melhores resultados foram encontrados para a carga correspondente à parcela de atrito lateral, cuja relação apresentou-se 0,6\% acima do valor unitário e com o menor coeficiente de variação.

Fez-se também a previsão da curva carga $x$ recalque comparando-a com a curva experimental. Em alguns casos, apesar da relação $\rho_{c} / \rho_{m}$ apresentar um valor distante do unitário, houve boa concordância com a curva experimental. Em outros casos, a curva apresenta uma boa concordância no seu trecho inicial da curva, havendo uma diferença significativa apenas nos pontos próximos a carga máxima do ensaio.

Para que este método de cálculo apresente bons resultados, é necessário que a sondagem seja executada até o indeformável ou pelo menos a uma distância próxima. Nos casos estudados, quando a distância da ponta da estaca até o limite inferior da sondagem apresenta valores abaixo de $6 \mathrm{~m}$, não houve boa concordância entre a curvas real e a prevista, salvo algumas exceções. Notou-se ainda que os resultados nem sempre são satisfatórios para todos os níveis de carregamento analisados, sendo que também em relação as curvas, melhores concordâncias São obtidas para a carga correspondente ao atrito lateral.

Já para as curvas ajustadas pelos três pontos, pode-se dizer que em metade das estacas nas quais se aplicou o método obtiveram-se bons resultados quanto a concordância, porém a carga última extrapolada resultou 
muito acima da carga extrapolada, considerando todos os pontos da curva. Os casos que não apresentaram bons resultados em termos de concordância, apresentaram, para algumas estacas, valores da carga última muito próximos (diferença menor que 10\%) dos valores extrapolados, utilizando-se todos os pontos da curva. 


\section{REFERÊNCIAS BIBLIOGRÁFICAS}

1. ABNT (1996) - "Projeto e Execução de Fundações". NBR 6122/96. Rio de janeiro, 33p.

2. AB'SABER, A. N. (1966). "Notas a respeito do sítio urbano de Curitiba". Goemorfologia - USP, v. 3, p. 1 - 7. São Paulo.

3. AMARAL, A. B. T. (1982). "Capacidade de carga de estacas em solos argilosos da Formação Guabirotuba". In: CONGRESSO BRASILEIRO DE MECÂNICA DOS SOLOS E ENGENHARIA DE FUNDAÇÕES, 7, Anais, ABMS, v.2, p. 9 - 18, Olinda.

4. AMARAL, A. B. T. (1999). "Capacidade de carga a compressão em estacas pré-moldadas levando em conta os recalques". In: CARACTERÍSTICAS DA FORMAÇÃO GUABIROTUBA, 1, Anais, ABMS, setembreo 1999, p.129 - 138, Curitiba.

5. AOKI, N. (1976). “Considerações sobre a capacidade de carga de estacas isoladas". Curso de extensão universitária em engenharia de fundações, Universidade Gama Filho, Rio de Janeiro, 44 p.

6. AOKI, N. (1985a). "Prática de fundações em estacas pré-moldadas em terra". Palestra proferida no Curso Pile Foundations for Offshore Structures", COPPE - UFRJ, Rio de Janeiro, 45 p.

7. AOKI, N. (1985b). “Previsão da curva carga x recalque”. Notas de cálculo. 
8. AOKI, N. (1996). "Engenharia de Fundações". Notas de Aula, Curso de Pós-graduação, Departamento de Geotecnia da USP/SC, São Carlos, SP.

9. AOKI, N. \& VELLOSO, D. A. (1975). “An approximate method to estimate the bearing capacity of piles". In: V PANAMERICAN CONFERENCE ON SOIL MECHANICS AND FOUNDATION ENGINEERING, Buenos Aires, v.1, p. $367-376$.

10. AZEVEDO, F. F. (1981). “Thecamoebianas e organófitas na Formação Guabirotuba". In: SIMPÓSIO REGIONAL DE GEOLOGIA, 3, Atas, SBG, v. 2, p. $226-242$, Curitiba.

11. BECKER, R. D. (1982). “Distribuição dos sedimentos cenozóicos na Região Metropolitana de Curitiba e sua relação com a estrutura geológica e morfológica regional". Tese (Doutorado). Universidade Federal do Rio Grande do Sul.

12. BERG, E. A. T.; LOURENÇO, O. B. (1973). "Sobre a composição mineralógica das argilas dos solos do Estado do Paraná". Boletim Paranaense de Geociências, n. ${ }^{\circ}$ 31, p. 16.

13. BIGARELLA, J. J.; SALAMUNI, R. (1957). "Aspectos geográficos e geológicos da cidade de Curitiba e arredores". 4p, Curitiba. (Reimpresso do v. Comemorativo do Primeiro Centenário da Farmácia Stellfeld).

14. BIGARELLA, J. J.; SALAMUNI, R. (1959). “Notas complementares à planta geológica da Cidade de Curitiba e arredores". Boletim do Instituto de Biologia e Pesquisas Tecnológicas, n. ${ }^{\circ}$ 40, p. 1 - 14, Curitiba.

15. BIGARELLA, J. J.; SALAMUNI, R. (1962). “Caracteres texturais dos sedimentos da Bacia de Curitiba". Boletim da Universidade Federal do Paraná. Instituto de Geologia, n. ${ }^{0}$ 7, p.1 -164, Curitiba.

16. BIGARELLA, J. J.; SALAMUNI, R.; AB'SABER, A. N. (1961). “Origem e ambiente de deposição da Bacia de Curitiba". Boletim Paranaense de Geografia, UFPR, n. ${ }^{\circ}$ 4/5, p. 71 - 81, Curitiba. 
17. BIGARELLA, J. J ; MOUSINHO, M. R. ; SILVA, J. X.(1965). “Pediplanos, sedimentos e seus depósitos correlativos no Brasil". Boletim Paranaense de geografia, UFPR, $n^{\circ}$ 16/17, p. 117 - 151, Curitiba.

18. BOSZCZOWSKI, R. B.; BORGA, P. C. (1998). “Desenvolvimento de metodologia para o levantamento de fundações executada na região de Curitiba". In: EVENTO DE INICIAÇÀO CIENTÍFICA DA UNIVERSIDADE FEDERAL DO PARANÁ (EVINCI), 6, outubro, p.164, Curitiba.

19. CANALI, N. E.; MURATORI, A. M. (1981). "Síntese da evolução geomorfológica da Bacia Sedimentar de Curitiba". In: SIMPÓSIO REGIONAL DE GEOLOGIA, 3, Atas, SBG, v. 2, p. 363 - 371, Curitiba.

20. CHAMECKI, P. R.; KORMANN, A. M.; NASCIMENTO, N. A.; DYMINSKI, A. S. (1998). “Sítio Experimental de Geotecnia da UFPR Objetivos e dados preliminares". In: CONGRESSO BRASILEIRO DE MECÂNICA DOS SOLOS E ENGENHARIA DE FUNDAÇÕES, 11, Anais, ABMS, v.2, novembro, p. 819 - 826, Brasília.

21. CHIN, K. F. (1970). "Estimation of the ultimate load of piles from tests not carriad to failure". In: SOUTH - EAST ASIAN CONFERENCE ON SOIL ENGINEERING HELD, 2, proceedings, p. 81 - 90, Singapore.

22. CHIN, K. F. (1978). "Diagnosis of pile condition". Geotechnical Engineering, vol 9, p. 85 - 104.

23. COIMBRA, A. M.; RICCOMINI, C.; SANT'ANNA, L. G.; VALARELLI, J. V. (1996). "Bacia de Curitiba - estratigrafia e correlações regionais". In: CONGRESSO BRASILEIRO DE GEOLOGIA, 39, Anais, SBG, v.1, p. 135 137, Salvador.

24. COUTINHO, J. M. V. (1955). "Lantanita de Curitiba, PR". Boletim de Faculdade de Ciências e Letras da Universidade de São Paulo, n. ${ }^{\circ}$ 186, p. 119 - 126, São Paulo. 
25. DÉCOURT, L. (1982). "Prediction of the bearing capacity of piles based exclusively on values of the SPT. In: $2^{\mathrm{ND}}$ EUROP. SYMP. ON PENETRATION TEST, Amsterdam, v.1, p. 29 - 34.

26. DÉCOURT, L. \& QUARESMA, A. R. (1978). “Capacidade de carga de estacas a partir de valores de SPT". In: VI CONGRESSO BRASILEIRO DE MECÂNICA DOS SOLOS E ENGENHARIA DE FUNDAÇÕES, Rio de Janeiro, v.1 , p. $45-54$.

27. DÉCOURT, L. \& NIYAMA, S. (1994). “Predicted and Measured Behavior of Displacement Piles in Residual Soils". XIII ICSMFE, New Delhi, vol II, p. $477-486$.

28. DUARTE, J. M. G. (1986). “Um estudo sobre o solo da Formação Guabirotuba, com ênfase na determinação da resistência residual". Dissertação (Mestrado). Escola Politécnica da Universidade de São Paulo.

29. FELIPE, R. S. (1998). “A gestão de riscos geológicos urbanos - erosão e movimento gravitacional de massa na Formação Guabirotuba". Monografia (Especialização em Gestão Técnica do Meio Urbano). Pontifícia Universidade Católica do Paraná e Université de Technologie de Compiègne - UTC - France.

30. FELIPE, R. S.; SALAZAR JR., O.; SIEDLECKI, K. N. (1994). “Mapeamento geológico - geotécnico na região do Alto Iguaçú". Programa de geologia aplicada ao planejamento da Região Metropolitana de Curitiba. Convênio 04/93 - MINEROPAR / COMEC. 2v., outubro, Curitiba.

31. FORTIN, P. (1989). "Mobilisation, fractionnement et accumulation de terres rares lors de l'altération latéritique de sediments argilo - sableux du Bassin de Curitiba (Brésil)". Tese (Doutorado). École de Mines de Paris.

32. FORTIN, P.; TRESCASES, J. J.; MELF, A. J.; SCHITT, J. M.; THIRY,M. (1989). Rare earth elements (REE) accumulations in the Curitiba Basin (Brasil)". In: INTERNATIONAL GEOCHEMICAL EXPLORATION 
SYMPOSIUM, 13, Abstracts, Sociedade Brasileira de Geoquímica, p. 66 68, Rio de janeiro.

33. GIUSTI, D. A. (1989). “Contribuição à geologia ambiental no Município de Curitiba - PR". Dissertação (Mestrado). Universidade de São Paulo.

34. HACH-HACH, A. (1998). "Inventário das feições erosivas e dos movimentos de massa gravitacionais na região leste da Grande Curitiba Paraná, escala 1:20000. Dissertação (Mestrado). 2 v. Escola de Engenharia de São Carlos. Universidade de São Paulo.

35. HACH-HACH, A. \& ZUQUETE, L. V.(1998). “Inventário dos movimentos de massa gravitacionais na região leste da Grande Curitiba - Pr - Brasil". In: CONGRESSO BRASILEIRO DE MACÂNICA DOS SOLOS E ENGENHARIA GEOTÉCNICA, 10, Anais, AMBS, v. 1, p. 505 - 513, Brasília.

36. LOPES, J. A. U. (1966). "Nota explicativa da folha geológica de Curitiba". Boletim da Universidade Federal do Paraná. Instituto de Geologia. n. ${ }^{\circ}$ 20, Curitiba.

37. MASSAD, F.; ROCHA, J. R.; YASSUDA, A. J. (1981). "Algumas características geotécnicas de solos da Formação Guabirotuba, Paraná". In: SIMPÓSIO BRASILEIRO DE SOLOS TROPICAIS EM ENGENHARIA, 1, Anais, p. $706-723$, Rio de Janeiro.

38. MURATORI, A. M.; GIUSTI, D. A.; CANALI, N. E. (1982). “Interpretação gravimétrica preliminar da configuração topográfica do embasamento cristalino no município de Curitiba". In: CONGRESSO BRASILEIRO DE GEOLOGIA, 32, Anais, SBG, v. 4, p. 1576 - 1580, Salvador.

39. NASCIMENTO, N. A. (1992). “Um estudo laboratorial em amostras indeformadas do solo sedimentar da Bacia de Curitiba e do solo residual de basalto do Paraná". Tese (Professor Titular). Universidade Federal do Paraná. 
40. NASCIMENTO, N. A.; CHAMECKI, P. R.; RUSO NETO, L. MERCURI, A. (1994). Estudo paramétrico preliminar dos solos sedimentares característicos da Bacia de Curitiba". In: CONGRESSO BRASILEIRO DE MECÂNICA DOS SOLOS E ENGENHARIA DE FUNDAÇÕES, 10, ABMS, v.4, novembro, p.1277 - 1284, Foz do Iguaçu.

41. OLIVEIRA, L. M.; FELIPE, R. S.; BONACIM, E. A.; SALAZAR JR., O. (1997). “Mapeamento geológico - geotécnico nas folhas COMEC A 100, A 103 e A 93 (parcial)". Projeto geotecnia - região Metropolitana de Curitiba. Convênio 04/95, COMEC/MINEROPAR, 3v. setembro, Curitiba.

42. PEREIRA, E. M. "Avaliação da susceptibilidade a expansão e desagregação de rochas sedimentares na região do Alto Iguaçu - PR". Inédito.

43. POLIDORO, G. B. F.; LIMA, R.E.; FELIPE, R. S. (1997). “A ocupação da Região Metropolitana de Curitiba sobre o quaternário e o risco geológico”. In: CONGRESSO DA ASSOCIAÇÃO BRASILEIRA DE ESTUDOS DO QUATERNÁRIO (ABEQUA), 6, Resumos Expandidos, julho, Curitiba.

44. RELATÓRIO AMBIENTAL DA REGIÃO METROPOLITANA DE CURITIBA. COMEC. Abril, 1997.

45. SALAMUNI, E. (1998). “Tectônica da Bacia Sedimentar de Curitiba”. Tese (Doutorado). Universidade Estadual Paulista. Instituto de Geociências e Ciências Exatas. Campus de Rio Claro.

46. SALAZAR JR., O.; FELIPE, R. S.; RIBAS, S. M.; OLIVEIRA, L. M.; SIEDLECKI, K. N.; PEREIRA, E. M. (1996). “Mapeamento geológico geotécnico nas folhas COMEC A 137, A 138, A 139, A 140". Projeto geotecnia - Região Metropolitana de Curitiba. Convênio 04/95. COMEC/MINEROPAR. 3 v., Curitiba.

47. SCHUSSEL, Z. G. L. (1997). “Relatório ambiental da Região Metropolitana de Curitiba". COMEC/PNUD, 100p, Curitiba. 
48. SIEDLECKI, K. N. (1998). "Respostas de um solo residual da Formação Guabirotuba (PR) frente à interação com soluções contaminantes". Dissertação (Mestrado). Universidade Federal do Paraná.

49. TRESCASES,J.J.; FORTIN,N.; MELFI,A.; NAHON,D. -1986- Rare earth elements accumulation in lateritic weathering of pliocene sediments Curitiba Basin (Brazil). Granada, p.259-272. (International Meeting Geochemistry of the Earth Surface and Processes of Mineral Formation).

50. VAN DER VEEN, C. (1953) - "The Bearing Capacity of a Pile". III Int. Conf. on Soil Mech. and Found. Eng., Zurich, v. 2, p. 125-151.

51. VESIC, A. S. (1967). "Ultimate loads nd settlements of deep foundations in sand". In: SYMPOSIUM ON BEARING CAPACITY AND SETTLEMENT OF FOUNDATIONS, Duke University, USA, p. 53 - 68. 
ANEXO 1

Características das Estacas 

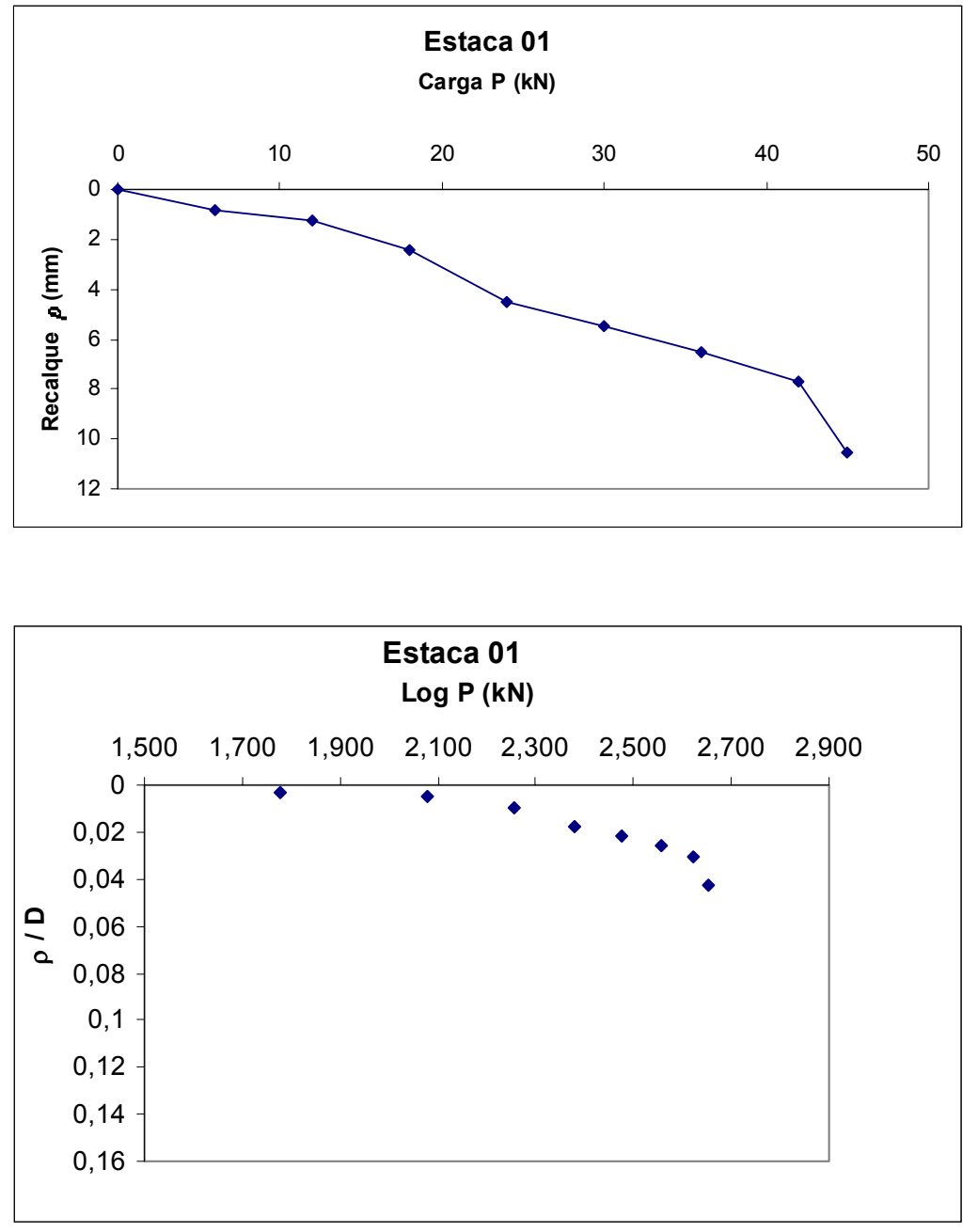

\begin{tabular}{|c|c|}
\hline \multicolumn{2}{|c|}{$\begin{array}{l}\mathrm{D}=25 \mathrm{~cm} \\
\mathrm{~L}=14 \mathrm{~m}\end{array}$} \\
\hline N SPT & Tipo de solo \\
\hline 2 & Argila siltosa orgânica com areia fina, preta, muito mole \\
\hline 2 & Silte argiloso com areia fina e mica, cinza fofo. \\
\hline 2 & \\
\hline 2 & \\
\hline $1 / 15$ & Silte argiloso com areia fina e variegado, fofo \\
\hline 3 & Silte argiloso com areia fina e mica, vermelho, fofo \\
\hline 4 & Silte argiloso com areia fina e mica variegado, fofo \\
\hline 7 & \\
\hline 5 & Silte argiloso com areia fina e mica variegado, pouco compacto \\
\hline 5 & \\
\hline 6 & \\
\hline 5 & Silte argiloso com areia fina e mica, variegado, pouco compacto e \\
\hline 10 & medianamente compacto \\
\hline 8 & \\
\hline 10 & \\
\hline 12 & \\
\hline 19 & Silte arenoso com pedregulhos e mica, variegado, compacto, solo \\
\hline 17 & $\begin{array}{l}\text { residual } \\
\end{array}$ \\
\hline 22 & \\
\hline $27 / 27$ & \\
\hline
\end{tabular}



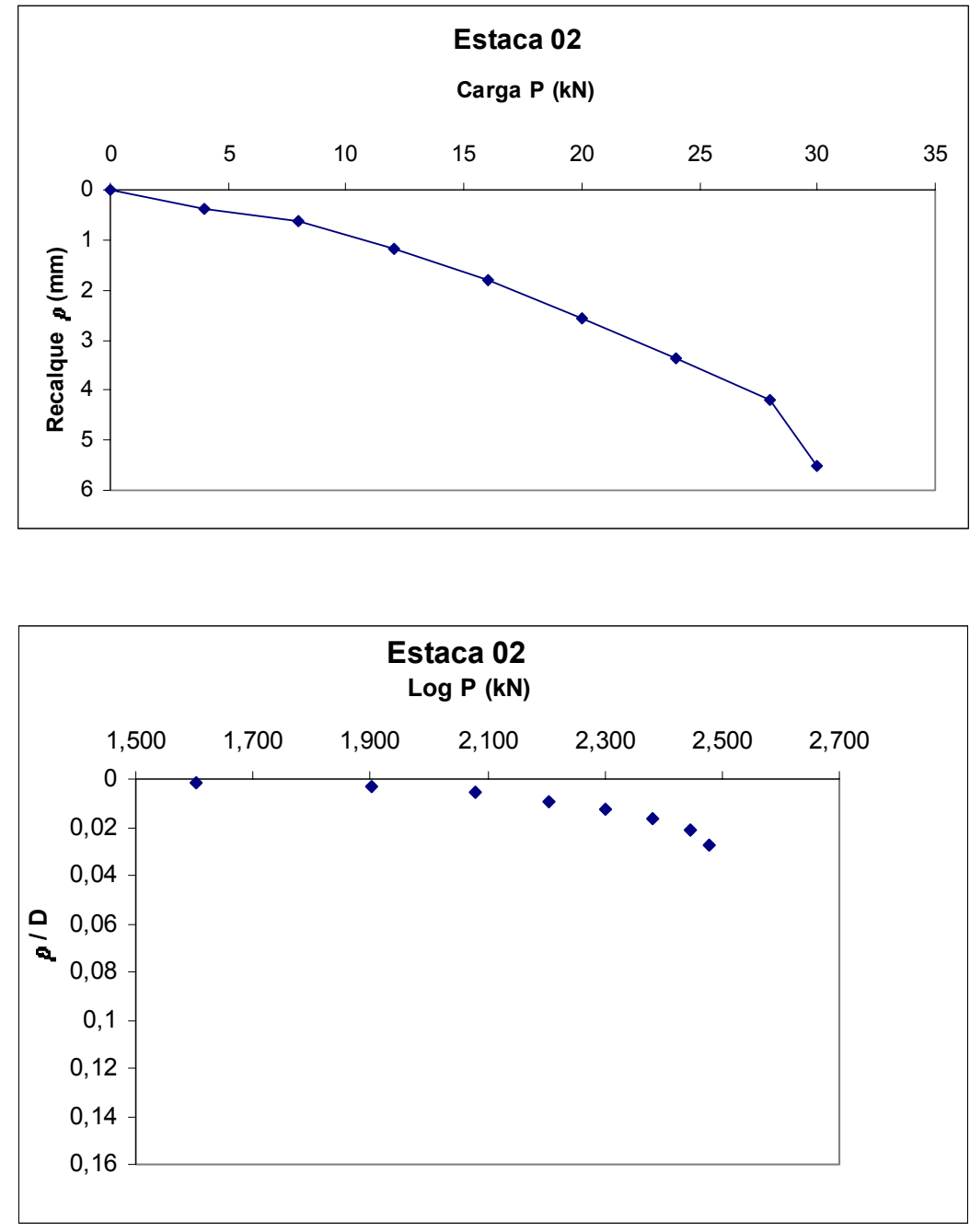

\begin{tabular}{c|c}
\hline \multicolumn{2}{c}{$\mathrm{D}=20 \mathrm{~cm}$} \\
$\mathrm{~L}=12,9 \mathrm{~m}$
\end{tabular}



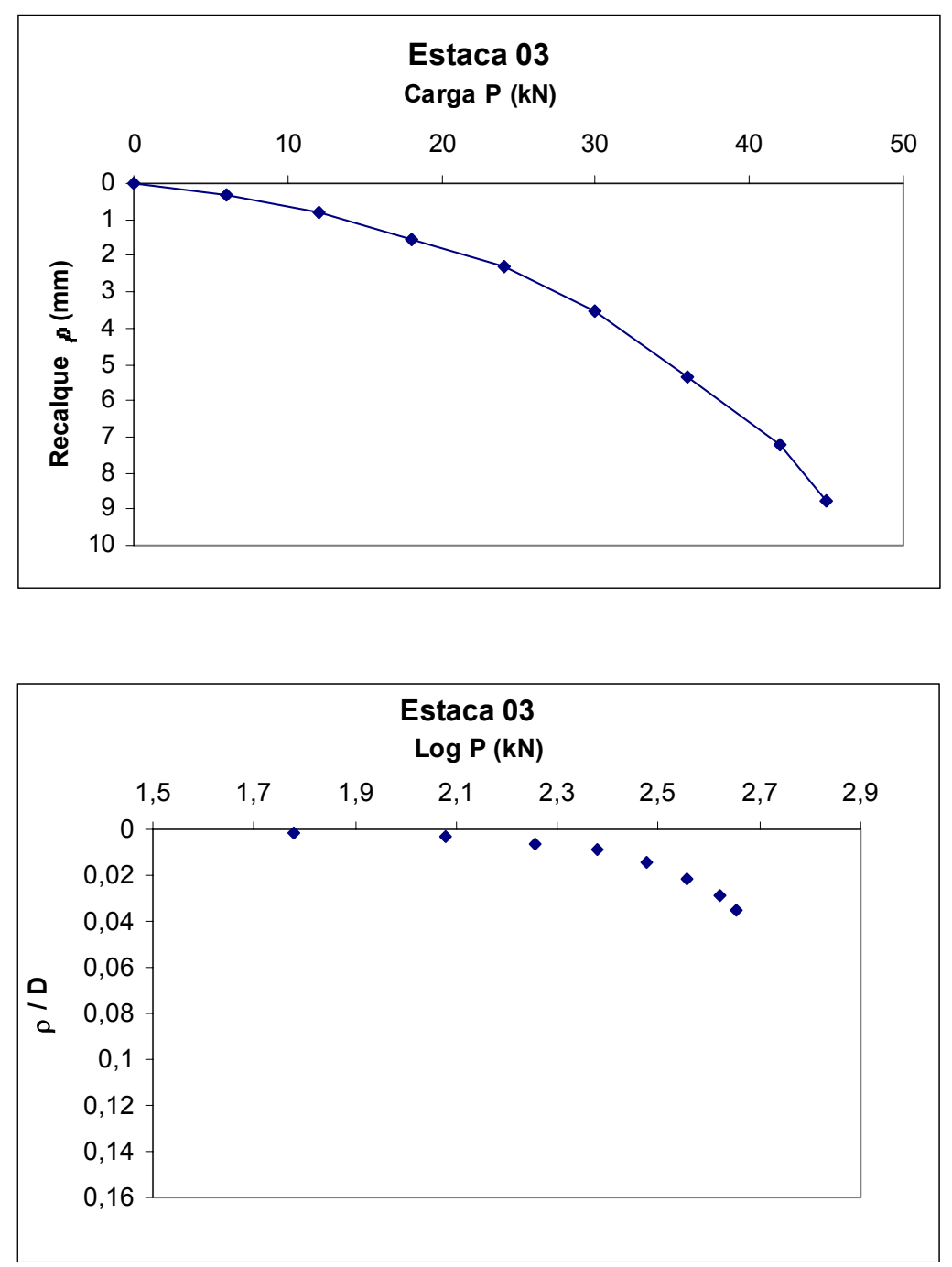

\begin{tabular}{c|c}
\hline \multicolumn{2}{c}{$\mathrm{D}=25 \mathrm{~cm}$} \\
$\mathrm{~L}=12,9 \mathrm{~m}$ \\
\hline N sPT & Tipo de solo \\
\hline $4 / 23$ & Argila siltosa com areia fina, conza, mole \\
4 & \\
$3 / 33$ & \\
2 & \\
$2 / 40$ & \\
$2 / 29$ & \\
3 & \\
4 & \\
3 & \\
3 & \\
4 & \\
9 & \\
11 & \\
10 & \\
11 & \\
10 & \\
9 & \\
22 & Silte argileso argiloso com areia fina, variegado, fofo \\
$28 / 22$ & \\
\cline { 2 - 2 } & \\
\cline { 2 - 2 } & \\
\hline
\end{tabular}



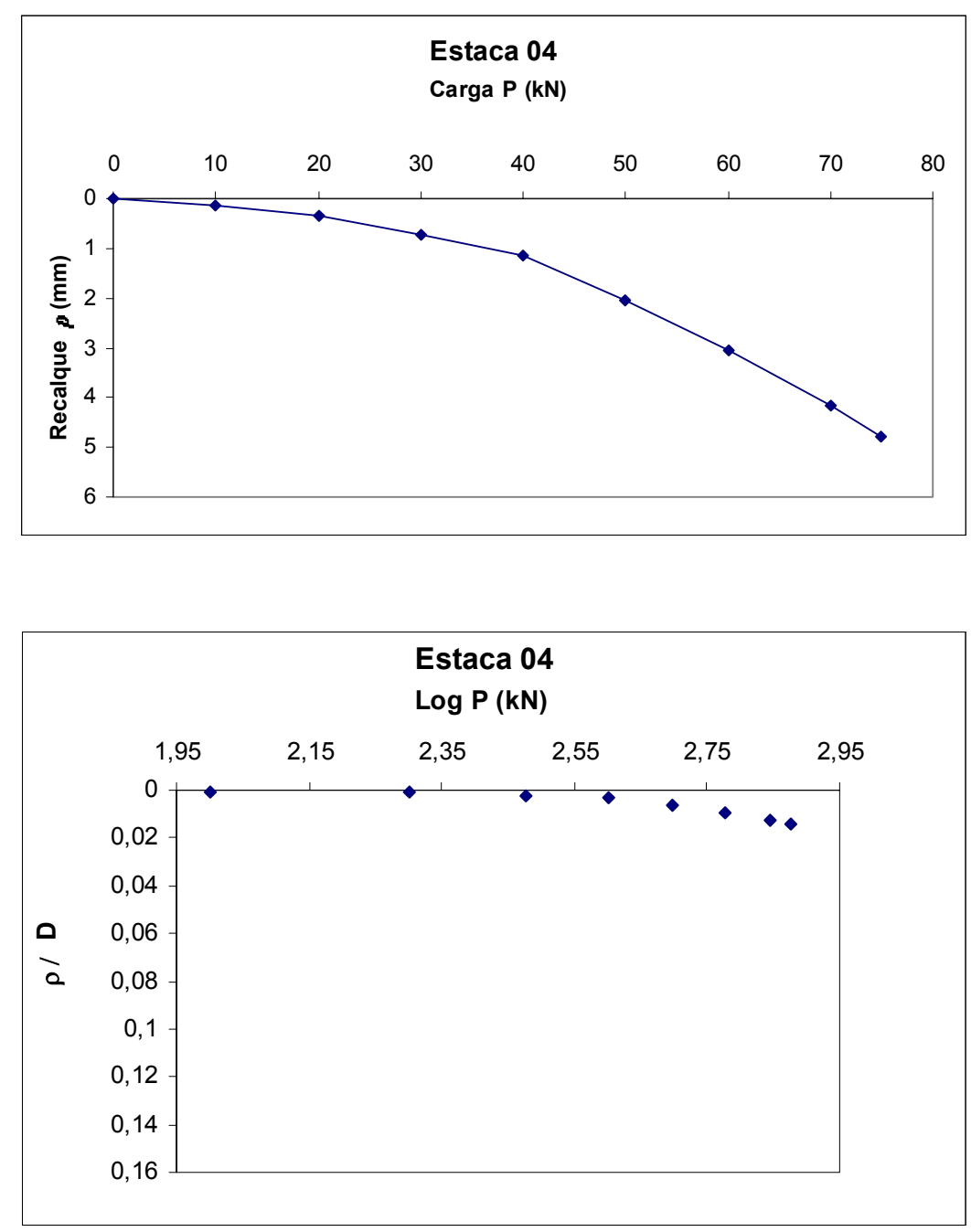

\begin{tabular}{c|c}
\hline \multicolumn{2}{c}{$\mathrm{D}=33 \mathrm{~cm}$} \\
$\mathrm{~L}=12 \mathrm{~m}$ \\
\hline $\mathrm{N}_{\text {SPT }}$ \\
\hline 0 & \\
0 & Argila orgânica siltosa muito mole preta \\
0 & \\
9 & \\
\cline { 2 - 2 } 2 & \\
\cline { 2 - 2 } 22 & Silte argiloso médio verde \\
\cline { 2 - 2 } 26 & Silte argiloso duro verde \\
\cline { 2 - 2 } 27 & Silte argiloso duro amarelo e cinza \\
\cline { 2 - 2 }
\end{tabular}



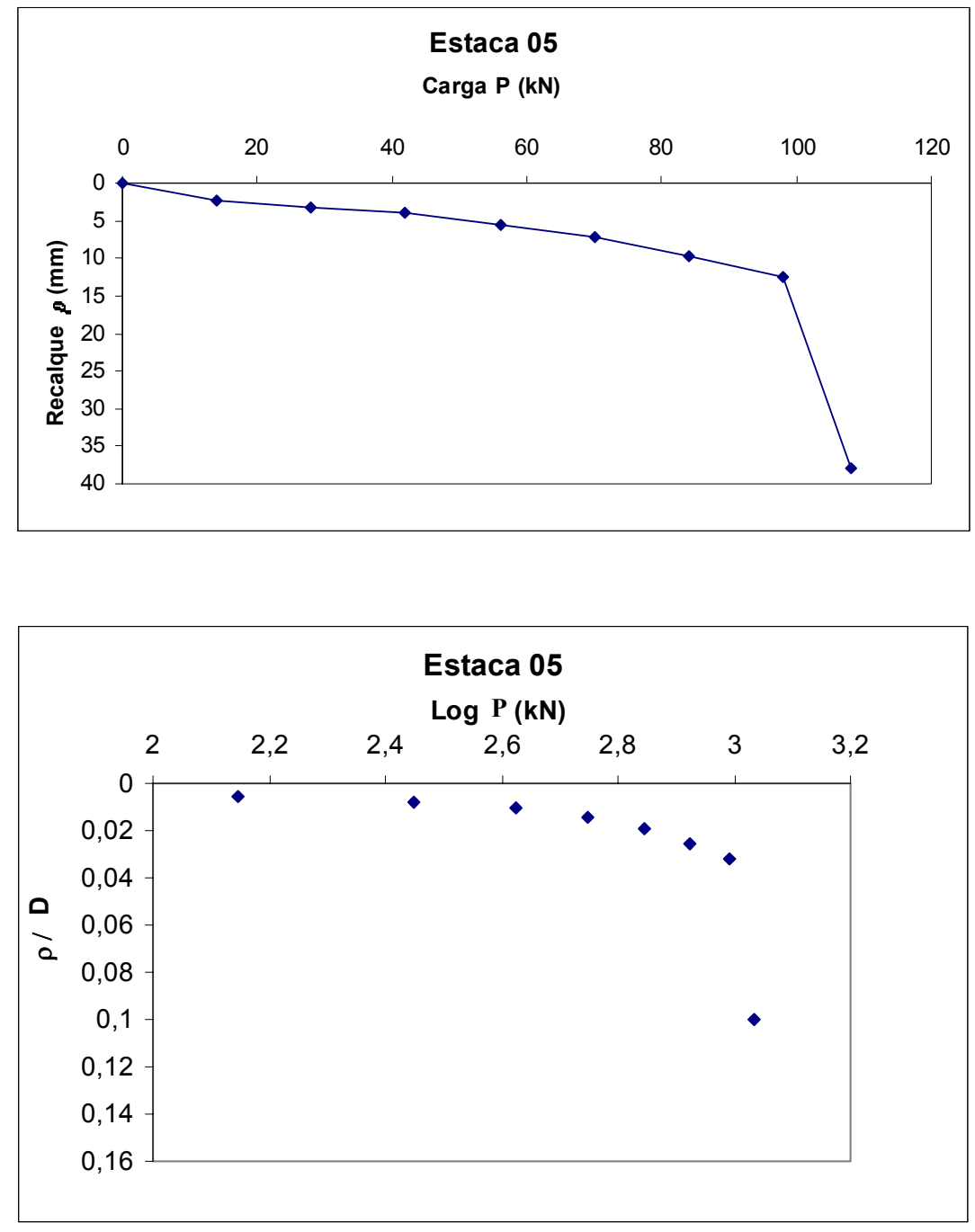

\begin{tabular}{c|c}
\hline \multicolumn{2}{c}{$\mathrm{D}=38 \mathrm{~cm}$} \\
$\mathrm{~L}=10 \mathrm{~m}$ \\
\hline $\mathrm{N}_{\mathrm{SPT}}$ & Tipo de solo \\
\hline 0 & \\
0 & \\
0 & \\
9 & Srgila orgânica siltosa muito mole preta \\
9 & \\
\cline { 2 - 2 } 22 & Silte argiloso médio verde \\
\cline { 2 - 2 } 36 & Silte argiloso duro amarelo e cinza \\
\hline 27 & Silte argiloso duro amarelo \\
\hline
\end{tabular}



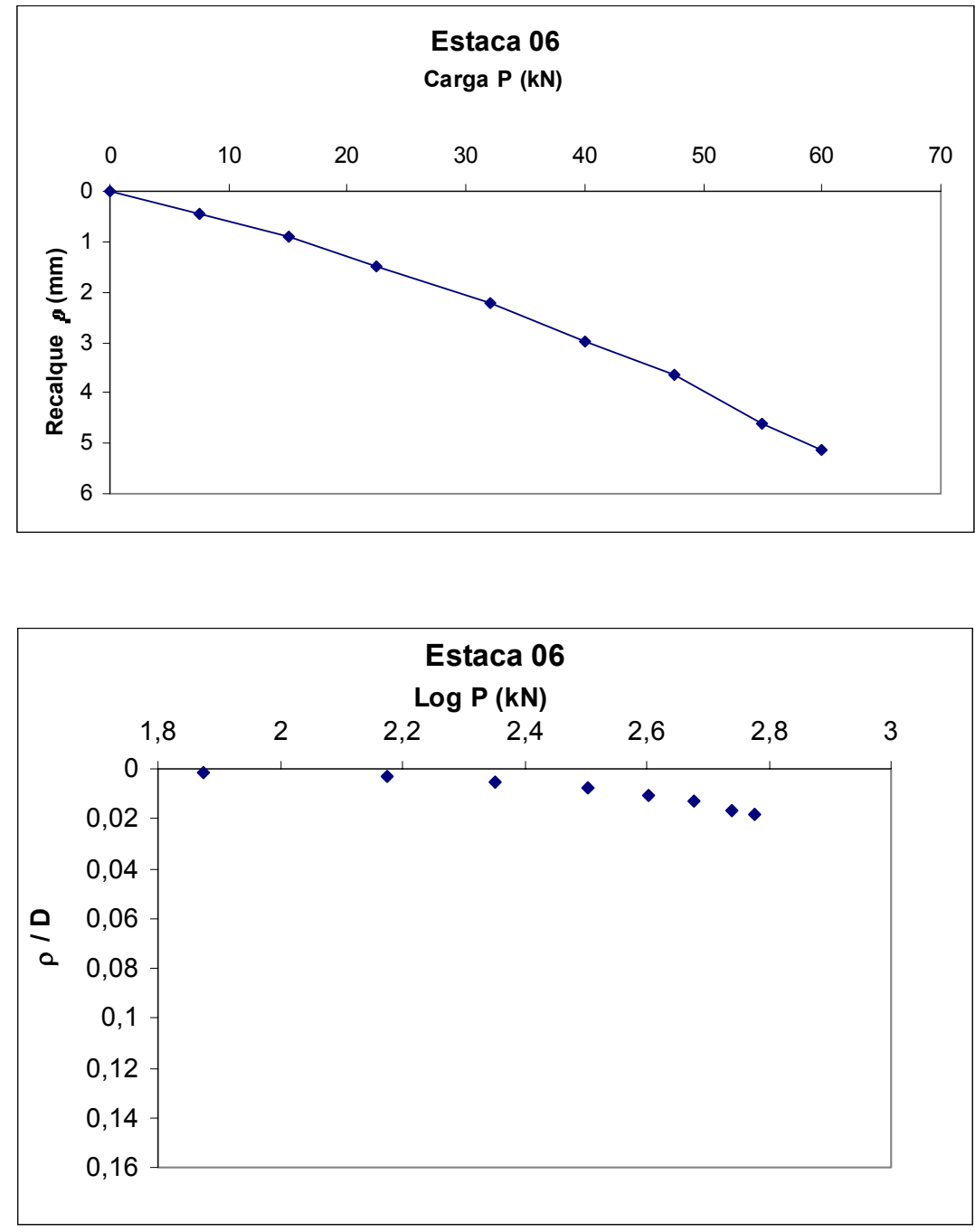

\begin{tabular}{c|c}
\hline \multicolumn{2}{c}{$\mathrm{D}=28 \mathrm{~cm}$} \\
$\mathrm{~L}=10 \mathrm{~m}$ \\
\hline N sPT & Tipo de solo \\
\hline 0 & \\
2 & \\
14 & \\
17 & Argila orgânica siltosa muito mole preta \\
10 & \\
\cline { 2 - 2 } 12 & \\
\cline { 2 - 2 } 13 & \\
18 & \\
21 & \\
\hline
\end{tabular}



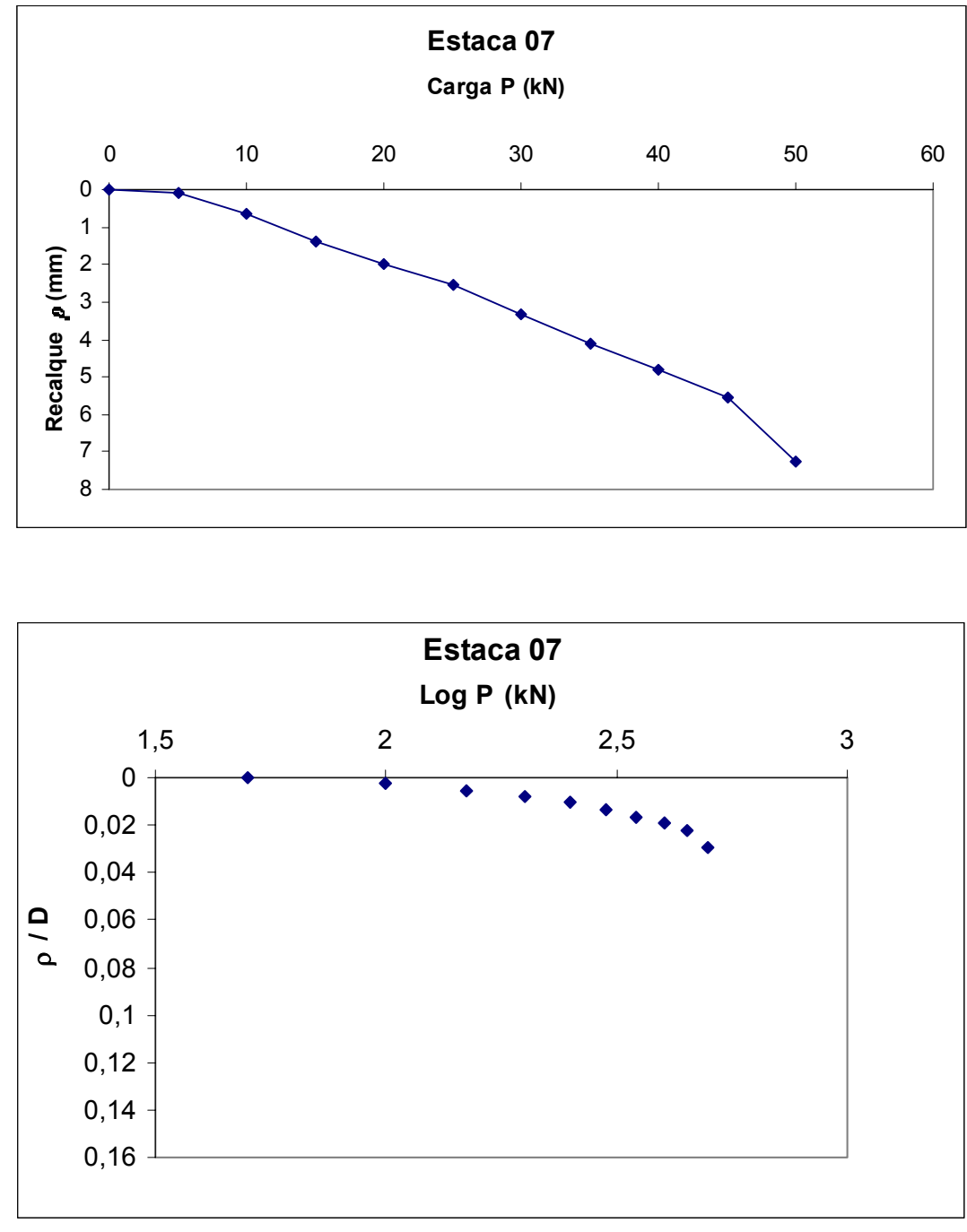

\begin{tabular}{c|c}
\hline \multicolumn{2}{c}{$\begin{array}{c}\mathrm{D}=25 \mathrm{~cm} \\
\mathrm{~L}=16,2 \mathrm{~m}\end{array}$} \\
\hline $\mathrm{N}$ SPT & Tipo de solo \\
\hline 5 & Argila siltosa com areia fina, variegada, consistência média e \\
7 & \\
6 & \\
5 & \\
4 & \\
5 & \\
6 & \\
7 & \\
14 & \\
8 & \\
7 & \\
9 & \\
14 & \\
19 & \\
35 & \\
42 & \\
$43 / 23$ & Silte argiloso com areia fina, variegado, medianamente compacto \\
\cline { 2 - 2 } & \\
\cline { 2 - 2 } & \\
\hline
\end{tabular}



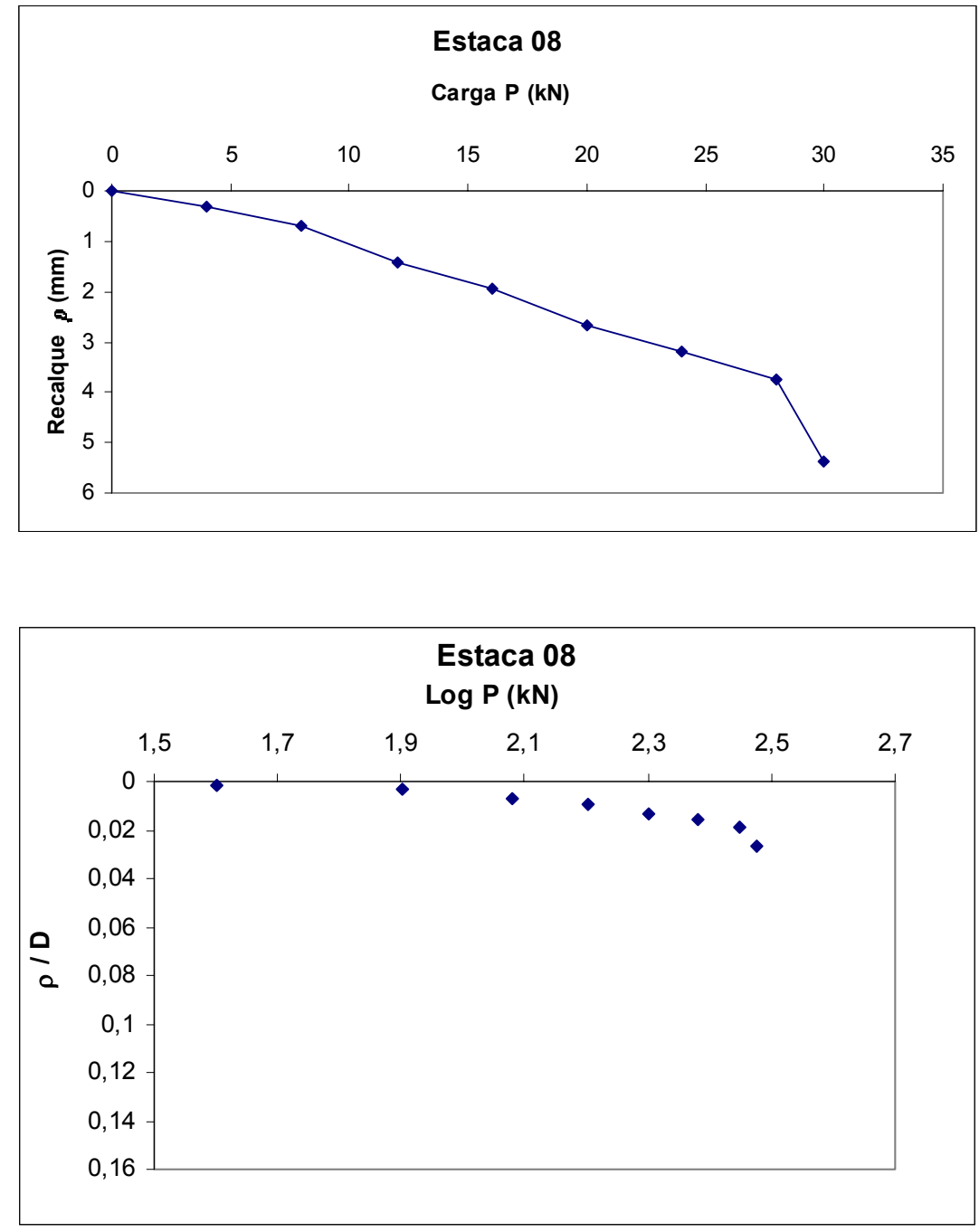

\begin{tabular}{c|c}
\hline \multicolumn{2}{c}{$\mathrm{D}=20 \mathrm{~cm}$} \\
$\mathrm{~L}=13 \mathrm{~m}$ \\
\hline $\mathrm{N}$ SPT & Tipo de solo \\
\hline 4 & Argila siltosa com areia fina e pedregulho, variegada, \\
6 & \\
7 & \\
17 & \\
$6 / 15$ & Areia arg. com silte e ped. variegada med. compacta média \\
\cline { 2 - 2 } 7 & Argila siltosa com areia fina e pedregulho, cinza rija \\
13 & \\
17 & \\
24 & \\
\cline { 2 - 2 } 10 & Arg. silt. Com areia fina e ped. cinza muito rija a cons. média \\
\cline { 2 - 2 } 15 & Areia argilosa com silte pedregulho, cinza, medianamente \\
13 & \\
12 & \\
\cline { 2 - 2 } 14 & compacta \\
17 & \\
21 & \\
\cline { 2 - 2 } $30 / 27$ & Argila siltosa com areia fina e pedregulho variegada rija \\
\hline
\end{tabular}




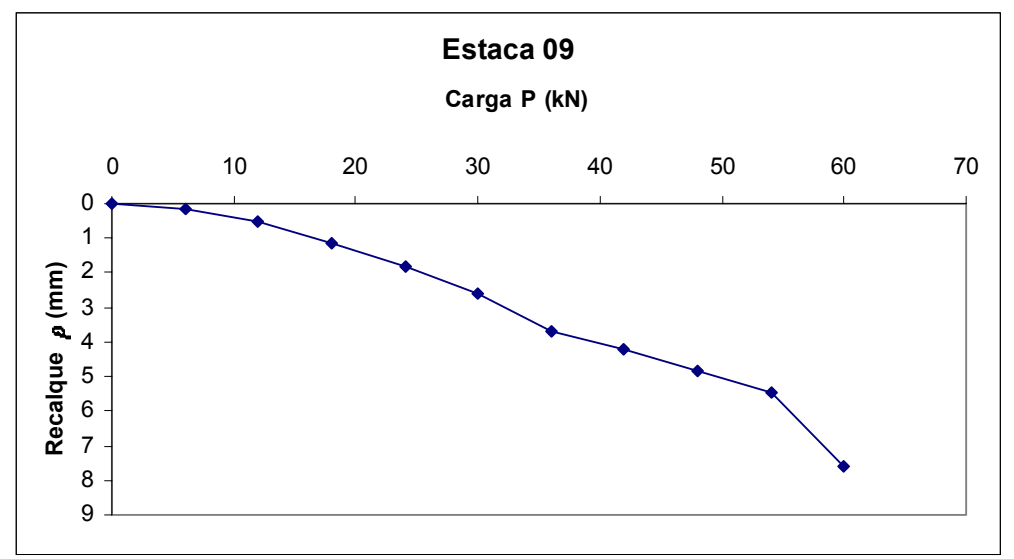

\begin{tabular}{|c|c|}
\hline \multicolumn{2}{|c|}{$\begin{array}{l}\mathrm{D}=25 \mathrm{~cm} \\
\mathrm{~L}=17,3 \mathrm{~m}\end{array}$} \\
\hline $\mathrm{N}_{\mathrm{SPT}}$ & Tipo de solo \\
\hline 8 & Aterro - argila silto-arenosa variegada \\
\hline 7 & \multirow[t]{4}{*}{ Argila siltosa com areia fina cinza escura consistência média } \\
\hline 6 & \\
\hline 13 & \\
\hline 12 & \\
\hline 9 & \multirow{3}{*}{$\begin{array}{c}\text { Areia média e grossa, siltosa com pedregulho, variegada, } \\
\text { medianamente compacta }\end{array}$} \\
\hline 8 & \\
\hline 4 & \\
\hline 5 & \multirow{4}{*}{$\begin{array}{l}\text { Argila siltosa com areia fina, variegada, mole e consistência } \\
\text { média }\end{array}$} \\
\hline 5 & \\
\hline 7 & \\
\hline 6 & \\
\hline 8 & \multirow[t]{8}{*}{ Silte argiloso com areia fina, variegado, medianamente compacto } \\
\hline 13 & \\
\hline 12 & \\
\hline 14 & \\
\hline 10 & \\
\hline 17 & \\
\hline 15 & \\
\hline 18 & \\
\hline 20 & \multirow[t]{3}{*}{ Silte argiloso com areia fina, variegado compacto } \\
\hline 23 & \\
\hline 22 & \\
\hline $53 / 19$ & \multirow{5}{*}{$\begin{array}{l}\begin{array}{l}\text { Silte argiloso com areia fina, variegado muito compacto e } \\
\text { compacto }\end{array}\end{array}$} \\
\hline 26 & \\
\hline 43 & \\
\hline 25 & \\
\hline $30 / 23$ & \\
\hline
\end{tabular}

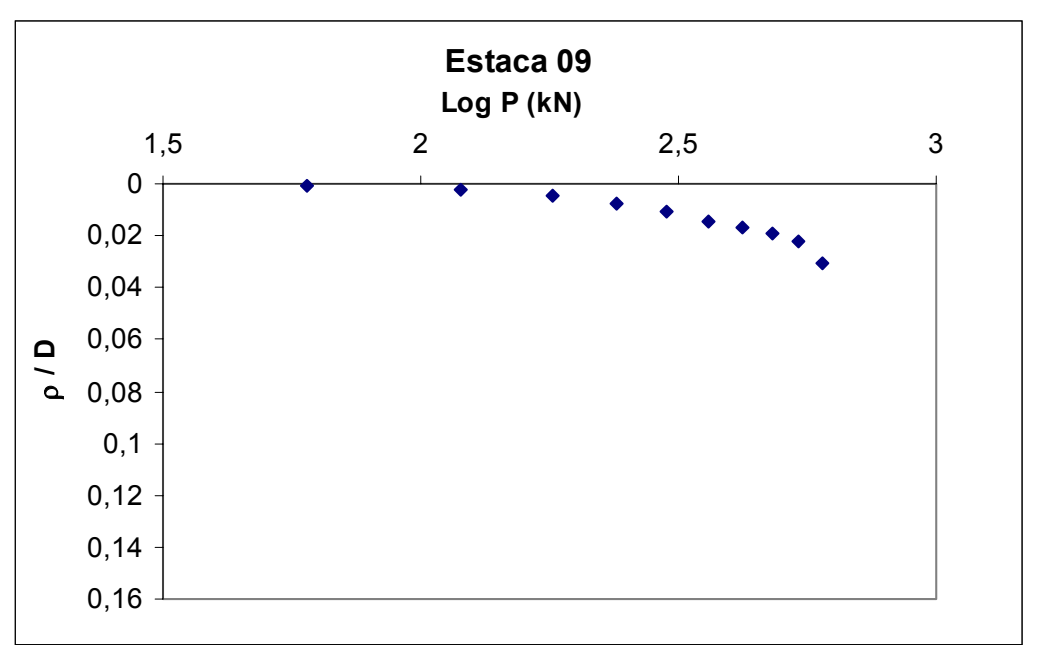



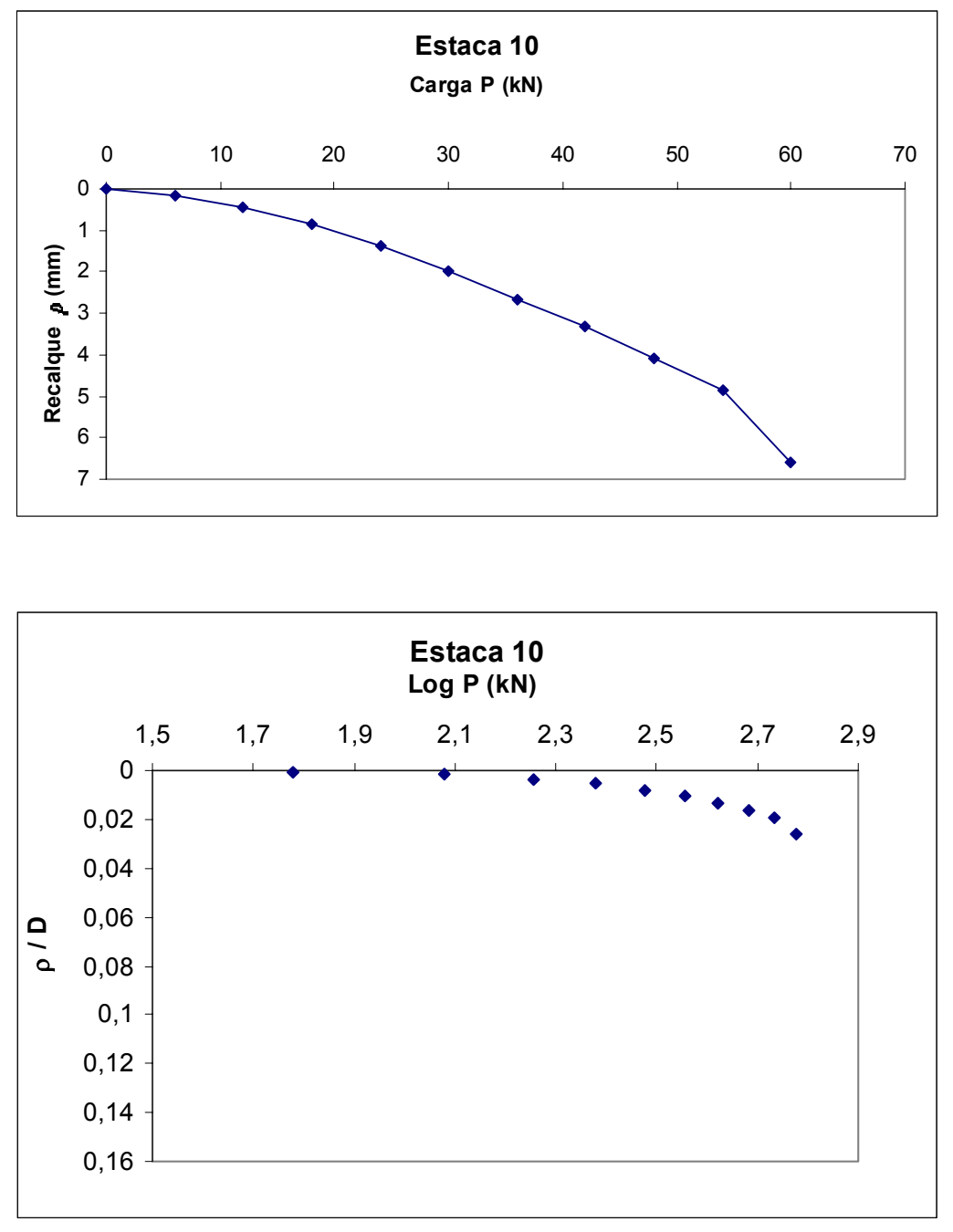

\begin{tabular}{c|c}
\hline \multicolumn{2}{c}{$\mathrm{D}=25 \mathrm{~cm}$} \\
$\mathrm{~L}=15,75 \mathrm{~m}$ \\
\hline $\mathrm{N}$ SPT & Tipo de solo \\
\hline 16 & Argila siltosa com areia fina, variegada, rija \\
15 & \\
8 & \\
6 & \\
2 & Argila silto - arenosa, variegada, muito mole \\
2 & \\
2 & \\
$4 / 15$ & \\
10 & \\
9 & \\
7 & \\
10 & \\
11 & \\
7 & \\
8 & \\
19 & \\
20 & \\
19 & \\
25 & \\
31 & \\
$30 / 23$ & argila siltosa com areia grossa, variegada, média \\
$30 / 10$ & \\
$30 / 15$ & \\
\cline { 2 - 2 } & \\
\hline
\end{tabular}




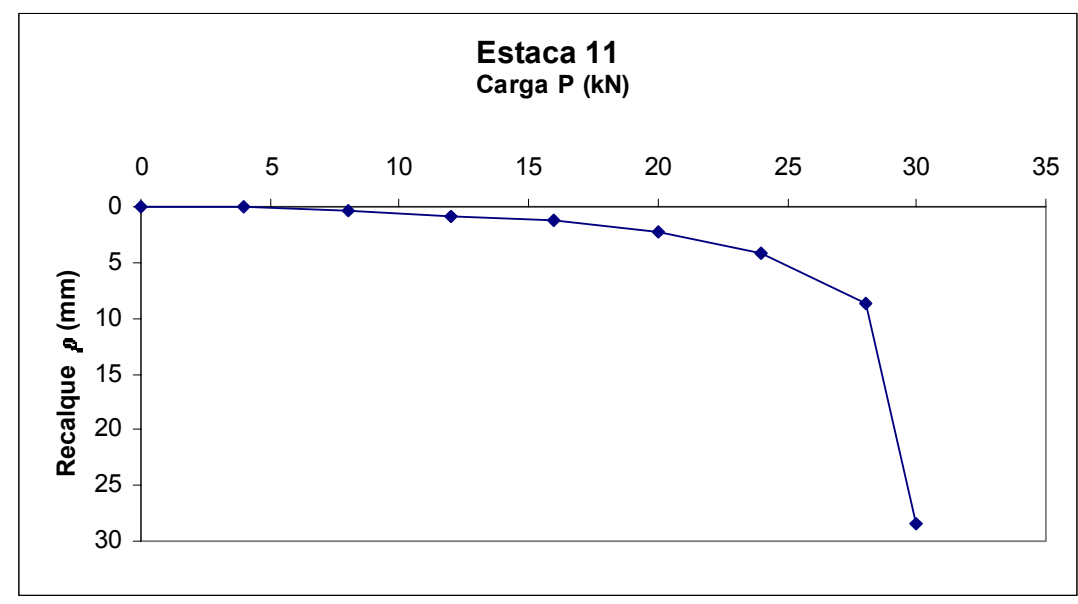

\begin{tabular}{c|c}
\hline \multicolumn{2}{c}{$\mathrm{D}=20 \mathrm{~cm}$} \\
$\mathrm{~L}=12 \mathrm{~m}$ \\
\hline N SPT & Tipo de solo \\
\hline $4 / 15$ & Aterro - Argila siltosa orgânica com areia fina, preta, muito mole \\
\cline { 2 - 2 } 3 & Aterro - Argila orgânica, cinza escura \\
\cline { 2 - 2 } 2 & \\
4 & \\
5 & \\
4 & \\
2 & \\
2 & \\
5 & \\
14 & \\
20 & \\
22 & \\
\cline { 2 - 2 } 20 & \\
25 & \\
31 & \\
36 & \\
43 & \\
\hline
\end{tabular}

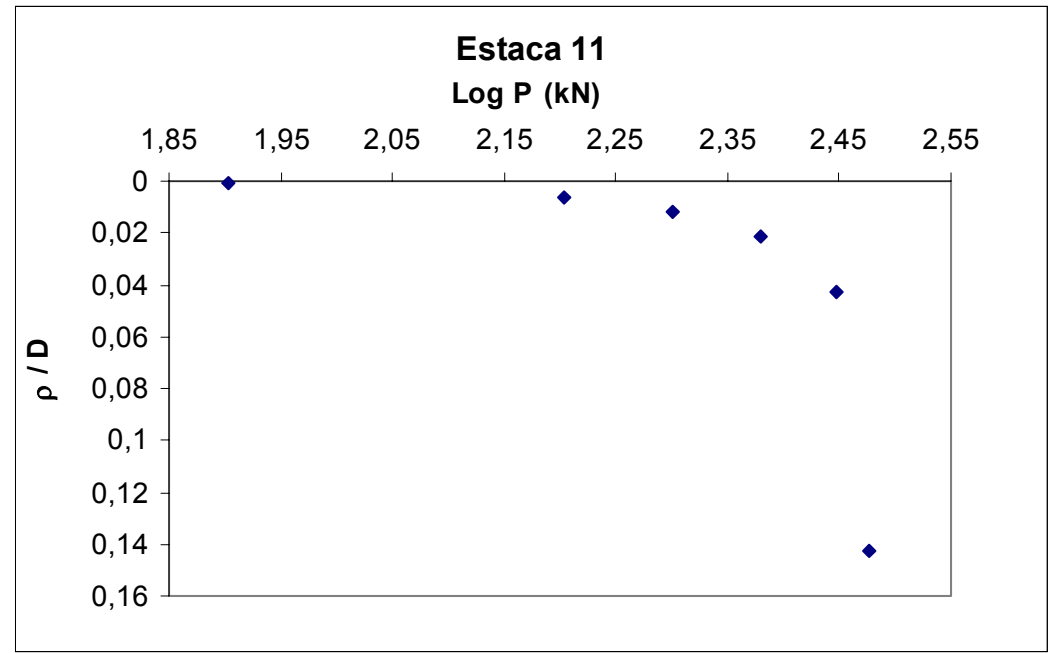



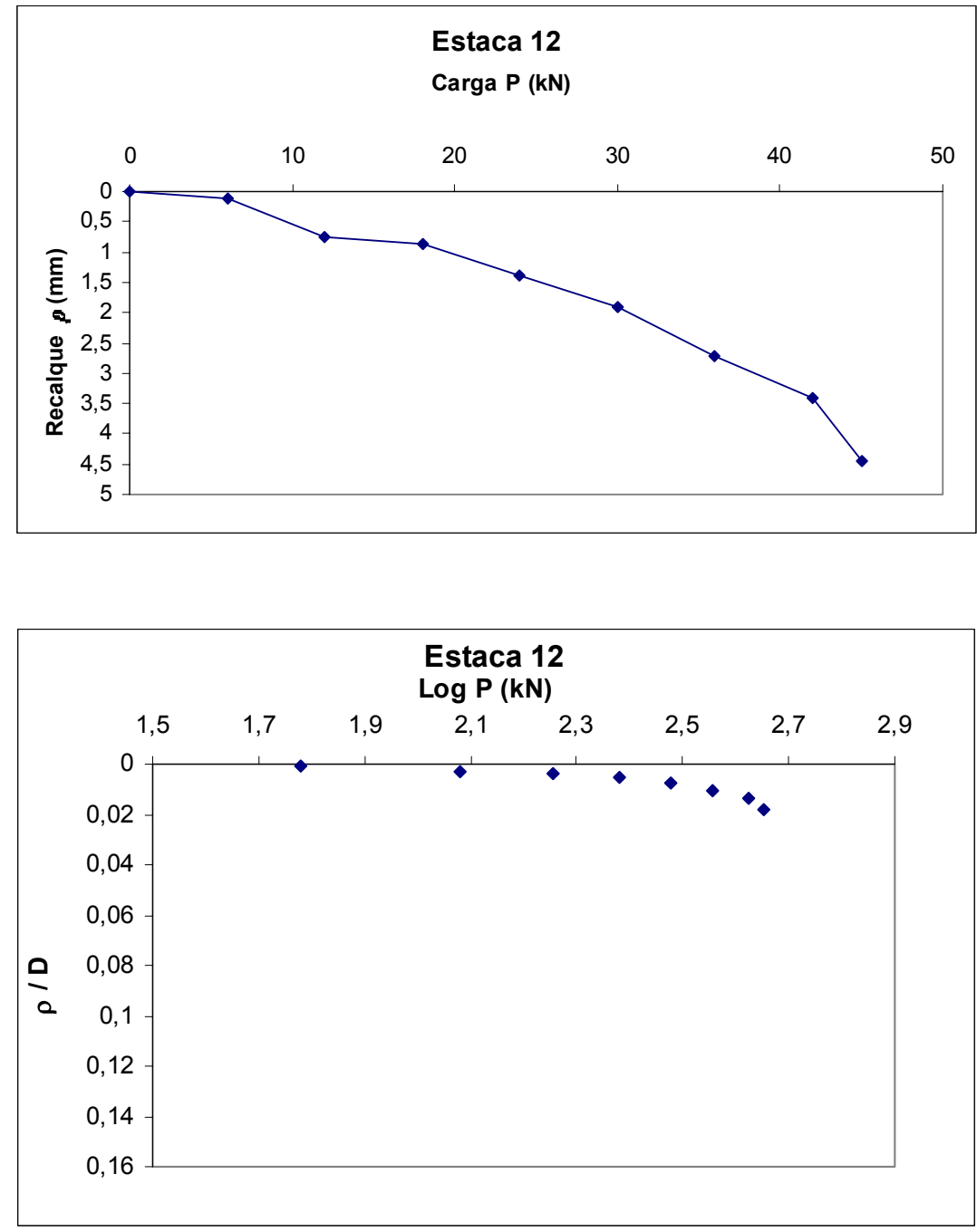

\begin{tabular}{c|c}
\hline \multicolumn{2}{c}{$\mathrm{D}=25 \mathrm{~cm}$} \\
$\mathrm{~L}=14 \mathrm{~m}$ \\
\hline N SPT & Tipo de solo \\
\hline $4 / 15$ & Aterro - Argila siltosa orgânica com areia fina, preta, muito mole \\
\cline { 2 - 2 } 3 & Aterro - Argila orgânica, cinza escura \\
\cline { 2 - 2 } 2 & Silte argiloso com areia fina e variegado, fofo \\
\cline { 2 - 2 } 5 & \\
5 & \\
4 & \\
2 & \\
2 & \\
5 & \\
14 & \\
20 & \\
22 & \\
\cline { 2 - 2 } 20 & \\
25 & \\
31 & \\
36 & \\
43 & \\
\hline
\end{tabular}



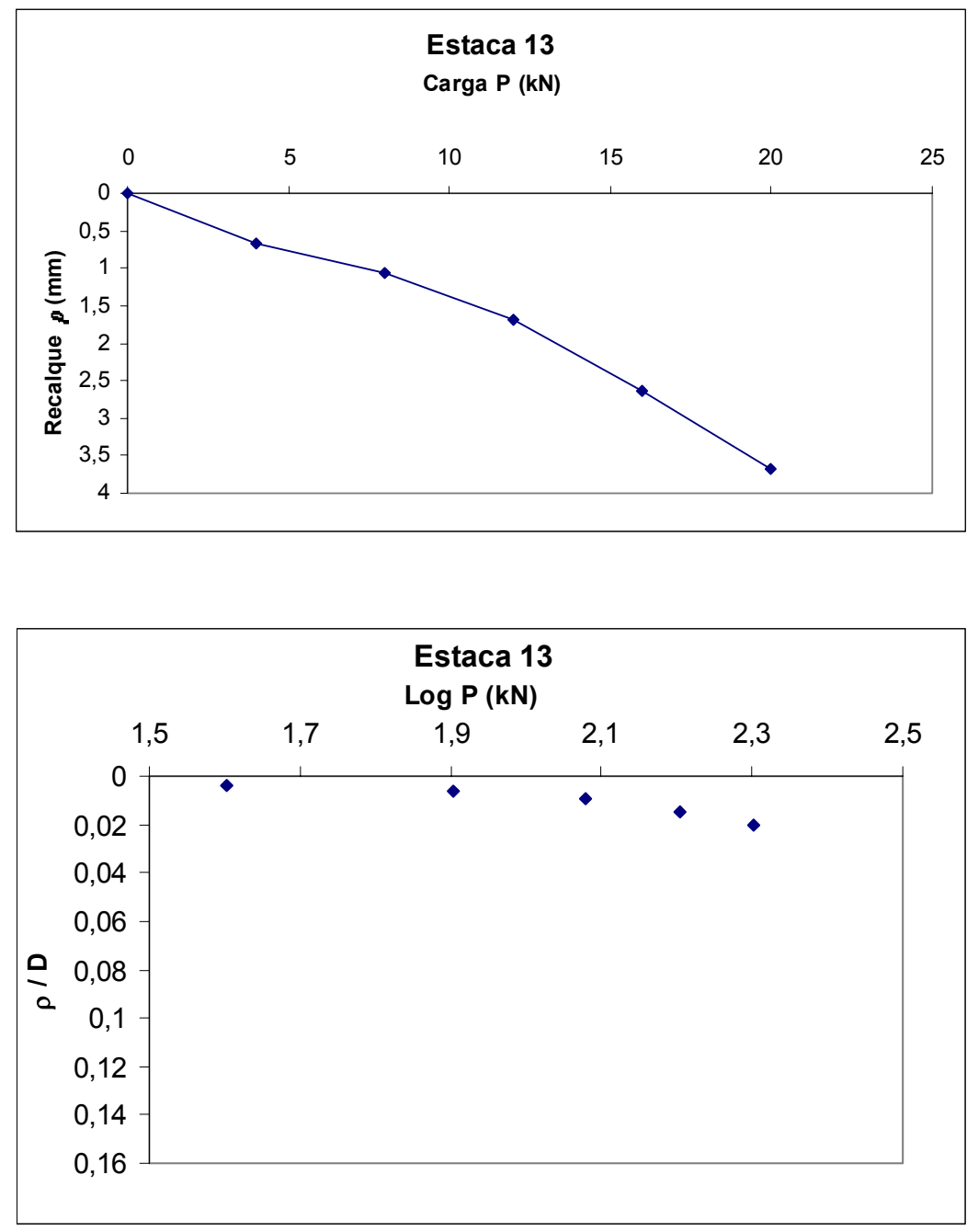

\begin{tabular}{|c|c|}
\hline \multicolumn{2}{|c|}{$\begin{aligned} \mathrm{D} & =18 \mathrm{~cm} \\
\mathrm{~L} & =11 \mathrm{~m}\end{aligned}$} \\
\hline $\mathrm{N}_{\mathrm{SPT}}$ & Tipo de solo \\
\hline- & $\begin{array}{l}\text { Solo superficial } \\
\end{array}$ \\
\hline- & Argila orgânica siltosa, pouco arenosa, muito mole, preta \\
\hline 2 & Idem, arenosa, marrom e cinza \\
\hline 4 & Idem, mole \\
\hline 5 & Argila Siltosa, pouco arenosa, mole, cinza \\
\hline 8 & \\
\hline 4 & Idem, consistência média \\
\hline 13 & Idem, Rija \\
\hline 15 & \\
\hline 18 & \\
\hline 25 & Idem, dura \\
\hline 24 & \\
\hline 23 & Idem, arenosa \\
\hline 28 & \\
\hline 36 & \\
\hline 30 & Idem, pouco arenosa \\
\hline 28 & \\
\hline 30 & Idem, arenosa \\
\hline 33 & \\
\hline 36 & \\
\hline
\end{tabular}



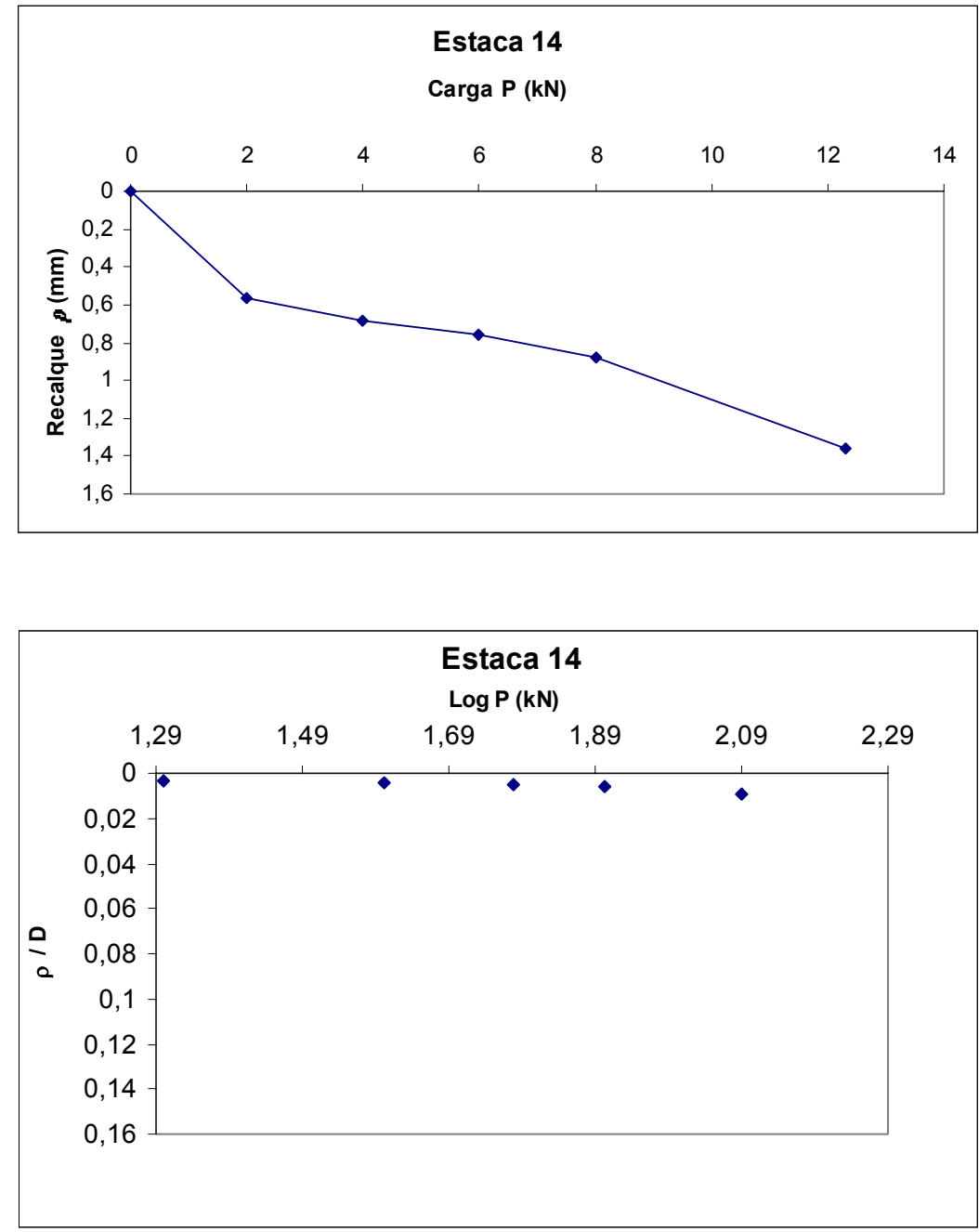

\begin{tabular}{|c|c|}
\hline \multicolumn{2}{|c|}{$\begin{aligned} \mathrm{D} & =15 \mathrm{~cm} \\
\mathrm{~L} & =10 \mathrm{~m}\end{aligned}$} \\
\hline$\overline{N_{\text {SPT }}}$ & Tipo de solo \\
\hline- & Aterro de materiais diversos \\
\hline- & Argila orgânica siltosa, pouco arenosa, muito mole, preta \\
\hline 6 & \\
\hline 6 & \\
\hline 7 & Idem, cinza \\
\hline 10 & \\
\hline 13 & Idem, rija, marrom \\
\hline 14 & \\
\hline 15 & Idem, amarela \\
\hline 18 & Idem, cinza \\
\hline 21 & \\
\hline 23 & \\
\hline 24 & \\
\hline 26 & Idem, dura \\
\hline 29 & \\
\hline 33 & \\
\hline 39 & \\
\hline 35 & \\
\hline 31 & \\
\hline 34 & \\
\hline
\end{tabular}



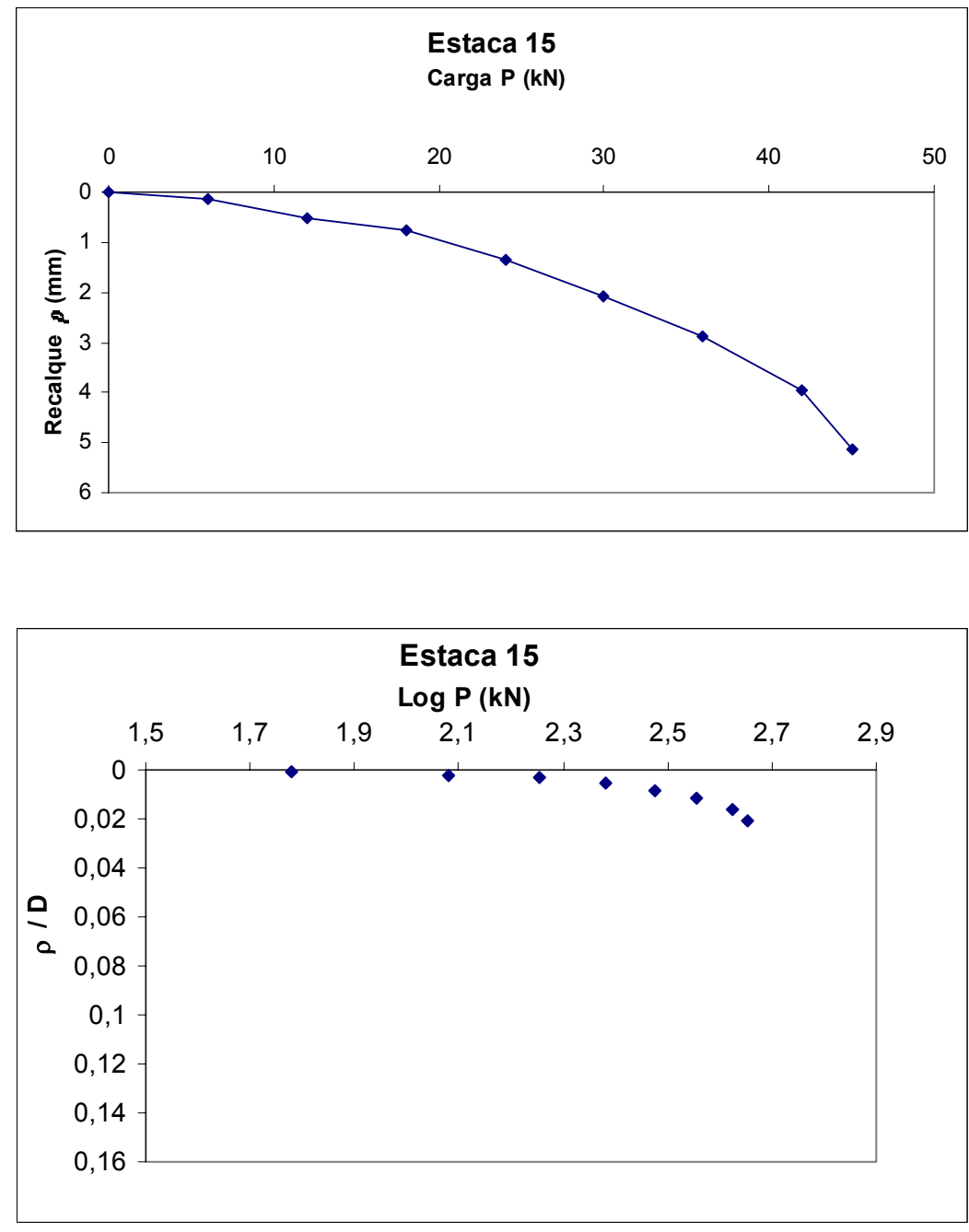

\begin{tabular}{c|c}
\hline \multicolumn{2}{c}{$\mathrm{D}=25 \mathrm{~cm}$} \\
$\mathrm{~L}=12 \mathrm{~m}$ \\
\hline N SPT & Tipo de solo \\
\hline 3 & Silte argiloso com areia fina e pedregulho, marrom, fofo \\
2 & \\
2 & \\
3 & \\
3 & \\
3 & Argila siltosa com areia fina, cinza, muito mole \\
9 & \\
\cline { 2 - 2 } 11 & Argila siltosa com areia fina e pedregulho, cinza, consistência \\
9 & média a rija \\
\cline { 2 - 2 } 10 & \\
9 & \\
11 & \\
18 & \\
19 & \\
21 & \\
23 & \\
25 & \\
43 & \\
49 & \\
\cline { 2 - 2 } & \\
\hline
\end{tabular}



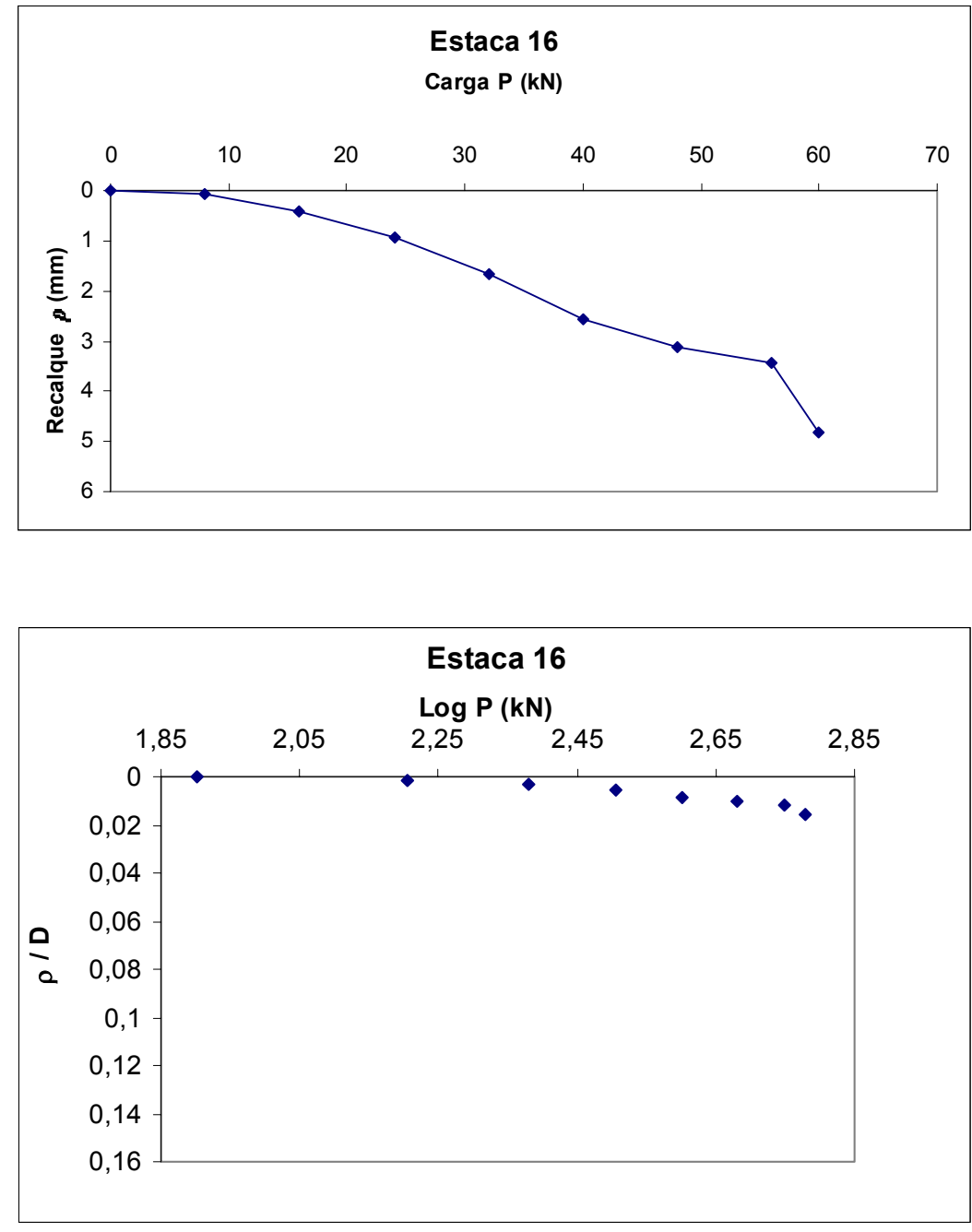

\begin{tabular}{c|c}
\hline \multicolumn{2}{c}{$\mathrm{D}=30 \mathrm{~cm}$} \\
$\mathrm{~L}=14 \mathrm{~m}$ \\
\hline $\mathrm{N}_{\mathrm{SPT}}$ & Tipo de solo \\
\hline \multicolumn{1}{c}{11} & Aterro - Argila siltosa com areia fina, rija à média \\
\cline { 2 - 2 } 7 & \\
\cline { 2 - 2 } 5 & \\
8 & \\
6 & \\
5 & \\
5 & \\
5 & \\
9 & \\
\cline { 2 - 2 } 11 & \\
13 & \\
16 & \\
12 & \\
23 & \\
31 & \\
30 & \\
27 & \\
37 & \\
\hline
\end{tabular}



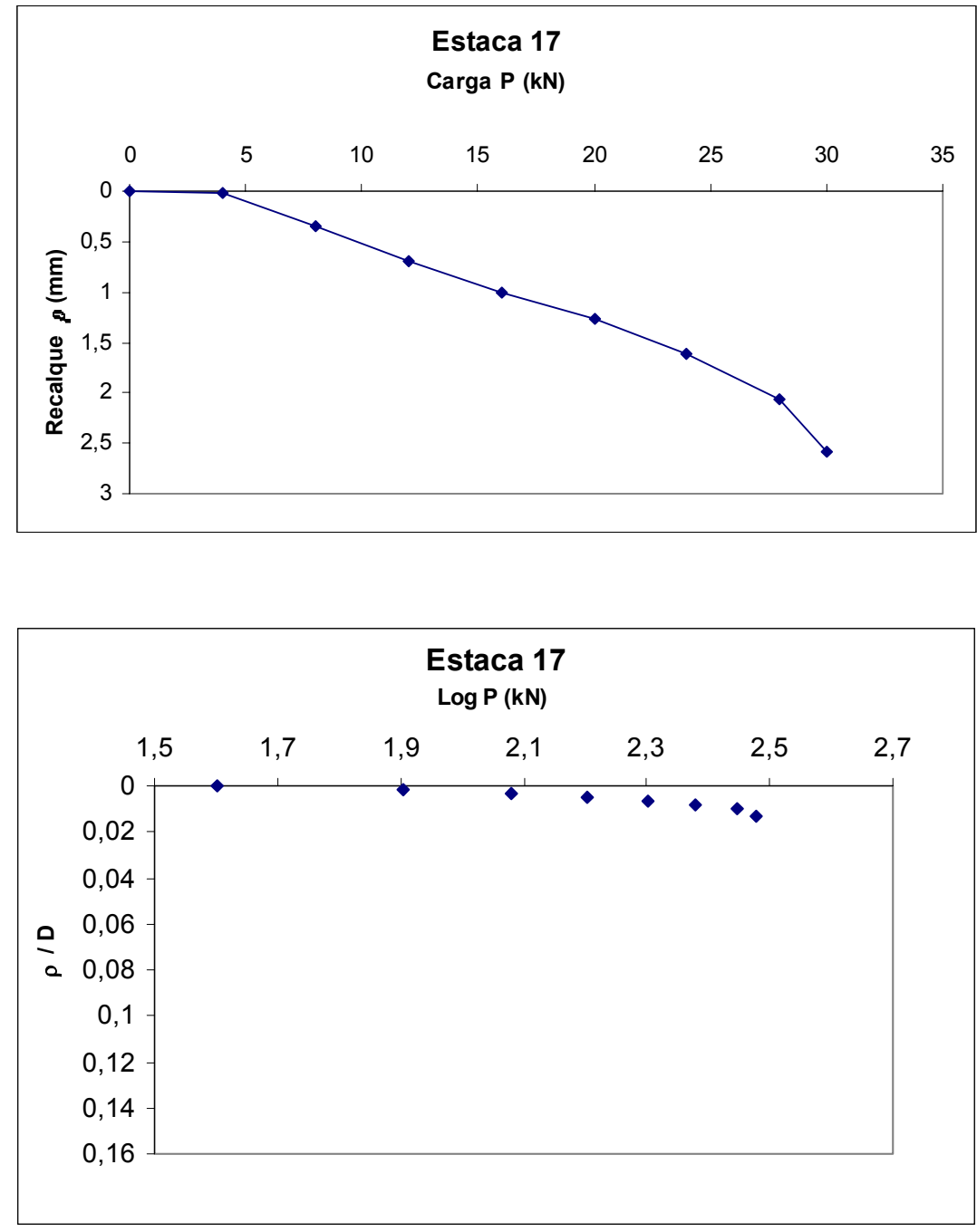

\begin{tabular}{|c|c|}
\hline \multicolumn{2}{|c|}{$\begin{array}{l}\mathrm{D}=20 \mathrm{~cm} \\
\mathrm{~L}=13 \mathrm{~m}\end{array}$} \\
\hline $\mathrm{N}_{\text {SPT }}$ & Tipo de solo \\
\hline 5 & \multirow{4}{*}{ Silte argiloso com areia fina, vermelho, pouco compacto e fofo } \\
\hline 4 & \\
\hline 5 & \\
\hline 4 & \\
\hline 6 & \multirow{4}{*}{ Argila Siltosa com areia fina, vermelha, média } \\
\hline 9 & \\
\hline 5 & \\
\hline 6 & \\
\hline 5 & \multirow{3}{*}{ Argila siltosa com areia grossa, variegada, média } \\
\hline 5 & \\
\hline 6 & \\
\hline 8 & \multirow[t]{2}{*}{ Argila siltosa com areia fina e média, variegada, média } \\
\hline 6 & \\
\hline 9 & \multirow{2}{*}{$\begin{array}{l}\text { Argila siltosa com areia de textura variegada, pedregulho e } \\
\text { fragmentos de rocha, variegada, média }\end{array}$} \\
\hline 7 & \\
\hline 5 & \multirow{3}{*}{ Argila siltosa com areia fina e média, variegada, rija à média } \\
\hline 12 & \\
\hline 7 & \\
\hline 8 & \multirow[t]{2}{*}{ Argila siltosa com areia fina e média, mica, variegada, média } \\
\hline 7 & \\
\hline 12 & \multirow{4}{*}{ Argila siltosa com areia fina e média, mica, variegada, rija } \\
\hline 14 & \\
\hline 17 & \\
\hline 15 & \\
\hline
\end{tabular}



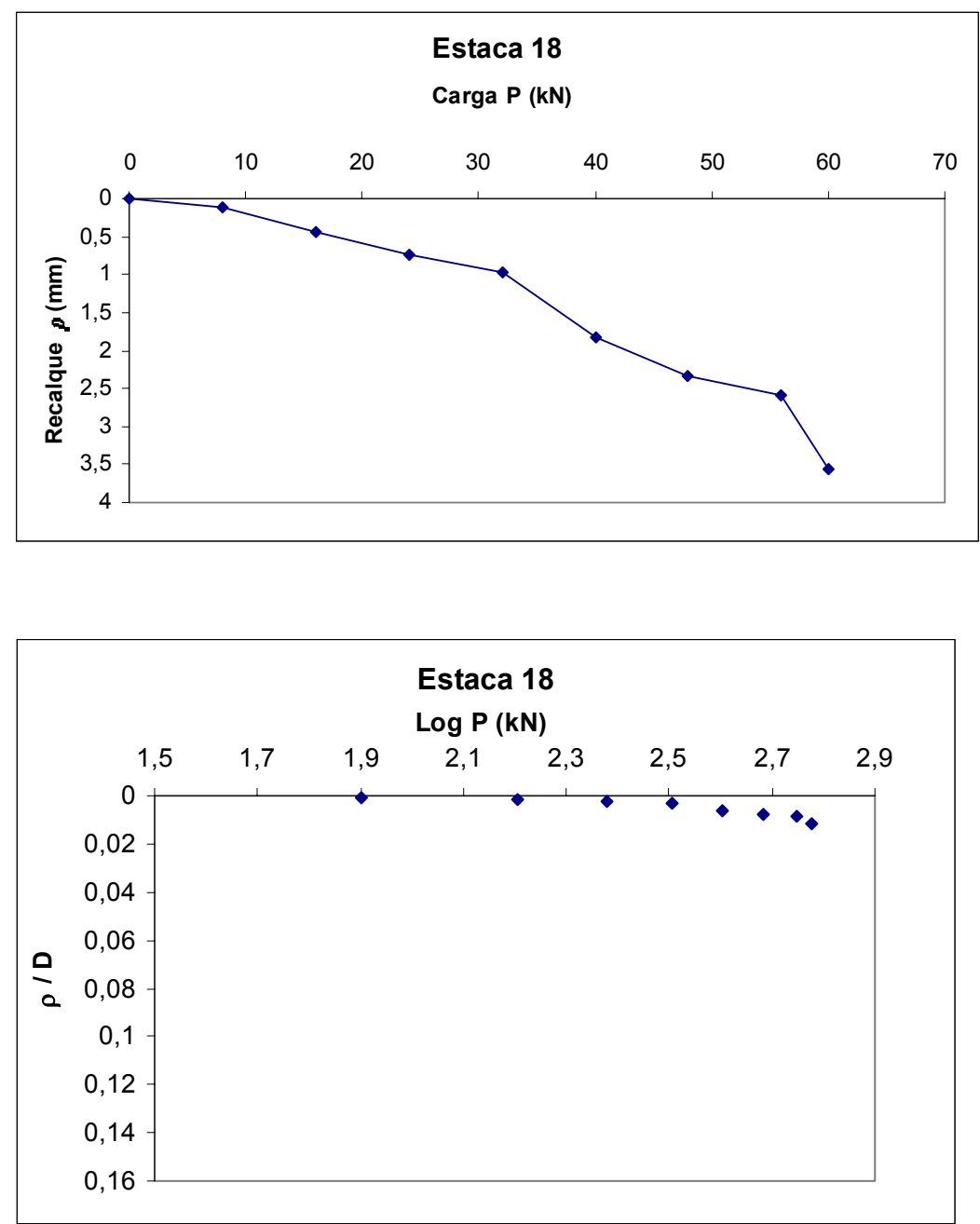

\begin{tabular}{|c|c|}
\hline \multicolumn{2}{|c|}{$\begin{array}{l}\mathrm{D}=30 \mathrm{~cm} \\
\mathrm{~L}=16 \mathrm{~m}\end{array}$} \\
\hline $\mathrm{N}_{\mathrm{SPT}}$ & $\begin{array}{l}\text { Tipo de solo } \\
\end{array}$ \\
\hline 2 & Silte argiloso com areia fina, vermelho, fofo \\
\hline 5 & Silte argiloso com areia fina, vermelho, pouco compacto \\
\hline 8 & \\
\hline 10 & \multirow{8}{*}{ Argila Siltosa com areia fina, variegada, média } \\
\hline 10 & \\
\hline 7 & \\
\hline 7 & \\
\hline 9 & \\
\hline 7 & \\
\hline 7 & \\
\hline 8 & \\
\hline 8 & \multirow[t]{3}{*}{ Argila siltosa com areia fina e média, variegada, média } \\
\hline 9 & \\
\hline 6 & \\
\hline 7 & \multirow{2}{*}{$\begin{array}{c}\text { Argila siltosa com areia de textura variada e pedregulho, } \\
\text { variegada, média }\end{array}$} \\
\hline 6 & \\
\hline 12 & \multirow[t]{2}{*}{$\begin{array}{l}\text { Areia de textura variada, pouco argilosa, variegada, } \\
\text { medianamente compacta }\end{array}$} \\
\hline 11 & \\
\hline $\begin{array}{l}15 \\
14\end{array}$ & $\begin{array}{c}\text { Argila siltosa com pedregulho, fragmentos de rocha, variegada, } \\
\text { rija }\end{array}$ \\
\hline 20 & \multirow[t]{3}{*}{ Argila siltosa com muita areia fina, variegada, rija } \\
\hline 21 & \\
\hline 21 & \\
\hline $33 / 25$ & Idem, dura \\
\hline
\end{tabular}



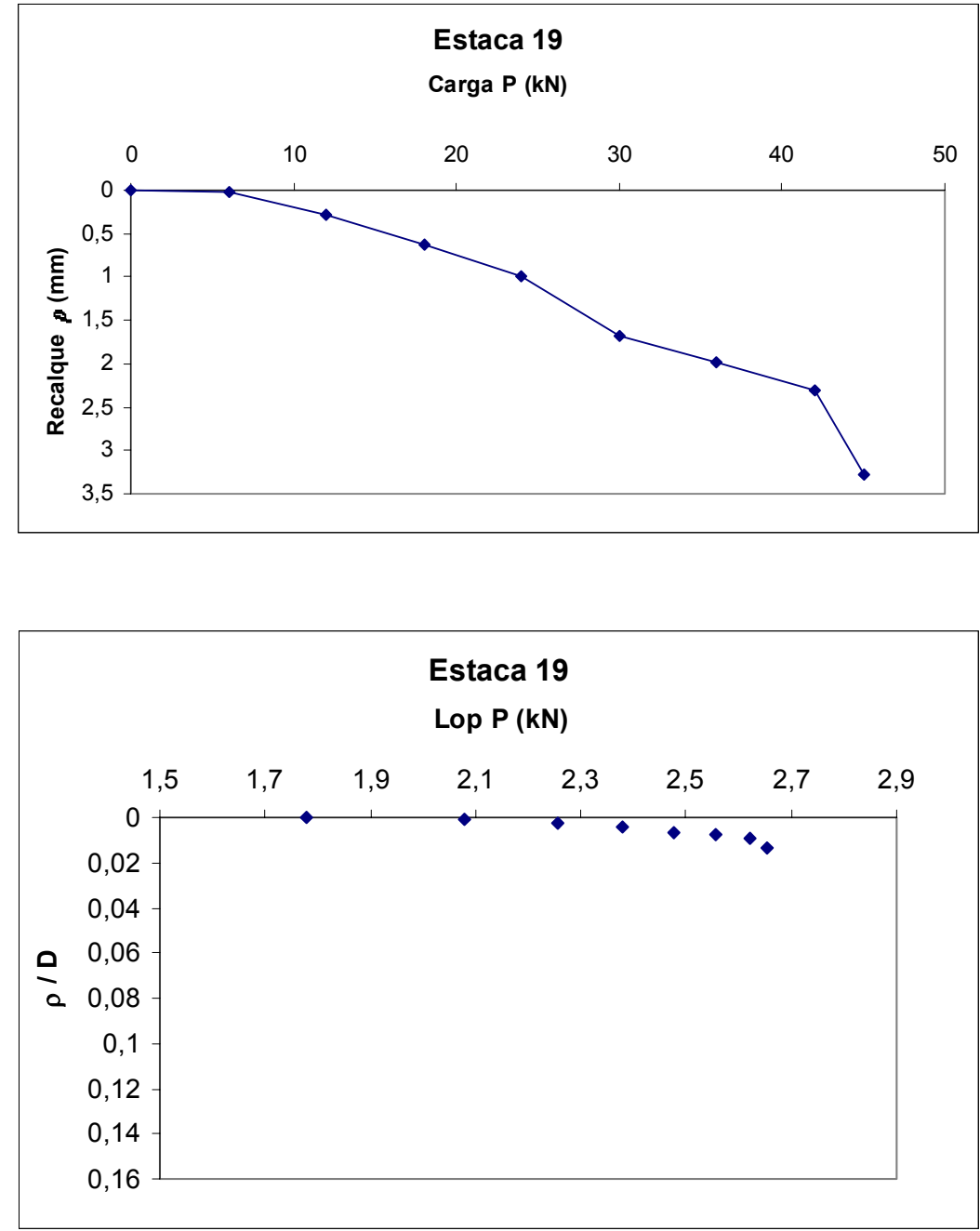

\begin{tabular}{|c|c|}
\hline \multicolumn{2}{|c|}{$\begin{array}{l}\mathrm{D}=25 \mathrm{~cm} \\
\mathrm{~L}=15 \mathrm{~m}\end{array}$} \\
\hline $\mathrm{N}_{\text {SPT }}$ & Tipo de solo \\
\hline 14 & Silte argiloso com areia fina, marrom escuro, médio \\
\hline \multicolumn{2}{|r|}{ 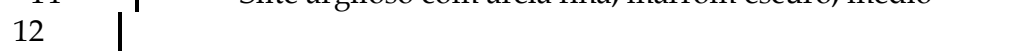 } \\
\hline 4 & \multirow[t]{2}{*}{ Argila siltosa com areia fina, variegada, mole a muito mole } \\
\hline 3 & \\
\hline 8 & $\begin{array}{l}\text { Silte argiloso com areia de textura variada, pedregulho, } \\
\text { variegado, médio }\end{array}$ \\
\hline 9 & \multirow[t]{3}{*}{ Argila siltosa com areia fina, variegada, média } \\
\hline 7 & \\
\hline 4 & \\
\hline 8 & \multirow[t]{2}{*}{$\begin{array}{c}\text { Argila siltosa com areia de textura variada, pedregulho, } \\
\text { variegada, média }\end{array}$} \\
\hline 7 & \\
\hline 6 & \multirow[t]{2}{*}{ Argila siltosa com areia, pedregulho, variegada, média } \\
\hline 10 & \\
\hline 11 & \multirow{4}{*}{ Argila siltosa com areia fina, pedregulho, variegada, rija e média } \\
\hline 10 & \\
\hline 9 & \\
\hline 15 & \\
\hline 30 & \multirow{3}{*}{$\begin{array}{l}\text { Silte arenoso com pouca argila e pedregulho, variegado, muito } \\
\text { compacto }\end{array}$} \\
\hline $50 / 20$ & \\
\hline $48 / 23$ & \\
\hline
\end{tabular}



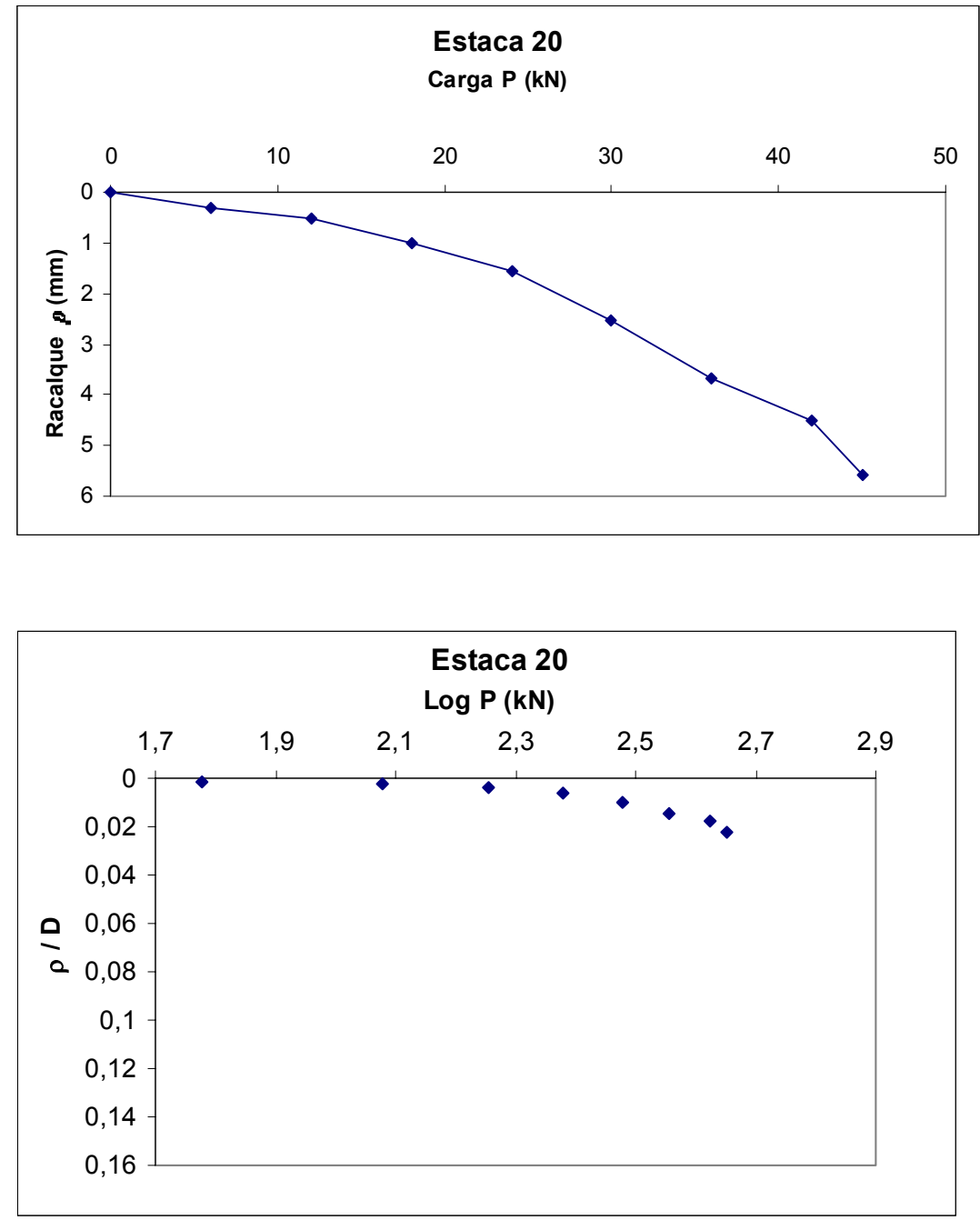

\begin{tabular}{|c|c|}
\hline \multicolumn{2}{|c|}{$\begin{array}{l}\mathrm{D}=25 \mathrm{~cm} \\
\mathrm{~L}=14,00 \mathrm{~m}\end{array}$} \\
\hline$\overline{N_{\text {SPT }}}$ & Tipo de solo \\
\hline 9 & \multirow{6}{*}{ Argila arenosa com silte, vermelha, consistência média e rija. } \\
\hline 11 & \\
\hline 13 & \\
\hline 12 & \\
\hline 10 & \\
\hline 9 & \\
\hline 6 & \multirow{5}{*}{ Argila arenosa com silte, vermelha, consistência média e mole. } \\
\hline 5 & \\
\hline 5 & \\
\hline 5 & \\
\hline 8 & \\
\hline 15 & \multirow{7}{*}{ Argila siltosa com areia variegada mole e muito mole. } \\
\hline 4 & \\
\hline 3 & \\
\hline 4 & \\
\hline $2 / 33$ & \\
\hline 12 & \\
\hline 15 & \\
\hline 11 & \multirow{3}{*}{ Argila siltosa com areia variegada rija e dura. } \\
\hline 12 & \\
\hline $55 / 20$ & \\
\hline
\end{tabular}



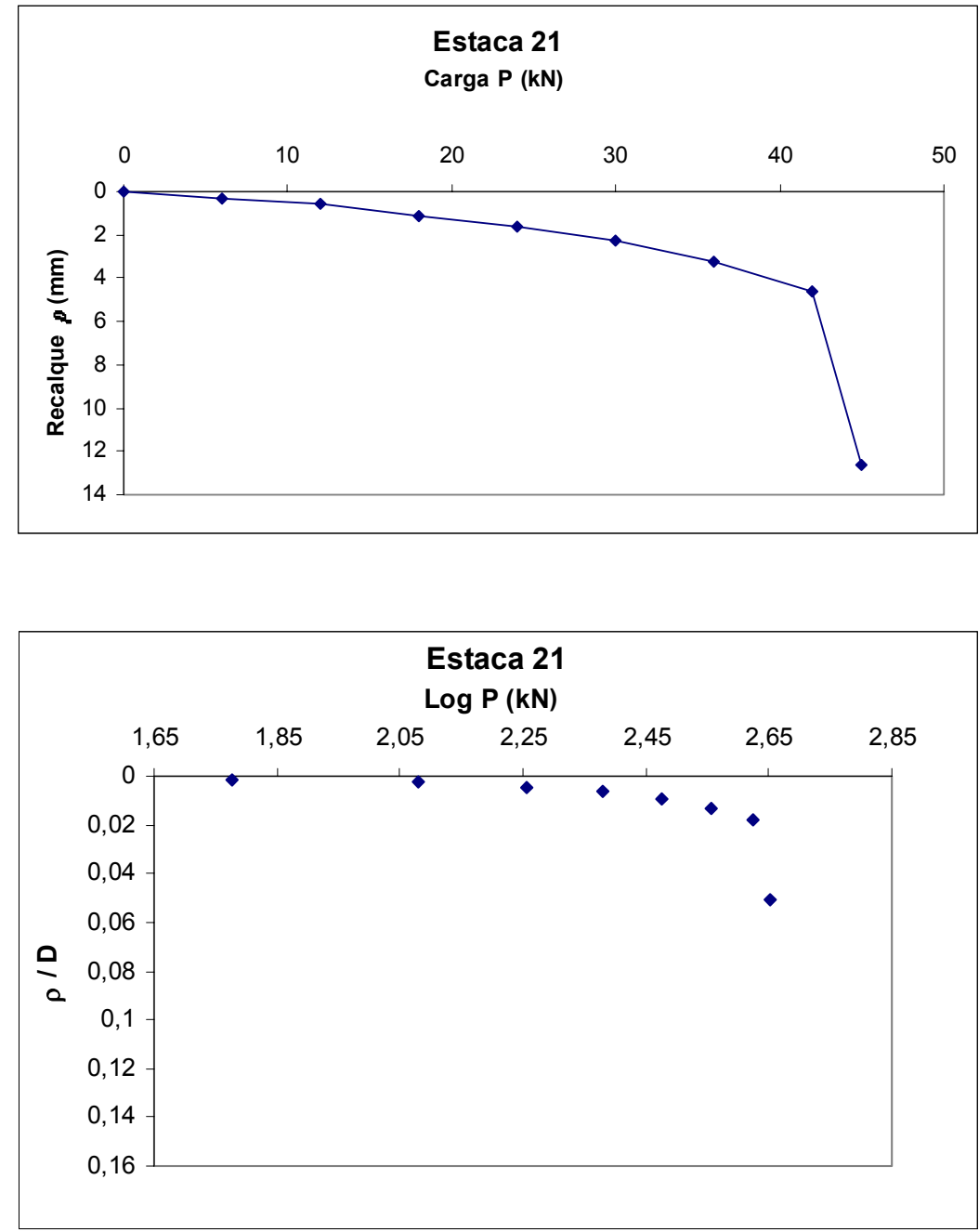

\begin{tabular}{c|c}
\hline \multicolumn{2}{c}{$\mathrm{D}=25 \mathrm{~cm}$} \\
$\mathrm{~L}=11,50 \mathrm{~m}$ \\
\hline N SPT & Tipo de solo \\
\hline 4 & \\
5 & \\
8 & \\
7 & \\
$15 / 8$ & Argila silto-arenosa, vermelha, muito mole a mole. \\
6 & \\
\cline { 2 - 2 } 6 & Argila siltosa com areia grossa e pedregulho, variegada \\
6 & consistência média. \\
7 & \\
8 & \\
7 & \\
8 & \\
15 & \\
19 & \\
31 & \\
23 & \\
21 & \\
21 & \\
30 & \\
19 & \\
20 & \\
$31 / 25$ & \\
& \\
\end{tabular}



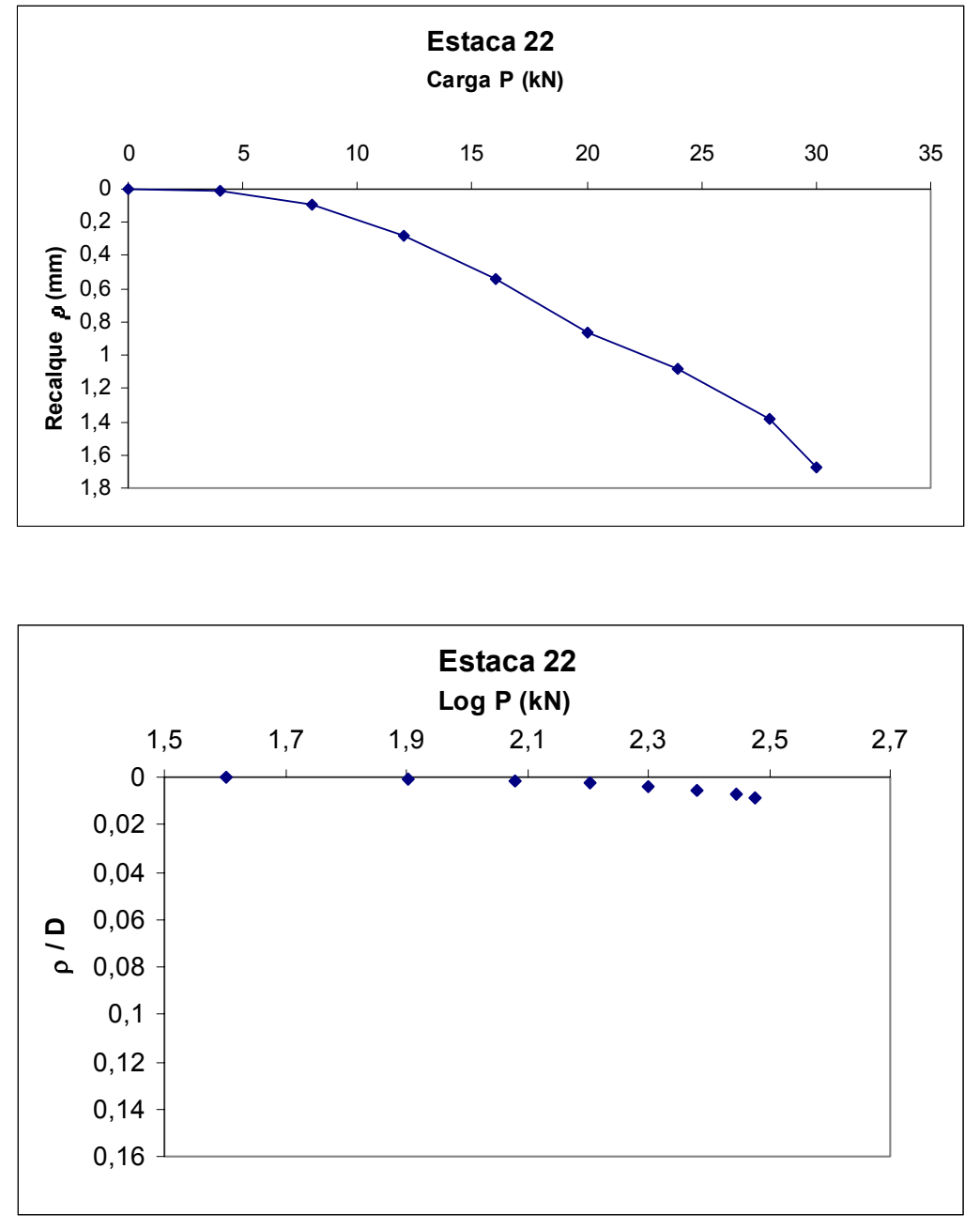

\begin{tabular}{c|c}
\hline \multicolumn{2}{c}{$\mathrm{D}=20 \mathrm{~cm}$} \\
$\mathrm{~L}=13,45 \mathrm{~m}$
\end{tabular}



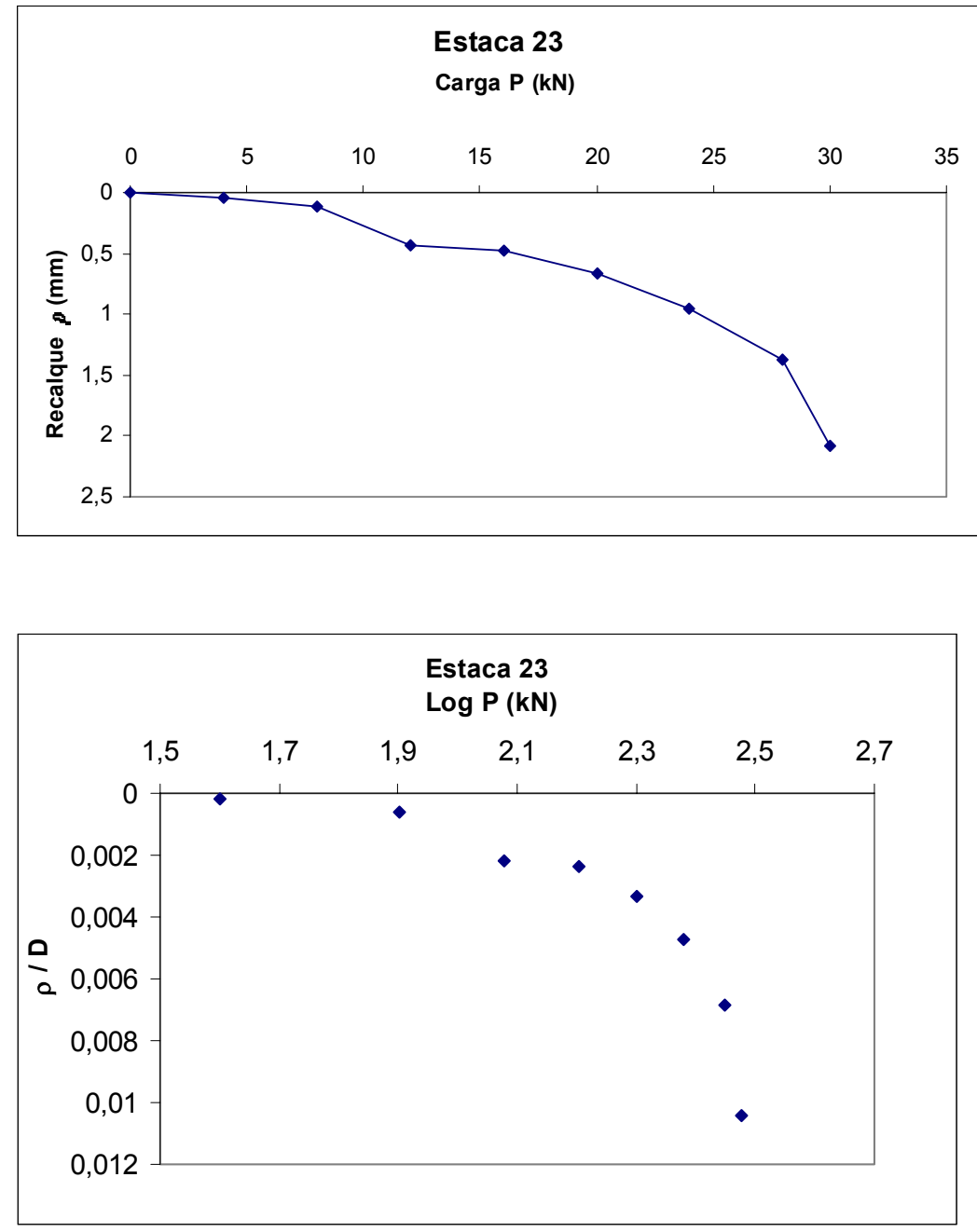

\begin{tabular}{c|c}
\hline \multicolumn{2}{c}{$\mathrm{D}=20 \mathrm{~cm}$} \\
$\mathrm{~L}=9,00 \mathrm{~m}$ \\
\hline $\mathrm{N}_{\text {SPT }}$ & Tipo de solo \\
\hline 4 & \\
$3 / 25$ & Argila siltosa, variegada, mole a consistência média. \\
7 & \\
8 & \\
11 & Argila siltosa, variegada, rija a consistência média. \\
10 & \\
12 & Argila siltosa, cinza, rija a dura. \\
\cline { 2 - 2 } 36 & \\
\hline
\end{tabular}



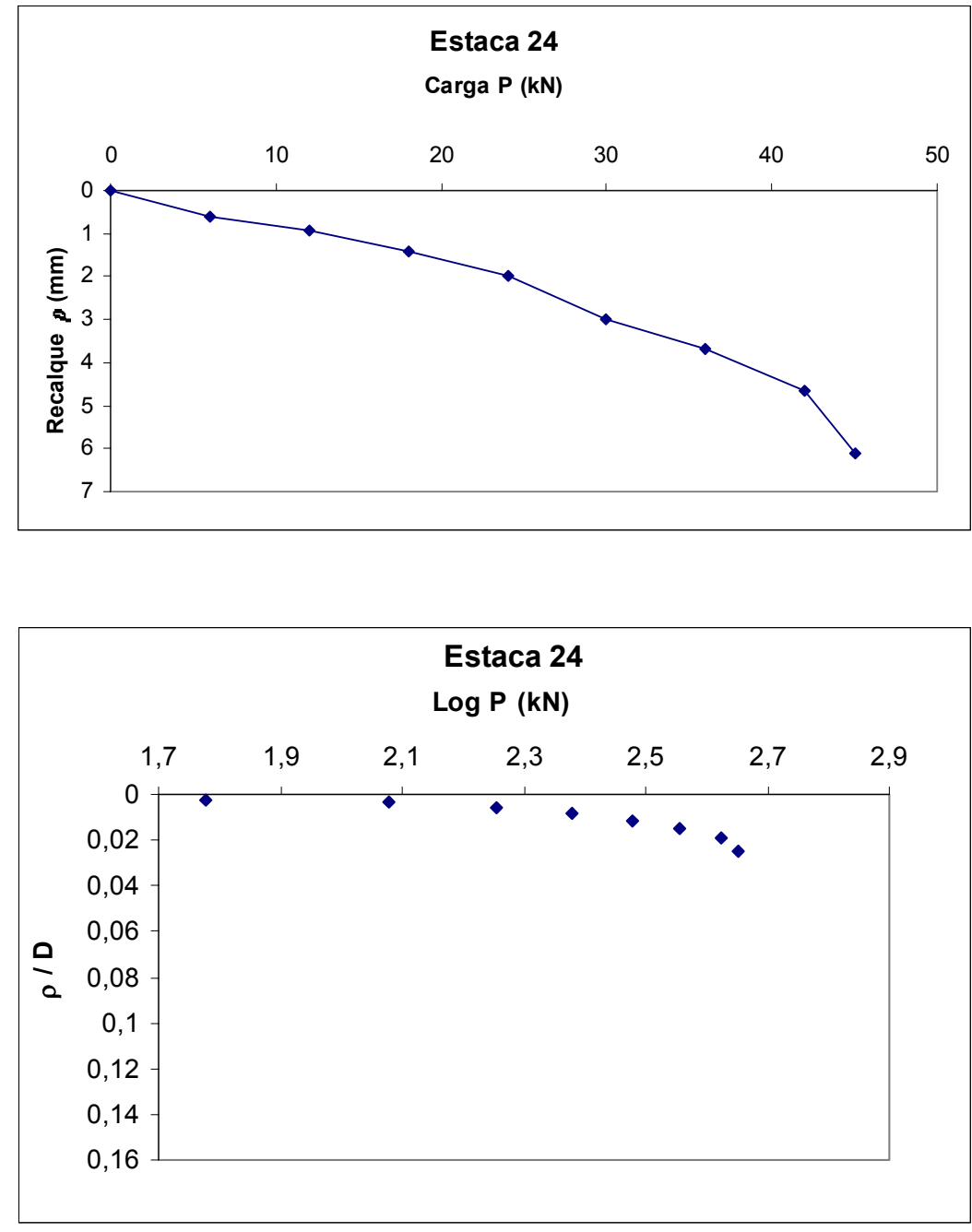

\begin{tabular}{|c|c|}
\hline \multicolumn{2}{|c|}{$\begin{array}{l}\mathrm{D}=25 \mathrm{~cm} \\
\mathrm{~L}=14,00 \mathrm{~m}\end{array}$} \\
\hline N SPT & Tipo de solo \\
\hline 6 & \multirow{5}{*}{$\begin{array}{l}\text { Silte argiloso com areia fina e pedregulho, vermelho, pouco } \\
\text { compacto. }\end{array}$} \\
\hline 5 & \\
\hline 6 & \\
\hline 7 & \\
\hline 8 & \\
\hline 5 & \multirow{5}{*}{ Argila siltosa com areia fina e pedregulho, cinza, mole. } \\
\hline 5 & \\
\hline 4 & \\
\hline 4 & \\
\hline 10 & \\
\hline 11 & \multirow{6}{*}{ Argila siltosa com areia fina e pedregulho, cinza, rija. } \\
\hline 14 & \\
\hline 19 & \\
\hline 17 & \\
\hline 14 & \\
\hline 25 & \\
\hline 19 & \multirow[t]{2}{*}{ Argila siltosa com areia, amarela rija. } \\
\hline 19 & \\
\hline 15 & \multirow{3}{*}{ Argila siltosa com areia fina, cinja, rija a muito rija. } \\
\hline 22 & \\
\hline 38 & \\
\hline $25 / 18$ & \multirow[t]{2}{*}{ Areia argilosa com silte e pedregulho, cinza, muito compacto. } \\
\hline $25 / 14$ & \\
\hline
\end{tabular}



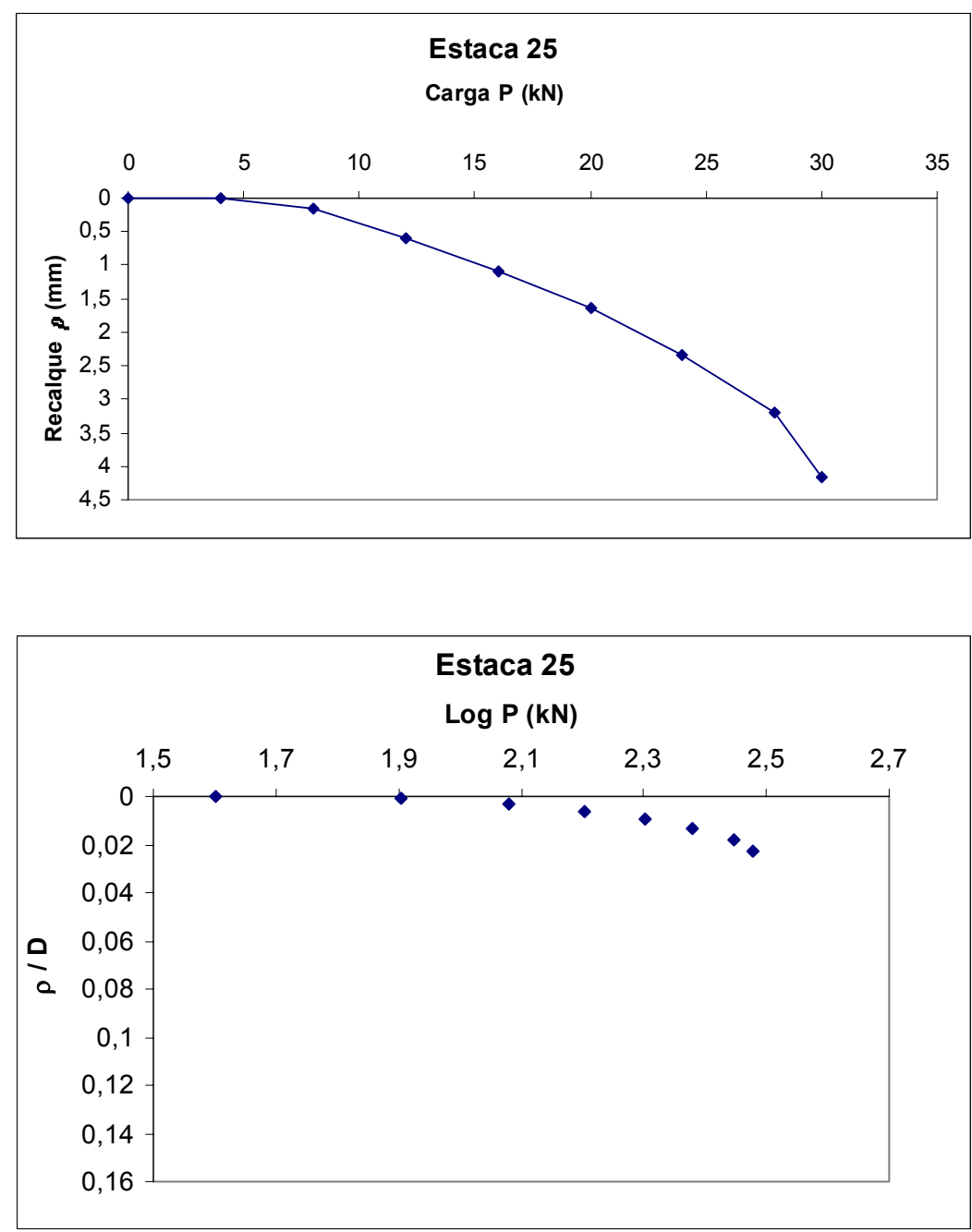

\begin{tabular}{|c|c|c|}
\hline \multicolumn{2}{|c|}{$\begin{array}{l}\mathrm{D}=18 \mathrm{~cm} \\
\mathrm{~L}=12,20 \mathrm{~m}\end{array}$} & \\
\hline $\mathrm{N}_{\text {SPT }}$ & Tipo de solo & \\
\hline 4 & Aterro - argila siltosa, marrom, mole. & - \\
\hline 4 & & \\
\hline 5 & & \\
\hline 6 & Argila siltosa, variegada, média. & \\
\hline 6 & & \\
\hline 5 & & \\
\hline 5 & Argila arenosa, variegada, mole. & \\
\hline 5 & & \\
\hline 5 & & \\
\hline 6 & & \\
\hline 7 & Argila siltosa, cinza, mole. & \\
\hline 8 & & \\
\hline 10 & & \\
\hline 13 & & \\
\hline 15 & Argila siltosa, cinza, rija a dura. & \\
\hline 27 & & \\
\hline 23 & & \\
\hline 25 & & \\
\hline 27 & Argila arenosa, cinza, dura. & \\
\hline 27 & & \\
\hline
\end{tabular}



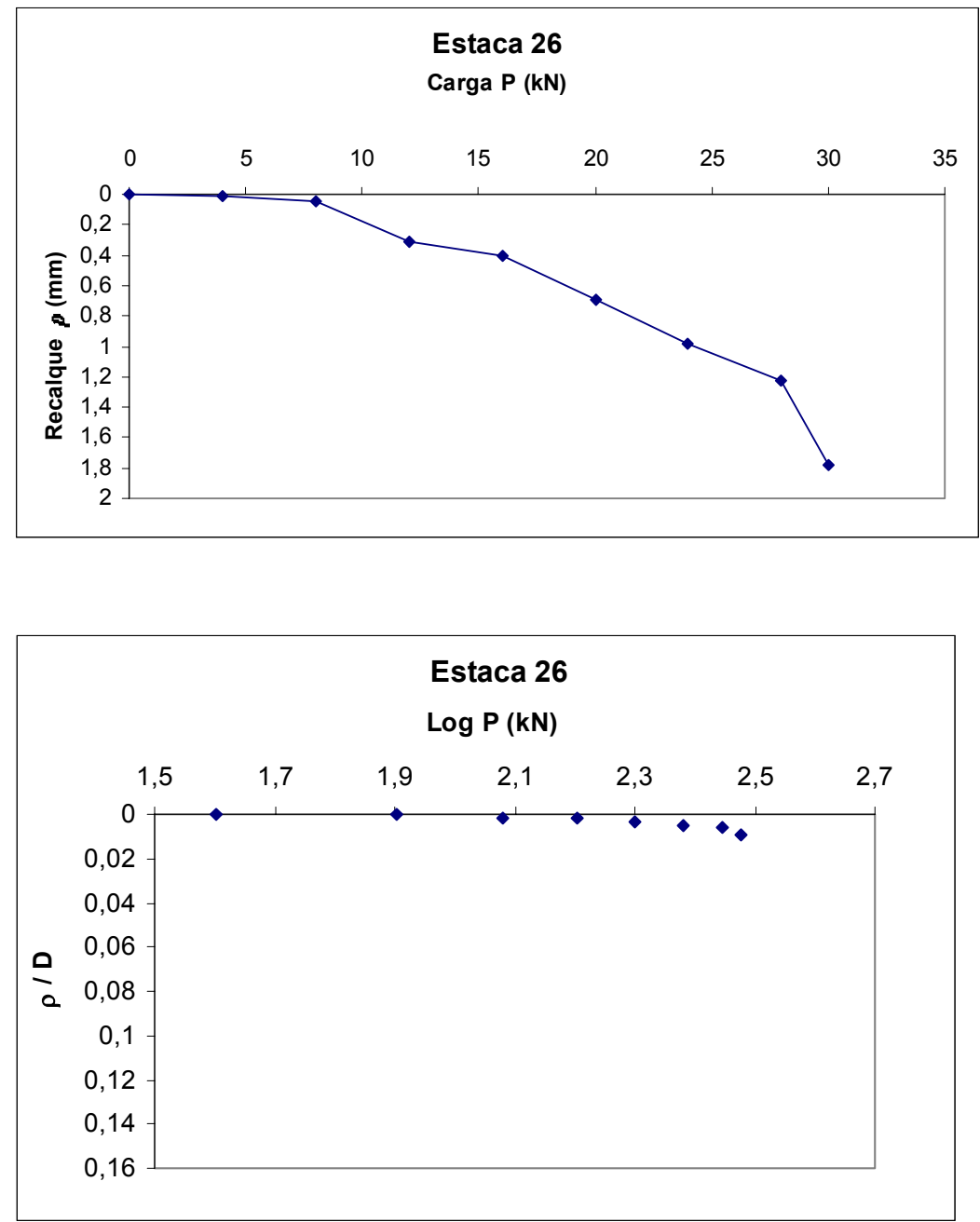

\begin{tabular}{c|c}
\hline \multicolumn{2}{c}{$\mathrm{D}=20 \mathrm{~cm}$} \\
$\mathrm{~L}=13,90 \mathrm{~m}$ \\
\hline N sPT & Tipo de solo \\
\hline 10 & Argila siltosa com areia fina, vermelha, consistência média. \\
8 & \\
8 & \\
3 & \\
3 & \\
3 & Argila siltosa com areia fina, cinza, muito mole. \\
9 & \\
5 & \\
\cline { 2 - 2 } 5 & \\
13 & Argila siltosa com areia fina, variegada muito mole e consitência \\
11 & \\
\cline { 2 - 2 } 19 & \\
17 & \\
20 & \\
21 & \\
26 & \\
28 & \\
& \\
\hline
\end{tabular}



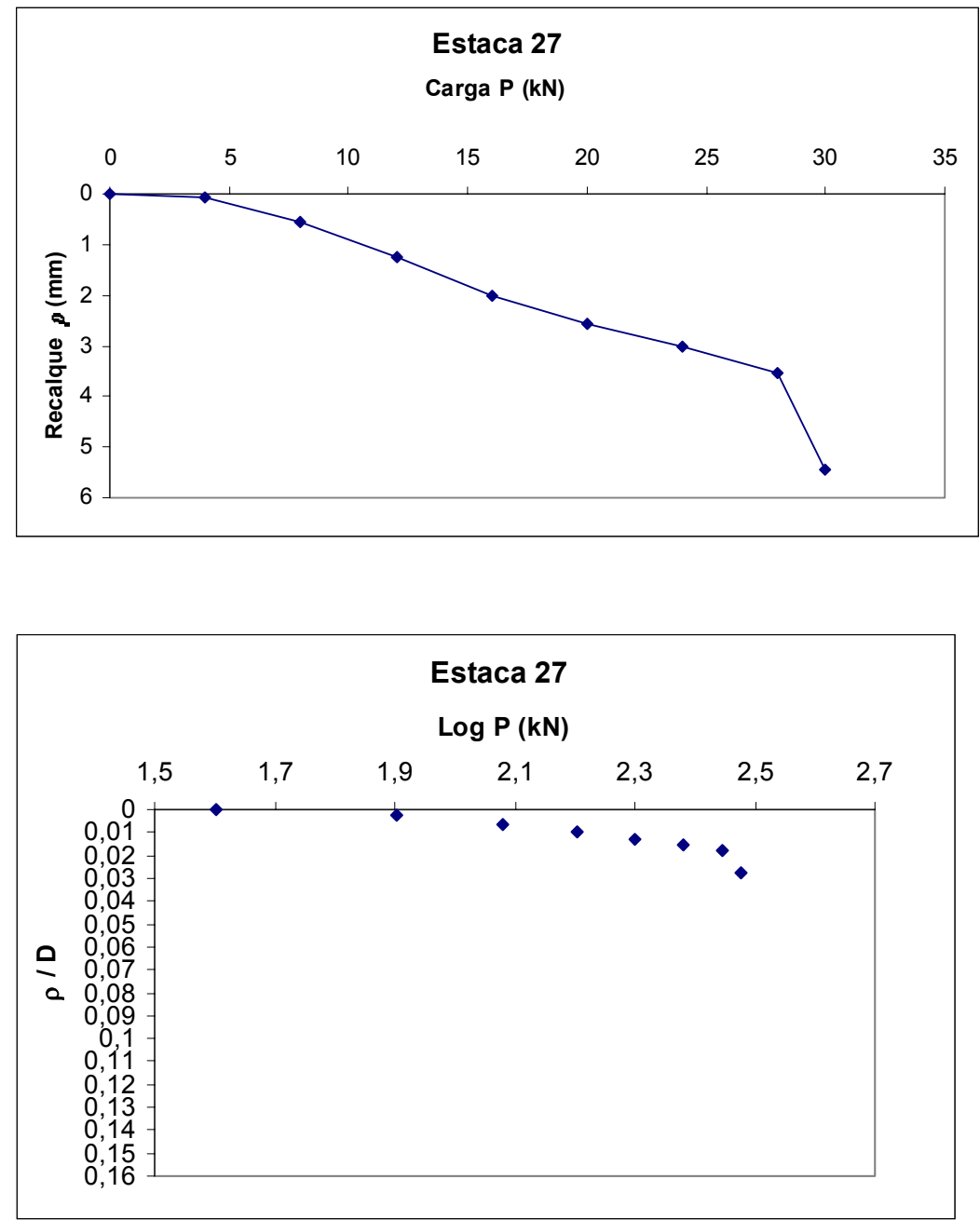

\begin{tabular}{c|c}
\hline \multicolumn{2}{c}{$\mathrm{D}=20 \mathrm{~cm}$} \\
$\mathrm{~L}=11,90 \mathrm{~m}$ \\
\hline N SPT & Tipo de solo \\
\hline 17 & \\
5 & \\
5 & \\
7 & \\
11 & \\
17 & \\
14 & \\
16 & \\
18 & \\
17 & \\
20 & \\
29 & \\
20 & \\
24 & \\
34 & \\
38 & \\
\cline { 2 - 2 } & \\
\hline
\end{tabular}



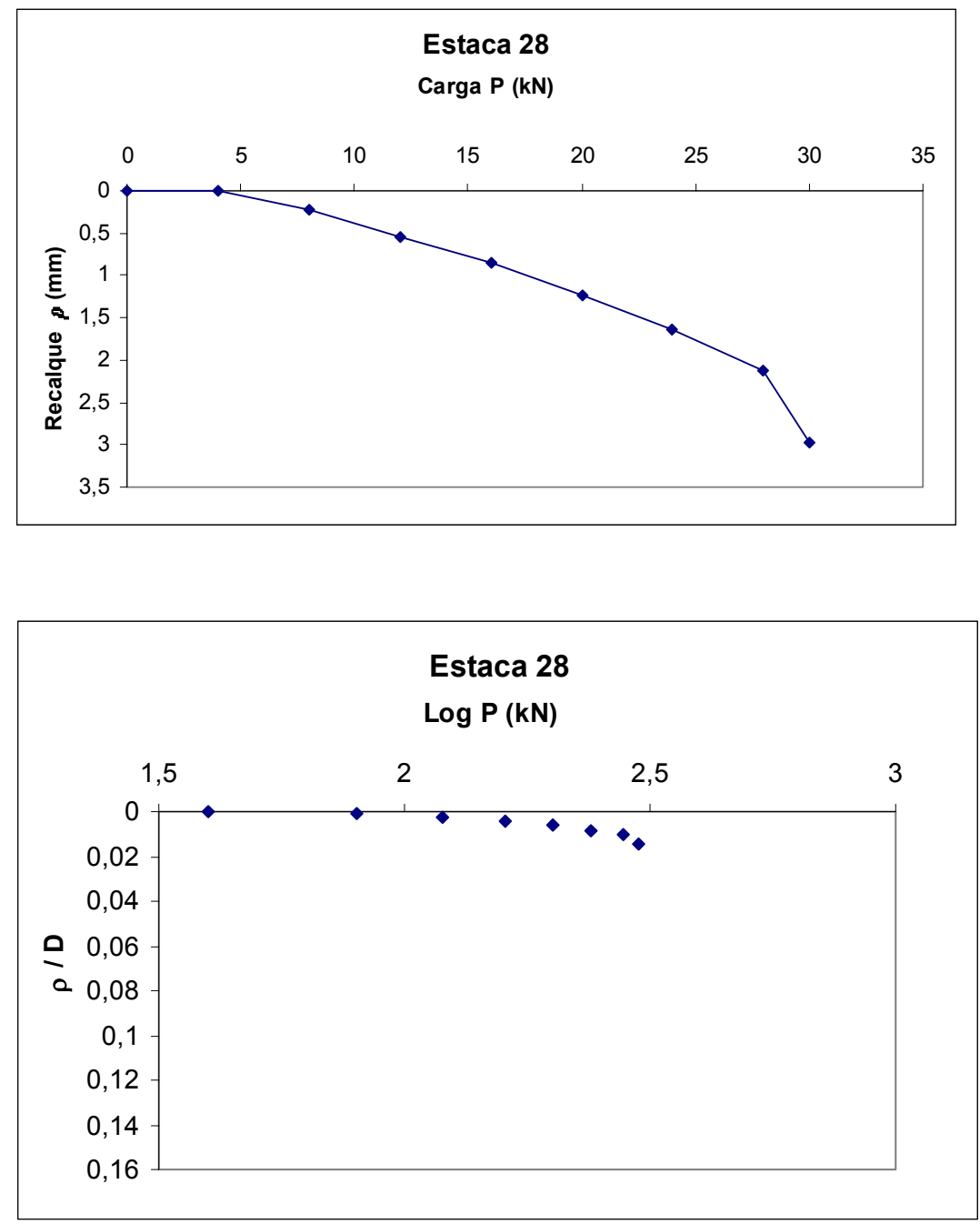

\begin{tabular}{c|c}
\hline \multicolumn{2}{c}{$\mathrm{D}=20 \mathrm{~cm}$} \\
$\mathrm{~L}=12,10 \mathrm{~m}$ \\
\hline $\mathrm{N}_{\text {SPT }}$ & Tipo de solo \\
\hline 12 & \\
10 & \\
6 & \\
6 & Argila siltosa, variegada. \\
4 & \\
5 & \\
5 & \\
6 & \\
9 & \\
10 & \\
15 & \\
17 & \\
14 & \\
\hline
\end{tabular}



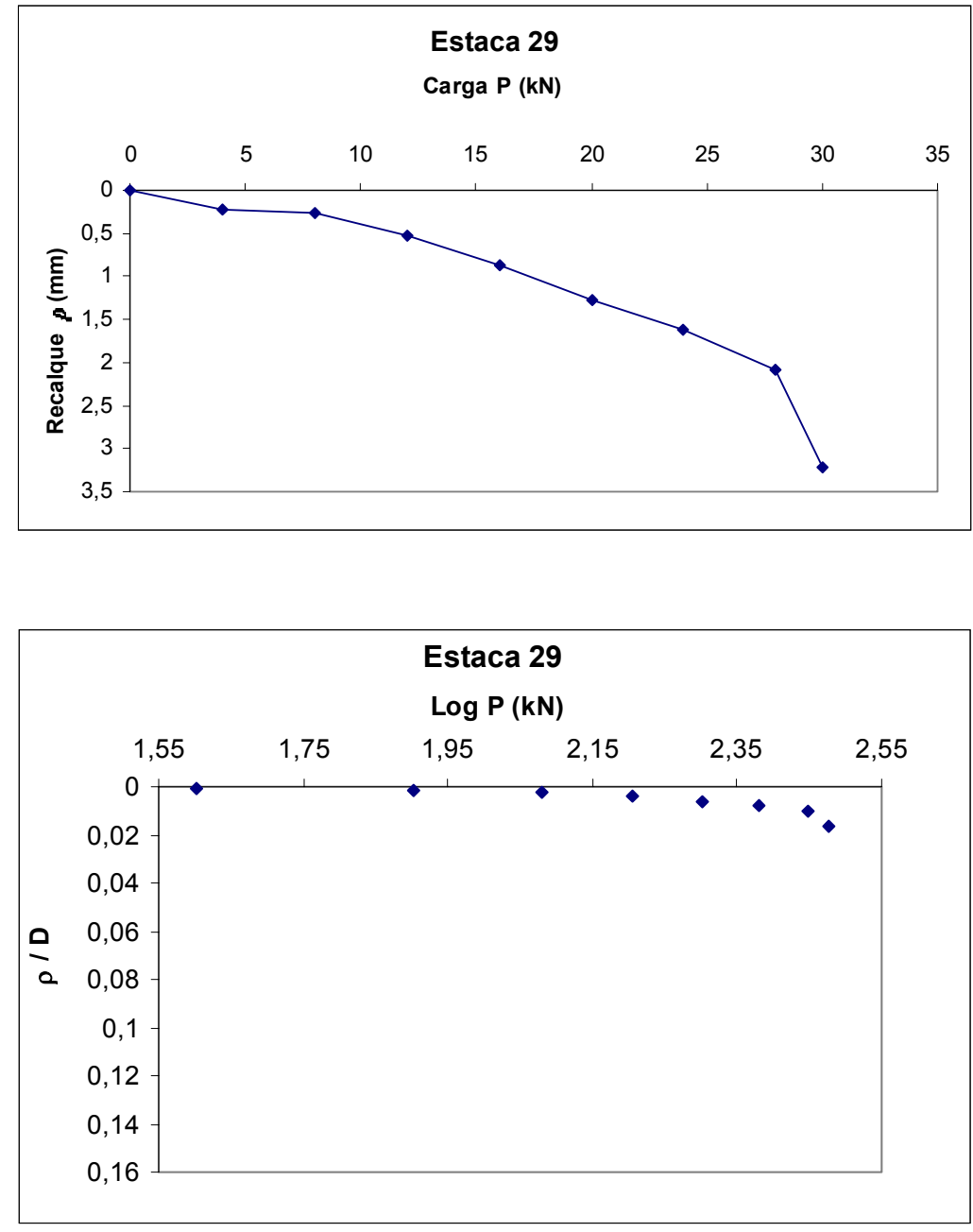

\begin{tabular}{|c|c|}
\hline \multicolumn{2}{|c|}{$\begin{array}{l}\mathrm{D}=20 \mathrm{~cm} \\
\mathrm{~L}=10,30 \mathrm{~m}\end{array}$} \\
\hline$\overline{N_{\text {SPT }}}$ & Tipo de solo \\
\hline 3 & \multirow{3}{*}{ Argila siltosa com areia fina, marrom, muito mole. } \\
\hline 3 & \\
\hline 5 & \\
\hline 7 & \multirow{3}{*}{ Argila siltosa com areia fina, marrom, consistência média. } \\
\hline 8 & \\
\hline 8 & \\
\hline 10 & \multirow[t]{2}{*}{ Argila arenosa com silte variegada, consistência média a rija. } \\
\hline 12 & \\
\hline 14 & \multirow{4}{*}{ Argila siltosa, cinza clara, rija a muito rija. } \\
\hline 15 & \\
\hline 21 & \\
\hline 23 & \\
\hline 28 & \multirow[t]{2}{*}{ Argila siltosa com areia fina, cinza clara muito rija. } \\
\hline 29 & \\
\hline 26 & \multirow{3}{*}{ Argila arenosa com silte, cinza clara, muito rija. } \\
\hline 28 & \\
\hline 35 & \\
\hline
\end{tabular}



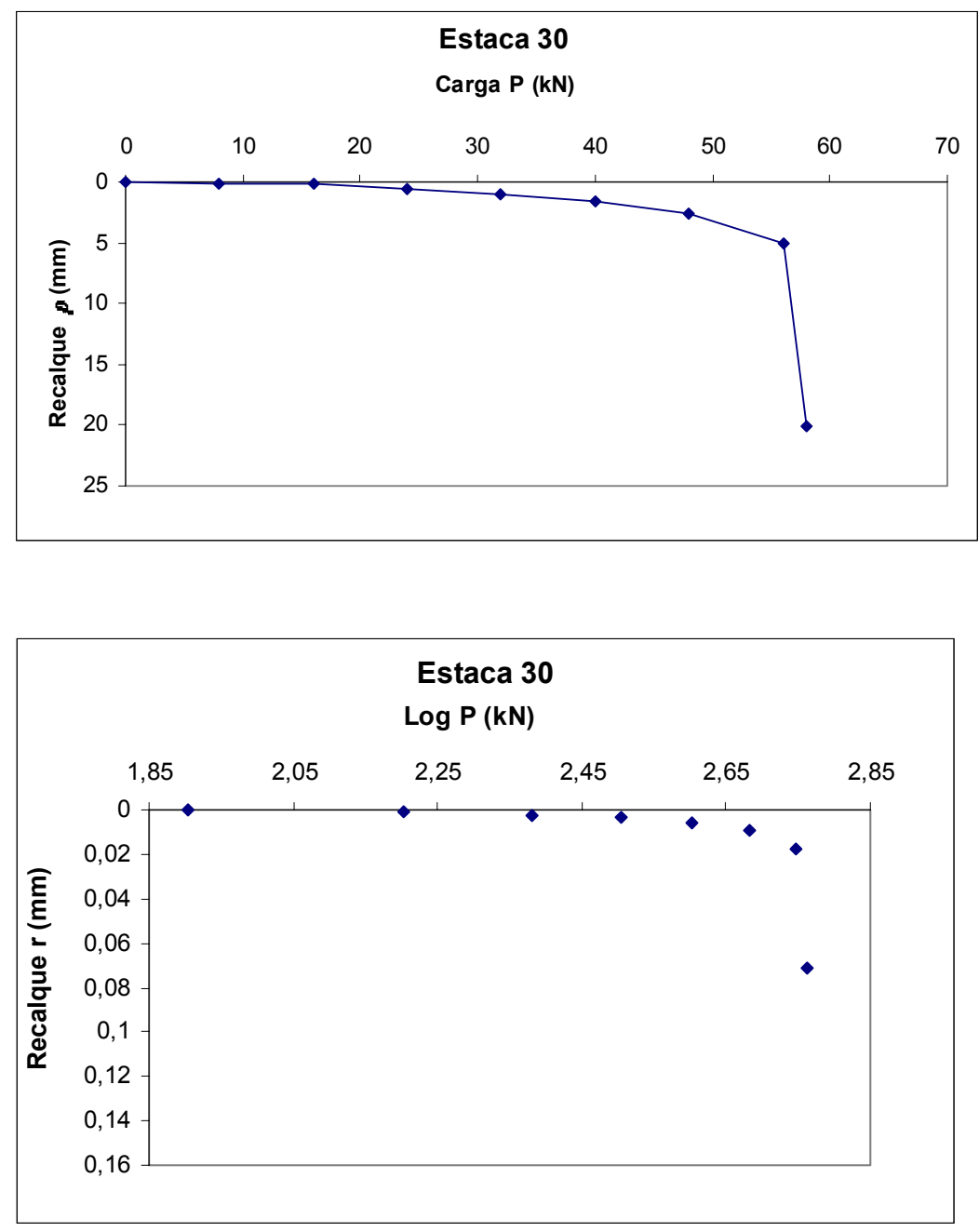

\begin{tabular}{|c|c|c|}
\hline \multicolumn{3}{|c|}{$\begin{aligned} \mathrm{D} & =28 \mathrm{~cm} \\
\mathrm{~L} & =10,60 \mathrm{~m}\end{aligned}$} \\
\hline $\mathrm{N}_{\mathrm{SPT}}$ & \multicolumn{2}{|l|}{ Tipo de solo } \\
\hline 5 & \multirow{2}{*}{\multicolumn{2}{|c|}{ Aterro - argila siltosa, marrom, mole. }} \\
\hline 4 & & \\
\hline 6 & \multicolumn{2}{|l|}{ Argila siltosa, preta, média. } \\
\hline 5 & \multirow{5}{*}{ Argila siltosa, variegada, mole. } & \\
\hline 6 & & \\
\hline 7 & & \\
\hline 8 & & \\
\hline 5 & & \\
\hline 6 & \multirow{2}{*}{\multicolumn{2}{|c|}{ Argila siltosa, roxa, média. }} \\
\hline 7 & & \\
\hline 6 & \multirow{2}{*}{\multicolumn{2}{|c|}{ Argila siltosa, variegada, rija. }} \\
\hline 13 & & \\
\hline 13 & \multirow{4}{*}{ Argila siltosa, variegada, rija. } & \\
\hline 16 & & \\
\hline 18 & & \\
\hline 20 & & \\
\hline 22 & \multirow{6}{*}{ Silte arenoso com pedregulhos, variegado compacto. } & \\
\hline 25 & & \\
\hline 33 & & \\
\hline 30 & & \\
\hline 31 & & \\
\hline 59 & & \\
\hline
\end{tabular}



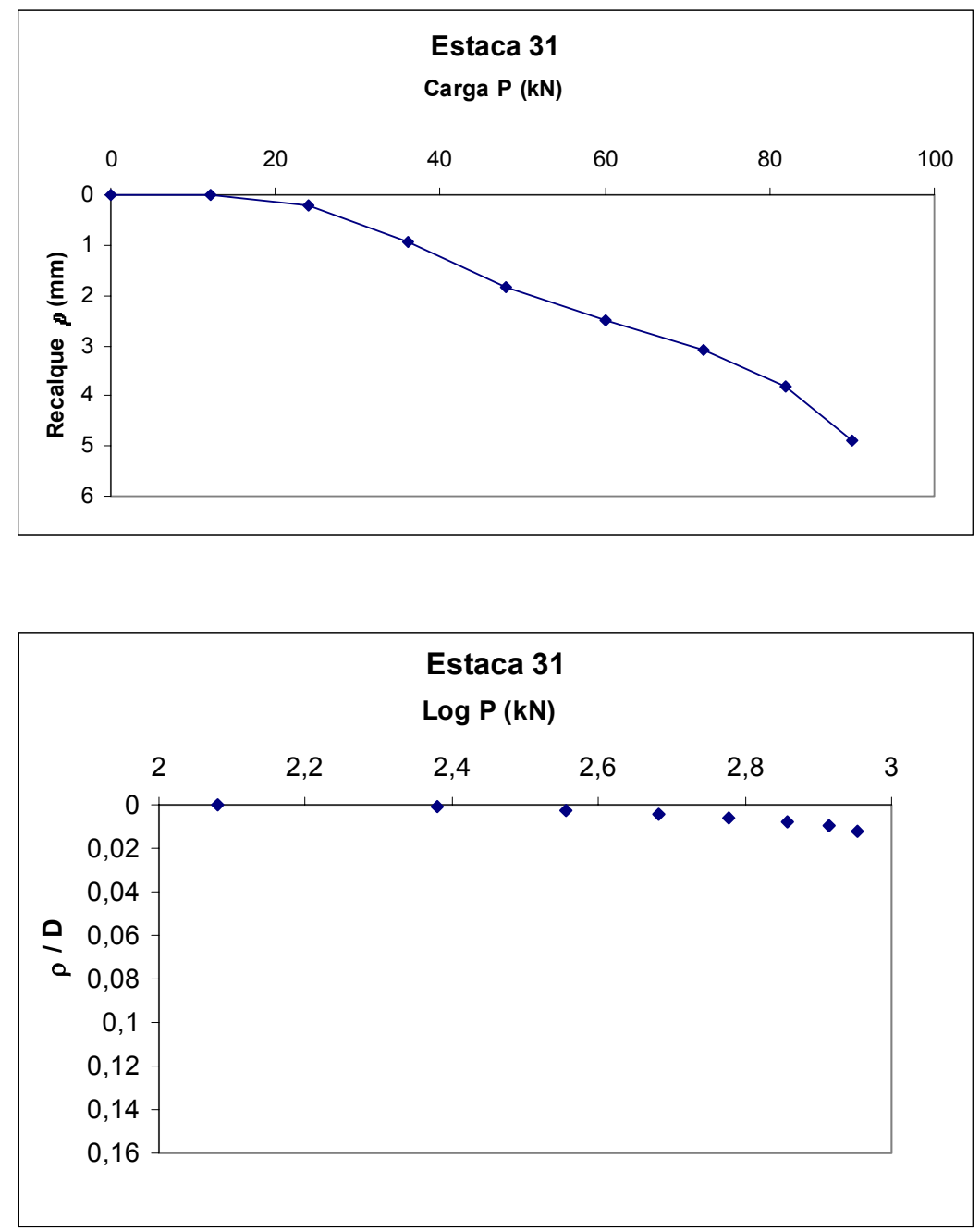

\begin{tabular}{c|c}
\hline \multicolumn{2}{c}{$\mathrm{D}=40 \mathrm{~cm}$} \\
$\mathrm{~L}=12,00 \mathrm{~m}$ \\
\hline $\mathrm{N}_{\text {SPT }}$ & Tipo de solo \\
\hline 4 & Silte com areia média, marrom avermelhado, pouco compacto. \\
7 & \\
8 & \\
5 & Argila siltosa, cinza, mole. \\
5 & \\
\cline { 2 - 2 } 10 & \\
10 & \\
11 & \\
12 & \\
14 & \\
20 & \\
30 & \\
30 & \\
38 & \\
\cline { 2 - 2 } & \\
\hline
\end{tabular}



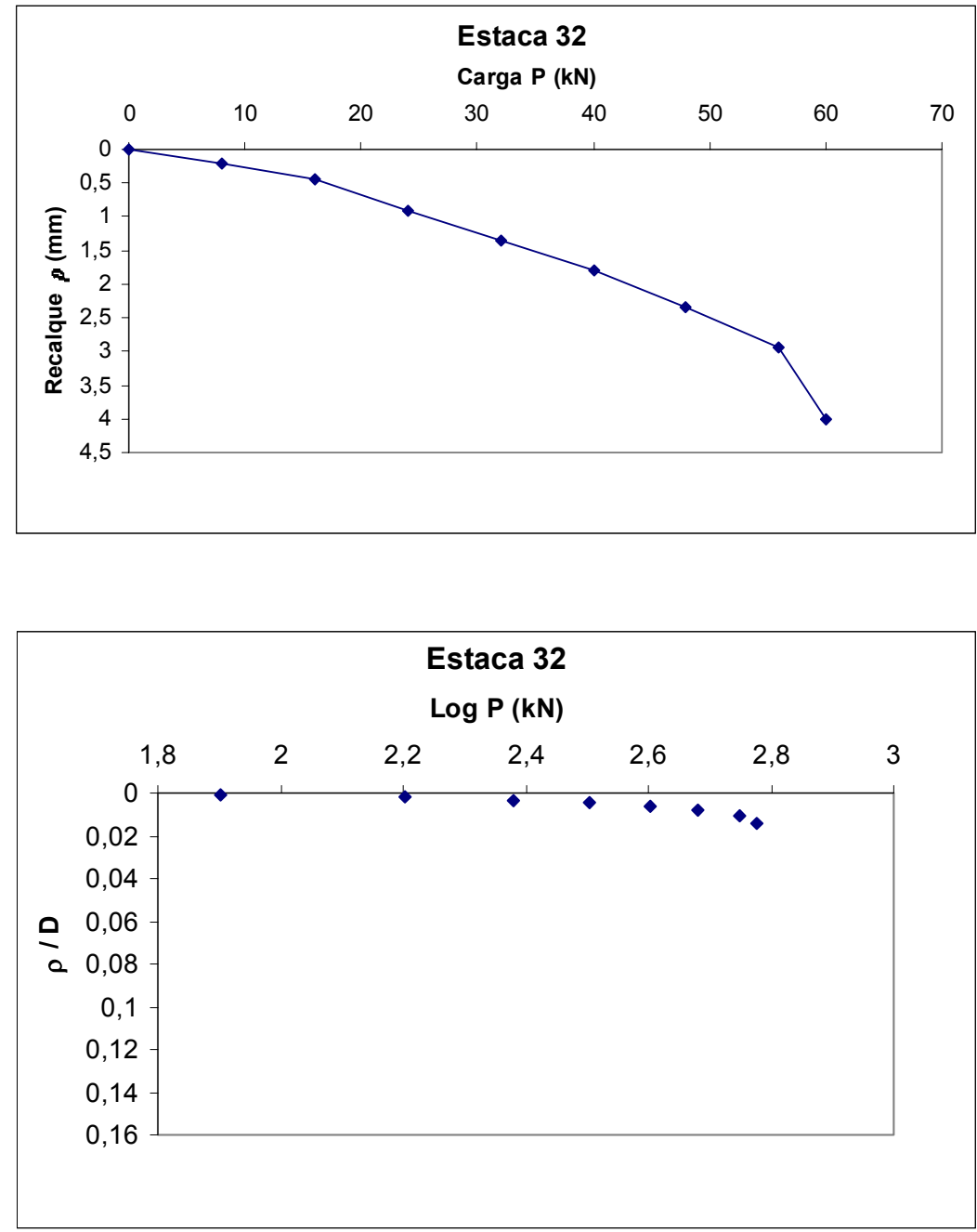

\begin{tabular}{c|c}
\hline \multicolumn{2}{c}{$\mathrm{D}=28 \mathrm{~cm}$} \\
$\mathrm{~L}=12,00 \mathrm{~m}$
\end{tabular}



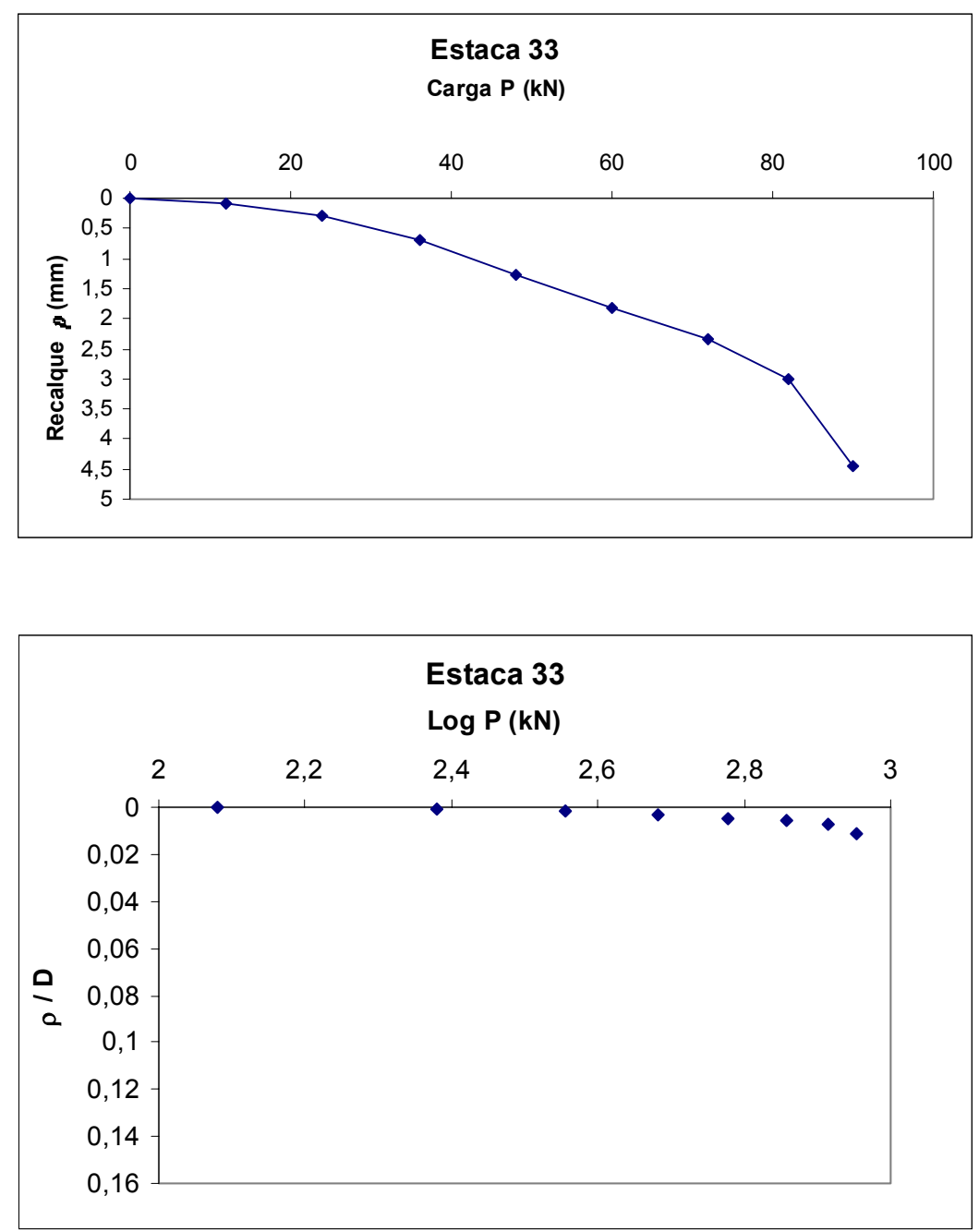

\begin{tabular}{c|c}
\hline \multicolumn{2}{c}{$\mathrm{D}=40 \mathrm{~cm}$} \\
$\mathrm{~L}=12,3 \mathrm{~m}$
\end{tabular}



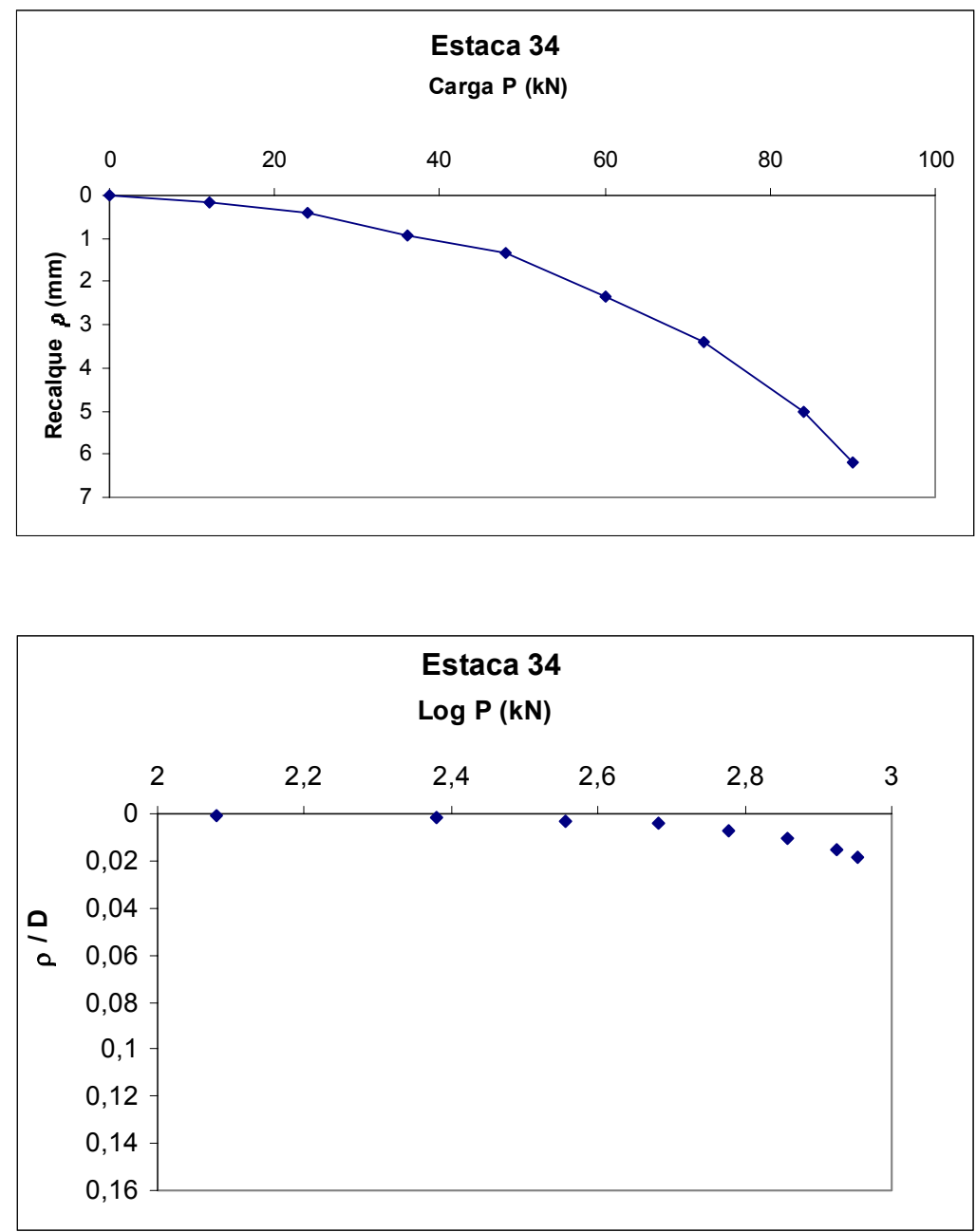

\begin{tabular}{c|c}
\hline \multicolumn{2}{c}{$\mathrm{D}=33 \mathrm{~cm}$} \\
$\mathrm{~L}=12 \mathrm{~m}$ \\
\hline $\mathrm{N}_{\text {SPT }}$ & \\
\hline 4 & Aterro - Argila siltosa vermelha mole \\
5 & \\
8 & \\
7 & \\
6 & \\
6 & \\
4 & \\
9 & \\
7 & \\
7 & \\
19 & \\
17 & \\
17 & \\
20 & \\
17 & \\
21 & \\
28 & \\
21 & \\
20 & \\
21 & \\
& \\
\hline
\end{tabular}


ANEXO 2

Tabelas - Capacidade de Carga 


\begin{tabular}{|c|c|c|c|c|}
\hline Estaca & $\begin{array}{l}\text { R (kN) Aoki - } \\
\text { Velloso (1975) }\end{array}$ & $\begin{array}{l}\text { R (kN) Décourt - } \\
\text { Quaresma (1978) }\end{array}$ & $\begin{array}{c}\mathrm{R}(\mathrm{kN}) \text { Amaral } \\
(1982,1999)\end{array}$ & $\begin{array}{c}\mathrm{Pu}(\mathrm{kN}) \text { Van der } \\
\text { Veen }\end{array}$ \\
\hline 1 & 156 & 380 & 544 & 629 \\
\hline 2 & 114 & 256 & 371 & 358 \\
\hline 3 & 164 & 353 & 509 & 516 \\
\hline 4 & 516 & 866 & 1059 & 884 \\
\hline 5 & 648 & 1086 & 1316 & 1080 \\
\hline 6 & 433 & 956 & 790 & 1093 \\
\hline 7 & 388 & 565 & 794 & 757 \\
\hline 8 & 365 & 532 & 700 & 378 \\
\hline 9 & 390 & 664 & 983 & 865 \\
\hline 10 & 329 & 576 & 745 & 739 \\
\hline 11 & 226 & 281 & 424 & 300 \\
\hline 12 & 413 & 489 & 710 & 529 \\
\hline 13 & 294 & 325 & 420 & 303 \\
\hline 14 & 167 & 220 & 270 & 151 \\
\hline 15 & 223 & 186 & 481 & 501 \\
\hline 16 & 441 & 705 & 1040 & 830 \\
\hline 17 & 151 & 257 & 401 & 413 \\
\hline 18 & 573 & 749 & 790 & 759 \\
\hline 19 & 297 & 504 & 720 & 563 \\
\hline 20 & 197 & 338 & 510 & 541 \\
\hline 21 & 231 & 335 & 508 & 450 \\
\hline 22 & 197 & 313 & 440 & 393 \\
\hline 23 & 265 & 336 & 409 & 327 \\
\hline 24 & 385 & 504 & 698 & 523 \\
\hline 25 & 107 & 203 & 310 & 338 \\
\hline 26 & 287 & 389 & 560 & 328 \\
\hline 27 & 382 & 360 & 570 & 358 \\
\hline 28 & 220 & 349 & 480 & 335 \\
\hline 29 & 193 & 304 & 414 & 327 \\
\hline 30 & 250 & 381 & 570 & 580 \\
\hline 31 & 663 & 917 & 1240 & 1210 \\
\hline 32 & 259 & 413 & 613 & 704 \\
\hline 33 & 1130 & 1138 & 1260 & 987 \\
\hline 34 & 399 & 555 & 809 & 991 \\
\hline
\end{tabular}




\begin{tabular}{|c|c|c|}
\hline \multicolumn{3}{|c|}{ Método Aoki - Velloso adaptado } \\
\hline Estaca & $\mathrm{R}^{*}(\mathrm{kN})$ & $\mathrm{Pu}(\mathrm{kN})$ Van der \\
\hline 1 & 208 & 629 \\
\hline 2 & 150 & 358 \\
\hline 3 & 204 & 516 \\
\hline 4 & 717 & 884 \\
\hline 5 & 853 & 1080 \\
\hline 6 & 561 & 1093 \\
\hline 7 & 741 & 757 \\
\hline 8 & 510 & 378 \\
\hline 9 & 520 & 865 \\
\hline 10 & 439 & 739 \\
\hline 11 & 315 & 300 \\
\hline 12 & 549 & 529 \\
\hline 13 & 412 & 303 \\
\hline 14 & 234 & 151 \\
\hline 15 & 296 & 501 \\
\hline 16 & 561 & 830 \\
\hline 17 & 203 & 413 \\
\hline 18 & 458 & 759 \\
\hline 19 & 396 & 563 \\
\hline 20 & 321 & 541 \\
\hline 21 & 295 & 450 \\
\hline 22 & 276 & 393 \\
\hline 23 & 370 & 327 \\
\hline 24 & 513 & 523 \\
\hline 25 & 150 & 338 \\
\hline 26 & 399 & 328 \\
\hline 27 & 393 & 358 \\
\hline 28 & 307 & 335 \\
\hline 29 & 237 & 327 \\
\hline 30 & 324 & 580 \\
\hline 31 & 784 & 1210 \\
\hline 32 & 321 & 704 \\
\hline 33 & 1075 & 987 \\
\hline 34 & 481 & 991 \\
\hline
\end{tabular}




\begin{tabular}{|c|c|c|}
\hline \multicolumn{3}{|c|}{$\begin{array}{l}\text { Método Aoki Velloso adaptado e corrigido com o fator } \\
\text { global }\end{array}$} \\
\hline Estaca & $\mathrm{R}^{\prime}(\mathrm{kN})$ & $\mathrm{Pu}(\mathrm{kN})$ Van der \\
\hline 1 & 270 & 629 \\
\hline 2 & 195 & 358 \\
\hline 3 & 265 & 516 \\
\hline 4 & 933 & 884 \\
\hline 5 & 1109 & 1080 \\
\hline 6 & 729 & 1093 \\
\hline 7 & 964 & 757 \\
\hline 8 & 662 & 378 \\
\hline 9 & 676 & 865 \\
\hline 10 & 570 & 739 \\
\hline 11 & 410 & 300 \\
\hline 12 & 714 & 529 \\
\hline 13 & 535 & 303 \\
\hline 14 & 304 & 151 \\
\hline 15 & 385 & 501 \\
\hline 16 & 730 & 830 \\
\hline 17 & 264 & 413 \\
\hline 18 & 596 & 759 \\
\hline 19 & 515 & 563 \\
\hline 20 & 418 & 541 \\
\hline 21 & 383 & 450 \\
\hline 22 & 359 & 393 \\
\hline 23 & 480 & 327 \\
\hline 24 & 667 & 523 \\
\hline 25 & 195 & 338 \\
\hline 26 & 519 & 328 \\
\hline 27 & 511 & 358 \\
\hline 28 & 399 & 335 \\
\hline 29 & 308 & 327 \\
\hline 30 & 421 & 580 \\
\hline 31 & 1019 & 1210 \\
\hline 32 & 418 & 704 \\
\hline 33 & 1397 & 987 \\
\hline 34 & 625 & 991 \\
\hline
\end{tabular}




\begin{tabular}{|c|c|c|}
\hline \multicolumn{3}{|c|}{$\begin{array}{l}\text { Método Aoki Velloso adaptado e corrigido com o fator } \\
\text { parcial }\end{array}$} \\
\hline Estaca & $\mathrm{R}^{\prime \prime}(\mathrm{kN})$ & $\begin{array}{l}\text { Pu }(\mathrm{kN}) \text { Van der } \\
\text { Veen }\end{array}$ \\
\hline 1 & 275 & 629 \\
\hline 2 & 197 & 358 \\
\hline 3 & 255 & 516 \\
\hline 4 & 888 & 884 \\
\hline 5 & 1041 & 1080 \\
\hline 6 & 627 & 1093 \\
\hline 7 & 915 & 757 \\
\hline 8 & 715 & 378 \\
\hline 9 & 733 & 865 \\
\hline 10 & 621 & 739 \\
\hline 11 & 390 & 300 \\
\hline 12 & 701 & 529 \\
\hline 13 & 514 & 303 \\
\hline 14 & 309 & 151 \\
\hline 15 & 389 & 501 \\
\hline 16 & 739 & 830 \\
\hline 17 & 279 & 413 \\
\hline 18 & 630 & 759 \\
\hline 19 & 539 & 563 \\
\hline 20 & 463 & 541 \\
\hline 21 & 399 & 450 \\
\hline 22 & 385 & 393 \\
\hline 23 & 466 & 327 \\
\hline 24 & 665 & 523 \\
\hline 25 & 207 & 338 \\
\hline 26 & 528 & 328 \\
\hline 27 & 519 & 358 \\
\hline 28 & 413 & 335 \\
\hline 29 & 314 & 327 \\
\hline 30 & 421 & 580 \\
\hline 31 & 989 & 1210 \\
\hline 32 & 417 & 704 \\
\hline 33 & 1318 & 987 \\
\hline 34 & 595 & 991 \\
\hline
\end{tabular}




\begin{tabular}{|c|c|c|}
\hline \multicolumn{3}{|c|}{ Método Décourt - Quaresma corrigido com o fator global } \\
\hline Estaca & $\mathrm{R}^{\prime}(\mathrm{kN})$ & $\begin{array}{c}\mathrm{Pu}(\mathrm{kN}) \text { Van der } \\
\text { Veen }\end{array}$ \\
\hline 1 & 456 & 629 \\
\hline 2 & 287 & 358 \\
\hline 3 & 397 & 516 \\
\hline 4 & 1052 & 884 \\
\hline 5 & 1303 & 1080 \\
\hline 6 & 640 & 1093 \\
\hline 7 & 767 & 757 \\
\hline 8 & 638 & 378 \\
\hline 9 & 773 & 865 \\
\hline 10 & 691 & 739 \\
\hline 11 & 337 & 300 \\
\hline 12 & 587 & 529 \\
\hline 13 & 406 & 303 \\
\hline 14 & 276 & 151 \\
\hline 15 & 223 & 501 \\
\hline 16 & 846 & 830 \\
\hline 17 & 299 & 413 \\
\hline 18 & 647 & 759 \\
\hline 19 & 551 & 563 \\
\hline 20 & 512 & 541 \\
\hline 21 & 380 & 450 \\
\hline 22 & 385 & 393 \\
\hline 23 & 403 & 327 \\
\hline 24 & 605 & 523 \\
\hline 25 & 245 & 338 \\
\hline 26 & 454 & 328 \\
\hline 27 & 407 & 358 \\
\hline 28 & 419 & 335 \\
\hline 29 & 314 & 327 \\
\hline 30 & 468 & 580 \\
\hline 31 & 1100 & 1210 \\
\hline 32 & 468 & 704 \\
\hline 33 & 1138 & 987 \\
\hline 34 & 637 & 991 \\
\hline
\end{tabular}




\begin{tabular}{|c|c|c|}
\hline \multicolumn{3}{|c|}{ Método Décourt - Quaresma corrigido com o fator parcial } \\
\hline Estaca & $\mathrm{R}^{\prime \prime}(\mathrm{kN})$ & $\begin{array}{c}\text { Pu }(\mathrm{kN}) \text { Van der } \\
\text { Veen }\end{array}$ \\
\hline 1 & 444 & 629 \\
\hline 2 & 271 & 358 \\
\hline 3 & 400 & 516 \\
\hline 4 & 1200 & 884 \\
\hline 5 & 1562 & 1080 \\
\hline 6 & 682 & 1093 \\
\hline 7 & 770 & 757 \\
\hline 8 & 646 & 378 \\
\hline 9 & 738 & 865 \\
\hline 10 & 654 & 739 \\
\hline 11 & 329 & 300 \\
\hline 12 & 581 & 529 \\
\hline 13 & 396 & 303 \\
\hline 14 & 257 & 151 \\
\hline 15 & 201 & 501 \\
\hline 16 & 840 & 830 \\
\hline 17 & 269 & 413 \\
\hline 18 & 589 & 759 \\
\hline 19 & 507 & 563 \\
\hline 20 & 443 & 541 \\
\hline 21 & 349 & 450 \\
\hline 22 & 345 & 393 \\
\hline 23 & 408 & 327 \\
\hline 24 & 573 & 523 \\
\hline 25 & 222 & 338 \\
\hline 26 & 427 & 328 \\
\hline 27 & 387 & 358 \\
\hline 28 & 390 & 335 \\
\hline 29 & 306 & 327 \\
\hline 30 & 445 & 580 \\
\hline 31 & 1142 & 1210 \\
\hline 32 & 445 & 704 \\
\hline 33 & 1163 & 987 \\
\hline 34 & 634 & 991 \\
\hline
\end{tabular}




\begin{tabular}{|c|c|c|}
\hline \multicolumn{3}{|c|}{ Método Amaral corrigido com o fator global } \\
\hline Estaca & $\mathrm{R}^{\prime}(\mathrm{kN})$ & $\begin{array}{c}\text { Pu }(\mathrm{kN}) \text { Van der } \\
\text { Veen }\end{array}$ \\
\hline 1 & 462 & 629 \\
\hline 2 & 315 & 358 \\
\hline 3 & 433 & 516 \\
\hline 4 & 900 & 884 \\
\hline 5 & 1119 & 1080 \\
\hline 6 & 672 & 1093 \\
\hline 7 & 675 & 757 \\
\hline 8 & 595 & 378 \\
\hline 9 & 836 & 865 \\
\hline 10 & 633 & 739 \\
\hline 11 & 360 & 300 \\
\hline 12 & 604 & 529 \\
\hline 13 & 357 & 303 \\
\hline 14 & 230 & 151 \\
\hline 15 & 409 & 501 \\
\hline 16 & 884 & 830 \\
\hline 17 & 341 & 413 \\
\hline 18 & 672 & 759 \\
\hline 19 & 612 & 563 \\
\hline 20 & 434 & 541 \\
\hline 21 & 432 & 450 \\
\hline 22 & 374 & 393 \\
\hline 23 & 348 & 327 \\
\hline 24 & 593 & 523 \\
\hline 25 & 264 & 338 \\
\hline 26 & 476 & 328 \\
\hline 27 & 485 & 358 \\
\hline 28 & 408 & 335 \\
\hline 29 & 352 & 327 \\
\hline 30 & 485 & 580 \\
\hline 31 & 1054 & 1210 \\
\hline 32 & 521 & 704 \\
\hline 33 & 1071 & 987 \\
\hline 34 & 688 & 991 \\
\hline
\end{tabular}




\begin{tabular}{|c|c|c|}
\hline \multicolumn{3}{|c|}{ Método Composto } \\
\hline Estaca & $\mathrm{R}(\mathrm{kN})$ & $\begin{array}{c}\text { Pu }(\mathrm{kN}) \text { Van der } \\
\text { Veen }\end{array}$ \\
\hline 1 & 363 & 629 \\
\hline 2 & 249 & 358 \\
\hline 3 & 336 & 516 \\
\hline 4 & 792 & 884 \\
\hline 5 & 883 & 1080 \\
\hline 6 & 509 & 1093 \\
\hline 7 & 843 & 757 \\
\hline 8 & 468 & 378 \\
\hline 9 & 603 & 865 \\
\hline 10 & 540 & 739 \\
\hline 11 & 375 & 300 \\
\hline 12 & 604 & 529 \\
\hline 13 & 460 & 303 \\
\hline 14 & 276 & 151 \\
\hline 15 & 276 & 501 \\
\hline 16 & 718 & 830 \\
\hline 17 & 270 & 413 \\
\hline 18 & 583 & 759 \\
\hline 19 & 504 & 563 \\
\hline 20 & 443 & 541 \\
\hline 21 & 359 & 450 \\
\hline 22 & 344 & 393 \\
\hline 23 & 412 & 327 \\
\hline 24 & 615 & 523 \\
\hline 25 & 215 & 338 \\
\hline 26 & 449 & 328 \\
\hline 27 & 411 & 358 \\
\hline 28 & 385 & 335 \\
\hline 29 & 282 & 327 \\
\hline 30 & 442 & 580 \\
\hline 31 & 969 & 1210 \\
\hline 32 & 442 & 704 \\
\hline 33 & 1230 & 987 \\
\hline 34 & 637 & 991 \\
\hline
\end{tabular}


ANEXO 3

Método de Chin 

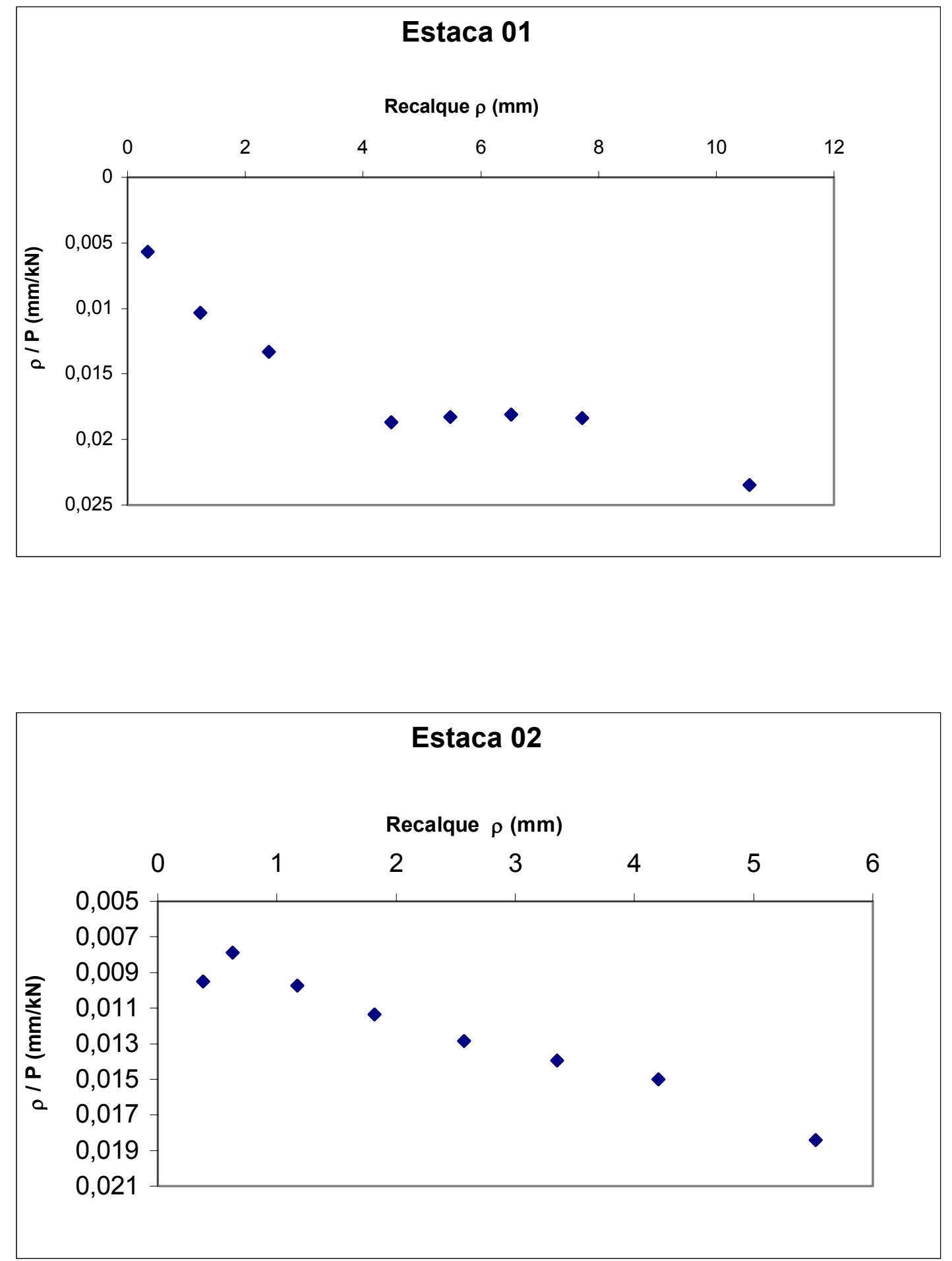

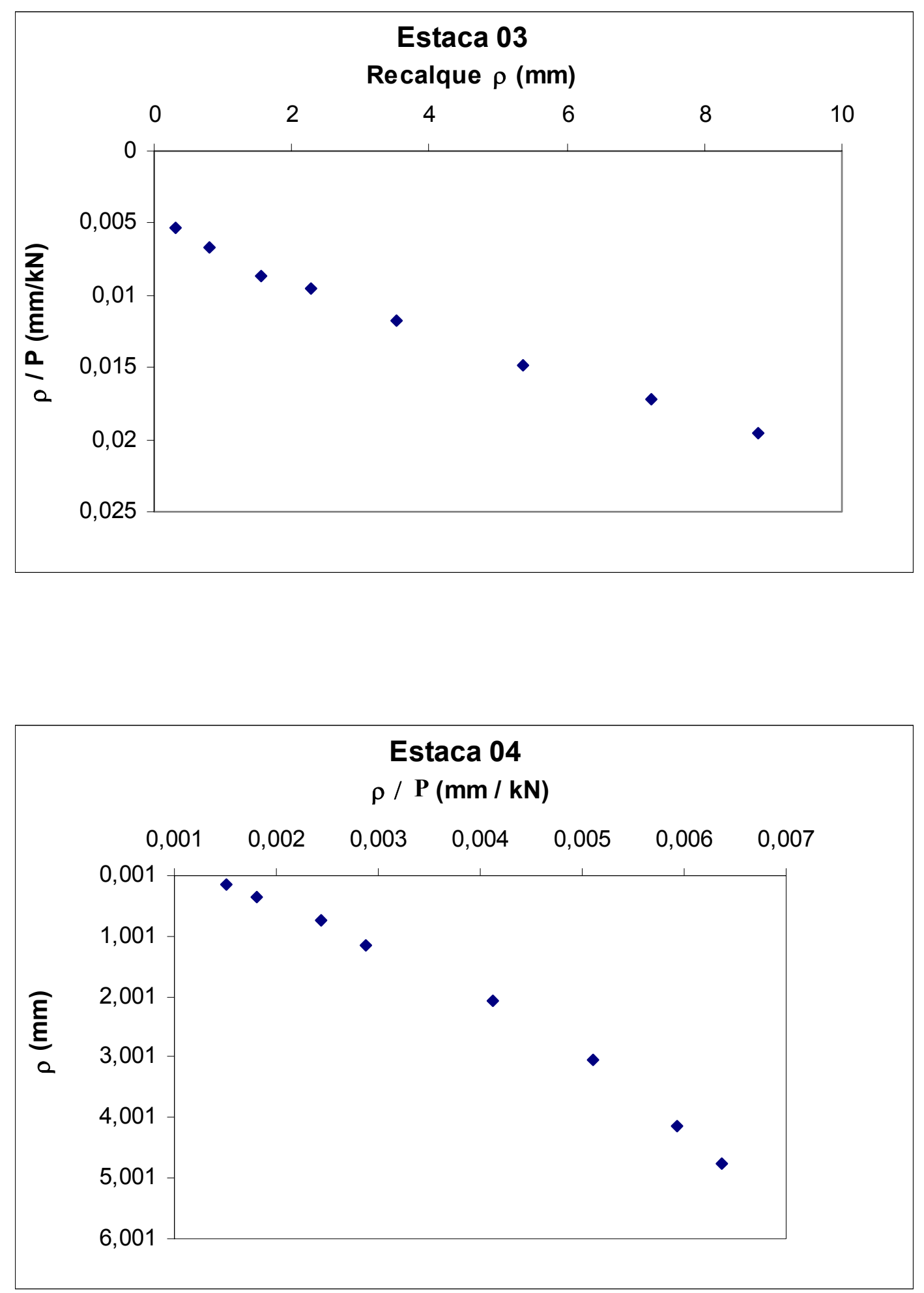

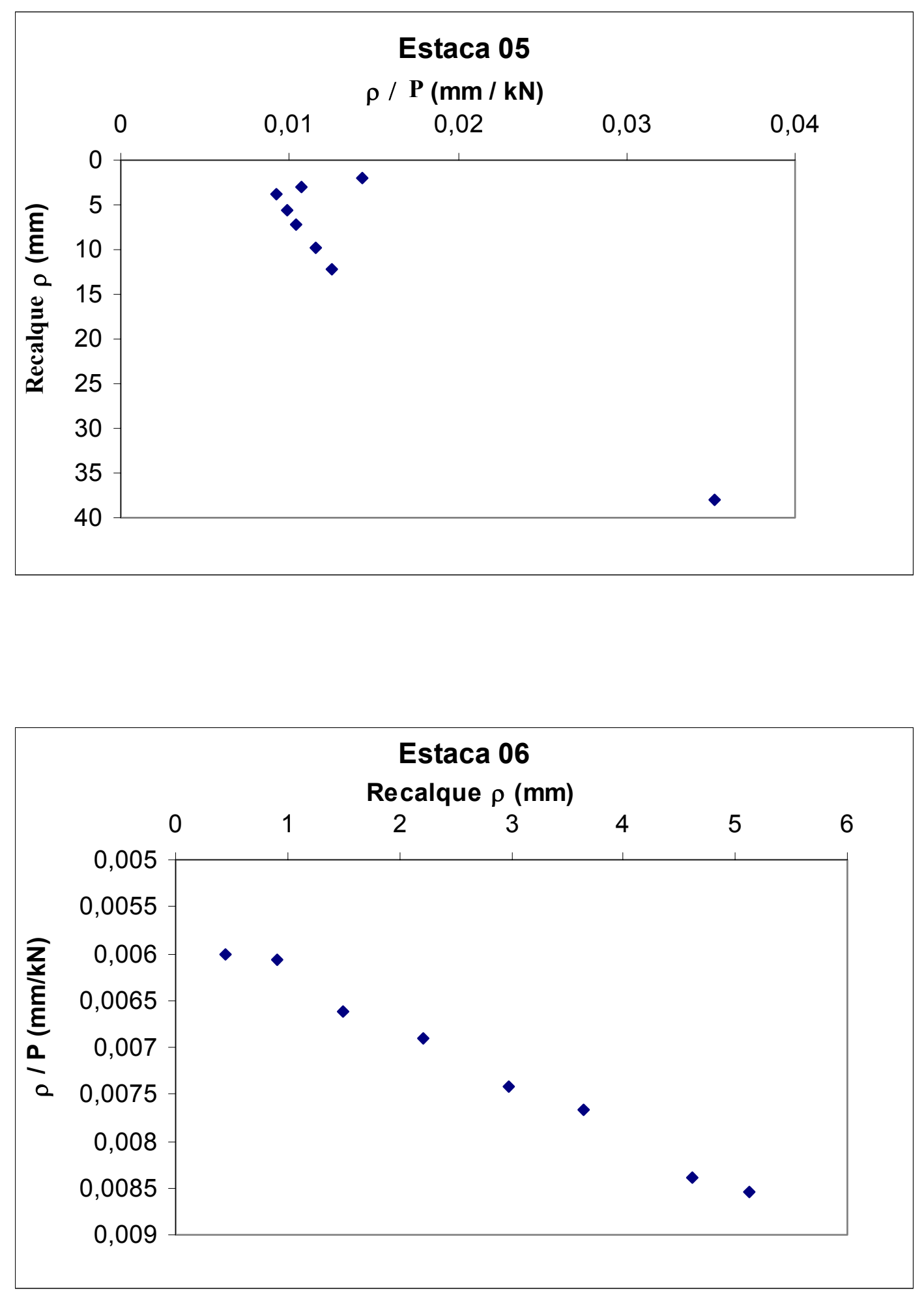

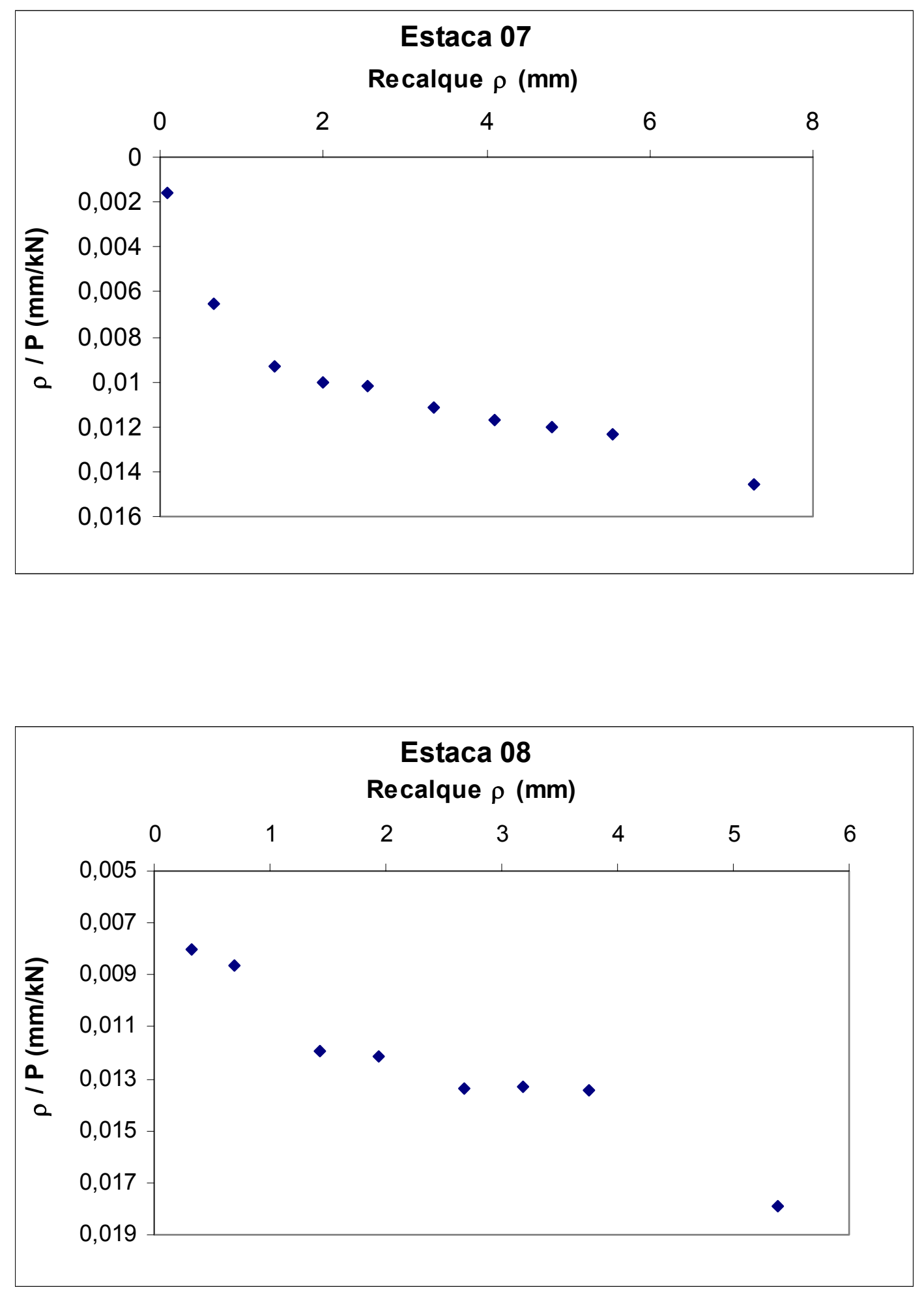

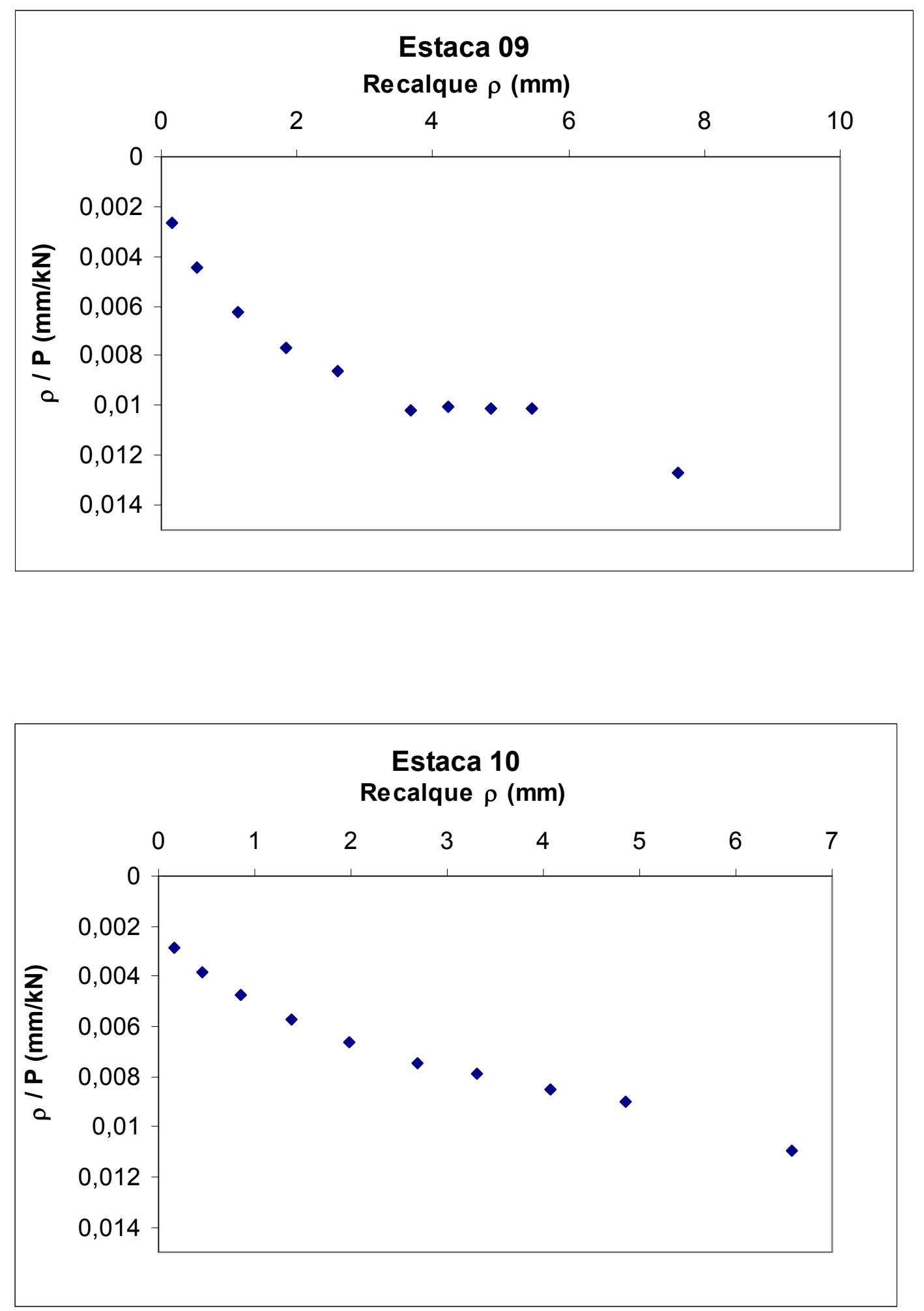

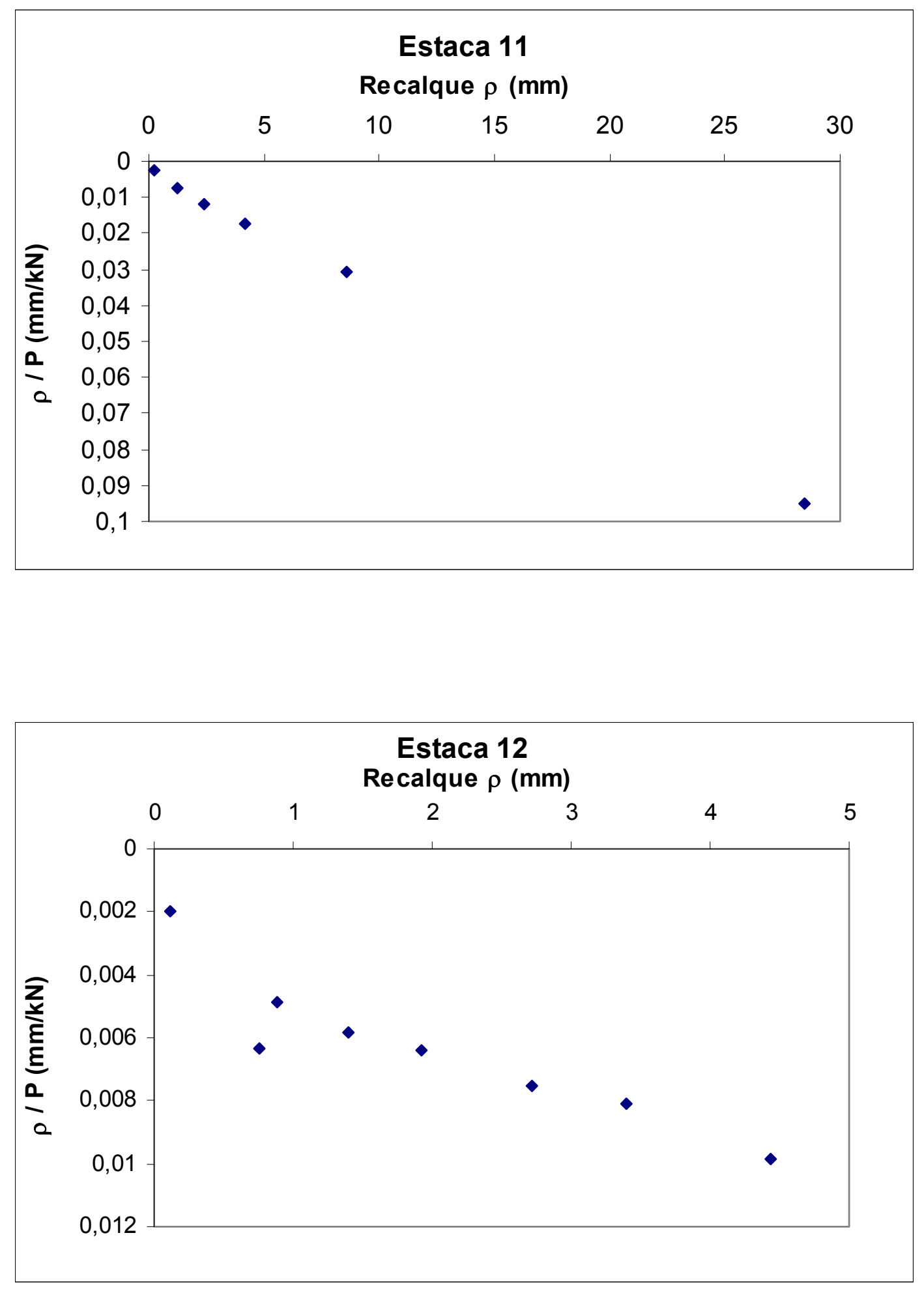

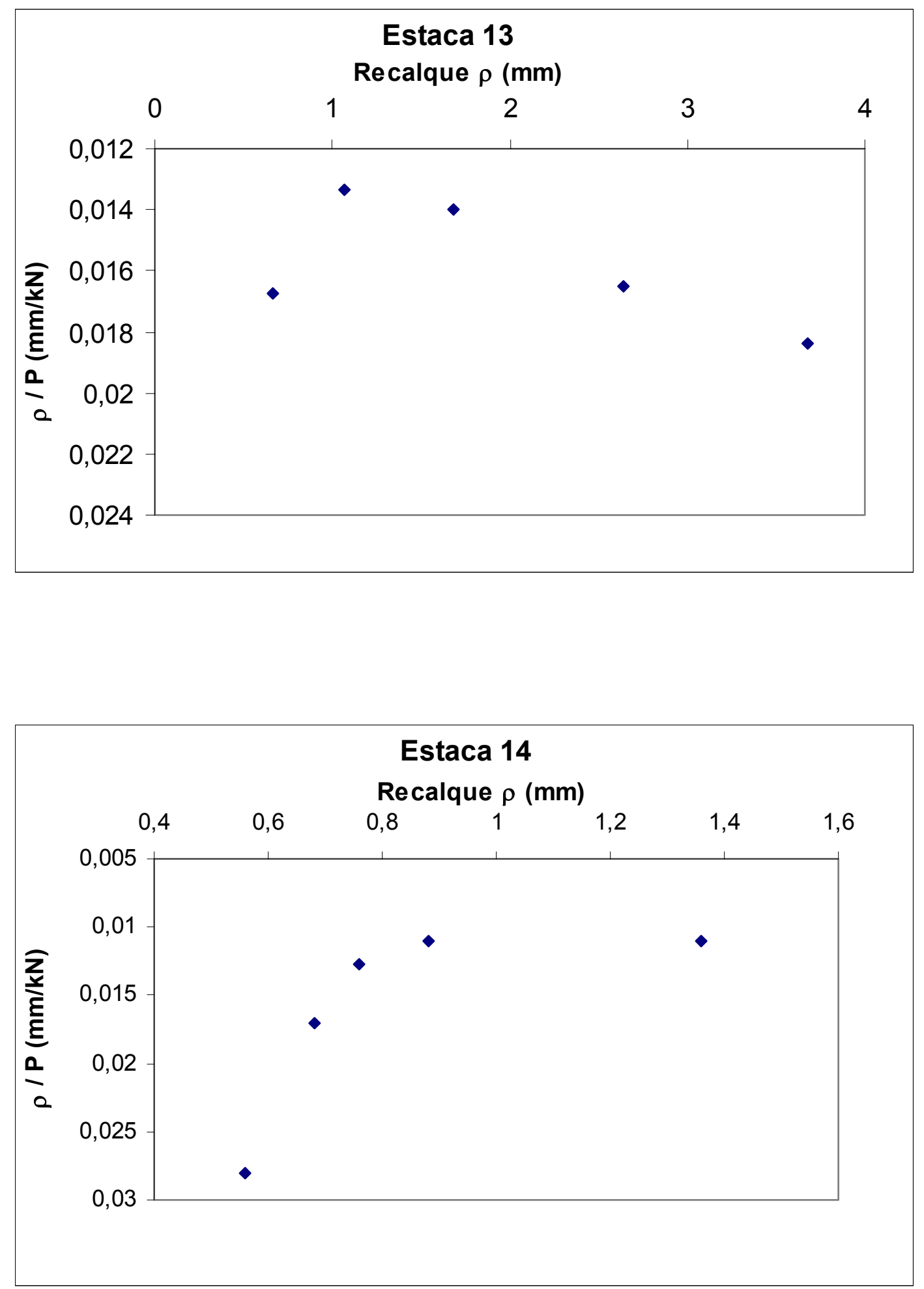

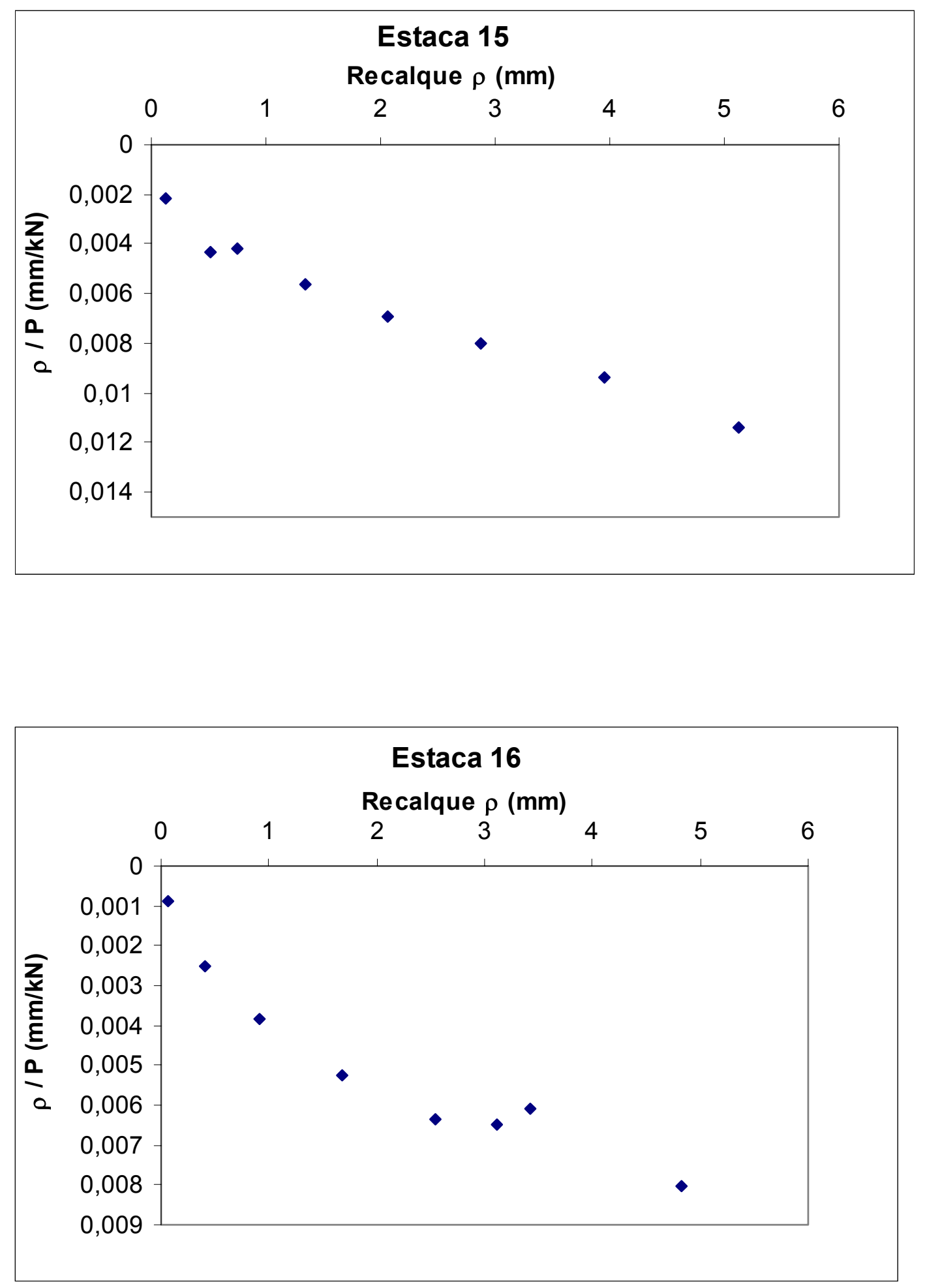

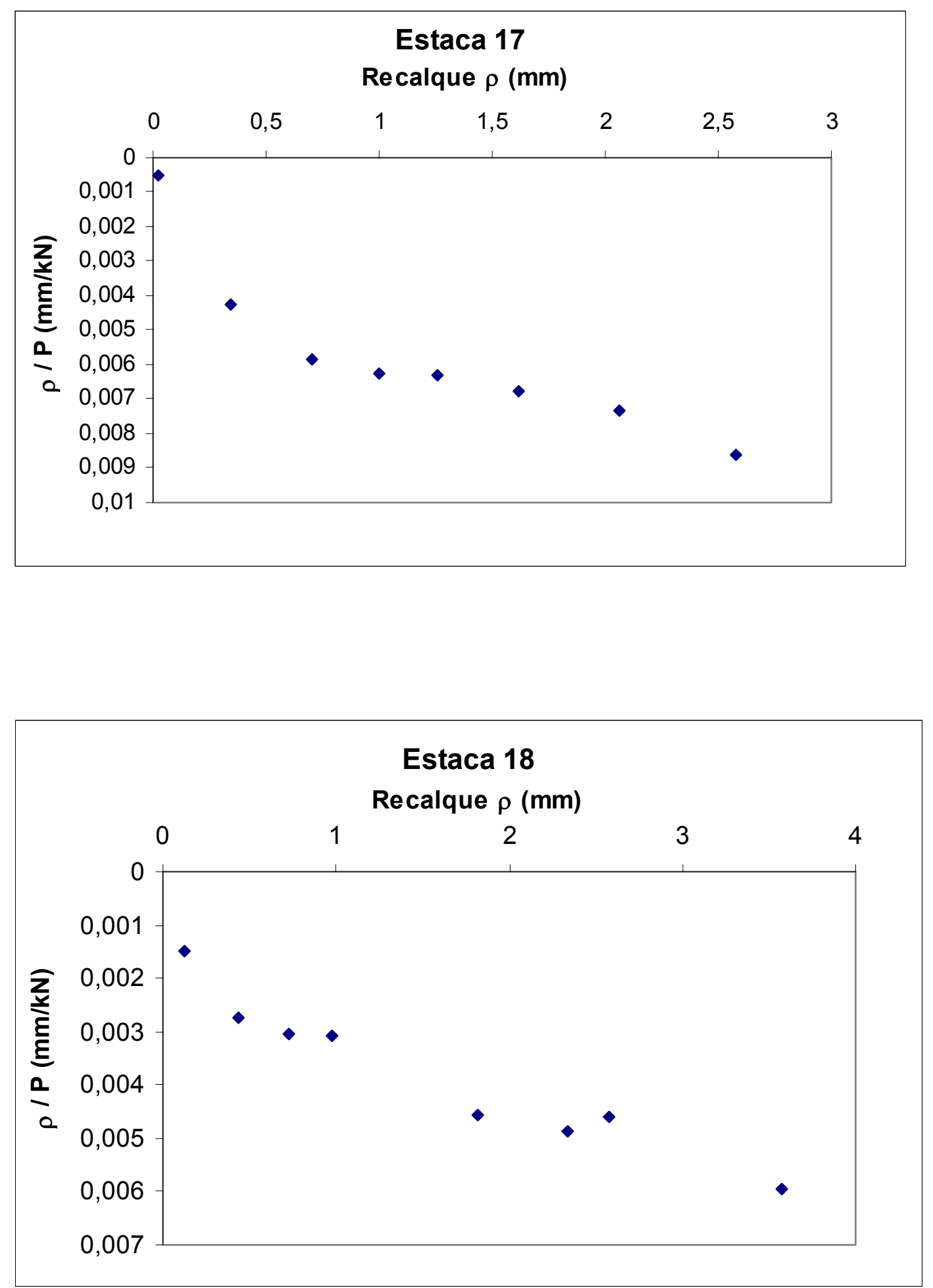

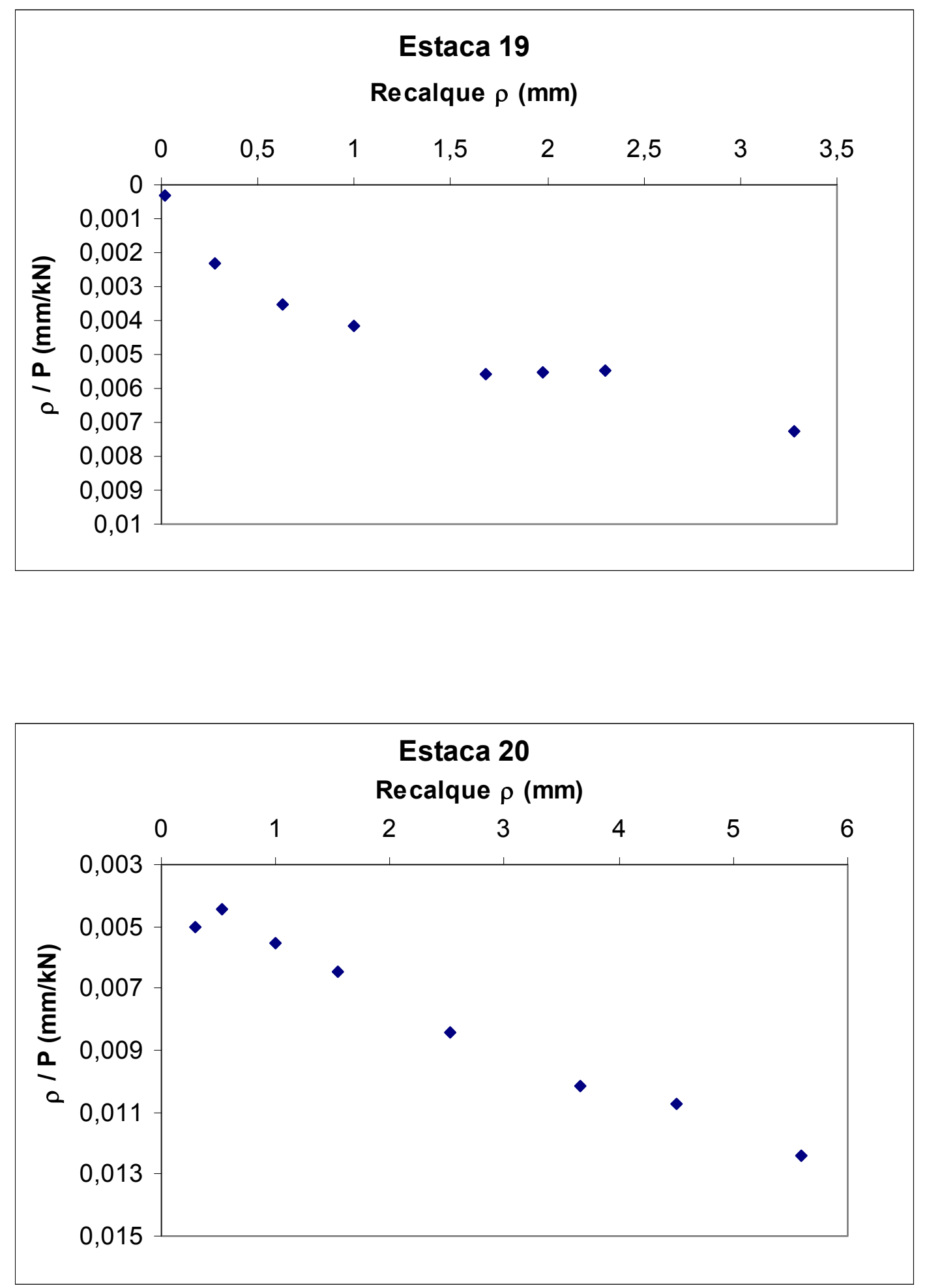

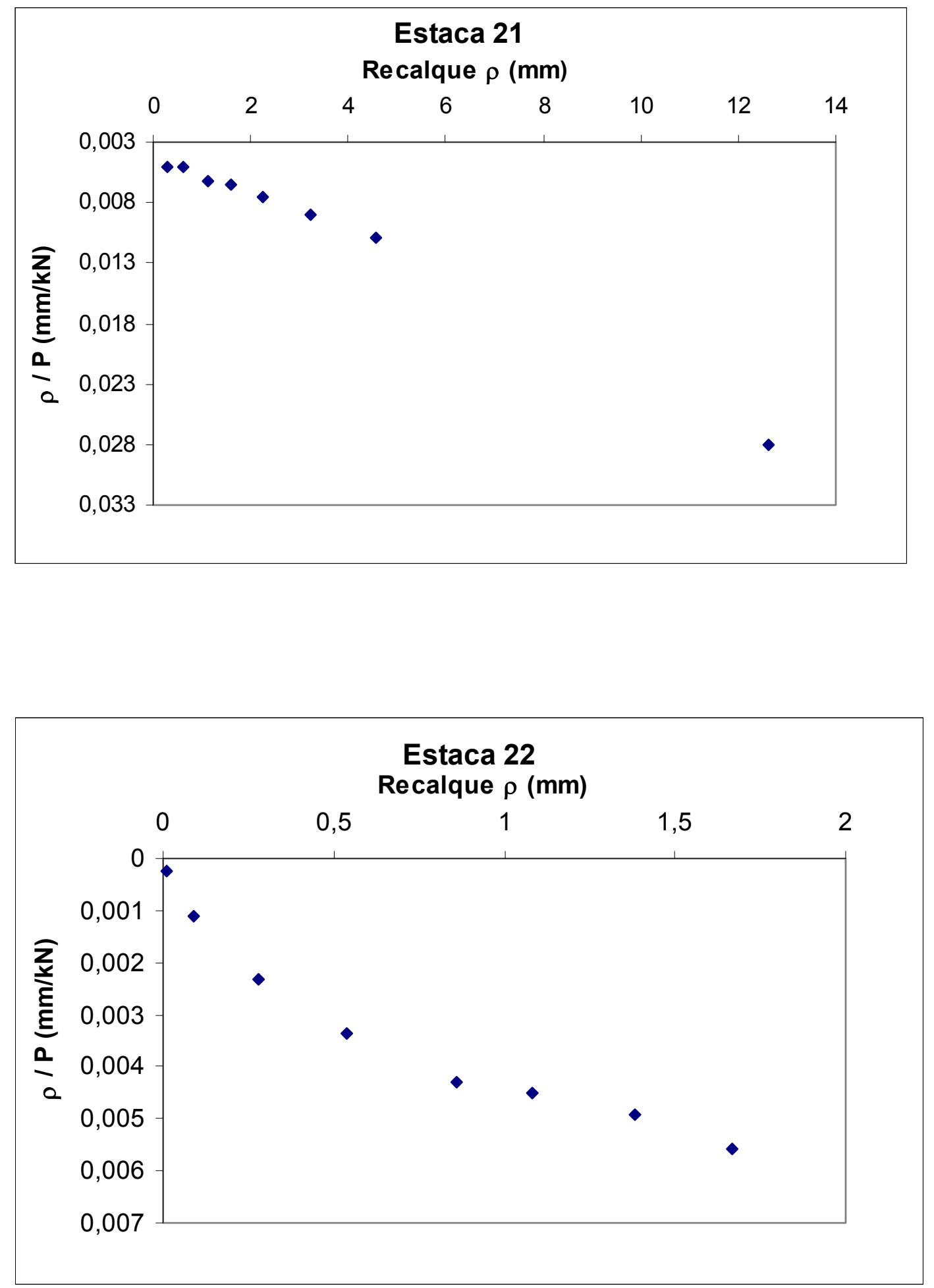

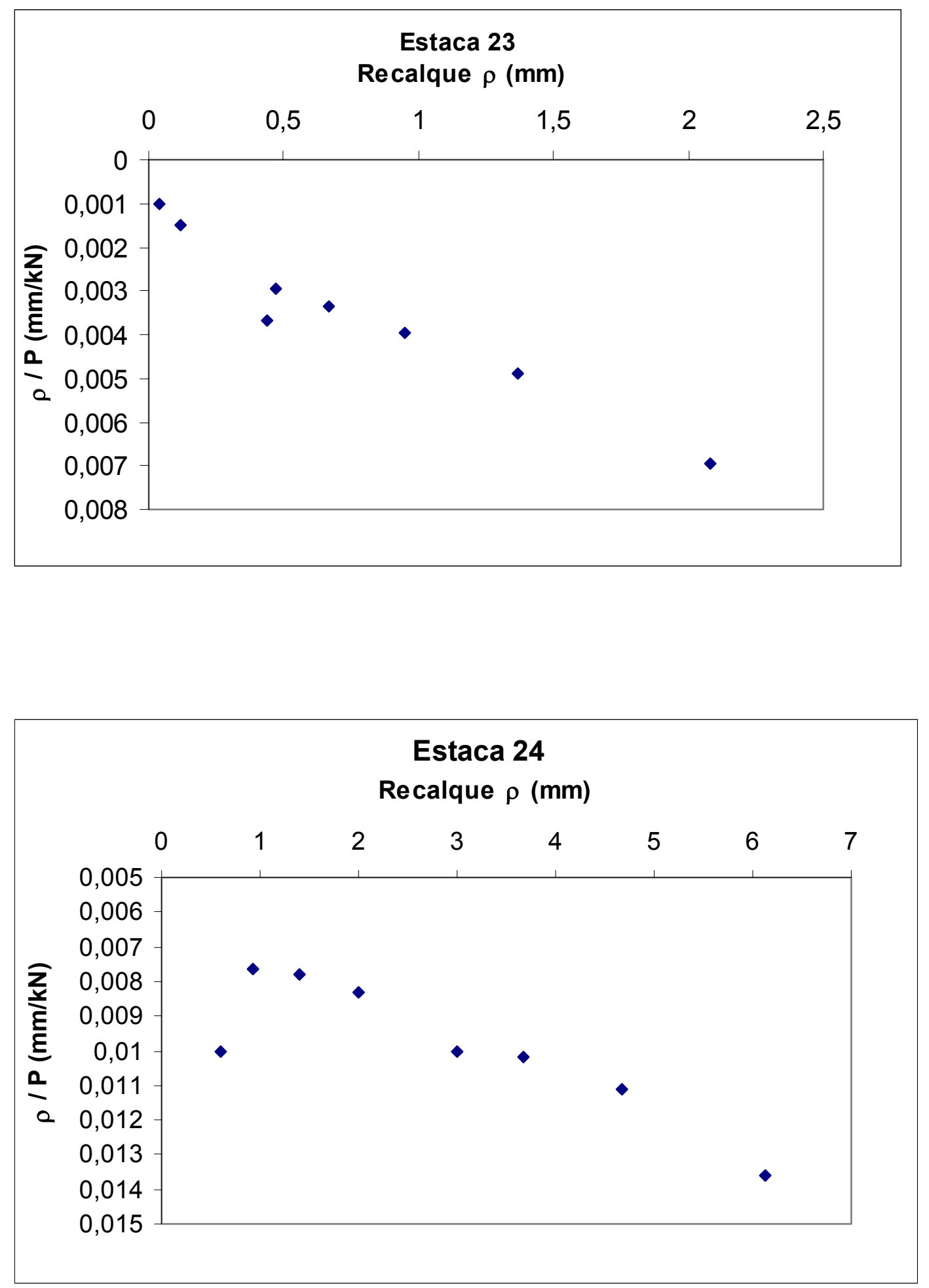

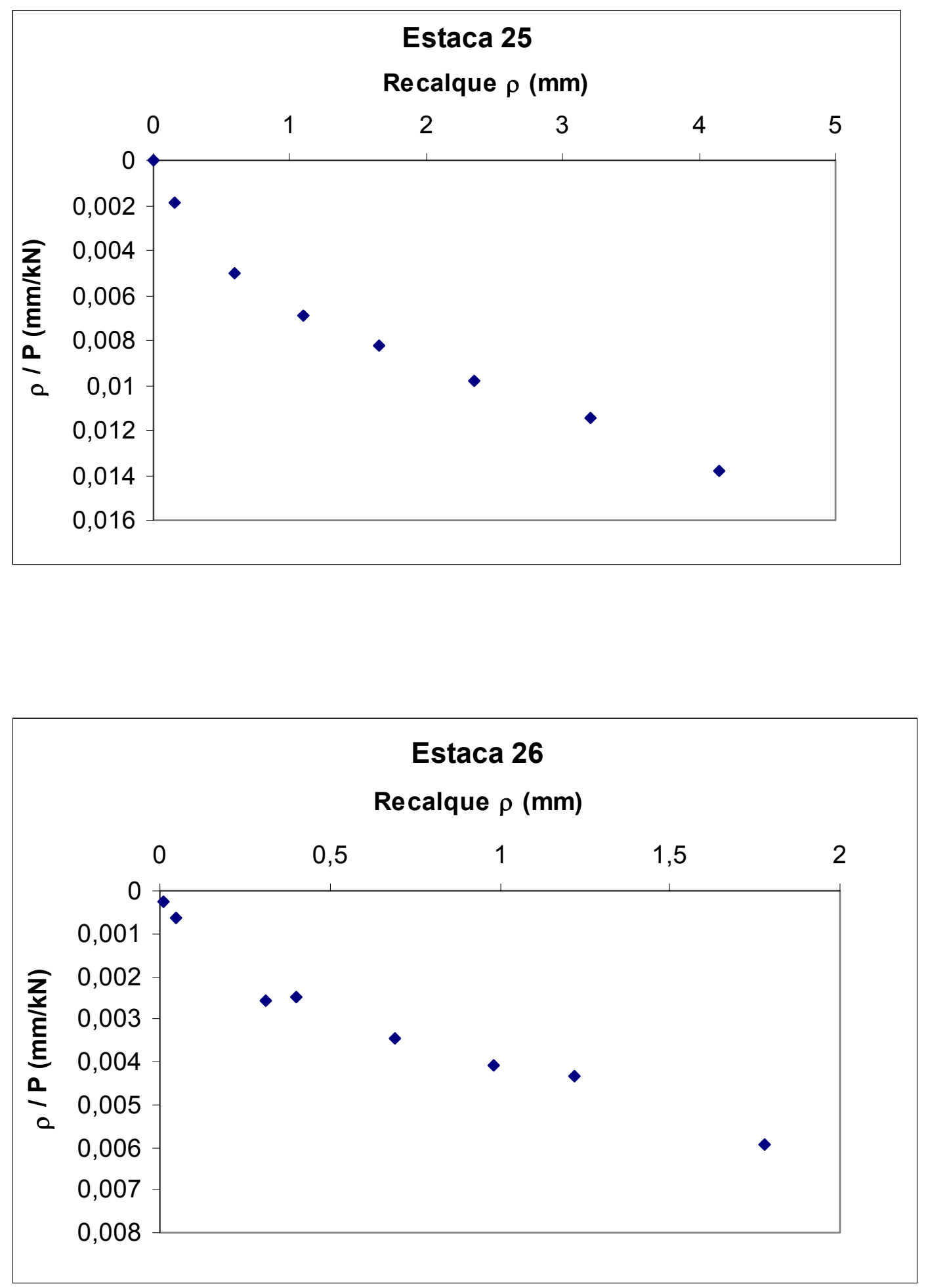

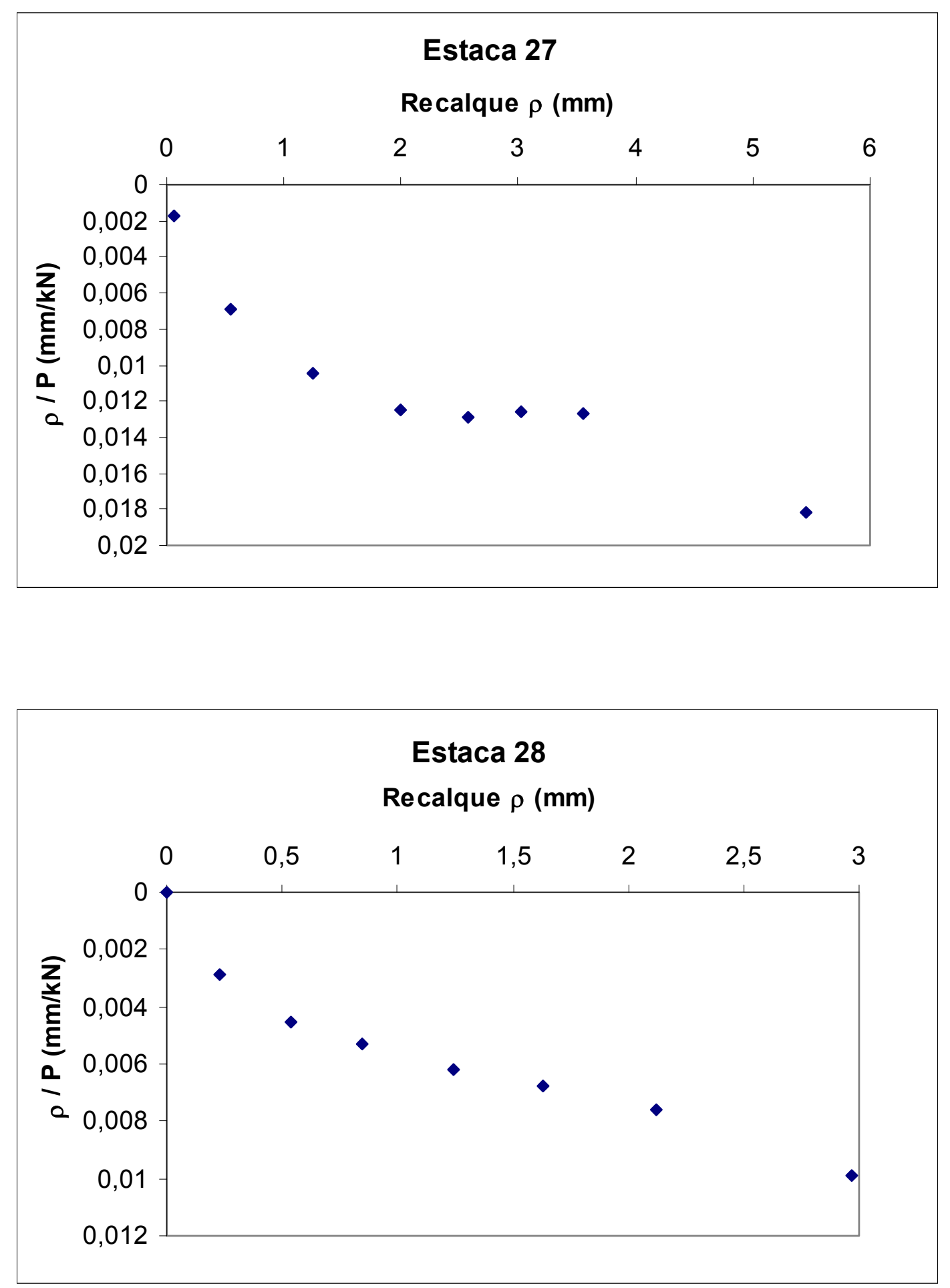

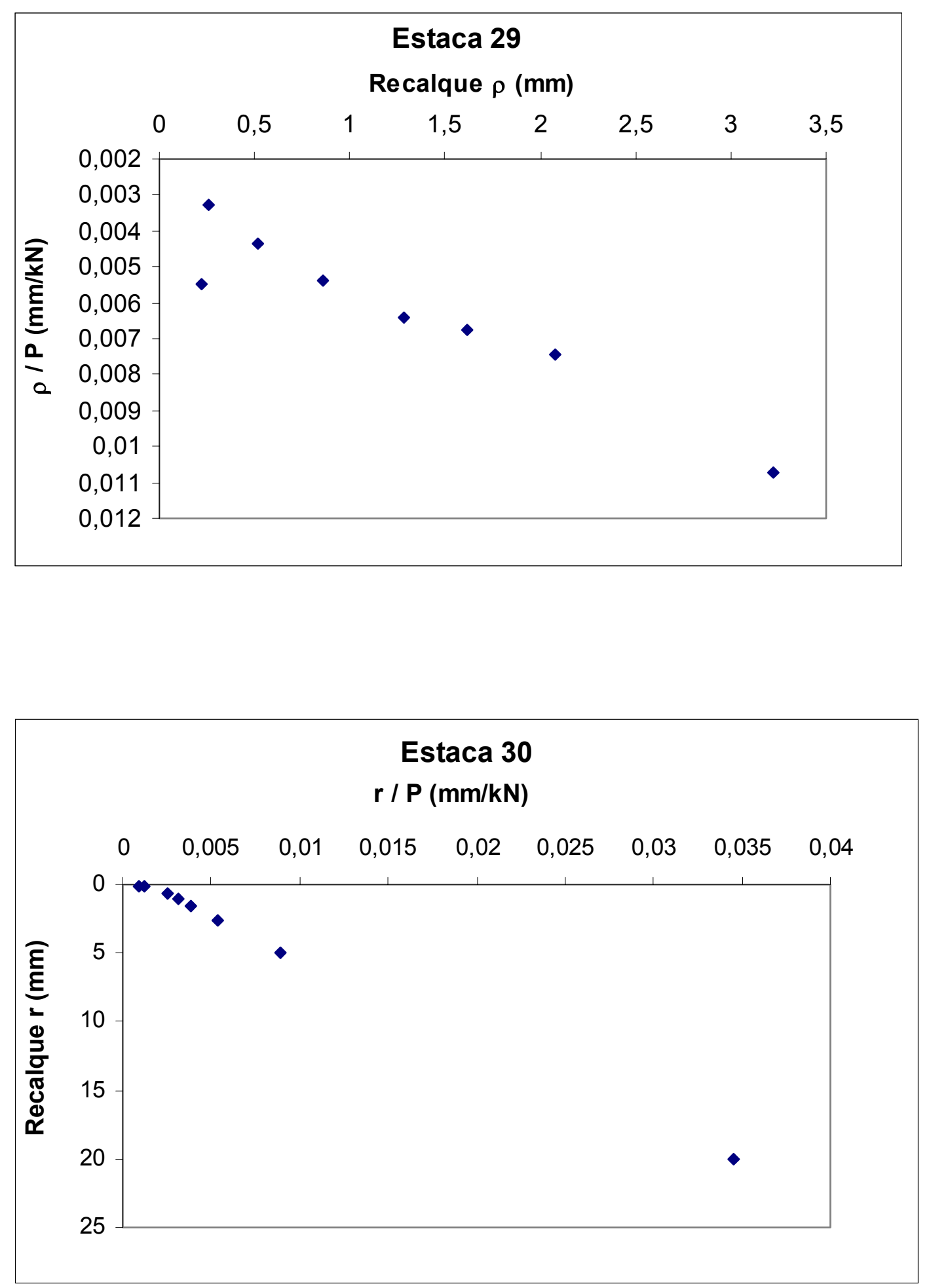

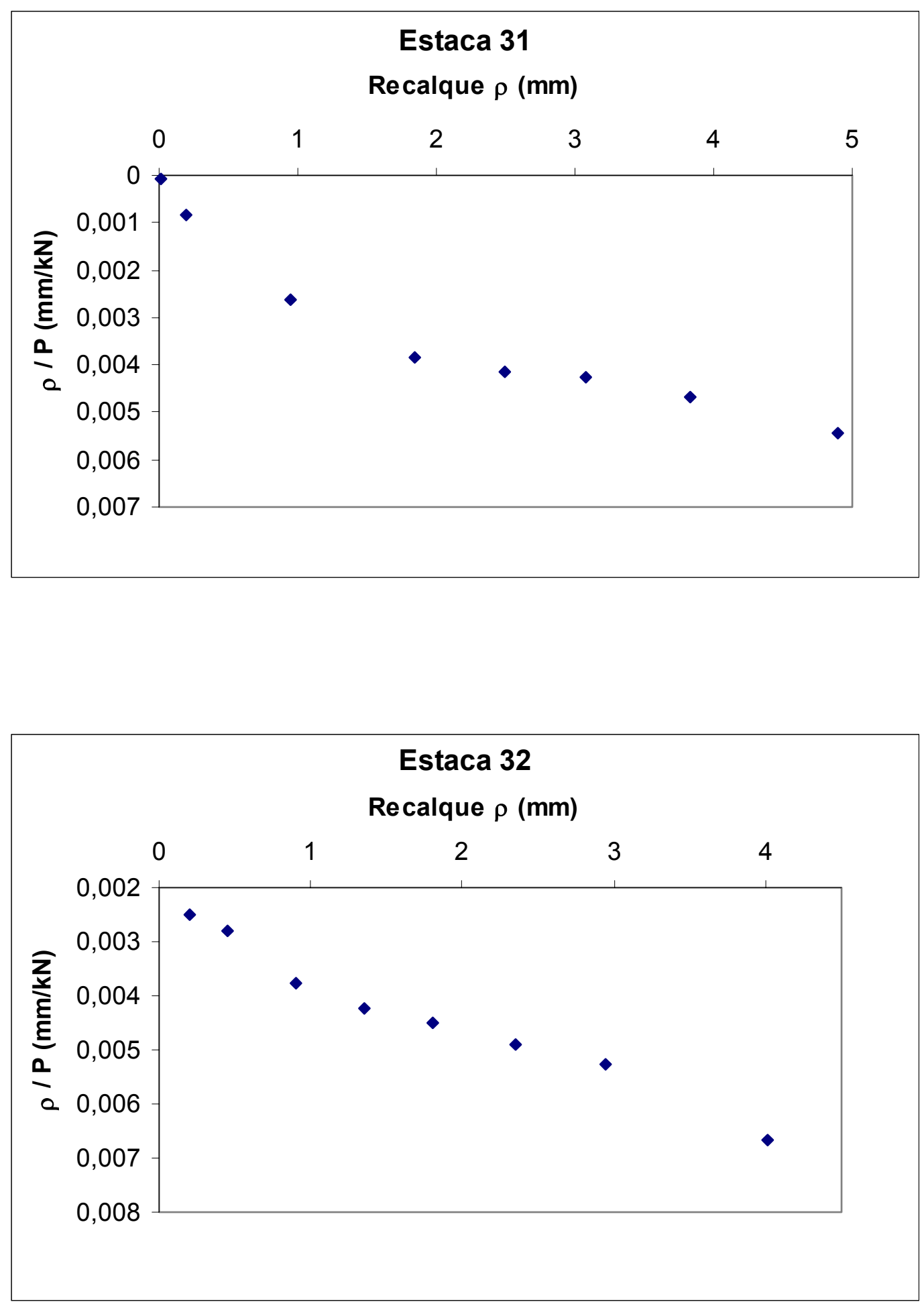

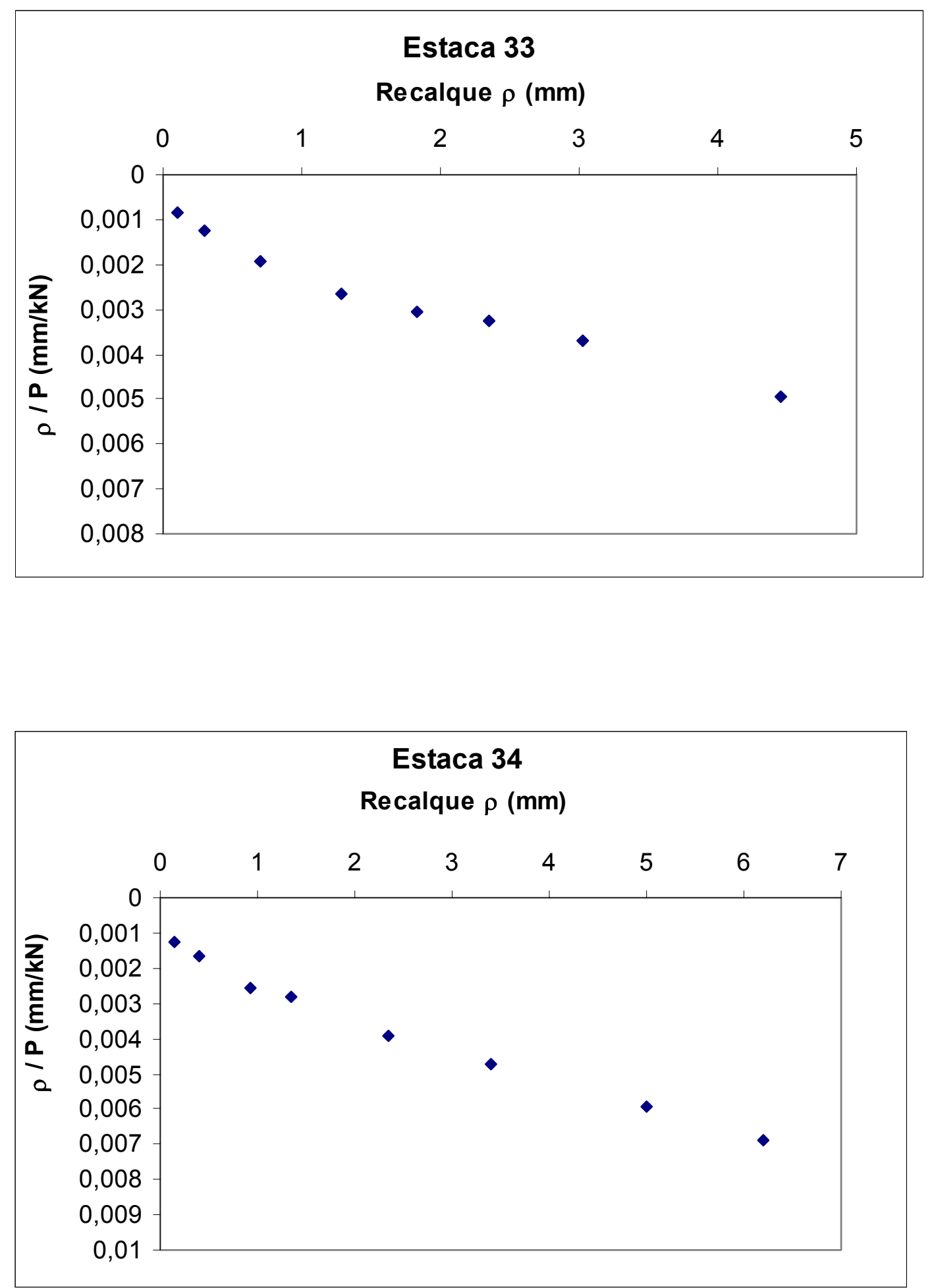
ANEXO 4

Tabela - Recalques 


\begin{tabular}{cccccccccc}
\hline Prova & $\begin{array}{c}\mathrm{R}_{1} \\
(\mathrm{kN})\end{array}$ & $\begin{array}{c}\rho_{1} \\
(\mathrm{~mm})\end{array}$ & $\begin{array}{c}\rho_{\mathrm{m}} \\
(\mathrm{mm})\end{array}$ & $\begin{array}{c}\mathrm{R}_{2} \\
(\mathrm{kN})\end{array}$ & $\begin{array}{c}\rho_{2} \\
(\mathrm{~mm})\end{array}$ & $\begin{array}{c}\rho_{\mathrm{m}} \\
(\mathrm{mm})\end{array}$ & $\begin{array}{c}\mathrm{R}_{3} \\
(\mathrm{kN})\end{array}$ & $\begin{array}{c}\rho_{3} \\
(\mathrm{~mm})\end{array}$ & $\begin{array}{c}\rho_{\mathrm{m}} \\
(\mathrm{mm})\end{array}$ \\
\hline 03 & 152 & 1,10 & 1,20 & 301 & 4,75 & 3,52 & 450 & 6,71 & 8,78 \\
06 & 511 & 1,99 & 3,82 & 556 & 2,26 & 4,73 & 600 & 2,52 & 5,13 \\
10 & 546 & 3,50 & 4,94 & 573 & 3,94 & 5,27 & 600 & 4,37 & 6,59 \\
11 & 200 & 1,82 & 3,40 & 240 & 2,84 & 5,40 & 280 & 3,46 & 8,60 \\
15 & 278 & 2,00 & 1,70 & 364 & 3,54 & 2,93 & 450 & 4,68 & 5,12 \\
17 & 229 & 2,50 & 1,50 & 265 & 4,63 & 1,82 & 300 & 6,15 & 2,58 \\
20 & 426 & 3,14 & 4,60 & 438 & 3,67 & 4,90 & 450 & 4,11 & 5,59 \\
21 & 300 & 1,92 & 2,39 & 360 & 2,72 & 3,36 & 420 & 3,23 & 4,58 \\
23 & 290 & 1,76 & 1,48 & 295 & 1,82 & 1,56 & 300 & 1,88 & 2,08 \\
25 & 170 & 1,77 & 1,20 & 235 & 3,70 & 2,20 & 300 & 5,14 & 4,15 \\
30 & 400 & 1,43 & 0,90 & 480 & 1,97 & 1,80 & 560 & 2,61 & 8,30 \\
31 & 615 & 1,40 & 2,55 & 758 & 2,63 & 3,30 & 900 & 3,76 & 4,89 \\
33 & 729 & 1,49 & 2,30 & 815 & 2,12 & 2,75 & 900 & 2,65 & 4,45 \\
34 & 342 & 1,31 & 0,80 & 621 & 3,48 & 2,50 & 900 & 5,16 & 6,12 \\
\hline
\end{tabular}




\section{ANEXO 5}

Tabela - Coeficientes a e b de Van der Veen 


\begin{tabular}{|c|c|c|}
\hline ESTACA & $\mathrm{a}\left(\mathrm{mm}^{-1}\right)$ & $\mathrm{b}$ \\
\hline 1 & 0,122 & 0,022 \\
\hline 2 & 0,334 & 0,006 \\
\hline 3 & 0,241 & 0,054 \\
\hline 4 & 0,365 & 0,090 \\
\hline 5 & 0,204 & $-0,333$ \\
\hline 6 & 0,175 & 0,000 \\
\hline 7 & 0,149 & 0,025 \\
\hline 8 & 0,309 & $-0,003$ \\
\hline 9 & 0,155 & 0,037 \\
\hline 10 & 0,208 & 0,041 \\
\hline 11 & 0,272 & 0,391 \\
\hline 12 & 0,430 & 0,012 \\
\hline 13 & 0,343 & $-0,025$ \\
\hline 14 & 1,938 & $-0,970$ \\
\hline 15 & 0,411 & 0,056 \\
\hline 16 & 0,263 & 0,066 \\
\hline 17 & 0,330 & 0,032 \\
\hline 18 & 0,436 & 0,047 \\
\hline 19 & 0,485 & 0,067 \\
\hline 20 & 0,298 & 0,053 \\
\hline 21 & 0,494 & 0,045 \\
\hline 22 & 0,774 & 0,087 \\
\hline 23 & 1,220 & 0,041 \\
\hline 24 & 0,339 & $-0,072$ \\
\hline 25 & 0,473 & 0,105 \\
\hline 26 & 1,010 & 0,095 \\
\hline 27 & 0,343 & 0,030 \\
\hline 28 & 0,752 & 0,054 \\
\hline 29 & 0,797 & 0,023 \\
\hline 30 & 0,175 & 0,560 \\
\hline 31 & 0,228 & 0,077 \\
\hline 32 & 0,488 & 0,002 \\
\hline 33 & 0,404 & 0,062 \\
\hline 34 & 0,404 & 0,078 \\
\hline
\end{tabular}


De acordo com Aoki (1976), os pontos de uma prova de carga em realização permitem que se determine o valor de a. A norma brasileira estabelece os seguintes valores para a carga admissível $P_{\text {adm: }}$ :

$$
\mathrm{P}_{\mathrm{adm}}=\frac{\mathrm{R}}{2}=\frac{\mathrm{P}_{15 \mathrm{~mm}}}{1,5}
$$

Supondo válida a expressão proposta por Van der Veen (1953), a condição acima conduzirá a:

$$
\begin{aligned}
& P_{15 \mathrm{~mm}}=\frac{3}{4} R \\
& 0,75 \mathrm{R}=\mathrm{R}\left(1-\mathrm{e}^{-15 a}\right) \\
& \mathrm{a} \cong 0,0924 \mathrm{~mm}^{-1}
\end{aligned}
$$

Se $\mathrm{a} \cong 0,0924 \mathrm{~mm}^{-1}$ é provável que $\mathrm{P}_{15 \mathrm{~mm}}=3 / 4 \mathrm{R}$. Se $\mathrm{a}>0,0924 \mathrm{~mm}^{-1}$, é prudente não confiar no valor da carga admissível calculada pela expressão:

$$
\begin{gathered}
\mathrm{P}_{\mathrm{adm}}=\frac{\mathrm{P}_{15 \mathrm{~mm}}}{1,5}, \text { uma vez que } \\
\frac{\mathrm{R}}{2}<\frac{\mathrm{P}_{15 \mathrm{~mm}}}{1,5}
\end{gathered}
$$

O ideal seria prosseguir com o carregamento até a ruptura e adotar:

$$
\mathrm{P}_{\mathrm{adm}}=\frac{\mathrm{R}}{2}
$$

Se a $<0,0924 \mathrm{~mm}^{-1}$, bastaria prosseguir com o carregamento até um recalque de $15 \mathrm{~mm}$ e adotar para a carga admissível o valor: 


$$
\begin{gathered}
P_{\text {adm }}=\frac{P_{15 \mathrm{~mm}}}{1,5} \text {, uma vez que neste caso teríamos } \\
\frac{\mathrm{R}}{2}>\frac{\mathrm{P}_{15 \mathrm{~mm}}}{1,5}
\end{gathered}
$$

